\title{
Probing the metal-ion-binding strength of the hydroxyl group
}

Al-Sogair, F M ; Operschall, B P ; Sigel, Astrid ; Sigel, Helmut ; Schnabl, J ; Sigel, Roland K O

DOI: https://doi.org/10.1021/cr100415s

Posted at the Zurich Open Repository and Archive, University of Zurich ZORA URL: https://doi.org/10.5167/uzh-60542

Journal Article

Originally published at:

Al-Sogair, F M; Operschall, B P; Sigel, Astrid; Sigel, Helmut; Schnabl, J; Sigel, Roland K O (2011). Probing the metal-ion-binding strength of the hydroxyl group. Chemical Reviews, 111(8):4964-5003. DOI: https://doi.org/10.1021/cr100415s 


\title{
Probing the Metal-lon-Binding Strength of the Hydroxyl Group
}

\author{
Fawzia M. Al-Sogair, ${ }^{+, \neq, \S}$ Bert P. Operschall," Astrid Sigel," Helmut Sigel,, ${ }^{*, l}$ Joachim Schnabl, ${ }^{\dagger}$ and \\ Roland K. O. Sigel ${ }^{*,+}$ \\ ${ }^{\dagger}$ Institute of Inorganic Chemistry, University of Zürich, Winterthurerstrasse 190, CH-8057 Zürich, Switzerland \\ ${ }^{\ddagger}$ Science Department, College of Basic Education, Public Authority for Applied Education and Training (PAAET), P.O. Box 23167, \\ Safat, 13092 Kuwait \\ "Department of Chemistry, Inorganic Chemistry, University of Basel, Spitalstrasse 51, CH-4056 Basel, Switzerland
}

\section{CONTENTS}

1. Introduction

2. How Is the Extent of a Weak Interaction Best Quantified?

3. Metal-Ion Complexes with Phosph(on)ate Groups as

Primary Binding Sites

3.1. Extent of the Hydroxyl- $\mathrm{M}^{2+}$ Interaction in Complexes of Hydroxymethylphosphonate

3.2. Metal-Ion-Glycerol 1-Phosphate Systems: A Decreasing Solvent Polarity Favors Hydro$\mathrm{xyl}-\mathrm{M}^{2+}$ Interactions

3.3. Some Generalizations Regarding Phosph(on)ate Ligands with a Weakly Coordinating Second Site

4. Metal-Ion Complexes with Carboxylate Groups as Primary Binding Sites

4.1. Extent of Chelate Formation in Complexes of Hydroxyacetate and Related Ligands at $I=0.1 \mathrm{M} 4969$

4.1.1. Construction of the Reference Lines for Several $\mathrm{M}^{2+}$-Carboxylate Systems

4.1.2. Extent of Chelate Formation in Metal-Ion Complexes Formed with Hydroxy Carboxylates and Related Ligands

4.2. Extent of Chelate Formation in Complexes of Hydroxyacetate-Type Ligands at $I=2 \mathrm{M}$

4.3. Effect of Chelate-Ring Enlargement on the Hydroxyl-Metal-lon Interaction

4.4. Decreasing Solvent Polarity Favors the Hydroxyl-Metal-Ion Interaction in Complexes of Hydroxyacetate and Related O Ligands But Inhibits Thioether Interactions

5. Metal-Ion Complexes with Amino Groups as Primary Binding Sites

5.1. Estimation of Straight-Line Parameters for Complexes Formed with $\mathrm{RCH}_{2}-\mathrm{NH}_{2}$ Ligands

5.2. Extent of Hydroxyl Group-Metal-Ion Binding in Complexes of 2-Aminoethanol and Related Ligands 4976 4976
4964

4970

5.3. Comparison of the Metal-lon-Binding Properties of 2-Aminoethanol and Triethanolamine 4980

6. Imidazole Residue as a Primary Binding Site in Ligands Containing also a Hydroxyl Group

7. Pyridyl Nitrogen Is an Ideal Primary Metal-lon-Binding Site for a Hydroxyl-Metal-Ion Interaction

8. Isomeric Quantification of Metal-lon Binding with Ligands Offering Two Hydroxyl Groups

9. Effect of the Primary Binding Site on the Extent of the Hydroxyl-Metal-Ion Interaction

10. Extent of Hydroxyl-Metal-Ion Interactions in Complexes Having a Bidentate Primary Binding Site 4988

11. Metal-Ion Complexes of Ligands with Two or More Hydroxyl Groups and at Least Four Binding Sites

4991

11.1. Complexes of the Alkaline Earth lons with Bistris and Some Related Buffers: Reduced Solvent Polarity Favors Metal-lon-Hydroxyl Group Interactions

11.2. Complexes of Several 3d and Related Metal Ions with Bistris and Derivatives

11.3. Quest for Selectivity in Metal-Ion Coordination Involving Hydroxyl Groups

12. General Conclusions

Biographies

5000

Acknowledgment

5000

Abbreviations and Definitions

5001

References

\section{INTRODUCTION}

Knowledge on the binding of biologically relevant divalent

Published: May 19, 2011 
at high $\mathrm{pH}$ values, ${ }^{4-6}$ that is, commonly outside of the physiological $\mathrm{pH}$ range.

Due to our general interest in coordination chemistry ${ }^{7-10}$ and the fact that the indicated interactions are of relevance, e.g., for ribozymes, ${ }^{11,12}$ which are also in the focus of our interest, ${ }^{13-16}$ we initiated a study allowing an overview on metal-ionhydroxyl group interactions. To this end, we made use of the equilibrium constants available in the literature ${ }^{17,18}$ by selecting those data that we considered as most reliable.

From previous work it is known that weakly interacting or coordinating groups can be identified and the extent of their interaction quantified if they are linked to a stronger primary binding site. ${ }^{19-22}$ The reason for this is that even a very weak interaction, next to the one occurring with the primary binding site (PBS), must be reflected in a stability enhancement. ${ }^{23-26}$ This stability enhancement may be tiny, and this is why error limits of the experimental data employed are important. A tiny stability enhancement means that the intramolecular equilibrium 1 is largely on its left side, whereas a high one indicates that chelate formation dominates

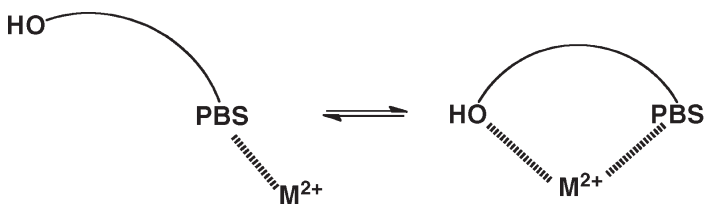

A few general remarks about the situation depictured in equilibrium 1 also seem appropriate at this point: In a $\mathrm{M}(\mathrm{PBS})$ complex (the charge of PBS remaining undefined), the coordination sites of the metal ion, which are not occupied by the donor atom(s) of the primary binding site, are filled with water molecules. Upon formation of the chelate, assuming hydroxylgroup binding occurs inner sphere, one water molecule is released from the coordination sphere of the metal ion. Overall, this release will lead to an increase in entropy because the entropy loss by coordination of the hydroxyl group will be smaller than the entropy gain due to water release, since the hydroxyl group is already in the open isomer restricted in its movements and located relatively close to the metal ion. Hence, equilibrium 1 on its way from the left to the right is expected to be partly entropy but also partly enthalpy driven because the donor strength of the coordinating $\mathrm{O}$ atom increases from $\mathrm{H}_{2} \mathrm{O}$ to $\mathrm{ROH}$ (where $\mathrm{R}$ is an alkyl group). ${ }^{27}$ To the best of our knowledge, no detailed study of the thermodynamic parameters exists for any of the equilibria discussed below. However, it is evident that a long or rigid chain between PBS and the hydroxyl group will inhibit chelate formation. Thus, the observation that the stability decreases in the order 5-membered $>6$-membered $>7$-membered ring (sections $3.3,4.3$, and 5.2) is at least tentatively understandable, though with multidentate ligands the situation may change. ${ }^{27}$ Obviously, a 4-membered ring is strained and therefore usually disfavored. Clearly, the net change in $\Delta G$ will always encompass all the indicated contributions, and chelate formation, reflected in a stability enhancement, will only occur, of course, if $\Delta G$ is overall negative (see also section 12).

In this review we will now evaluate the situation regarding equilibrium 1 for simple ligands which carry a hydroxyl group and as primary binding site a phosph(on)ate, carboxylate, amino, imidazolyl, or pyridyl residue. The various ligands will be discussed in this order including their complexes of the metal ions, $\mathrm{Ba}^{2+}, \mathrm{Sr}^{2+}, \mathrm{Ca}^{2+}, \mathrm{Mg}^{2+}, \mathrm{Mn}^{2+}, \mathrm{Co}^{2+}, \mathrm{Ni}^{2+}, \mathrm{Cu}^{2+}, \mathrm{Zn}^{2+}$,
$\mathrm{Cd}^{2+}$, and $\mathrm{Pb}^{2+}$, as far as stability data are available. At the end of the review we will consider the ligand $N$-hydroxyethylglycine, which has a glycinate-like bidentate primary binding site next to a hydroxyl residue, and also some polyhydroxyl ligands like the buffer Bistris.

It is fascinating to observe that the stability enhancement due to a $-\mathrm{OH} / \mathrm{M}^{2+}$ interaction can vary from about 0.05 to several log units, depending on the primary binding site and the kind of metal ion involved. For a few examples it will also be shown that a decreasing solvent polarity can promote the intensity of the $-\mathrm{OH} / \mathrm{M}^{2+}$ interaction.

\section{HOW IS THE EXTENT OF A WEAK INTERACTION BEST QUANTIFIED?}

If we define the open (op) isomer at the left in equilibrium 1 as $\mathrm{M}(\mathrm{PBS}-\mathrm{OH})_{\text {op }}$ by neglecting any charges and the chelated or closed $(\mathrm{cl})$ isomer as $\mathrm{M}(\mathrm{PBS}-\mathrm{OH})_{\mathrm{cl}}$, this equilibrium can be rewritten (eq 2)

$$
\mathrm{M}(\mathrm{PBS}-\mathrm{OH})_{\mathrm{op}} \rightleftharpoons \mathrm{M}(\mathrm{PBS}-\mathrm{OH})_{\mathrm{cl}}
$$

The position of this intramolecular equilibrium is defined by the dimensionless equilibrium constant, $K_{\mathrm{I}}$ (eq 3 )

$$
K_{\mathrm{I}}=\left[\mathrm{M}(\mathrm{PBS}-\mathrm{OH})_{\mathrm{cl}}\right] /\left[\mathrm{M}(\mathrm{PBS}-\mathrm{OH})_{\mathrm{op}}\right]
$$

Commonly employed methods for determination of complex stability constants, like potentiometric $\mathrm{pH}$ titrations or spectrophotometric measurements, do not distinguish between different isomeric species, that is, the total (tot) concentration of the complex species, $\mathrm{M}(\mathrm{PBS}-\mathrm{OH})_{\text {tot }}$ is determined and the stability constant of a simple 1:1 complex is then defined as given below (charges are neglected for simplicity) ${ }^{24-26}$

$$
\begin{gathered}
\mathrm{M}+\mathrm{PBS}-\mathrm{OH} \rightleftharpoons \mathrm{M}(\mathrm{PBS}-\mathrm{OH})_{\mathrm{tot}} \\
K_{\mathrm{M}(\mathrm{PBS}-\mathrm{OH})}^{\mathrm{M}}=\left[\mathrm{M}(\mathrm{PBS}-\mathrm{OH})_{\mathrm{tot}}\right] /([\mathrm{M}][\mathrm{PBS}-\mathrm{OH}])
\end{gathered}
$$

Taking into account the isomer formation of equilibrium 2, one obtains equilibrium 5

$$
\mathrm{M}+\mathrm{PBS}-\mathrm{OH} \rightleftharpoons \mathrm{M}(\mathrm{PBS}-\mathrm{OH})_{\mathrm{op}} \rightleftharpoons \mathrm{M}(\mathrm{PBS}-\mathrm{OH})_{\mathrm{cl}}
$$

and the corresponding stability constant is then defined by eq 6

$$
\begin{aligned}
K_{\mathrm{M}(\mathrm{PBS}-\mathrm{OH})}^{\mathrm{M}} & =\frac{\left[\mathrm{M}(\mathrm{PBS}-\mathrm{OH})_{\text {tot }}\right]}{[\mathrm{M}][\mathrm{PBS}-\mathrm{OH}]} \\
& =\frac{\left[\mathrm{M}(\mathrm{PBS}-\mathrm{OH})_{\mathrm{op}}\right]+\left[\mathrm{M}(\mathrm{PBS}-\mathrm{OH})_{\mathrm{cl}}\right]}{[\mathrm{M}][\mathrm{PBS}-\mathrm{OH}]}
\end{aligned}
$$

If no chelated isomer is formed, this expression reduces to eq 7

$$
K_{\mathrm{M}(\mathrm{PBS}-\mathrm{OH})_{\mathrm{op}}}^{\mathrm{M}}=[\mathrm{M}(\mathrm{PBS}-\mathrm{OH}) \mathrm{op}] /([\mathrm{M}][\mathrm{PBS}-\mathrm{OH}])
$$

which defines the stability of the open isomer. The combination of eqs 3,6, and 7 leads to eqs $8 \mathrm{a}$ and $8 \mathrm{~b}$

$$
\begin{aligned}
K_{\mathrm{M}(\mathrm{PBS}-\mathrm{OH})}^{\mathrm{M}}= & K_{\mathrm{M}(\mathrm{PBS}-\mathrm{OH}) \mathrm{op}}^{\mathrm{M}}+K_{\mathrm{I}} \cdot K_{\mathrm{M}(\mathrm{PBS}-\mathrm{OH}) \mathrm{op}}^{\mathrm{M}} \\
& =K_{\mathrm{M}(\mathrm{PBS}-\mathrm{OH})_{\mathrm{op}}}^{\mathrm{M}}\left(1+K_{\mathrm{I}}\right)
\end{aligned}
$$


Equation $8 \mathrm{~b}$ can be solved for $K_{\mathrm{I}}$, giving eq 9

$$
K_{\mathrm{I}}=\frac{\left[\mathrm{M}(\mathrm{PBS}-\mathrm{OH})_{\mathrm{cl}}\right]}{\left[\mathrm{M}(\mathrm{PBS}-\mathrm{OH})_{\mathrm{op}}\right]}=\frac{K_{\mathrm{M}(\mathrm{PBS}-\mathrm{OH})}^{\mathrm{M}}}{K_{\mathrm{M}(\mathrm{PBS}-\mathrm{OH})_{\mathrm{op}}}^{\mathrm{M}}}-1
$$

A value for $K_{\mathrm{I}}$ can now be calculated provided an experimental value exists for $K_{\mathrm{M}(\mathrm{PBS}-\mathrm{OH})}^{\mathrm{M}}$ and that a value for $K_{\mathrm{M}(\mathrm{PBS}-\mathrm{OH}) \text { op }}^{\mathrm{M}}$ can be obtained. The latter point is clearly the more difficult part.

Commonly, the stability of the open isomer is obtained by making use of the observation ${ }^{24}$ that for a family of structurally closely related ligands (PBS) plots of $\log K_{\mathrm{M}(\mathrm{PBS})}^{\mathrm{M}}$ versus $\mathrm{p} K_{\mathrm{H}(\mathrm{PBS})}^{\mathrm{H}}$ result in straight lines. Such a straight line is defined by the slope $m$ and the intercept $b$ with the $y$ axis $\left(=\log K_{\mathrm{M}(\mathrm{PBS})}^{\mathrm{M}}\right.$ axis)

$$
\log K_{\mathrm{M}(\mathrm{PBS})}^{\mathrm{M}}=m \cdot \mathrm{p} K_{\mathrm{H}(\mathrm{PBS})}^{\mathrm{H}}+b
$$

Once the parameters for $m$ and $b$ are known, one may calculate the corresponding complex stability constant based on the also known acidity constant of a ligand. The following is a specific example: From the plot of the data due to a family of closely related carboxylate ligands $\left(\mathrm{CA}^{-}\right)$, that is, of $\log K_{\mathrm{M}(\mathrm{CA})}^{\mathrm{M}}$ versus $\mathrm{p} K_{\mathrm{H}(\mathrm{CA})}^{\mathrm{H}}$, the parameters for eq 10 follow. This allows one now to calculate the stability of the open isomer of the complex formed, e.g., with hydroxyacetate $\left(\mathrm{HOAc}^{-}\right)$by applying $\mathrm{p} K_{\mathrm{H}(\mathrm{HOAc})}^{\mathrm{H}}$ (see Figure 5 in section 4.1.2).

Hence, based on the experimentally (exp) measured stability constants and the calculated (calc) ones the stability difference or better the stability enhancement for a certain complex system, which offers, e.g., a hydroxyl group next to the PBS unit for $\mathrm{M}^{2+}$ binding (eq 1), can now be defined

$$
\begin{aligned}
& \log \Delta_{\mathrm{M} / \mathrm{PBS}-\mathrm{OH}}=\log K_{\mathrm{M}(\mathrm{PBS}-\mathrm{OH})}^{\mathrm{M}}-\log K_{\mathrm{M}(\mathrm{PBS}-\mathrm{OH}) \mathrm{op}}^{\mathrm{M}} \\
& =\log K_{\mathrm{M}(\mathrm{PBS}-\mathrm{OH}) \exp }^{\mathrm{M}}-\log K_{\mathrm{M}(\mathrm{PBS}-\mathrm{OH}) \text { calc }}^{\mathrm{M}}=\log \Delta
\end{aligned}
$$

The corresponding equality of the various terms in eqs 11a and $11 \mathrm{~b}$ is evident, but it is also clear that well-defined error limits are needed for any quantitative evaluation.

With eqs $11 \mathrm{a}$ and $11 \mathrm{~b}$, eq 9 can be rewritten as given in eq 12

$$
K_{\mathrm{I}}=\left(\left[\mathrm{M}(\mathrm{PBS}-\mathrm{OH})_{\mathrm{cl}}\right]\right) /\left(\left[\mathrm{M}(\mathrm{PBS}-\mathrm{OH})_{\mathrm{op}}\right]\right)=10^{\log \Delta}-1
$$

and with now known values for $K_{\mathrm{I}}$, the percentages of the closed or chelated isomers occurring in equilibria 1 and 2 follow from eq 13

$$
\% \mathrm{M}(\mathrm{PBS}-\mathrm{OH})_{\mathrm{cl}}=100 \cdot K_{\mathrm{I}} /\left(1+K_{\mathrm{I}}\right)
$$

This procedure is applied in the sections to follow. Finally, it may be added that the acidity constants of the various monoprotonated ligands are defined in the common manner, i.e., as given in eqs $14 \mathrm{a}$ and $14 b$

$$
\begin{gathered}
\mathrm{H}(\mathrm{PBS})^{+} \rightleftharpoons \mathrm{PBS}+\mathrm{H}^{+} \\
K_{\mathrm{H}(\mathrm{PBS})}^{\mathrm{H}}=[\mathrm{PBS}]\left[\mathrm{H}^{+}\right] /\left[\mathrm{H}(\mathrm{PBS})^{+}\right]
\end{gathered}
$$
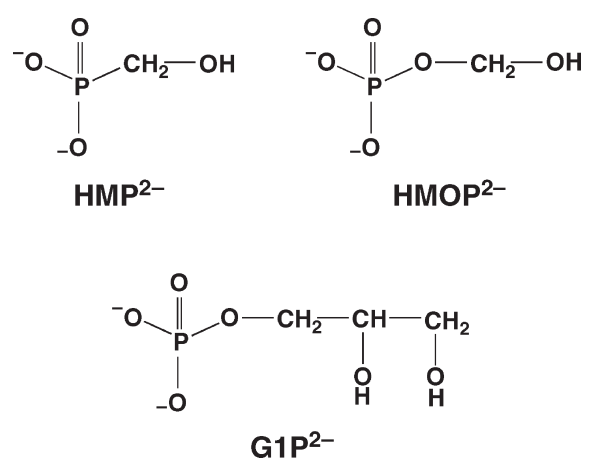

Figure 1. Considered phosph(on)ate ligands containing a hydroxyl group: hydroxymethylphosphonate $\left(\mathrm{HMP}^{2-}\right)$, hydroxymethyl phosphate $\left(\mathrm{HMOP}^{2-}\right)$, and glycerol 1-phosphate $\left(\mathrm{G}_{1} \mathrm{P}^{2-}=\alpha\right.$-glycerophosphate; in many biochemistry texts also designated as glycerol 3-phosphate).

\section{METAL-ION COMPLEXES WITH PHOSPH(ON)ATE GROUPS AS PRIMARY BINDING SITES}

From a coordination chemical point of view it would be interesting to deal with a series of ligands that allow formation of 5-, 6-, and 7-membered chelates. In this sense, the ligands depictured in Figure 1 are the correct ones to deal with. However, for hydroxymethyl phosphate $\left(\mathrm{HMOP}^{2-}\right)$ no equilibrium data are available, ${ }^{17,18}$ which is no surprise as $\mathrm{HMOP}^{2-}$ is the phosphate ester of the geminal diol $\mathrm{CH}_{2}(\mathrm{OH})_{2}$. For the other two ligands some though quite limited information is available, which is discussed in the following two subsections.

Fortunately, the straight-line parameters for a number of complexes with simple phosphate monoester ${ }^{28}$ and phosphonate ${ }^{29}$ ligands have been determined previously (see also below the legend of Figure 2 in section 3.1). The parameters for those metal ions for which also complexes with $\mathrm{PBS}-\mathrm{OH}$ ligands exist are listed in Table $1^{28-31}$

3.1. Extent of the Hydroxyl- $\mathrm{M}^{2+}$ Interaction in Complexes of Hydroxymethylphosphonate

From the structure of hydroxymethylphosphonate $\left(\mathrm{HMP}^{2-}\right)$ seen in Figure 1 it is evident that this ligand may form 5-membered chelates by involving the hydroxyl group. Reliable stability constants were found in ref 17 for the $\mathrm{Mg}(\mathrm{HMP}), \mathrm{Ca}(\mathrm{HMP})$, and $\mathrm{Cu}(\mathrm{HMP})$ complexes. Figure 2 shows plots of $\log \mathrm{K}_{\mathrm{M}\left(\mathrm{R}-\mathrm{PO}_{3}\right)}^{\mathrm{M}}$ versus $\mathrm{pK}_{\mathrm{H}\left(\mathrm{R}-\mathrm{PO}_{3}\right)}^{\mathrm{H}}$ for the $1: 1$ complexes of $\mathrm{Ca}^{2+}, \mathrm{Mg}^{2+}$, and $\mathrm{Cu}^{2+}$ with eight simple $\mathrm{R}-\mathrm{PO}_{3}^{2-}$ ligands (see legend of Figure 2), allowing only a phosph(on)ate- $\mathrm{M}^{2+}$ interaction. ${ }^{28,29}$ The corresponding least-squares reference lines, the parameters of which are listed in Table 1, define the relation between phosph(on)ate complex stability and phosph(on)ate group basicity. The three solid points in Figure 2, which refer to $\mathrm{Ca}(\mathrm{HMP}), \mathrm{Mg}(\mathrm{HMP})$, and $\mathrm{Cu}(\mathrm{HMP})$, are not much, yet beyond the error limits, above their reference lines, thus proving an increased stability for these complexes.

A quantitative evaluation of the situation reflected in Figure 2 is possible by calculating with $\mathrm{p} K_{\mathrm{H}(\mathrm{HMP})}^{\mathrm{H}}=6.97$ (cf. ref 17) and the straight-line equations of Table 1 (eq 10) the expected stabilities for the $\mathrm{M}(\mathrm{HMP})$ complexes with a sole phosphonate $-\mathrm{M}^{2+}$ coordination as seen in equilibrium 1, i.e., for the $\mathrm{M}(\mathrm{HMP})_{\text {op }}$ species (eq 2). The corresponding results are listed in column 3 of Table 2; their comparison according to eqs $11 \mathrm{a}$ and $11 \mathrm{~b}$ with the 


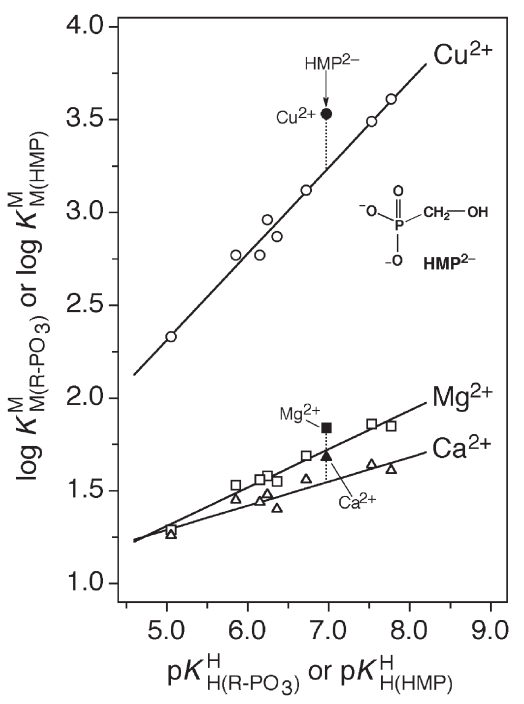

Figure 2. Evidence for an enhanced stability of the $\mathrm{Ca}^{2+}(\boldsymbol{\Delta}), \mathrm{Mg}^{2+}$ $(\mathbf{\square})$, and $\mathrm{Cu}^{2+}(\mathbf{O})$ 1:1 complexes of $\mathrm{HMP}^{2-}$ based on the relationship between $\log K_{\mathrm{M}\left(\mathrm{R}-\mathrm{PO}_{3}\right)}^{\mathrm{M}}$ and $\mathrm{p} K_{\mathrm{H}\left(\mathrm{R}-\mathrm{PO}_{3}\right)}^{\mathrm{H}}$ for $\mathrm{M}\left(\mathrm{R}-\mathrm{PO}_{3}\right)$ complexes of some simple phosphate monoester and phosphonate ligands $\left(\mathrm{R}-\mathrm{PO}_{3}^{2-}\right)(\triangle, \square, \mathrm{O})$ : 4-nitrophenyl phosphate $\left(\mathrm{NPhP}^{2-}\right)$, phenyl phosphate $\left(\mathrm{PhP}^{2-}\right)$, uridine $5^{\prime}$-monophosphate $\left(\mathrm{UMP}^{2-}\right)$, D-ribose 5 -monophosphate $\left(\operatorname{RibMP}^{2-}\right)$, thymidine $\left(=1-\left(2^{\prime}\right.\right.$-deoxy- $\beta$-D-ribofuranosyl)thymine) $5^{\prime}$-monophosphate $\left(\mathrm{dTMP}^{2-}\right), n$-butyl phosphate $\left(\mathrm{BuP}^{2-}\right)$, methanephosphonate $\left(\mathrm{MeP}^{2-}\right)$, and ethanephosphonate $\left(\mathrm{EtP}^{2-}\right)$ (from left to right). The least-squares reference lines (eq 10) are drawn through the corresponding eight data sets taken from ref 28 for the phosphate monoesters and from ref 29 for the phosphonates. The points due to the equilibrium constants for the $\mathrm{M}^{2+} / \mathrm{HMP}^{2-}$ systems $(\boldsymbol{\Lambda}, \mathbf{\square}, \mathbf{O})$ are based on the values listed in Table 2 (column 2 and footnote b). The vertical dotted lines emphasize the stability differences to the reference lines; they equal $\log \Delta_{\mathrm{M} / \mathrm{HMP}}$ as defined in eqs $11 \mathrm{a}$ and $11 \mathrm{~b}$ for the $\mathrm{M}(\mathrm{HMP})$ complexes. All plotted equilibrium constants refer to aqueous solutions at $25^{\circ} \mathrm{C}$ and $I=0.1 \mathrm{M}$.

measured stability constants (column 2) leads to the stability differences given in the fourth column of Table 2. Evidently all three M(HMP) complexes are more stable than expected on the basis of the basicity of the $\mathrm{HMP}^{2-}$ - phosphonate group.

As indicated in section 2, any increased stability must be attributed $^{24}$ to a further metal-ion-binding site interaction, i.e., in the present case to the oxygen of the $\mathrm{HMP}^{2-}-$ hydroxyl group (Figure 1). Consequently, 5-membered chelates, $\mathrm{M}(\mathrm{HMP})_{\mathrm{c}}$, must be formed to some extent and, thus, equilibria 1 and 2 operate. Application of the evaluation procedure described in section 2 (eqs $11 a-13$ ) gives the results summarized in Table 2 (columns 4-6). It is evident that for all three complexes studied at least some chelate formation occurs; the formation degrees vary between about $20 \%$ and $50 \%$.

The above results may be generalized, and the take home message then is as follows: The hydroxyl group, if supported by a suitably located primary binding site, may coordinate to the alkaline earth metal ions as well as to the divalent metal ions of the second half of the $3 \mathrm{~d}$ transition series. This statement is confirmed in the sections to follow.

3.2. Metal-Ion-Glycerol 1-Phosphate Systems: A Decreasing Solvent Polarity Favors Hydroxyl $-\mathrm{M}^{2+}$ Interactions

Glycerol 1-phosphate $\left(\mathrm{G}_{1} \mathrm{P}^{2-}\right)$ is, together with dihydroxyacetone phosphate, involved in the so-called $\alpha$-glycerophosphate shuttle. Both compounds are important intermediates
Table 1. Straight-Line Parameters for $\mathrm{M}^{2+}-$ Phosphate Monoester or - Phosphonate Complex Stabilities and Phosph(on)ate Group Basicities $\left(25^{\circ} \mathrm{C}, \mathrm{I}=0.1 \mathrm{M}, \mathrm{NaNO}_{3}\right)^{a, b}$

\begin{tabular}{ccccl} 
\%(v/v) 1,4-dioxane & $\mathrm{M}^{2+}$ & $m$ & $b$ & \multicolumn{1}{c}{$\mathrm{SD}$} \\
0 & $\mathrm{Ca}^{2+}$ & $0.131 \pm 0.020$ & $0.636 \pm 0.131$ & 0.048 \\
0 & $\mathrm{Mg}^{2+}$ & $0.208 \pm 0.015$ & $0.272 \pm 0.097$ & 0.033 \\
0 & $\mathrm{Cu}^{2+}$ & $0.465 \pm 0.025$ & $-0.015 \pm 0.164$ & 0.057 \\
30 & $\mathrm{Cu}^{2+}$ & $0.559 \pm 0.015$ & $-0.089 \pm 0.106$ & 0.03 \\
50 & $\mathrm{Cu}^{2+}$ & $0.571 \pm 0.022$ & $0.190 \pm 0.160$ & 0.03
\end{tabular}

${ }^{a}$ Slopes $(m)$ and intercepts $(b)$ for the straight-line plots of $\log$ $K_{\mathrm{H}\left(\mathrm{R}-\mathrm{PO}_{3}\right)}^{\mathrm{H}}$ (eqs $4 \mathrm{a}$ and $4 \mathrm{~b}$ ) versus $\mathrm{p} K_{\mathrm{H}\left(\mathrm{R}-\mathrm{PO}_{3}\right)}^{\mathrm{H}}$ (eqs $14 \mathrm{a}$ and $14 \mathrm{~b}$ ) as defined by eq 10 and as calculated by the least-squares procedure from the equilibrium constants for simple $\mathrm{R}-\mathrm{PO}_{3}^{2-} / \mathrm{H}^{+} / \mathrm{M}^{2+}$ systems $(\mathrm{R}=$ noncoordinating residue; for the ligands involved, see legends of Figures 2 and 3, vide infra) obtained in aqueous solutions ${ }^{28,29}$ and in water containing $30 \%$ or $50 \%(\mathrm{v} / \mathrm{v})$ 1,4-dioxane. ${ }^{30}$ The errors given with $m$ and $b$ correspond to one standard deviation $(1 \sigma)$. The column at the right lists three times the standard deviations (SD) resulting from the differences between the experimental and the calculated values for the various ligand systems. The listed SD values $(3 \sigma)$ are considered as reasonable error limits for any stability constant calculation in the $\mathrm{p} K_{\mathrm{H}\left(\mathrm{R}-\mathrm{PO}_{3}\right)}^{\mathrm{H}}$ range $5-8$ for aqueous solutions, $6-8.5$ for $30 \%$, and $6.5-9$ for $50 \%(\mathrm{v} / \mathrm{v}) 1,4-$ dioxane-water mixtures. ${ }^{b}$ The first three entries are from Tables 5 and 6 in ref 29 and the last two entries from Table 2 of ref 30 . Lists of the above parameters are also found in refs 25 and 31.

in biological processes, ${ }^{32-34}$ and many of these also depend on metal ions, ${ }^{35}$ as, for example, the $\alpha$-glycerophosphate shuttle, important for the synthesis of adenosine $5^{\prime}$-triphosphate $\left(\mathrm{ATP}^{4-}\right)^{36}$ and related reactions, ${ }^{37}$ which depend on the presence of $\mathrm{Ca}^{2+} \cdot 36,37$

Space-filling molecular models show that a phosphate-coordinated metal ion may easily reach the oxygen of the neighboring hydroxyl group in $\mathrm{G}^{2} \mathrm{P}^{2-}$ to form a 7-membered ring (see Figure 1). However, stability constant measurements in aqueous solution $\left(25^{\circ} \mathrm{C} ; \mathrm{I}=0.1 \mathrm{M}, \mathrm{NaNO}_{3}\right)^{38}$ showed no stability enhancements, that is, all the $\log \Delta_{M / G 1 P}$ values (eqs 1la and $11 \mathrm{~b}$ ) were between $-0.06 \pm 0.07\left(\mathrm{Ni}^{2+}\right)$ and $0.05 \pm 0.08\left(\mathrm{Mn}^{2+}\right) \log$ units for the corresponding $\mathrm{M}(\mathrm{G} 1 \mathrm{P})$ complexes of $\mathrm{Mn}^{2+}, \mathrm{Co}^{2+}, \mathrm{Ni}^{2+}, \mathrm{Cu}^{2+}$, $\mathrm{Zn}^{2+}$, or $\mathrm{Cd}^{2+}$. In other words, they were all zero within the error limits, meaning that at best a formation degree of about $20 \%$ may be reached for the $\mathrm{M}(\mathrm{G} 1 \mathrm{P})_{\mathrm{cl}}$ isomer.

There is a small discrepancy regarding the alkaline earth metalion complexes formed with $\mathrm{G}^{2} \mathrm{P}^{2-}$, which possibly may be explained by the fact that Schwarzenbach and Anderegg ${ }^{39}$ determined their values at $20^{\circ} \mathrm{C}(I=0.1 \mathrm{M}, \mathrm{KCl})$ whereas those measured by Liang and $\mathrm{H}$. Sigel et al. ${ }^{38}$ (see also ref 25$)$ refer to $25^{\circ} \mathrm{C}(I=0.1 \mathrm{M}$, $\mathrm{NaNO}_{3}$ ). The corresponding results are as follows

(i) ref 39: $\mathrm{p} K_{\mathrm{H}(\mathrm{G} 1 \mathrm{P})}^{\mathrm{H}}=6.07 ; \log K_{\mathrm{Ca}(\mathrm{G} 1 \mathrm{P})}^{\mathrm{Ca}}=1.66 \pm 0.05$, and $\log K_{\mathrm{Mg}(\mathrm{G} 1 \mathrm{P})}^{\mathrm{Mg}}=1.80 \pm 0.05$

(ii) ref 38: $\mathrm{p} K_{\mathrm{H}(\mathrm{G} 1 \mathrm{P})}^{\mathrm{H}}=6.23 \pm 0.01 ; \log K_{\mathrm{Ca}(\mathrm{G} 1 \mathrm{P})}^{\mathrm{Ca}}=1.43 \pm$ 0.05 , and $\log K_{\mathrm{Mg}(\mathrm{G} 1 \mathrm{P})}^{\mathrm{Mg}}=1.63 \pm 0.03$

Application of the straight-line parameters of Table 1 leads for (i) to $\log \Delta_{\mathrm{Ca} / \mathrm{G} 1 \mathrm{P}}=0.23 \pm 0.07$ and $\log \Delta_{\mathrm{Mg} / \mathrm{G} 1 \mathrm{P}}=0.27 \pm 0.06$, thus giving $\% \mathrm{Ca}(\mathrm{G} 1 \mathrm{P})_{\mathrm{cl}}=41 \pm 9$ and $\% \mathrm{Mg}(\mathrm{G} 1 \mathrm{P})_{\mathrm{cl}}=46 \pm 7$, and for (ii) to $\log \Delta_{\mathrm{Ca} / \mathrm{G} 1 \mathrm{P}}=-0.02 \pm 0.05$ and $\log \Delta_{\mathrm{Mg} / \mathrm{G} 1 \mathrm{P}}=0.06 \pm$ 0.04 , thus giving $\% \mathrm{Ca}(\mathrm{G} 1 \mathrm{P})_{\mathrm{cl}}<7$ and $\% \mathrm{Mg}(\mathrm{G} 1 \mathrm{P})_{\mathrm{cl}}=13 \pm 8$.

The discrepancy may be due to the different experimental conditions but possibly also due to traces of free phosphate in the early measurements. In any case, we believe that the values from refs 25 and 38 are closer to the "truth", yet at the same time, one 
Table 2. Comparison of the Measured Stability Constants, $K_{M}^{M}(\mathrm{HMP}) \exp$ (eqs 4a, 4b, and 6), of the 1:1 Complexes Formed between Hydroxymethylphosphonate $\left(\mathrm{HMP}^{2-}\right)$ and Several $\mathbf{M}^{2+}$ with the Stability Constants, $K_{M}^{\mathrm{M}}(\mathrm{HMP})$ op (eq 7 ), for the Isomers with a Sole Phosphonate Coordination of $\mathrm{M}^{2+}$, and Extent of the Intramolecular Chelate Formation According to Equilibria 1and 2 in the $\mathrm{M}(\mathrm{HMP})$ Complexes As Defined by $K_{\mathrm{I}}(\text { eqs 3, 9, and 12) and \% M(HMP) })_{\mathrm{cl}}(\mathrm{eq} 13)$ for Aqueous Solution at $25^{\circ} \mathrm{C}$ and $\mathrm{I}=0.1 \mathrm{M}$

\begin{tabular}{lccccc}
$\mathrm{M}^{2+}$ & $\log K_{\mathrm{M}(\mathrm{HMP}) \exp }^{\mathrm{M}}{ }^{2+}$ & $\log K_{\mathrm{M}(\mathrm{HMP}) \text { op }}^{\mathrm{M}}$ & $\log \Delta_{\mathrm{M} / \mathrm{HMP}}$ & \multicolumn{1}{c}{$K_{\mathrm{I}}$} & $\% \mathrm{M}(\mathrm{HMP})_{\mathrm{cl}}$ \\
$\mathrm{Mg}^{2+}$ & $1.84 \pm 0.10^{c}$ & $1.72 \pm 0.03$ & $0.12 \pm 0.10$ & $0.32(0.05 / 0.66)^{d}$ & $24(5 / 40)^{d}$ \\
$\mathrm{Ca}^{2+}$ & $1.68 \pm 0.06$ & $1.55 \pm 0.05$ & $0.13 \pm 0.08$ & $0.35 \pm 0.24$ & $26 \pm 13$ \\
$\mathrm{Cu}^{2+}$ & $3.53 \pm 0.06$ & $3.23 \pm 0.06$ & $0.30 \pm 0.08$ & $1.00 \pm 0.39$ & $50 \pm 10$
\end{tabular}

${ }^{a}$ All values are from ref 17 . Since no error limits are given in ref 17 an error limit of \pm 0.06 log unit is assumed, except in the case where the constant had to be corrected, "here an error of $\pm 0.10 \mathrm{log}$ unit is applied. ${ }^{b}$ Calculated with the straight-line equations defined in Table 1 for simple phosph(on)ate complexes and $\mathrm{p} K_{\mathrm{H}(\mathrm{HMP})}^{\mathrm{H}}=6.97 .{ }^{17}{ }^{c} \mathrm{In}$ ref 17 the value of 1.92 is listed for $I=0.1 \mathrm{M}$, which was kept constant with a tetraalkyl ammonium salt; to make the value comparable with solutions, where $I=0.1 \mathrm{M}$ is kept constant with $\mathrm{Na}^{+} / \mathrm{K}^{+}, 0.08$ log unit was deducted giving the above constant of $1.84 .{ }^{d}$ The lower and upper limits are given, respectively.

cannot exclude the possibility that traces of $\mathrm{M}(\mathrm{G} 1 \mathrm{P})_{\mathrm{cl}}$ are formed, especially in the case of $\mathrm{Mg}(\mathrm{G} 1 \mathrm{P})_{\mathrm{cl}}$.

However, the results seen in Figure 3 (cf. refs 25 and 38-40) prove that under special conditions 7 -membered chelates may form in $\mathrm{M}(\mathrm{G} 1 \mathrm{P})$ systems. These experiments ${ }^{38}$ were originally initiated by the fact that in proteins ${ }^{41}$ or in active-site cavities of enzymes ${ }^{42}$ the so-called "effective" or "equivalent-solution" dielectric constants (permittivities) are reduced compared to the situation in bulk water, namely, e.g., from about 80 to 35 . $^{42}$ The same is true for certain folds in RNA, ${ }^{14}$ and it has been shown recently ${ }^{43}$ that a decreased solvent permittivity indeed increases the metal-ion affinities of the RNA.

From Figure 3 it is evident that the overall stability of the $\mathrm{Cu}^{2+}$ complexes increases drastically with increasing amounts of 1,4dioxane, i.e., with a decreasing solvent polarity. More important in the present context, however, is the observation that the solid points due to the data pairs for the $\mathrm{Cu}(\mathrm{G} 1 \mathrm{P})$ complexes are more and more above the reference lines. Since the vertical distances between these points and their reference lines correspond to log $\Delta_{\mathrm{M} / \mathrm{G} 1 \mathrm{P}}$ as defined by eqs $11 \mathrm{a}$ and $11 \mathrm{~b}$, it is clear that the intramolecular interaction between $\mathrm{Cu}^{2+}$ and the $-\mathrm{OH}$ group in the $\mathrm{Cu}(\mathrm{G} 1 \mathrm{P})$ complex increases with increasing amounts of 1,4dioxane.

Application of the straight-line equations in Table 1 and of the acidity constants of $\mathrm{H}(\mathrm{G} 1 \mathrm{P})^{-}$(Table 3 , column 4) allows an exact quantification of the stability increases, $\log \Delta_{\mathrm{M} / \mathrm{G} 1 \mathrm{P}}$. These results are summarized in Table 3 together with some pertinent information about the solvents employed. ${ }^{44}$

The degree of formation of the chelated isomer of $\mathrm{Cu}(\mathrm{G} 1 \mathrm{P})$ is quite pronounced with about $40 \%$ in $50 \%(\mathrm{v} / \mathrm{v}) 1,4$-dioxanewater mixtures, and therefore, under these conditions equilibria 1 and 2 are important.

3.3. Some Generalizations Regarding Phosph(on)ate Ligands with a Weakly Coordinating Second Site

It is interesting to note that dihydroxyacetone phosphate $\left(\mathrm{DHAP}^{2-} ; \mathrm{HO}-\mathrm{CH}_{2}-\mathrm{C}(\mathrm{O})-\mathrm{CH}_{2}-\mathrm{O}-\mathrm{PO}_{3}^{2-}\right)$, which is part of the mentioned $\alpha$-glycerophosphate shuttle (section 3.2, opening paragraph) and has a carbonyl oxygen neighboring the phosphate group, meaning that its structure is rather similar to the one of G1P (Figure 1), may also form 7-membered chelates. Indeed, the $\mathrm{M}(\mathrm{DHAP})$ complexes show practically identical properties as the $\mathrm{M}(\mathrm{G} 1 \mathrm{P})$ species if formation of the closed isomers is considered. In aqueous solution the concentration of $\mathrm{M}(\mathrm{DHAP})_{\mathrm{cl}}$ is also diminishingly small, but again, a decreasing solvent polarity facilitates the intramolecular $-\mathrm{CO} / \mathrm{M}^{2+}$ interaction. $^{25,38}$ In both species, $\mathrm{M}(\mathrm{G} 1 \mathrm{P})_{\mathrm{cl}}$ and $\mathrm{M}(\mathrm{DHAP})_{\mathrm{cl}}$, as

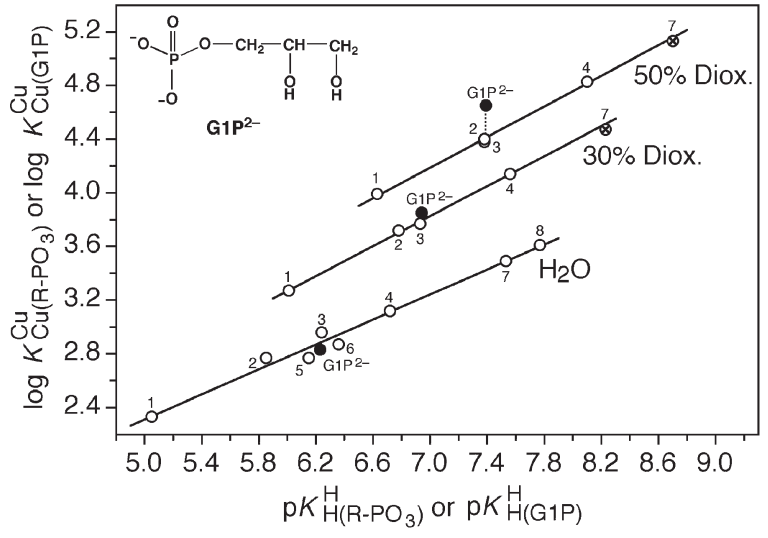

Figure 3. Evidence for an additional enhanced stability of the $\mathrm{Cu}(\mathrm{G} 1 \mathrm{P})$ complexes (1,4-dioxane-water mixtures as solvents based on the relationship between $\log K_{\mathrm{Cu}\left(\mathrm{R}-\mathrm{PO}_{3}\right)}^{\mathrm{Cu}}$ and $\mathrm{p} K_{\mathrm{H}\left(\mathrm{R}-\mathrm{PO}_{3}\right)}^{\mathrm{H}}$ for the $\mathrm{Cu}^{2+}$ 1:1 complexes of 4-nitrophenyl phosphate (1), phenyl phosphate (2), D-ribose 5-monophosphate (3), n-butyl phosphate (4), uridine $5^{\prime}$ monophosphate (5), thymidine $5^{\prime}$-monophosphate (6), methanephosphonate (7), and ethanephosphonate (8) in water and in water containing $30 \%$ or $50 \%(\mathrm{v} / \mathrm{v})$ 1,4-dioxane (adapted from ref 25$)$. The leastsquares lines are drawn in each case through the data shown $(\bigcirc) ;^{28-30}$ the equations for these reference lines are given in Table 1 . The data points due to the methanephosphonate system in the mixed solvents $(\otimes)$ (see ref 30) are shown to prove that simple phosphonates fit within the experimental error limits on the reference lines established with phosphate monoester systems (for details see ref 40). The data pairs for the points due to the $\mathrm{Cu}^{2+}$ 1:1 complexes formed with $\mathrm{G}^{2} \mathrm{P}^{2-}(\mathbf{0})$ in the three mentioned solvents are taken from Table 3 in ref 38 (see also Table 3 in section 3.2). The vertical dotted line emphasizes the stability difference to the corresponding reference line; these differences are equal to $\log \Delta_{\mathrm{Cu} / \mathrm{G} 1 \mathrm{P}}$ (eqs 11a and 11b), the values of which are listed in column 7 of Table 3 . All of the plotted equilibrium constants refer to $25^{\circ} \mathrm{C}$ and $I=0.1 \mathrm{M}\left(\mathrm{NaNO}_{3}\right)$.

far as they exist, the $-\mathrm{OH}$ group at $\mathrm{C} 3$ (see Figure 1) is most likely not involved in an interaction with $\mathrm{M}^{2+}$; otherwise, larger stability enhancements $\left(\log \Delta_{\mathrm{M} / \mathrm{PBS}-\mathrm{OH}}\right.$; eqs $11 \mathrm{a}$ and $\left.11 \mathrm{~b}\right)$ would be expected. Yet, most remarkably, the oxygen sites at $\mathrm{C} 2$, i.e., in the carbonyl group of $\mathrm{DHAP}^{2-}$, and in the hydroxyl group of $\mathrm{G}_{1} \mathrm{P}^{2-}$, behave quite alike in their metal-ion-binding properties. It may be added that for glycol phosphate (2-hydroxyethyl phosphate) no stability constants seem to be available. ${ }^{17,18}$

It is further worthwhile to mention that the ether oxygen in the dianion of (phosphonomethoxy)ethane $\left(\mathrm{PME}^{2-} ; \mathrm{CH}_{3} \mathrm{CH}_{2}-\right.$ $\left.\mathrm{O}-\mathrm{CH}_{2}-\mathrm{PO}_{3}^{2-}\right)$ can also participate in formation of 5-membered 
Table 3. Negative Logarithms of the Acidity Constants (eqs 14a and 14b) of H(G1P) ${ }^{-}$and Logarithms of the Stability Constants of the Corresponding $\mathrm{Cu}(\mathrm{G} 1 \mathrm{P})$ Complexes (eqs 4a, 4b, and 5) As Determined by Potentiometric $\mathrm{pH}$ Titrations ${ }^{38}$ in Dependence on the Amount of 1,4-Dioxane Added to Water and on the Resulting Dielectric Constant ${ }^{a, b}$

$\begin{array}{ccccccccc}\text { \% (v/v) dioxane } & \text { mole fraction dioxane } & \varepsilon^{c} & \mathrm{p} K_{\mathrm{H}(\mathrm{G} 1 \mathrm{P})}^{\mathrm{H}} & \log K_{\mathrm{Cu}(\mathrm{G} 1 \mathrm{P})}^{\mathrm{Cu}} & \log K_{\mathrm{Cu}(\mathrm{G} 1 \mathrm{P})}^{\mathrm{Culc}} & \log \Delta_{\mathrm{Cu} / \mathrm{G} 1 \mathrm{P}} & K_{\mathrm{I}} & \% \mathrm{Cu}(\mathrm{G} 1 \mathrm{P})_{\mathrm{cl}} \\ 0 & 0 & 78.5 & 6.23 \pm 0.01 & 2.83 \pm 0.05 & 2.88 \pm 0.06 & -0.05 \pm 0.08 & 0(<0.08) & 0(<7) \\ 30 & 0.083 & 52.7 & 6.94 \pm 0.01 & 3.85 \pm 0.02 & 3.79 \pm 0.03 & 0.06 \pm 0.04 & 0.15 \pm 0.10 & 13 \pm 7 \\ 50 & 0.175 & 35.2 & 7.39 \pm 0.03 & 4.65 \pm 0.02 & 4.41 \pm 0.03 & 0.24 \pm 0.04 & 0.74 \pm 0.14 & 42 \pm 5\end{array}$

${ }^{a}$ The stability constants for a pure $\mathrm{Cu}^{2+}$-phosphate residue coordination, i.e., for $\mathrm{M}(\mathrm{G} 1 \mathrm{P})$ op (eq 7), were calculated (calc) with the listed acidity constants and the straight-line equations given in Table 1 ; the resulting stability differences, $\log \Delta_{\mathrm{Cu} / \mathrm{G} 1 \mathrm{P}}$, are defined by eqs $11 \mathrm{a}$ and $11 \mathrm{~b}$. The extent of chelate formation according to equilibrium 1 in the $\mathrm{Cu}(\mathrm{G} 1 \mathrm{P})$ complexes is quantified by the dimensionless equilibrium constant $K_{\mathrm{I}}$ (eqs 3 and 12 ) and the percentage of the closed isomer, $\mathrm{Cu}(\mathrm{G} 1 \mathrm{P})_{\mathrm{cl}}(\mathrm{eq} 13)\left(25^{\circ} \mathrm{C} ; \mathrm{I}=0.1 \mathrm{M}, \mathrm{NaNO}_{3}\right)$. The values in columns 2 and 3 are taken from Table 3 in ref 38 . The values listed in columns 6-9 are revised ${ }^{25}$ compared to those given in ref $38 .{ }^{b}$ The error limits given for data from our own laboratories (which applies to the above values) are three times the standard error of the mean value or the sum of the probable systematic errors, whichever is larger. The error limits of all derived data, e.g., $\log \Delta_{\mathrm{Cu} / \mathrm{G} 1 \mathrm{P}}$, were calculated according to the error propagation after Gauss. ${ }^{c}$ The dielectric constants (permittivities) for the 1, 4-dioxane-water mixtures are interpolated from the data given in ref 44 .

chelates in aqueous solution. ${ }^{25,29,45,46}$ The formation degrees of the $\mathrm{M}(\mathrm{PME})_{\mathrm{cl}}$ species vary depending on the metal ion involved between about $15 \%\left(\mathrm{Ba}^{2+}\right)$ and $67 \%\left(\mathrm{Cu}^{2+}\right) .{ }^{25}$ Enlargement of the chelate to a 6-membered ring, as it occurs with the anion of (2-phosphonoethoxy)ethane $\left(\mathrm{PEE}^{2-} ; \mathrm{CH}_{3} \mathrm{CH}_{2}-\mathrm{O}-\mathrm{CH}_{2} \mathrm{CH}_{2}-\right.$ $\left.\mathrm{PO}_{3}^{2-}\right){ }^{47}$ reduces the formation degrees of the $\mathrm{M}(\mathrm{PEE})_{\mathrm{cl}}$ species significantly, that is, in aqueous solution the stability enhancement $\left(\log \Delta_{\mathrm{M} / \mathrm{PEE}}\right.$; eqs $11 \mathrm{a}$ and $\left.11 \mathrm{~b}\right)$ for the complexes of $\mathrm{Ba}^{2+}, \mathrm{Sr}^{2+}, \mathrm{Ca}^{2+}, \mathrm{Mg}^{2+}, \mathrm{Mn}^{2+}$, and $\mathrm{Cd}^{2+}$ is zero within the error limits and for the $3 \mathrm{~d}$ transition ions, $\mathrm{Co}^{2+}$, $\mathrm{Ni}^{2+}, \mathrm{Cu}^{2+}$, and $\mathrm{Zn}^{2+}$, it is small, being for $\mathrm{Cu}(\mathrm{PEE})$ only $0.17 \pm 0.07 \log$ unit, which amounts to a formation degree for $\mathrm{Cu}(\mathrm{PEE})_{\mathrm{cl}}$ of $32 \%{ }^{47}$

Generalization of the described results leads to the conclusion that in phosph(on)ate complexes with an oxygen atom in the second binding site the formation degree of the closed species, $\mathrm{M}(\mathrm{PBS}-\mathrm{OH})_{\mathrm{cl}}$ (eq 1), depends strongly on the size of the chelate ring and decreases in the order 5-membered > 6-membered > 7-membered ring.

Finally, since only a few studies in mixed solvents exist (see also section 4.4), we would like to point out that the properties of $\mathrm{Cu}(\mathrm{PME})$ were also quantified in the presence of 1,4 -dioxane. ${ }^{25}$ However, in this case there is no significant difference in the formation degree of $\mathrm{Cu}(\mathrm{PME})_{\mathrm{cl}}$ in water and in water containing $30 \%$ or $50 \%(\mathrm{v} / \mathrm{v}) 1,4$-dioxane; it amounts in all three solvents to about $62 \%{ }^{25,30}$ In this case the promoting effect of the ether $-\mathrm{O} / \mathrm{Cu}^{2+}$ interaction by the decreasing solvent polarity is offset by the solvation of the terminating $-\mathrm{CH}_{2} \mathrm{CH}_{3}$ residue by the ethylene bridges of 1,4-dioxane, which thus inhibits sterically the ether $-\mathrm{O} / \mathrm{Cu}^{2+}$ coordination.

\section{METAL-ION COMPLEXES WITH CARBOXYLATE GROUPS AS PRIMARY BINDING SITES}

The most typical ligand to be considered in this section regarding an evaluation of the binding strength of a hydroxyl group is clearly hydroxyacetate ( $\mathrm{HOAc}^{-}$; see Figure 4). Closely related to $\mathrm{HOAc}^{-}$is lactate, i.e., D-2-hydroxypropanoate $\left(2 \mathrm{HOPr}^{-}\right)$. For reasons of comparison, two ligands with an ether oxygen atom will also be taken into account, namely, methoxyacetate $\left(\mathrm{CH}_{3} \mathrm{OAc}^{-}\right)$and ethoxyacetate $\left(\mathrm{EtOAc}^{-}\right)$(see Figure 4).

Though quite a number of studies exist, ${ }^{17,18}$ which deal with equilibrium constants involving the four ligands seen in Figure 4, no straight-line correlations for $\log K_{\mathrm{M}(\mathrm{CA})}^{\mathrm{M}}$ versus $\mathrm{p} K_{\mathrm{H}(\mathrm{CA})}^{\mathrm{H}}$ plots, which can be employed here, are available. Please note, the

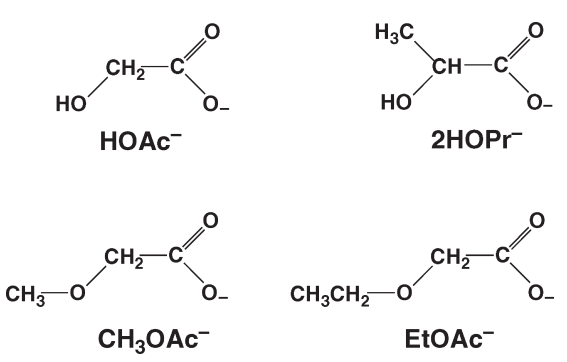

Figure 4. Carboxylate ligands which allow formation of 5-membered chelates involving the oxygen atom of a hydroxyl or ether group: Hydroxyacetate $\left(=\right.$ glycolate, $\left.\mathrm{HOAc}^{-}\right)$, D-2-hydroxypropanoate (= lactate; $\left.2 \mathrm{HOPr}^{-}\right)$, methoxyacetate $\left(\mathrm{CH}_{3} \mathrm{OAc}^{-}\right)$, and ethoxyacetate $\left(\mathrm{EtOAc}^{-}\right)$. Where needed, all four ligands are abbreviated with the symbol OAc${ }^{-}$(see section 4.1.2).

abbreviation $\mathrm{CA}^{-}$represents in this context simple carboxylate ligands like formate, acetate, or propionate. Unfortunately, the largest parts of the available equilibrium constants have been determined at an ionic strength $(I)$ of either 0.1 or $2 \mathrm{M}$, with only a few metal ions studied under both conditions. ${ }^{17,18}$ We decided therefore to evaluate the available data at $I=0.1$ and $2 \mathrm{M}$ independently of each other and to construct for both conditions the necessary reference lines; $I=0.1 \mathrm{M}$ will be dealt with in section 4.1 and $I=2 \mathrm{M}$ in section 4.2.

\subsection{Extent of Chelate Formation in Complexes of Hydro-} xyacetate and Related Ligands at $I=0.1 \mathrm{M}$

4.1.1. Construction of the Reference Lines for Several $\mathrm{M}^{2+}$-Carboxylate Systems. The acidity constants of simple carboxylate ligands, $\mathrm{H}(\mathrm{CA})$, together with the corresponding stability constants of various metal-ion complexes, $\mathrm{M}(\mathrm{CA})^{+}$, were collected from the literature $e^{17,48,49}$ and are summarized in Table 4. Plots of the $\log K_{\mathrm{M}(\mathrm{CA})}^{\mathrm{M}}$ versus $\mathrm{p} K_{\mathrm{H}(\mathrm{CA})}^{\mathrm{H}}$ data resulted, as expected, in straight lines. The results of the corresponding leastsquares calculations are summarized in Table 5 for the seven metal ions that could be considered.

The slopes $(m)$ and intercepts $\left(b=y_{0}\right)$ for the $\mathrm{Cu}^{2+}$ and $\mathrm{Zn}^{2+}$ systems have previously been determined as $m_{\mathrm{Cu}}=0.170 \pm$ $0.035(1 \sigma), y_{0 / \mathrm{Cu}}=0.965 \pm 0.159$ and $m_{\mathrm{Zn}}=0.039 \pm 0.031$, $y_{0 / \mathrm{Zn}}=0.802 \pm 0.141$, respectively (see the legend to Figure 2 in ref 45), in good agreement with the present values, meaning that the results overlap within the error limits $(1 \sigma)$. It should be mentioned that the straight line for the $\mathrm{Mn}^{2+} / \mathrm{H}^{+} / \mathrm{CA}^{-}$system 
Table 4. Logarithms of the Stability Constants for the 1:1 Complexes (eqs 4a, 4b, and 6) Formed between Several Divalent Metal Ions $\left(\mathrm{M}^{2+}\right)$ and Simple Carboxylate Ligands $\left(\mathrm{CA}^{-}\right)$As Well As Negative Logarithms of the Acidity Constants (eqs 14a and 14b) of the Corresponding $\mathrm{H}(\mathrm{CA})$ Species, Mostly Determined by Potentiometric $\mathrm{pH}$ Titrations, for Aqueous Solutions at $25{ }^{\circ} \mathrm{C}$ and $I=0.1 \mathrm{M}^{a}$

\begin{tabular}{|c|c|c|c|c|c|c|c|c|c|}
\hline \multirow[b]{2}{*}{ no. ${ }^{b}$} & \multirow[b]{2}{*}{$\mathrm{CA}^{-a}$} & \multirow[b]{2}{*}{$\mathrm{p} K_{\mathrm{H}(\mathrm{CA})}^{\mathrm{H}}$} & \multicolumn{7}{|c|}{$\log K_{\mathrm{M}(\mathrm{CA})}^{\mathrm{M}}$ for $\mathrm{M}^{2+}=$} \\
\hline & & & $\mathrm{Ba}^{2+}$ & $\mathrm{Sr}^{2+}$ & $\mathrm{Ca}^{2+}$ & $\mathrm{Mg}^{2+}$ & $\mathrm{Mn}^{2+}$ & $\mathrm{Cu}^{2+}$ & $\mathrm{Zn}^{2+}$ \\
\hline 1 & $\mathrm{ClAc}^{-}$ & $2.71 \pm 0.02$ & & & & & & $1.46 \pm 0.13$ & $0.84^{c}$ \\
\hline 2 & $\mathrm{HCOO}^{-}$ & $3.58 \pm 0.01$ & & & & & & $1.58 \pm 0.04$ & $0.95 \pm 0.03$ \\
\hline 3 & $\mathrm{Ac}^{-}$ & $4.57 \pm 0.01$ & & & & & & $1.73 \pm 0.04$ & $0.93 \pm 0.03$ \\
\hline 4 & $2 \mathrm{MPr}^{-}$ & $4.67 \pm 0.01$ & & & & & & $1.79 \pm 0.03$ & $1.01 \pm 0.02$ \\
\hline 5 & $3 \mathrm{MBu}^{-}$ & $4.61 \pm 0.01$ & & & & & & $1.70 \pm 0.03$ & $0.96 \pm 0.03$ \\
\hline 6 & $4 \mathrm{MVa}^{-}$ & $4.68 \pm 0.01$ & & & & & & $1.73 \pm 0.04$ & $0.99 \pm 0.04$ \\
\hline 7 & $5 \mathrm{MHx}^{-}$ & $4.69 \pm 0.01$ & & & & & & $1.79 \pm 0.07$ & $0.99 \pm 0.04$ \\
\hline 8 & $6 \mathrm{MHp}^{-}$ & $4.72 \pm 0.01$ & & & & & & $1.80 \pm 0.04$ & $1.02 \pm 0.05$ \\
\hline 9 & $\mathrm{ClAc}^{-}$ & $2.69 \pm 0.04$ & & & $0.14 \pm 0.05$ & $0.23 \pm 0.04$ & & & \\
\hline 10 & $\mathrm{BrAc}^{-}$ & 2.71 & $0.10^{d}$ & & & & & & \\
\hline 11 & $\mathrm{HCOO}^{-}$ & $3.57 \pm 0.03$ & & & $0.32^{e}$ & $0.38^{e}$ & & $1.61 \pm 0.04$ & $1.01 \pm 0.06$ \\
\hline 12 & $\mathrm{Bz}^{-}$ & $4.01 \pm 0.02$ & & & & & $0.70^{f}$ & & \\
\hline 13 & $\mathrm{Ac}^{-}$ & $4.56 \pm 0.03$ & $0.44 \pm 0.05$ & $0.47 \pm 0.04$ & $0.55 \pm 0.05$ & $0.51 \pm 0.05$ & 0.80 & $1.79 \pm 0.06$ & $1.07 \pm 0.07$ \\
\hline 14 & $\operatorname{Pr}^{-}$ & $4.69 \pm 0.03$ & 0.34 & 0.43 & 0.50 & 0.54 & & 1.91 & 1.01 \\
\hline
\end{tabular}

${ }^{a}$ In most instances the ionic strength $(I)$ was kept constant with $\mathrm{NaNO}_{3}$. In those cases where an error limit is given, it is taken from the cited references.

${ }^{b}$ The ligand abbreviations are defined as $\mathrm{ClAc}^{-}=$chloroacetate, $\mathrm{HCOO}^{-}=$formate, $\mathrm{Ac}^{-}=$acetate, $2 \mathrm{MPr}^{-}=2-$ methylpropanoate, $3 \mathrm{MBu}^{-}=$ 3-methylbutanoate, $4 \mathrm{MVa}^{-}=4$-methylvalerate $=4$-methylpentanoate, $5 \mathrm{MHx}^{-}=5$-methylhexanoate, $6 \mathrm{MHp}^{-}=6$-methylheptanoate, $\mathrm{BrAc}^{-}=$ bromoacetate, $\mathrm{Bz}^{-}=$benzoate, $\mathrm{Pr}^{-}=$propanoate. The values for entry 1 in columns 3 and 9 are from ref 48 , those in entries $2-8$ are from ref 49 , and those in entries 9-14 are from ref 17 . ${ }^{c}$ This value is an estimate: For $30^{\circ} \mathrm{C}$ and $I=0.5 \mathrm{M}, \log K=0.56$ is listed in ref 17 . For $\mathrm{Zn}(\mathrm{HCOO})^{+}$the difference of the values given for $30(I=0.5 \mathrm{M})$ and $25^{\circ} \mathrm{C}(I=0.1 \mathrm{M})$ equals $0.28 \log$ unit; ${ }^{17}$ hence, $\log K_{\mathrm{Zn}(\mathrm{ClAc})}^{\mathrm{Zn}}=0.56 \pm 0.28=0.84 .{ }^{d}$ Estimated value: For $25{ }^{\circ} \mathrm{C}$ and $I=0 \mathrm{M}, \log K=0.24$ is listed in ref 17 . On the basis of comparisons in ref 17 , between $I=0.1 \mathrm{M}$ and $I=0 \mathrm{M}$ the mentioned constant is reduced to log $K_{\mathrm{Ba}(\mathrm{BrAc})}^{\mathrm{Ba}}=0.10 .{ }^{e}$ Corrected values: For $30^{\circ} \mathrm{C}(I=0.5 \mathrm{M})$, listed in ref $17, \log K=0.27$ and 0.34 for $\mathrm{Ca}(\mathrm{HCOO})^{+}$and $\mathrm{Mg}(\mathrm{HCOO})^{+}$, respectively. These values are corrected by 0.05 and $0.04 \log$ unit based on the differences for $\mathrm{M}(\mathrm{Ac})^{+}$complexes at $30(I=0.5 \mathrm{M})$ and $\left.25^{\circ} \mathrm{C}(I=0.1 \mathrm{M})\right)^{17 f} \mathrm{For} 25^{\circ} \mathrm{C}(I=$ $1 \mathrm{M}), \log K=0.62$ is listed in ref 17 ; this value is corrected by $0.08 \log$ unit based on values for $\mathrm{M}(\mathrm{Ac})^{+}$complexes at $25(I=1 \mathrm{M})$ and $25^{\circ} \mathrm{C}(I=0.1 \mathrm{M}) .^{17}$

Table 5. Straight-Line Parameters for $\mathrm{M}^{2+} 1: 1$ Complexes Formed with Simple Carboxylate Ligands $\left(\mathrm{CA}^{-}\right)$, Valid for Aqueous Solutions at $25^{\circ} \mathrm{C}$ and $I=0.1 \mathrm{M}^{a, b}$

\begin{tabular}{lll}
$\mathrm{M}^{2+}$ & \multicolumn{1}{c}{$m$} & \multicolumn{1}{c}{$b$} \\
$\mathrm{Ba}^{2+}$ & $0.148 \pm 0.054$ & $-0.298 \pm 0.221$ \\
$\mathrm{Sr}^{2+}$ & 0.148 & -0.235 \\
$\mathrm{Ca}^{2+}$ & $0.197 \pm 0.023$ & $-0.385 \pm 0.093$ \\
$\mathrm{Mg}^{2+}$ & $0.151 \pm 0.007$ & $-0.170 \pm 0.026$ \\
$\mathrm{Mn}^{2+}$ & 0.182 & -0.029 \\
$\mathrm{Cu}^{2+}$ & $0.169 \pm 0.025$ & $0.994 \pm 0.109$ \\
$\mathrm{Zn}^{2+}$ & $0.060 \pm 0.022$ & $0.724 \pm 0.095$
\end{tabular}

${ }^{a}$ The slopes $(m)$ and intercepts $(b)$ for the straight reference lines from plots of $\log K_{\mathrm{M}(\mathrm{CA})}^{\mathrm{M}}$ versus $\mathrm{p} K_{\mathrm{H}(\mathrm{CA})}^{\mathrm{H}}$ were calculated by the least-squares procedure from the experimentally determined equilibrium constants listed in Table 4 (see also Figure 5). In the case of $\mathrm{Sr}^{2+}$ the slope, $m=0.148$, of $\mathrm{Ba}^{2+}$ was also applied. ${ }^{b}$ The straight-line equation is defined by eq 10 . With a known $\mathrm{p} K_{\mathrm{H}(\mathrm{CA})}^{\mathrm{H}}$ value of any carboxylate

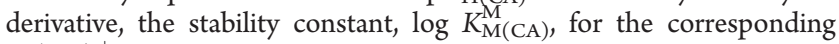
$\mathrm{M}(\mathrm{CA})^{+}$complex can be calculated. The errors given with the slopes $m$ and intercepts $b$ correspond to one standard deviation $(1 \sigma)$.

is defined by only two data points (see Table 4 and Figure 5 in section 4.1.2) and that for the $\mathrm{Sr}^{2+} / \mathrm{H}^{+} / \mathrm{CA}^{-}$system the same slope $(m)$ was assumed as determined for the $\mathrm{Ba}^{2+} / \mathrm{H}^{+} / \mathrm{CA}^{-}$ system (see footnotes in Table 5). However, this is not a problem because the slopes $m$ are small as are the needed extrapolations; moreover, these shortcomings in the $\mathrm{Sr}^{2+}$ and $\mathrm{Mn}^{2+}$ systems were also taken into account in the applied error limits.

Table 6 lists the deviations from the least-squares line for each individual complex of the ligands listed in Table 4 (column 2). There is a single deviation of $0.12 \log$ unit for the $\mathrm{Cu}^{2+} / \mathrm{H}^{+} / \mathrm{Pr}^{-}$ system (Table 6, entry 14); all other deviations are mostly below \pm 0.07 log unit. To provide a reliable error limit for any stability constant calculated with the equations of Table 5 and a given $\mathrm{p} K_{\mathrm{H}(\mathrm{CA})}^{\mathrm{H}}$ value, for each of the seven metal ions treated, the standard deviation of the data points from the relevant leastsquares line was calculated; the corresponding values are given in Table 6 in the bottom row following the SD term.

Users of the results described in this section are recommended to apply the equations of Table 5 for carboxylate ligands in the $\mathrm{p} K_{\mathrm{H}(\mathrm{CA})}^{\mathrm{H}}$ range of $2.5-5$ and to consider as error limits of the calculated stability constant $\log K_{\mathrm{M}(\mathrm{CA})}^{\mathrm{M}}$ three times the standard deviation (SD) given in the bottom row of Table 6 for the corresponding metal-ion system. An application of this procedure is given below in the next section.

4.1.2. Extent of Chelate Formation in Metal-Ion Complexes Formed with Hydroxy Carboxylates and Related Ligands. Are the stabilities of the $\mathrm{M}(\mathrm{HOCA})^{+}$complexes solely determined by the coordinating properties of the carboxylate group or does the hydroxyl group also have an effect? The answer to this question may be obtained by making use of the straightline correlations for $\log K_{\mathrm{M}(\mathrm{CA})}^{\mathrm{M}}$ versus $\mathrm{p} K_{\mathrm{H}(\mathrm{CA})}^{\mathrm{H}}$ plots as established in the preceding section. Four examples of such plots are shown in Figure 5 for the $1: 1$ complexes of $\mathrm{Ba}^{2+}, \mathrm{Ca}^{2+}, \mathrm{Mn}^{2+}$, 


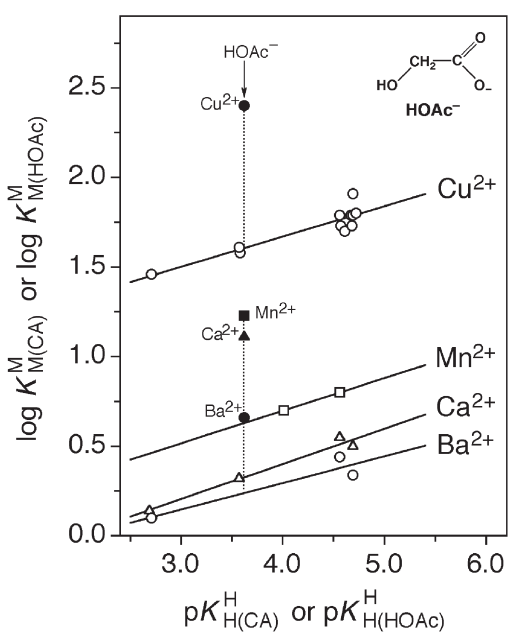

Figure 5. Evidence for an enhanced complex stability of the $\mathrm{Ba}^{2+}(\mathbf{0})$, $\mathrm{Ca}^{2+}(\mathbf{\Delta}), \mathrm{Mn}^{2+}(\boldsymbol{\square})$, and $\mathrm{Cu}^{2+}(\mathbf{O})$ 1:1 complexes of $\mathrm{HOAc}^{-}$based on the relationship between $\log K_{\mathrm{M}(\mathrm{CA})}^{\mathrm{M}}$ and $\mathrm{p} K_{\mathrm{H}(\mathrm{CA})}^{\mathrm{H}}$ for the simple carboxylate ligands $\left(\mathrm{CA}^{-}\right)$listed in Table 4 . The parameters of the corresponding least-squares reference lines (eq 10) are summarized in Table 5. The data for the points due to the equilibrium constants of the $\mathrm{M}^{2+} / \mathrm{HOAc}^{-}$systems are given in Table 7. The vertical dotted lines emphasize the stability differences to the reference lines; they equal $\log \Delta_{\mathrm{M} / \mathrm{HOAc}}$, as defined in eqs 11a and $11 \mathrm{~b}$ (see also Table 7, column 5). All plotted equilibrium constants refer to aqueous solutions at $25^{\circ} \mathrm{C}$ and $I=0.1 \mathrm{M}$.

and $\mathrm{Cu}^{2+}$ with simple $\mathrm{CA}^{-}$ligands that have no binding site next to the carboxylate group (open symbols). The solid symbols refer to the $\mathrm{HOAc}^{-}$complexes of the mentioned metal ions. Evidently, the data points for all $\mathrm{M}(\mathrm{HOAc})^{+}$complexes are far above their corresponding reference lines, indicating chelate formation according to equilibrium 1 .

A quantitative evaluation of the situation seen in Figure 5 is possible by applying $\mathrm{p} K_{\mathrm{H}(\mathrm{HOAc})}^{\mathrm{H}}$ and the straight-line parameters listed in Table 5 to eq 10. The results define the stabilities of the open isomers of the $\mathrm{M}(\mathrm{HOAc})^{+}$complexes in which $\mathrm{M}^{2+}$ is solely bound to the carboxylate group (eq 1 ). These

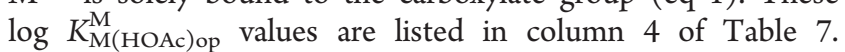
Comparison of these values with the experimentally determined stability constants (column 3 ) according to eqs $11 \mathrm{a}$ and $11 \mathrm{~b}$ provides the stability enhancement, $\log \Delta_{\mathrm{M} / \mathrm{HOAc}}$ which quantifies the intensity of the $-\mathrm{OH} / \mathrm{M}^{2+}$ interaction in the individual $\mathrm{M}(\mathrm{HOAc})^{+}$complexes. Now use can be made of eqs 12 and 13, which results in the formation degrees of the chelated species. The corresponding percentages are listed in column 7 of Table 7. The analogous results for the $\mathrm{M}(2 \mathrm{HOPr})^{+}$and $\mathrm{M}\left(\mathrm{CH}_{3} \mathrm{OAc}\right)^{+}$ complexes are also summarized in Table 7.

Comparison of the results assembled in Table 7, where $\mathrm{OAc}^{-}=\mathrm{HOAc}^{-}, 2 \mathrm{HOPr}^{-}$, or $\mathrm{CH}_{3} \mathrm{OAc}^{-}$, with those of Table 2 shows that with a singly negatively charged carboxylate group as a primary binding site, compared with the situation of the 2 -fold negatively charged phosphonate group, the formation degrees of the chelated species are considerably larger. Indeed, the stability enhancements, $\log \Delta_{\mathrm{M} / \mathrm{PBS}-\mathrm{OH}}$, for $\mathrm{Mg}^{2+}, \mathrm{Ca}^{2+}$, and $\mathrm{Cu}^{2+}$, for which a direct comparison is possible, are by about $0.4-0.65 \mathrm{log}$ units larger for the $\mathrm{M}(\mathrm{HOAc})^{+}$species, compared with the $\mathrm{M}(\mathrm{HMP})$ ones.

Interestingly, replacement of a $\mathrm{H}$ atom in the methylene unit of $\mathrm{HOAc}^{-}$by a $\mathrm{CH}_{3}$ group leading to $2 \mathrm{HOPr}^{-}$(see Figure 4) has no significant influence on the observed stability enhancements
Table 6. Logarithmic Differences between the Experimentally Determined Stability Constants $\left(\log K_{M(\mathrm{CA})}^{\mathrm{M}}\right.$ of Table 4$)$ of the $\mathrm{M}^{2+}$ Complexes for the Simple Carboxylate Ligands $\left(\mathrm{CA}^{-}\right)$Listed in Column 2 of Table 4 and the Least-Squares Lines of the $\log K_{\mathrm{M}(\mathrm{CA})}^{\mathrm{M}}$ versus $\mathrm{p} K_{\mathrm{H}(\mathrm{CA})}^{\mathrm{H}}$ Plots as Defined in Table 5 (the bottom line of the table gives the standard deviation (SD) ${ }^{b}$ resulting from the listed differences)

\begin{tabular}{lllllllrl} 
& & \multicolumn{5}{c}{$\mathrm{M}(\mathrm{CA})^{+}$complexes for $\mathrm{M}^{2+}=$} \\
\cline { 4 - 8 } no. $^{a}$ & $\mathrm{CA}^{-a}$ & $\mathrm{Ba}^{2+}$ & $\mathrm{Sr}^{2+}$ & $\mathrm{Ca}^{2+}$ & $\mathrm{Mg}^{2+}$ & $\mathrm{Mn}^{2+}$ & $\mathrm{Cu}^{2+}$ & $\mathrm{Zn}^{2+}$ \\
1 & $\mathrm{ClAc}^{-}$ & & & & & & 0.01 & -0.05 \\
2 & $\mathrm{HCOO}^{-}$ & & & & & -0.02 & 0.01 \\
3 & $\mathrm{Ac}^{-}$ & & & & & & -0.04 & -0.07 \\
4 & $2 \mathrm{MPr}^{-}$ & & & & & & 0.01 & 0.01 \\
5 & $3 \mathrm{MBu}^{-}$ & & & & & & -0.07 & -0.04 \\
6 & $4 \mathrm{MVa}^{-}$ & & & & & & -0.06 & -0.01 \\
7 & $5 \mathrm{MHx}^{-}$ & & & & & & 0.00 & -0.02 \\
8 & $6 \mathrm{MHp}^{-}$ & & & & & & 0.01 & 0.01 \\
9 & $\mathrm{ClAc}^{-}$ & & & 0.00 & -0.01 & & \\
10 & $\mathrm{BrAc}^{-}$ & 0.00 & & & & & & \\
11 & $\mathrm{HCOO}^{-}$ & & & 0.00 & 0.01 & 0.01 & 0.07 \\
12 & $\mathrm{Bz}^{-}$ & & & & & 0.00 & & \\
13 & $\mathrm{Ac}^{-}$ & 0.06 & 0.03 & 0.04 & -0.01 & 0.00 & 0.03 & 0.07 \\
14 & $\mathrm{Pr}^{-}$ & -0.06 & -0.03 & -0.04 & 0.00 & 0.12 & 0.00 \\
& $\mathrm{SD}^{b}$ & 0.035 & $0.04^{c}$ & 0.016 & $0.01^{c}$ & $0.04^{c}$ & 0.015 & 0.013
\end{tabular}

${ }^{a}$ The entry numbers correspond to those of Table 4 to facilitate comparisons. For the definition of the abbreviations see footnote " $a$ " of Table $4{ }^{b}$ The standard deviation (SD) times three is considered as a reasonable error limit for any calculation of the stability of a $\mathrm{M}(\mathrm{CA})^{+}$ complex based on the straight lines defined in Table 5 for the $\mathrm{p} K_{\mathrm{a}}$ range $2.5-5 .{ }^{c}$ Error limit enlarged from 0.03 to $0.04\left(\mathrm{Sr}^{2+}\right)$, from 0.005 to $0.01\left(\mathrm{Mg}^{2+}\right)$, and from 0.00 to $0.04\left(\mathrm{Mn}^{2+}\right)$.

$\left(\log \Delta_{\mathrm{M} / \mathrm{OAc}}\right)$ and the formation degrees of the closed species $\left(\% \mathrm{M}(\mathrm{OAc})_{\mathrm{cl}}^{+}\right)$(see Table 7, columns 5 and 7 ). In fact, the values are mostly the same within the error limits for the $\mathrm{M}(\mathrm{HOAc})^{+}$ and $\mathrm{M}(2 \mathrm{HOPr})^{+}$species.

Even though only two systems are available $\left(\mathrm{Ca}^{2+}\right.$ and $\left.\mathrm{Cu}^{2+}\right)$ for which the $\mathrm{H}$ atom of the $\mathrm{OH}$ group in $\mathrm{HOAc}^{-}$was replaced by $\mathrm{CH}_{3}$, giving an ether oxygen as a potential binding site, it seems clear that the methyl group inhibits somewhat the $\mathrm{O} / \mathrm{M}^{2+}$ interaction, that is, $\% \mathrm{M}(\mathrm{HOAc})^{+}>\% \mathrm{M}\left(\mathrm{CH}_{3} \mathrm{OAc}\right)^{+}$. Since in both cases the difference between $\log \Delta_{\mathrm{M} / \mathrm{HOAc}}$ and $\log$ $\Delta_{\mathrm{M} / \mathrm{CH}_{3} \mathrm{OAc}}$ amounts to about $0.4 \log$ unit, and this despite the fact that one example is from an alkali earth metal ion $\left(\mathrm{Ca}^{2+}\right)$ and the other one from a $3 \mathrm{~d}$ transition-metal ion $\left(\mathrm{Cu}^{2+}\right)$, one may conclude that the ether oxygen is a poorer ligand also for the other metal ions which appear in Table 7.

Another remarkable result is the observation that $\mathrm{Ca}^{2+}$ has an especially pronounced affinity toward the $-\mathrm{OH}$ site. For both types of complexes, $\mathrm{M}(\mathrm{HOAc})^{+}$and $\mathrm{M}(2 \mathrm{HOPr})^{+}$, the series holds: $\mathrm{Ba}(\mathrm{OAc})_{\mathrm{cl}}^{+}<\mathrm{Sr}(\mathrm{OAc})_{\mathrm{cl}}^{+}<\mathrm{Ca}(\mathrm{OAc})_{\mathrm{cl}}^{+}>\mathrm{Mg}(\mathrm{OAc})_{\mathrm{cl}}^{+}$. Indeed, more astonishing is that $\% \mathrm{Ca}(\mathrm{OAc})_{\mathrm{cl}}^{+}$is very similar to $\% \mathrm{Cu}(\mathrm{OAc})_{\mathrm{cl}}^{+}(\mathrm{Table} 7)$ and this despite the fact that the $\mathrm{Cu}(\mathrm{OAc})^{+}$complexes are by a factor of about 20 (or more) more stable than the $\mathrm{Ca}(\mathrm{OAc})^{+}$ones (Table 7 , column 3). It is interesting to note in this context that $\mathrm{Ca}^{2+}$ is able to inhibit strongly the $\mathrm{Mg}^{2+}$-promoted self-splicing reaction of a RNA (group II intron). ${ }^{50,51}$ With regard to biological systems ${ }^{52}$ it is further noteworthy that $\mathrm{Mg}^{2+}$ and $\mathrm{Mn}^{2+}$ have within the error 
Table 7. Comparison of the Measured (exp) Stability Constants, $K_{M}^{M}(\mathrm{OAc}) \exp \left(\right.$ eqs $4 \mathrm{a}$, 4b, and 6), of the $\mathbf{M}^{2+} 1: 1 \mathrm{Complexes}^{\mathrm{M}}$ Formed by Hydroxyacetate $\left(\mathrm{HOAc}^{-}\right)^{b}$ and the Related Ligands D-2-Hydroxypropanoate $\left(2 \mathrm{HOPr}^{-}=\mathrm{lactate}^{b}\right.$ and $\mathrm{Methoxy}^{-}$ acetate $\left(\mathrm{CH}_{3} \mathrm{OAc}^{-}\right){ }^{b}$ with the Calculated Stability Constants for the Open Isomers with a Sole Carboxylate- $\mathrm{M}^{2+} \mathrm{Coordination}$, $K_{\mathbf{M}(\mathrm{OAc}) \text { op }}^{\mathrm{M}}(\text { eqs } 1 \text { and } 7)^{a}$

\begin{tabular}{|c|c|c|c|c|c|c|}
\hline $\mathrm{OAc}^{-}$ & $\mathrm{M}^{2+}$ & 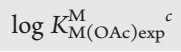 & $\log K_{\mathrm{M}(\mathrm{OAc}) \mathrm{op}}^{\mathrm{M}}$ & $\log \Delta_{\mathrm{M} / \mathrm{OAc}}$ & $K_{\mathrm{I}}$ & $\% \mathrm{M}(\mathrm{OAc})_{\mathrm{cl}}^{+}$ \\
\hline \multirow[t]{7}{*}{$\mathrm{HOAc}^{-}$} & $\mathrm{Ba}^{2+}$ & $0.66 \pm 0.06$ & $0.24 \pm 0.11$ & $0.42 \pm 0.13$ & $1.63 \pm 0.76$ & $62 \pm 11$ \\
\hline & $\mathrm{Sr}^{2+}$ & $0.80 \pm 0.06$ & $0.30 \pm 0.12$ & $0.50 \pm 0.13$ & $2.16 \pm 0.98$ & $68 \pm 10$ \\
\hline & $\mathrm{Ca}^{2+}$ & $1.11 \pm 0.06$ & $0.33 \pm 0.05$ & $0.78 \pm 0.08$ & $5.03 \pm 1.08$ & $83 \pm 3$ \\
\hline & $\mathrm{Mg}^{2+}$ & $0.92 \pm 0.06$ & $0.38 \pm 0.03$ & $0.54 \pm 0.07$ & $2.47 \pm 0.54$ & $71 \pm 4$ \\
\hline & $\mathrm{Mn}^{2+}$ & $1.23 \pm 0.10^{d}$ & $0.63 \pm 0.12$ & $0.60 \pm 0.16$ & $2.98 \pm 1.43$ & $75 \pm 9$ \\
\hline & $\mathrm{Cu}^{2+}$ & $2.40 \pm 0.06$ & $1.61 \pm 0.05$ & $0.79 \pm 0.08$ & $5.17 \pm 1.11$ & $84 \pm 3$ \\
\hline & $\mathrm{Zn}^{2+}$ & $1.98 \pm 0.04$ & $0.94 \pm 0.04$ & $1.04 \pm 0.06$ & $9.96 \pm 1.43$ & $91 \pm 1$ \\
\hline \multirow[t]{7}{*}{$2 \mathrm{HOPr}^{-}$} & $\mathrm{Ba}^{2+}$ & $0.55 \pm 0.06$ & $0.24 \pm 0.11$ & $0.31 \pm 0.13$ & $1.04 \pm 0.59$ & $51 \pm 14$ \\
\hline & $\mathrm{Sr}^{2+}$ & $0.70 \pm 0.06$ & $0.31 \pm 0.12$ & $0.39 \pm 0.13$ & $1.45 \pm 0.76$ & $59 \pm 13$ \\
\hline & $\mathrm{Ca}^{2+}$ & $1.07 \pm 0.06$ & $0.34 \pm 0.05$ & $0.73 \pm 0.08$ & $4.37 \pm 0.97$ & $81 \pm 3$ \\
\hline & $\mathrm{Mg}^{2+}$ & $0.93 \pm 0.06$ & $0.38 \pm 0.03$ & $0.55 \pm 0.07$ & $2.55 \pm 0.55$ & $72 \pm 4$ \\
\hline & $\mathrm{Mn}^{2+}$ & $1.19 \pm 0.06$ & $0.64 \pm 0.12$ & $0.55 \pm 0.13$ & $2.55 \pm 1.10$ & $72 \pm 9$ \\
\hline & $\mathrm{Cu}^{2+}$ & $2.54 \pm 0.06$ & $1.61 \pm 0.05$ & $0.93 \pm 0.08$ & $7.51 \pm 1.53$ & $88 \pm 2$ \\
\hline & $\mathrm{Zn}^{2+}$ & $1.86 \pm 0.06$ & $0.94 \pm 0.04$ & $0.92 \pm 0.07$ & $7.32 \pm 1.38$ & $88 \pm 2$ \\
\hline \multirow[t]{2}{*}{$\mathrm{CH}_{3} \mathrm{OAc}^{-}$} & $\mathrm{Ca}^{2+}$ & $0.70 \pm 0.10^{e}$ & $0.27 \pm 0.05$ & $0.43 \pm 0.11$ & $1.69 \pm 0.69$ & $63 \pm 10$ \\
\hline & $\mathrm{Cu}^{2+}$ & $1.92 \pm 0.10^{f}$ & $1.56 \pm 0.05$ & $0.36 \pm 0.11$ & $1.29 \pm 0.59$ & $56 \pm 11$ \\
\hline
\end{tabular}

${ }^{a}$ The observed stability increase is expressed by $\log \Delta_{\mathrm{M} / \mathrm{OAc}}$ (eqs 11a and $11 \mathrm{~b}$ ). The extent of chelate formation according to the intramolecular equilibria 1 and 2 for the $\mathrm{M}(\mathrm{OAc})^{+}$complexes is quantified by the dimensionless equilibrium constant $K_{\mathrm{I}}$ (eqs 7 and 9) and the percentage of closed isomers $\mathrm{M}(\mathrm{OAc})_{\mathrm{cl}}^{+}$(eq 13). All data refer to aqueous solutions at $25{ }^{\circ} \mathrm{C}$ and $I=0.1 \mathrm{M} \cdot{ }^{17 b}$ The corresponding acidity constants (eqs $14 \mathrm{a}$ and $14 \mathrm{~b}$ ) are $\mathrm{p} K_{\mathrm{H}(\mathrm{HOAc})}^{\mathrm{H}}=3.62 \pm 0.03, \mathrm{p} K_{\mathrm{H}(2 \mathrm{HOPr})}^{\mathrm{H}}=3.66 \pm 0.03$, and $\mathrm{p} K_{\mathrm{H}\left(\mathrm{CH}_{3} \mathrm{OAc}\right)}^{\mathrm{H}}=3.32 .{ }^{17 c}$ If available, the error limits given in the literature ${ }^{17}$ are cited; otherwise, an error of $\pm 0.06 \mathrm{log}$ unit is assumed. In those instances, where a value had to be corrected for a change in ionic strength, an error limit of \pm 0.10 log unit is used. ${ }^{d}$ Corrected value: For $25^{\circ} \mathrm{C}$ and $I=0 \mathrm{M}, \log \mathrm{K}=1.58$ is listed in ref 17 . On the basis of the comparisons for $\mathrm{Mg}(\mathrm{HOAc})^{+}$and Co( $\left.\mathrm{HOAc}\right)^{+}$ between $I=0.1 \mathrm{M}$ and $I=0 \mathrm{M}$, the mentioned constant was reduced by $0.35 \log$ unit. ${ }^{e}$ Corrected value: For $25^{\circ} \mathrm{C}$ and $I=0 \mathrm{M}, \log K=1.12$ is listed in ref 17. On the basis of comparisons for $\mathrm{M}(\mathrm{HOAc})^{+}$with $\mathrm{M}^{2+}=\mathrm{Mg}^{2+}, \mathrm{Ca}^{2+}$, and $\mathrm{Ba}^{2+}$ between $I=0.1 \mathrm{M}$ and $I=0 \mathrm{M}$, the mentioned constant was reduced by $0.42 \log$ unit. ${ }^{f}$ Corrected value: For $25^{\circ} \mathrm{C}$ and $I=1 \mathrm{M}, \log K=1.83$ is listed in ref 17 . On the basis of the difference of $0.09 \log$ units for $\mathrm{Cu}(\mathrm{HOAc})^{+}$ between the values at $I=0.1$ and $1 \mathrm{M}$, the mentioned value is enhanced: $1.83+0.09=1.92$.

Table 8. Logarithms of the Stability Constants for the 1:1 Complexes (eqs 4a, 4b, and 6) Formed between Several Divalent Ions $\left(\mathrm{M}^{2+}\right)$ and Simple Carboxylate Ligands $\left(\mathrm{CA}^{-}\right)$As Well As Negative Logarithms of the Acidity Constants (eqs 14a and 14b) of the Corresponding H(CA) Species, Mostly Determined by Potentiometric $\mathrm{pH}$ Titrations, for Aqueous Solutions at $25{ }^{\circ} \mathrm{C}$ and $\mathrm{I}=2 \mathrm{M}$ $\left(\mathrm{NaClO}_{4}\right)^{a}$

\begin{tabular}{|c|c|c|c|c|c|c|c|c|}
\hline \multirow[b]{2}{*}{ no. ${ }^{b}$} & \multirow[b]{2}{*}{$\mathrm{CA}^{-c}$} & \multirow[b]{2}{*}{$\mathrm{p} K_{\mathrm{H}(\mathrm{CA})}^{\mathrm{H}}$} & \multicolumn{6}{|c|}{$\log K_{\mathrm{M}(\mathrm{CA})}^{\mathrm{M}}$ for $\mathrm{M}^{2+}=$} \\
\hline & & & $\mathrm{Co}^{2+}$ & $\mathrm{Ni}^{2+}$ & $\mathrm{Cu}^{2+}$ & $\mathrm{Zn}^{2+}$ & $\mathrm{Cd}^{2+}$ & $\mathrm{Pb}^{2+}$ \\
\hline 1 & $\mathrm{ClAc}^{-}$ & 2.74 & $0.00 \pm 0.04$ & $0.20 \pm 0.03$ & $1.26 \pm 0.19$ & $0.40 \pm 0.02$ & $0.84 \pm 0.01$ & 1.3 \\
\hline 2 & $\mathrm{HCOO}^{-}$ & 3.73 & $0.40 \pm 0.05$ & $0.46 \pm 0.02$ & $1.65 \pm 0.06$ & $0.70 \pm 0.03$ & $1.02 \pm 0.02$ & 1.44 \\
\hline 3 & $\mathrm{Ac}^{-}$ & $4.80 \pm 0.01$ & $0.66 \pm 0.04$ & $0.72 \pm 0.02$ & $2.11 \pm 0.01$ & $0.85 \pm 0.04$ & $1.08 \pm 0.04$ & $1.91 \pm 0.03$ \\
\hline 4 & $\operatorname{Pr}^{-}$ & 4.89 & $0.70 \pm 0.03$ & $0.73 \pm 0.03$ & $2.16 \pm 0.01$ & $1.00 \pm 0.03$ & $1.23 \pm 0.03$ & $2.07 \pm 0.06$ \\
\hline 5 & $\mathrm{Bu}^{-}$ & 4.86 & $0.66 \pm 0.01$ & $0.73 \pm 0.02$ & $2.08 \pm 0.02$ & $0.98 \pm 0.05$ & $1.20 \pm 0.03$ & $2.17 \pm 0.06$ \\
\hline 6 & $\mathrm{PhAc}^{-}$ & $4.30 \pm 0.04$ & 0.62 & 0.65 & & & 1.15 & \\
\hline
\end{tabular}

${ }^{a}$ In those instances where an error limit is given, it is taken from the cited references. The acidity constants in column 3 are from ref 17 . The value for formate is interpolated from those given for $I=1$ and $3 \mathrm{M}$; this agrees with the observations made for acetate. ${ }^{b}$ The stability constants listed in rows $1-5$ are from ref 53 except those for $\mathrm{Pb}(\mathrm{ClAc})^{+}, \mathrm{Pb}(\mathrm{HCOO})^{+}$, and $\mathrm{Cd}(\mathrm{HCOO})^{+}$which are from ref 17; the same holds for the stability constants given in

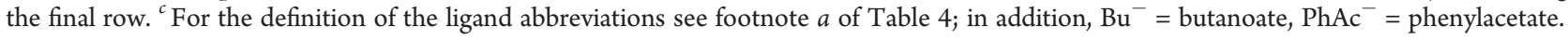

limits the same affinity toward the $-\mathrm{OH}$ group when already bound to the primary carboxylate site (Table 7).

\subsection{Extent of Chelate Formation in Complexes of Hydro- xyacetate-Type Ligands at $I=2 \mathrm{M}$}

Acidity constants of simple carboxylate ligands, $\mathrm{H}(\mathrm{CA})$, and the stability constants of their corresponding metal-ion complexes, $\mathrm{M}(\mathrm{CA})^{+}$, at $I=2 \mathrm{M}$, as taken from refs 53 and 17 , are listed in Table 8. As expected, plots of $\log K_{M}^{\mathrm{M}}$ (CA) versus $\mathrm{p} K_{\mathrm{H}(\mathrm{CA})}^{\mathrm{H}}$ result in straight lines, and these are defined by the parameters summarized in Table 9. Interestingly, the slopes $m$ of the plots are considerably steeper at $I=2 \mathrm{M}$ than at $I=$ $0.1 \mathrm{M}$ (cf. Table 5). This is most likely the consequence of the high salt concentration $\left(\mathrm{NaClO}_{4}\right)$ which "uses" a large part of the water molecules for its own solvation, leaving the carboxylate groups more exposed, that is, less screened by $\mathrm{H}_{2} \mathrm{O}$ molecules. 
Table 9. Straight-Line Parameters (eq 10) for $\mathrm{M}^{2+} 1: 1$ Complexes Formed with Simple Carboxylate Ligands $\left(\mathrm{CA}^{-}\right)$, Valid for Aqueous Solutions at $25^{\circ} \mathrm{C}$ and $\mathrm{I}=2 \mathrm{M}\left(\mathrm{NaClO}_{4}\right)^{a, b}$

\begin{tabular}{lcr}
$\mathrm{M}^{2+}$ & $m$ & \multicolumn{1}{c}{$b$} \\
$\mathrm{Co}^{2+}$ & $0.311 \pm 0.032$ & $-0.804 \pm 0.138$ \\
$\mathrm{Ni}^{2+}$ & $0.249 \pm 0.014$ & $-0.469 \pm 0.062$ \\
$\mathrm{Cu}^{2+}$ & $0.408 \pm 0.016$ & $0.139 \pm 0.067$ \\
$\mathrm{Zn}^{2+}$ & $0.253 \pm 0.032$ & $-0.279 \pm 0.139$ \\
$\mathrm{Cd}^{2+}$ & $0.156 \pm 0.031$ & $0.427 \pm 0.134$ \\
$\mathrm{~Pb}^{2+}$ & $0.385 \pm 0.075$ & $0.159 \pm 0.322$
\end{tabular}

${ }^{a}$ The slopes $(m)$ and intercepts $(b)$ for the straight reference lines from plots of $\log K_{\mathrm{M}(\mathrm{CA})}^{\mathrm{M}}$ versus $\mathrm{p} K_{\mathrm{H}(\mathrm{CA})}^{\mathrm{H}}$ were calculated by the least-squares procedure from the experimentally determined equilibrium constants listed in Table 8 (see also Figure 6). ${ }^{b}$ The straight-line equation is defined by eq 10 . With a known $\mathrm{p} K_{\mathrm{H}(\mathrm{CA})}^{\mathrm{H}}$ value of any carboxylate derivative the stability constant $\left(\log K_{\mathrm{M}(\mathrm{CA})}^{\mathrm{M}}\right)$ of the corresponding $\mathrm{M}(\mathrm{CA})^{+}$complex (eqs $4 \mathrm{a}, 4 \mathrm{~b}$, and 6 ) can be calculated; the errors given with $m$ and $b$ correspond to one standard deviation $(1 \sigma)$.

Table 10. Logarithmic Differences between Experimentally Determined Stability Constants $\left(\log K_{M(C A)}^{M}\right.$ Table 8$)$ of the $\mathrm{M}^{2+}$ Complexes for the Simple Carboxylate Ligands ( $\mathrm{CA}^{-}$) Listed in Column 2 of Table $8^{b}$ and the Least-Squares Lines of the $\log K_{\mathrm{M}(\mathrm{CA})}^{\mathrm{M}}$ versus $\mathrm{p} K_{\mathrm{H}(\mathrm{CA})}^{\mathrm{H}}$ Plots as Defined in Table $9^{a}$

\begin{tabular}{rlrrrrrr} 
& & \multicolumn{6}{c}{$\mathrm{M}(\mathrm{CA})^{+}$complexes for $\mathrm{M}^{2+}=$} \\
\cline { 3 - 8 } no. $^{b}$ & $\mathrm{CA}^{-d}$ & $\mathrm{Co}^{2+}$ & \multicolumn{1}{c}{$\mathrm{Ni}^{2+}$} & $\mathrm{Cu}^{2+}$ & $\mathrm{Zn}^{2+}$ & $\mathrm{Cd}^{2+}$ & $\mathrm{Pb}^{2+}$ \\
1 & $\mathrm{ClAc}^{-}$ & -0.05 & -0.01 & 0.00 & -0.01 & -0.01 & 0.09 \\
2 & $\mathrm{HCOO}^{-}$ & 0.04 & 0.00 & -0.01 & 0.04 & 0.01 & -0.16 \\
3 & $\mathrm{Ac}^{-}$ & -0.03 & -0.01 & 0.01 & -0.09 & -0.10 & -0.10 \\
4 & $\mathrm{Pr}^{-}$ & -0.02 & -0.02 & 0.03 & 0.04 & 0.04 & 0.03 \\
5 & $\mathrm{Bu}^{-}$ & -0.05 & -0.01 & -0.04 & 0.03 & 0.01 & 0.14 \\
6 & $\mathrm{PhAc}^{-}$ & 0.09 & 0.05 & & & 0.05 & \\
& $\mathrm{SD}^{c}$ & 0.023 & 0.010 & 0.012 & 0.025 & 0.027 & 0.057
\end{tabular}

${ }^{a}$ The bottom line of the table gives the standard deviation (SD $)^{d}$ resulting from the listed differences. ${ }^{b}$ The entry numbers correspond to those of Table 8 to facilitate comparisons. ${ }^{c}$ The standard deviation (SD) times three is considered as a reasonable error limit for any calculation of the stability of a $\mathrm{M}(\mathrm{CA})^{+}$complex based on the straight lines defined in Table 9 in the $\mathrm{p} K_{\mathrm{H}(\mathrm{CA})}^{\mathrm{H}}$ range of about $2.5-5 .{ }^{d}$ For the definition of the ligand abbreviations see footnote $a$ of Table 4 and $c$ of Table 8.

Table 10 provides the differences of the individual complex stability constants from the reference lines. The resulting values for the standard deviation (SD) are given in the bottom row of Table 10. These values times three are recommended as reasonable error limits for any $\log K_{\mathrm{M}(\mathrm{CA})}^{\mathrm{M}}$ calculation with the straightline parameters of Table 9. It may be emphasized that the evaluation indicated in this and the preceding paragraph follows exactly the procedure described in more detail in section 4.1.1 for $I=0.1 \mathrm{M}$.

As an example, Figure 6 shows the plots for the systems with $\mathrm{Co}^{2+}, \mathrm{Zn}^{2+}$, and $\mathrm{Cu}^{2+}$. In all three instances the data points (solid symbols) of the $\mathrm{M}^{2+} / \mathrm{H}^{+} / \mathrm{HOAc}^{-}$systems are far above their reference lines demonstrating unequivocally that the hydroxyl group of hydroxyacetate participates in metal-ion binding and that equilibrium 1 operates also under the present conditions defined by $I=2 \mathrm{M}$

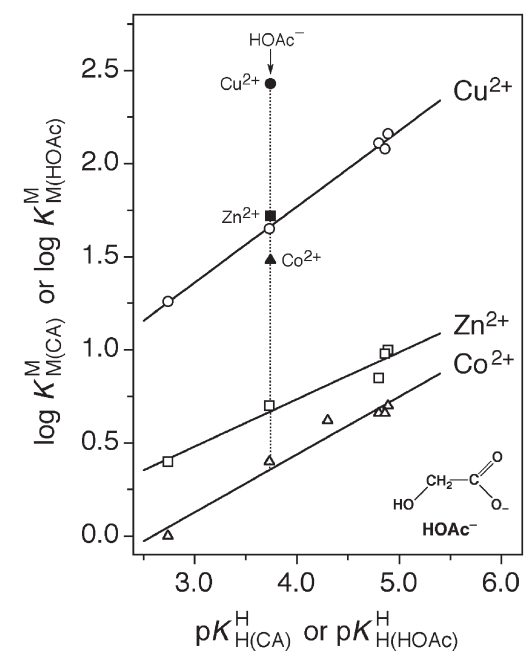

Figure 6. Evidence for an enhanced complex stability of the $\mathrm{Co}^{2+}(\boldsymbol{\Delta})$, $\mathrm{Zn}^{2+}(\boldsymbol{\square})$, and $\mathrm{Cu}^{2+}(\mathbf{O})$ 1:1 complexes of $\mathrm{HOAc}^{-}$based on the relationship between $\log K_{\mathrm{M}(\mathrm{CA})}^{\mathrm{M}}$ and $\mathrm{p} K_{\mathrm{H}(\mathrm{CA})}^{\mathrm{H}}$ for the simple carboxylate ligands $\left(\mathrm{CA}^{-}\right)$listed in Table 8 . The parameters of the corresponding least-squares reference lines (eq 10) are summarized in Table 9. The data for the points due to the equilibrium constants for the $\mathrm{M}^{2+} / \mathrm{HOAc}^{-}$ systems are given in Table 11. The vertical dotted lines emphasize the stability differences to the reference lines; they equal $\log \Delta_{\mathrm{M} / \mathrm{HOAc}}$, as defined in eqs 11a and $11 \mathrm{~b}$ (see also Table 11, column 5). All plotted equilibrium constants refer to aqueous solutions at $25^{\circ} \mathrm{C}$ and $I=2 \mathrm{M}$.

A quantitative evaluation of the results seen in Figure 6 is given in Table 11 for the biologically essential metal ions ${ }^{52}$ $\mathrm{Co}^{2+}, \mathrm{Ni}^{2+}, \mathrm{Cu}^{2+}$, and $\mathrm{Zn}^{2+}$ as well as for the commonly toxic ones, i.e., $\mathrm{Cd}^{2+}$ and $\mathrm{Pb}^{2+} .54$ Next to $\mathrm{HOAc}^{-}$also the ligands $2 \mathrm{HOPr}^{-}$(lactate) as well as the alkyl derivatives of $\mathrm{HOAc}^{-}$, that is, $\mathrm{CH}_{3} \mathrm{OAc}^{-}$and EtOAc $^{-}$, are considered (see Figure 4). ${ }^{17,53,55}$ The evaluation follows the pathway given in section 4.1 .2 by applying eqs 7 and $9-13$.

There are many comparisons possible; a few are given below:

(i) A comparison with the results obtained at $I=0.1 \mathrm{M}$ (Table 7) is possible only for a few instances, namely, for $\mathrm{Cu}(\mathrm{HOAc})^{+}$, $\mathrm{Zn}(\mathrm{HOAc})^{+}, \mathrm{Cu}(2 \mathrm{HOPr})^{+}$, and $\mathrm{Cu}\left(\mathrm{CH}_{3} \mathrm{OAc}\right)^{+}$. In three cases the values at $I=0.1$ (Table 7 ) and $2 \mathrm{M}$ (Table 11) for $\log \Delta_{\mathrm{M} / \mathrm{OAc}}$ and $\% \mathrm{M}(\mathrm{OAc})_{\mathrm{cl}}^{+}$are identical within the error limits. Only for $\mathrm{Cu}(2 \mathrm{HOPr})_{\mathrm{cl}}^{+}$do the values not overlap, but $\% \mathrm{Cu}(2 \mathrm{HOPr})_{\mathrm{cl}}^{+}$are with $88 \pm 2 \%$ (Table 7$)$ and $82 \pm 3 \%$ (Table 11), still very similar. This allows the conclusion that a change in $I$ from 0.1 to $2 \mathrm{M}$ does not affect equilibrium 1 very significantly. This observation is important because it means that the results of Tables 7 and 11 complement each other, and thus, generalizations with systems containing another primary binding site become possible (see section 9).

(ii) The formation degrees of the $\mathrm{M}(\mathrm{HOAc})^{+}$and the $\mathrm{M}(2 \mathrm{HOPr})^{+}$complexes (Table 11) are identical within the error limits for a given metal ion. This means that the additional methyl group present at the carbon which carries the $-\mathrm{OH}$ group has no remarkable influence on complex stability.

(iii) Replacement of the $\mathrm{H}$ atom in the $-\mathrm{OH}$ group of $\mathrm{HOAc}^{-}$ by a $\mathrm{CH}_{3}$ group leads to an ether oxygen. This ether oxygen is clearly less suitable for an $-\mathrm{O} / \mathrm{M}^{2+}$ interaction than the one of the $-\mathrm{OH}$ group. Indeed, for the three examples where a comparison is possible, i.e., the $\mathrm{Co}^{2+}, \mathrm{Ni}^{2+}$, and $\mathrm{Cu}^{2+}$ 
Table 11. Comparison of the Measured (exp) Stability Constants, $K_{M}^{\mathrm{M}}(\mathrm{OAc}) \exp \left(\right.$ eqs $4 \mathrm{a}, 4 \mathrm{~b}$, and 6), of the $\mathbf{M}^{2+} 1: 1$ Complexes Formed by Hydroxyacetate $\left(\mathrm{HOAc}^{-}\right)^{b}$ and the Related Ligands D-2-Hydroxypropanoate $\left(2 \mathrm{HOPr}^{-}=\text {lactate }\right)^{b} \mathrm{Methoxyacetate}^{b}$ $\left(\mathrm{CH}_{3} \mathrm{OAc}^{-}\right),{ }^{b}$ and Ethoxyacetate $\left(\mathrm{EtOAc}^{-}\right),{ }^{b}$ with the Calculated Stability Constants for the Open Isomers with a Sole Carboxylate $-\mathrm{M}^{2+}$ Coordination, $K_{\mathbf{M}(\mathrm{OAc}) \text { op }}^{\mathrm{M}}(\mathbf{e q s} 1 \text { and } 7)^{a}$

\begin{tabular}{|c|c|c|c|c|c|c|}
\hline $\mathrm{OAc}^{-}$ & $\mathrm{M}^{2+}$ & $\log K_{\mathrm{M}(\mathrm{OAc}) \exp ^{\mathrm{c}}}^{\mathrm{M}}$ & $\log K_{\mathrm{M}(\mathrm{OAc}) \text { op }}^{\mathrm{M}}$ & $\log \Delta_{\mathrm{M} / \mathrm{OAc}}$ & $K_{\mathrm{I}}$ & $\% \mathrm{M}(\mathrm{OAc})_{\mathrm{cl}}^{+}$ \\
\hline \multirow[t]{6}{*}{$\mathrm{HOAc}^{-d}$} & $\mathrm{Co}^{2+}$ & $1.48 \pm 0.03$ & $0.36 \pm 0.07$ & $1.12 \pm 0.08$ & $12.18 \pm 2.31$ & $92 \pm 1$ \\
\hline & $\mathrm{Ni}^{2+}$ & $1.69 \pm 0.02$ & $0.46 \pm 0.03$ & $1.23 \pm 0.04$ & $15.98 \pm 1.41$ & $94 \pm 1$ \\
\hline & $\mathrm{Cu}^{2+}$ & $2.43 \pm 0.03$ & $1.66 \pm 0.04$ & $0.77 \pm 0.05$ & $4.89 \pm 0.68$ & $83 \pm 2$ \\
\hline & $\mathrm{Zn}^{2+}$ & $1.72 \pm 0.06$ & $0.67 \pm 0.07$ & $1.05 \pm 0.09$ & $10.22 \pm 2.38$ & $91 \pm 2$ \\
\hline & $\mathrm{Cd}^{2+}$ & $1.51 \pm 0.02$ & $1.01 \pm 0.08$ & $0.50 \pm 0.08$ & $2.16 \pm 0.60$ & $68 \pm 6$ \\
\hline & $\mathrm{Pb}^{2+}$ & $2.12 \pm 0.10$ & $1.60 \pm 0.17$ & $0.52 \pm 0.20$ & $2.31 \pm 1.50$ & $70 \pm 14$ \\
\hline \multirow[t]{5}{*}{$2 \mathrm{HOPr}^{-e}$} & $\mathrm{Co}^{2+}$ & $1.39 \pm 0.06$ & $0.38 \pm 0.07$ & $1.01 \pm 0.09$ & $9.23 \pm 2.17$ & $90 \pm 2$ \\
\hline & $\mathrm{Ni}^{2+}$ & $1.57 \pm 0.06$ & $0.48 \pm 0.03$ & $1.09 \pm 0.07$ & $11.30 \pm 1.90$ & $92 \pm 1$ \\
\hline & $\mathrm{Cu}^{2+}$ & $2.43 \pm 0.06$ & $1.69 \pm 0.04$ & $0.74 \pm 0.07$ & $4.50 \pm 0.91$ & $82 \pm 3$ \\
\hline & $\mathrm{Cd}^{2+}$ & $1.40 \pm 0.08$ & $1.02 \pm 0.08$ & $0.38 \pm 0.11$ & $1.40 \pm 0.62$ & $58 \pm 11$ \\
\hline & $\mathrm{Pb}^{2+}$ & $2.16 \pm 0.06$ & $1.62 \pm 0.17$ & $0.54 \pm 0.18$ & $2.47 \pm 1.44$ & $71 \pm 12$ \\
\hline \multirow[t]{3}{*}{$\mathrm{CH}_{3} \mathrm{OAc}^{-e}$} & $\mathrm{Co}^{2+}$ & $1.16 \pm 0.06$ & $0.30 \pm 0.07$ & $0.86 \pm 0.09$ & $6.24 \pm 1.54$ & $86 \pm 3$ \\
\hline & $\mathrm{Ni}^{2+}$ & $1.26 \pm 0.06$ & $0.42 \pm 0.03$ & $0.84 \pm 0.07$ & $5.92 \pm 1.07$ & $86 \pm 2$ \\
\hline & $\mathrm{Cu}^{2+}$ & $1.81 \pm 0.06$ & $1.59 \pm 0.04$ & $0.22 \pm 0.07$ & $0.66 \pm 0.28$ & $40 \pm 10$ \\
\hline \multirow[t]{3}{*}{$\mathrm{EtOAc}^{-e}$} & $\mathrm{Co}^{2+}$ & $1.06 \pm 0.06$ & $0.33 \pm 0.07$ & $0.73 \pm 0.09$ & $4.37 \pm 1.14$ & $81 \pm 4$ \\
\hline & $\mathrm{Ni}^{2+}$ & $1.17 \pm 0.06$ & $0.44 \pm 0.03$ & $0.73 \pm 0.07$ & $4.37 \pm 0.83$ & $81 \pm 3$ \\
\hline & $\mathrm{Cu}^{2+}$ & $1.74 \pm 0.06$ & $1.62 \pm 0.04$ & $0.12 \pm 0.07$ & $0.32 \pm 0.22$ & $24 \pm 13$ \\
\hline
\end{tabular}

${ }^{a}$ The observed stability increase is expressed by $\log \Delta_{\mathrm{M} / \mathrm{OAc}}$ (eqs 11a and $11 \mathrm{~b}$ ). The extent of chelate formation according to the intramolecular equilibria 1 and 2 for the $\mathrm{M}(\mathrm{OAc})^{+}$complexes is quantified by the dimensionless equilibrium constant $K_{\mathrm{I}}$ (eqs 3 and 9 ) and the percentage of the closed isomers $\mathrm{M}(\mathrm{OAc})_{\mathrm{cl}}^{+}$(eq 13). All data refer to aqueous solutions at $25^{\circ} \mathrm{C}$ and $I=2 \mathrm{M}\left(\mathrm{NaClO}_{4}\right) \cdot{ }^{17,53} b^{b}$ The corresponding acidity constants ${ }^{17}$ are $\mathrm{p} K_{\mathrm{H}(\mathrm{HOAc})}^{\mathrm{H}}=3.74 \pm 0.03, \mathrm{p} K_{\mathrm{H}(2 \mathrm{HOPr})}^{\mathrm{H}}=3.80 \pm 0.02, \mathrm{p} K_{\mathrm{H}\left(\mathrm{CH}_{3} \mathrm{OAc}\right)}^{\mathrm{H}}=3.56 \pm 0.10$ (average of the values at $I=1$ and $\left.3 \mathrm{M}\right)$, and $\mathrm{p} K_{\mathrm{H}(\mathrm{EtOAc})}^{\mathrm{H}}=3.51+0.13$ (based on $\mathrm{HOAc}^{-}$) $=3.64 \pm 0.10$. $^{c}$ If available, the error limits given in the literature ${ }^{17,33}$ are cited; otherwise, an error of \pm 0.06 log unit is assumed. In those instances where a value had to be corrected for a change in ionic strength, an error limit of $\pm 0.10 \mathrm{log}$ unit is used. ${ }^{d}$ The stability constants are from ref 53 except the one for $\mathrm{Cu}(\mathrm{HOAc})^{+}$which is from ref 17 and that for $\mathrm{Pb}(\mathrm{HOAc})^{+}$which is the average of the values given in ref 17 for $I=1$ and $3 \mathrm{M}$. ${ }^{e}$ These stability constants are from ref 17 (for $2 \mathrm{HOPr}^{-}$, see also ref 55 ).

systems (Table 11), the $\log \Delta_{\mathrm{M} / \mathrm{OAc}}$ values decrease due to methylation by about (on average) 0.4 log unit. Replacement of the methyl group by an ethyl moiety diminishes the interaction further but only marginally.

4.3. Effect of Chelate-Ring Enlargement on the Hydroxyl-Metal-Ion Interaction

Hydroxyacetate $\left(\mathrm{HOAc}^{-}\right)$is the prime ligand considered in section 4 so far. It is thus natural to continue with its chain-enlarged analogues 3-hydroxypropanoate $\left(3 \mathrm{HOPr}^{-} ; \mathrm{HO}-\mathrm{CH}_{2} \mathrm{CH}_{2}-\right.$ $\left.\mathrm{COO}^{-}\right)$and 4-hydroxybutanoate $\left(4 \mathrm{HOBu}^{-} ; \mathrm{HO}-\mathrm{CH}_{2} \mathrm{CH}_{2}-\right.$ $\mathrm{CH}_{2}-\mathrm{COO}^{-}$); these ligands may form with $\mathrm{M}^{2+}$ 6- or 7-membered chelates, whereas $\mathrm{HOAc}^{-}$forms 5 -membered ones as we have already seen (sections 4.1.2 and 4.2).

The available stability constants of $\mathrm{M}(3 \mathrm{HOPr})^{+}$and $\mathrm{M}(4 \mathrm{HOBu})^{+}$complexes $^{17}$ are listed in column 4 of Table 12 , where $\mathrm{OCA}^{-}=3 \mathrm{HOPr}^{-}$and $4 \mathrm{HOBu}^{-}$; most of the experimental data were obtained at $I=2 \mathrm{M}$. Application of the straight-line parameters of Table 9 (and where appropriate of Table 5), together with the acidity constants, allowed one to calculate the stability of the open isomers (eqs 1 and 7) (Table 12, column 5). The resulting stability differences, $\log \Delta_{\mathrm{M} / \mathrm{OCA}}$ (eqs 11a and $11 \mathrm{~b}$ ), appear in the last column of Table 12 .

There is a discrepancy regarding the results for the $\mathrm{Cu}(3 \mathrm{HOPr})^{+}$ complex; however, we are convinced that the result listed for $I=$ $0.1 \mathrm{M}$ is the more correct one because from a coordination chemical point of view it makes much more sense than the negative value obtained for $\log \Delta_{\mathrm{Cu} / 3 \mathrm{HOPr}}$ at $I=2 \mathrm{M}$. Though the results for the
$\mathrm{Zn}^{2+}, \mathrm{Cd}^{2+}$, and $\mathrm{Pb}^{2+}$ complexes are practically zero within the error limits, small amounts of $\mathrm{M}(\mathrm{OCA})_{\mathrm{cl}}^{+}$species still may form. However, the $\log \Delta_{\mathrm{M} / 3 \mathrm{HOPr}}$ values for the $\mathrm{M}(3 \mathrm{HOPr})^{+}$complexes with $\mathrm{Co}^{2+}, \mathrm{Ni}^{2+}$, and $\mathrm{Cu}^{2+}$ (at $I=0.1 \mathrm{M}$ ) are clearly positive. Hence, in these instances 6-membered chelates form. The formation degree of the $\mathrm{M}(3 \mathrm{HOPr})_{\mathrm{cl}}^{+}$isomers is not overwhelming but from $\log \Delta_{\mathrm{M} / 3 \mathrm{HOPr}}=0.3$ follows a formation degree of about $50 \%$. Despite the fact that this number is remarkable, it is much smaller than the formation degrees found in Tables 7 and 11 for the corresponding $\mathrm{M}(\mathrm{HOAc})^{+}$complexes, and this means that the 5-membered chelates are more stable than the 6-membered ones.

The $\log \Delta_{\mathrm{M} / 4 \mathrm{HOBu}}$ values (Table 12, column 6) for the $\mathrm{M}(4 \mathrm{HOBu})^{+}$complexes are throughout either zero within the error limits or even negative. The only exception seems to be the value at $I=2 \mathrm{M}$ for $\mathrm{Cd}(4 \mathrm{HOBu})^{+}$. However, we do not believe that this value is correct, the stability constant for $\mathrm{Cd}(4 \mathrm{HOBu})^{+}$compared to the one for $\mathrm{Zn}(4 \mathrm{HOBu})^{+}$appears to us as too large (see column 4 of Table 12). In fact, the same also holds for the values of $\mathrm{Cd}(3 \mathrm{HOPr})^{+}$and $\mathrm{Zn}(3 \mathrm{HOPr})^{+}$; commonly these values are more similar or the trend is even reverse (see also Table 11). To conclude, we consider the result obtained at $I=1 \mathrm{M}$ for $\mathrm{Cd}(4 \mathrm{HOBu})^{+}$as the correct one, and this then means that throughout only traces of $\mathrm{M}(4 \mathrm{HOBu})_{\mathrm{cl}}^{+}$species are formed, if at all.

The overall result thus is, in accord with the conclusions presented in section 3.3, that the stability of the chelates decreases with increasing ring size in the order 5-membered $>6$-membered $>$ 7-membered ring. 
Table 12. Comparison of the Measured (exp) Stability Constants, $K_{M(O C A) \exp }^{M}\left(\right.$ eqs $4 a, 4 b$, and 6), of the $M^{2+} 1: 1$ Complexes Formed by 3-Hydroxypropanoate $\left(3 \mathrm{HOPr}^{-}\right)$or 4-Hydroxybutanoate $\left(4 \mathrm{HOBu}^{-}\right)$with the Calculated Stability Constants for the Open Isomers with a Sole Carboxylate$\mathbf{M}^{2+}$ Coordination, $K_{M}^{\mathrm{M}}(\mathrm{OCA})$ op $(\text { eqs } 1 \text { and } 7)^{a, b}$

\begin{tabular}{rrrrrr}
$\mathrm{OCA}^{-}$ & $\mathrm{M}^{2+}$ & $I$ & $\log K_{\mathrm{M}(\mathrm{OCA}) \exp }^{\mathrm{c}}$ & $\log K_{\mathrm{M}(\mathrm{OCA}) \mathrm{op}}{ }^{d}$ & \multicolumn{1}{c}{$\log \Delta_{\mathrm{M} / \mathrm{OCA}}$} \\
$3 \mathrm{HOPr}^{-}$ & $\mathrm{Co}^{2+}$ & 2 & $0.86 \pm 0.10$ & $0.61 \pm 0.07$ & $0.25 \pm 0.12$ \\
& $\mathrm{Ni}^{2+}$ & 2 & $0.96 \pm 0.10$ & $0.67 \pm 0.03$ & $0.29 \pm 0.10$ \\
& $\mathrm{Cu}^{2+}$ & 2 & $1.83 \pm 0.10$ & $2.00 \pm 0.04$ & $-0.17 \pm 0.11$ \\
& & 0.1 & $2.05 \pm 0.10^{e}$ & $1.74 \pm 0.05$ & $0.31 \pm 0.11$ \\
& $\mathrm{Zn}^{2+}$ & 2 & $0.86 \pm 0.10$ & $0.87 \pm 0.08$ & $-0.01 \pm 0.13$ \\
& $\mathrm{Cd}^{2+}$ & 2 & $1.28 \pm 0.10$ & $1.14 \pm 0.08$ & $0.14 \pm 0.13$ \\
& $\mathrm{~Pb}^{2+}$ & 2 & $2.10 \pm 0.10$ & $1.91 \pm 0.17$ & $0.19 \pm 0.20$ \\
& & 1 & $1.95 \pm 0.10$ & $1.88 \pm 0.17^{f}$ & $0.07 \pm 0.20$ \\
$4 \mathrm{HOBu}$ & $\mathrm{Co}^{2+}$ & 2 & $0.47 \pm 0.10$ & $0.70 \pm 0.07$ & $-0.23 \pm 0.12$ \\
& $\mathrm{Ni}^{2+}$ & 2 & $0.58 \pm 0.10$ & $0.74 \pm 0.03$ & $-0.16 \pm 0.10$ \\
& $\mathrm{Cu}^{2+}$ & 2 & $1.76 \pm 0.10$ & $2.12 \pm 0.04$ & $-0.36 \pm 0.11$ \\
& $\mathrm{Zn}^{2+}$ & 2 & $0.96 \pm 0.10$ & $0.95 \pm 0.08$ & $0.01 \pm 0.13$ \\
& $\mathrm{Cd}^{2+}$ & 2 & $1.39 \pm 0.10$ & $1.18 \pm 0.08$ & $0.21 \pm 0.13$ \\
& & 1 & $1.10 \pm 0.10$ & $1.14 \pm 0.08^{g}$ & $-0.04 \pm 0.13$ \\
& $\mathrm{~Pb}^{2+}$ & 2 & $2.18 \pm 0.10$ & $2.03 \pm 0.17$ & $0.15 \pm 0.20$
\end{tabular}

${ }^{a}$ The stability differences are expressed by $\log \Delta_{\mathrm{M} / \mathrm{OCA}}$ (eqs 11a and 11b) (aqueous solution; $25^{\circ} \mathrm{C}$; $I=0.1$ or $\left.2 \mathrm{M}\left(\mathrm{NaClO}_{4}\right)\right) .{ }^{17}{ }^{b}$ The corresponding acidity constants are $\mathrm{p} \mathrm{K}_{\mathrm{H}(3 \mathrm{HOPr})}^{\mathrm{H}}=4.56\left(\mathrm{I}=2 \mathrm{M}, \mathrm{NaClO}_{4}\right)$ and $4.40(I=0.1 \mathrm{M})$ as well as $\mathrm{p} K_{\mathrm{H}(4 \mathrm{HOBu})}^{\mathrm{H}}=4.85\left(I=2 \mathrm{M}, \mathrm{NaClO}_{4}\right)$ and $4.54\left(\mathrm{I}=1 \mathrm{M}, \mathrm{NaClO}_{4}\right) \cdot{ }^{17 c}$ The error limits are (deliberately generously) assumed to be $\pm 0.10 \log$ unit. ${ }^{d}$ Calculated with the acidity constants ${ }^{b}$ and the straight-line parameters of Tables $5(I=0.1 \mathrm{M})$ and $9(I=2 \mathrm{M}){ }^{e}$ This value was determined at $30^{\circ} \mathrm{C} .{ }^{17 f}$ Calculated with $\mathrm{p} K_{\mathrm{H}(3 \mathrm{HOPr})}^{\mathrm{H}}=4.48$ (average of the values at $I=0.1$ and $2 \mathrm{M}$ ) ${ }^{b}$ and the parameters of Table 9 $(I=2 \mathrm{M}) \cdot{ }^{g}$ Calculated with $\mathrm{p} K_{\mathrm{H}(4 \mathrm{HOBu})}^{\mathrm{H}}=4.54(I=1 \mathrm{M})$ and the parameters of Table $9(I=2 \mathrm{M})$.

4.4. Decreasing Solvent Polarity Favors the HydroxylMetal-Ion Interaction in Complexes of Hydroxyacetate and Related $\mathrm{O}$ Ligands But Inhibits Thioether Interactions

In section 3.3 (in the third to the last paragraph) it was already indicated that in certain cavities of proteins or nucleic acids the solvent polarity, that is, the permittivity, may be considerably reduced. Such conditions can be mimicked by, e.g., addition of 1,4-dioxane to an aqueous solution (see Table 3 ). Below we are investigating the effect of $50 \%(\mathrm{v} / \mathrm{v})$ aqueous dioxane on the weak interactions as they may occur with a hydroxyl group, an ether oxygen, or a thioether residue in the ligands shown in Figure 7 , i.e., hydroxyacetate $\left(\mathrm{HOAc}^{-}\right)$, tetrahydrofuran-2carboxylate (THF2CA ${ }^{-}$), or tetrahydrothiophen-2-carboxylate $\left(\right.$ THT2 $\left.2 A^{-}\right)$. The metal ions considered are $\mathrm{Mn}^{2+}, \mathrm{Cu}^{2+}$, and $\mathrm{Zn}^{2+}$.

In columns 4-7 of Table 13, we list the acidity constants of $\mathrm{H}(\mathrm{CA})$ species (eqs $14 \mathrm{a}$ and $14 \mathrm{~b}$ ) and the stability constants of their corresponding $\mathrm{M}(\mathrm{CA})^{+}$complexes (eqs $4 \mathrm{a}$ and $4 \mathrm{~b}$ ) for several simple carboxylate ligands $\left(\mathrm{CA}^{-}\right) .{ }^{56-58}$ With these values straight lines may be defined according to eq 10 (see also Figure 8 below); these results are given in footnote $b$ of Table 13 . The recommended error limits for the application of the straight-line parameters in the $\mathrm{p} K_{\mathrm{a}}$ range of about $4-7$ are defined in the bottom row of Table 13 and in footnote $c$ of the same table.

With the results of Table 13 we are now in the position to evaluate the complex stabilities of the $\mathrm{Mn}^{2+}, \mathrm{Cu}^{2+}$, and $\mathrm{Zn}^{2+}$<smiles>COC(=O)C(C)(C)O</smiles>
$\mathrm{HOAc}^{-}$<smiles>CC1(C)OC(C(=O)O)(C(=O)O)C1(C)C</smiles>

THF2CA ${ }^{-}$

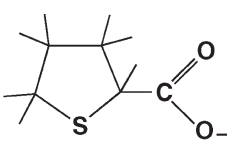

THT2CA $^{-}$
Figure 7. Indication of the structural relationship between hydroxyacetate $\left(\mathrm{HOAc}^{-}\right)$on the one hand and tetrahydrofuran-2-carboxylate (THF2CA ${ }^{-}$) and tetrahydrothiophen-2-carboxylate $\left(\right.$THT2CA $\left.^{-}\right)$on the other.

species formed with the ligands seen in Figure 7. The corresponding plots are shown in Figure 8 into which also the data points of the $\mathrm{M}^{2+} / \mathrm{H}^{+} / \mathrm{HOAc}^{-}, \mathrm{M}^{2+} / \mathrm{H}^{+} / \mathrm{THF}_{2} \mathrm{CA}^{-}$, and $\mathrm{M}^{2+} / \mathrm{H}^{+} / \mathrm{THT}_{2} \mathrm{CA}^{-}$systems have been inserted. ${ }^{56,58}$ From the vertical dotted lines in Figure 8 it is immediately evident that the two ligands, which offer next to the carboxylate group a further oxygen unit, form complexes which lead to a considerable stability enhancement. Replacement of the oxygen by a sulfur atom leads only for $\mathrm{Cu}(\mathrm{THT} 2 \mathrm{CA})^{+}$to a remarkable stability enhancement, whereas the affinity of $\mathrm{Zn}^{2+}$ and $\mathrm{Mn}^{2+}$ for the thioether unit is apparently low. This is a surprising result which needs to be discussed further (see below).

Application of eqs 6-13 allows a quantitative evaluation of the situation seen in Figure 8 . The corresponding results are summarized in Table 14, where $\mathrm{XCA}^{-}=\mathrm{HOAc}^{-}$, $\mathrm{THF}_{2} \mathrm{CA}^{-}$, or THT2 $\mathrm{CA}^{-}$.

From Table 14 many conclusions can be drawn, a few of which are given below:

(i) Comparison of the results obtained for an aqueous solution (Table 7) and for water containing $50 \%(\mathrm{v} / \mathrm{v})$ 1,4-dioxane (Table 14) reveals that the stability enhancements and consequently the formation degrees of the chelated species, $\mathrm{M}(\mathrm{HOAc})_{\mathrm{cl}}^{+}$, are significantly higher in the water-dioxane mixture, that is, a decreasing solvent polarity favors the $-\mathrm{OH} / \mathrm{M}^{2+}$ interaction.

(ii) For the $\mathrm{M}(\mathrm{THF} 2 \mathrm{CA})^{+}$complexes no data for aqueous solution are available. However, comparison with the data listed at the bottom of Table 7 for $\mathrm{M}\left(\mathrm{CH}_{3} \mathrm{OAc}\right)^{+}$suggests that the conclusion of point (i) is also valid for ethermetal-ion interactions.

(iii) Comparison of the results given in Table 14 for $\log \Delta_{\mathrm{M} / \mathrm{XCA}}$ and $\% \mathrm{M}(\mathrm{XCA})_{\mathrm{cl}}^{+}$shows that the values for $\mathrm{M}(\mathrm{HOAc})^{+}$are clearly larger than those for $\mathrm{M}(\mathrm{THF} 2 \mathrm{CA})^{+}$. This means, the $-\mathrm{OH} / \mathrm{M}^{2+}$ interaction is more intense than the ether-O/ $\mathrm{M}^{2+}$ one.

(iv) Of general interest are also the results obtained for the complexes of the thio ligand, THT2CA ${ }^{-}$(Figure 7), even though sulfur sites are not in the focus of this review. Only the $\mathrm{Cu}(\mathrm{THT} 2 \mathrm{CA})^{+}$complex reveals a significant stability enhancement in the mixed solvent, and the formation degree of the closed species involving a metalion-thioether interaction amounts to $93 \%$. That the thiophilicity of $\mathrm{Mn}^{2+}$ in aqueous solution is very poor is well known, ${ }^{5-61}$ and its consequences for so-called rescue experiments carried out with ribozymes have been pointed out. ${ }^{13,14,62,63}$ Thus, it is no surprise that this also holds for an aqueous solution containing $50 \%(\mathrm{v} / \mathrm{v})$ 1,4-dioxane. However, the result obtained for $\mathrm{Zn}(\mathrm{THT} 2 \mathrm{CA})^{+}$is a surprise: In aqueous solution $\mathrm{Zn}^{2+}$ shows a rather pronounced thiophilicity, ${ }^{59-61}$ and this is strongly reduced in the presence of dioxane; the stability enhancement log 
Table 13. Logarithms of the Stability Constants for the 1:1 Complexes (eqs 4a, 4b, and 6) Formed between $\mathrm{Mn}^{2+}, \mathrm{Cu}^{2+}$, or $\mathrm{Zn}^{2+}$ and Simple Carboxylate Ligands $\left(\mathrm{CA}^{-}\right)$As Well As Negative Logarithms of the Acidity Constants (eqs 14a and 14b) of the Corresponding H(CA) Species, Determined by Potentiometric $\mathrm{pH}$ Titrations in Water Containing 50\% (v/v) 1,4-Dioxane at $25{ }^{\circ} \mathrm{C}$ and $\mathrm{I}=0.1 \mathrm{M}\left(\mathrm{NaClO}_{4}\right)^{a}$

\begin{tabular}{|c|c|c|c|c|c|c|c|c|c|}
\hline no. & ref $^{d}$ & $\mathrm{CA}^{-e}$ & $\mathrm{p} K_{\mathrm{H}(\mathrm{CA})}^{\mathrm{H}}$ & $\log K_{\mathrm{Mn}(\mathrm{CA})}^{\mathrm{Mn}}$ & $\log K_{\mathrm{Cu}(\mathrm{CA})}^{\mathrm{Cu}}$ & $\log K_{\mathrm{Zn}(\mathrm{CA})}^{\mathrm{Zn}}$ & $\log \Delta_{M n}$ & $\log \Delta_{\mathrm{Cu}}$ & $\log \Delta_{\mathrm{Zn}}$ \\
\hline 1 & 56 & $\mathrm{ClAc}^{-}$ & $4.08 \pm 0.02$ & 1.66 & 2.53 & 1.83 & -0.04 & 0.00 & 0.03 \\
\hline 2 & 57 & $\mathrm{HCOO}^{-}$ & $4.73 \pm 0.02$ & $1.82^{f}$ & $2.79 \pm 0.02$ & $1.96 \pm 0.01$ & 0.04 & -0.01 & -0.02 \\
\hline 3 & 56 & $\mathrm{ClPr}^{-}$ & $5.50 \pm 0.02$ & 1.88 & 3.13 & 2.17 & 0.01 & 0.02 & -0.02 \\
\hline 4 & 57 & $\mathrm{Bz}^{-}$ & $5.76 \pm 0.01$ & $1.90^{f}$ & $3.24 \pm 0.02$ & $2.27 \pm 0.02$ & -0.01 & 0.03 & 0.01 \\
\hline 5 & 57 & $\mathrm{PhAc}^{-}$ & $5.88 \pm 0.01$ & & $3.22 \pm 0.02$ & $2.26 \pm 0.02$ & & -0.04 & -0.04 \\
\hline 6 & 57 & $\mathrm{Ac}^{-}$ & $5.97 \pm 0.01$ & $1.97^{f}$ & $3.31 \pm 0.02$ & $2.31 \pm 0.01$ & 0.04 & 0.02 & -0.01 \\
\hline 7 & 57 & $\mathrm{PhPr}^{-}$ & $6.18 \pm 0.01$ & & $3.36 \pm 0.01$ & $2.36 \pm 0.01$ & & -0.02 & -0.02 \\
\hline 8 & 58 & $\operatorname{Pr}^{-}$ & $6.29 \pm 0.01$ & $1.92^{f}$ & 3.45 & 2.41 & -0.05 & 0.03 & 0.00 \\
\hline 9 & 57 & $\mathrm{PhBu}^{-}$ & $6.36 \pm 0.01$ & & $3.44 \pm 0.02$ & $2.46 \pm 0.01$ & & -0.01 & 0.03 \\
\hline \multirow[t]{2}{*}{10} & 57 & $\mathrm{PhVa}^{-}$ & $6.43 \pm 0.01$ & & $3.48 \pm 0.01$ & $2.49 \pm 0.01$ & & 0.00 & 0.04 \\
\hline & & & & & & $\mathrm{SD}^{c}$ & 0.016 & 0.007 & 0.009 \\
\hline
\end{tabular}

${ }^{a}$ The $\log \Delta$ values in the three columns at the right are the logarithmic differences between the measured stability constants (columns 5, 6, and 7) and the calculated ones based on the straight reference lines (see Figure 8$)^{b}{ }^{b}$ The bottom line of the table lists the standard deviation (SD) ${ }^{c}$ resulting from the listed differences. ${ }^{b}$ The straight-line equations, as they follow from the data in columns $4-7, \operatorname{are} \log K_{\mathrm{Mn}(\mathrm{CA})}^{\mathrm{Mn}}=(0.123 \pm 0.023) \cdot \mathrm{p} K_{\mathrm{H}(\mathrm{CA})}^{\mathrm{H}}+(1.197 \pm$ $0.126), \log K_{\mathrm{Cu}(\mathrm{CA})}^{\mathrm{Cu}}=(0.403 \pm 0.010) \cdot \mathrm{p} K_{\mathrm{H}(\mathrm{CA})}^{\mathrm{H}}+(0.889 \pm 0.059)$, and $\log K_{\mathrm{Zn}(\mathrm{CA})}^{\mathrm{Zn}}=(0.277 \pm 0.012) \cdot \mathrm{p} K_{\mathrm{H}(\mathrm{CA})}^{\mathrm{H}}+(0.667 \pm 0.071) \cdot{ }^{c}{ }^{\mathrm{T}} \mathrm{The}$ standard deviation (SD) times three is considered as a reasonable error limit for any calculation of the stability of a $\mathrm{M}(\mathrm{CA})^{+}$complex based on the straight-line equations given above. ${ }^{b d}$ The constants listed in columns $4-7$ are taken from the references given above in column 2; exceptions are defined in footnote $f .{ }^{e}$ For the definition of the ligand abbreviations see footnotes $a$ of Table 4 and $c$ of Table 8; in addition, $\mathrm{ClPr}^{-}=3$-chloropropanoate, $\mathrm{PhPr}^{-}=$ 3-phenylpropanoate, $\mathrm{PhBu}^{-}=4$-phenylbutanoate, $\mathrm{PhVa}^{-}=5$-phenylvalerate $=5$-phenylpentanoate. ${ }^{f}$ Value from ref 56.

$\Delta_{\mathrm{Zn} / \mathrm{THT} 2 \mathrm{CA}}=0.14 \pm 0.07$ is rather small, and consequently, the formation degree of $\mathrm{Zn}(\mathrm{THT} 2 \mathrm{CA})_{\mathrm{cl}}^{+}$is low. We assume that this is the result of the low hydrophilicity of the tetrahydrothiophen residue which is therefore strongly solvated by dioxane with the result that the metalion-thioether interaction is somewhat inhibited. This inhibition is overcome by $\mathrm{Cu}^{2+}$ but not by $\mathrm{Zn}^{2+}$.

\section{METAL-ION COMPLEXES WITH AMINO GROUPS AS PRIMARY BINDING SITES}

The ligand in the focus of this section is 2-aminoethanol $(\mathrm{AEtOH})$ (Figure 9). The difficulty in evaluating its metal-ion binding properties is that straight-line plots of the type log $K_{\mathrm{M}\left(\mathrm{R}-\mathrm{NH}_{2}\right)}^{\mathrm{M}}$ versus $\mathrm{p} K_{\mathrm{H}\left(\mathrm{R}-\mathrm{NH}_{2}\right)}^{\mathrm{H}}$ cannot easily be constructed because no values for a series of simple $\mathrm{R}-\mathrm{NH}_{2}$ ligands exist. ${ }^{17,18}$ It would be necessary to have data available for complexes of the ligand-type $\mathrm{CH}_{3}-\mathrm{NH}_{2}, \mathrm{ClCH}_{2}-\mathrm{NH}_{2}, \mathrm{FCH}_{2}-\mathrm{NH}_{2}$, etc. This means we have to evaluate the steric effect that a $\mathrm{CH}_{2}$ residue exercises on metal-ion binding at an amino group in a different way.

To achieve this goal we employed the ligands shown in Figure 9. For seven metal ions there are enough equilibrium data regarding 2 -aminoethanol available to allow an evaluation. These constants together with those of related systems are collected in Table $15 .^{17,64-68} \mathrm{~A}$ few constants are given for comparison only, like, e.g., the stability constant of the glycinate $\left(\mathrm{Gly}^{-}\right)$complex with $\mathrm{Mn}^{2+}$, and will not actually be used because no value for the corresponding sarcosinate complex is available. ${ }^{17,18}$

In any case, that the replacement of a hydrogen atom by a methyl group in $\mathrm{NH}_{3}$ leads to steric inhibition is evident, e.g., from a comparison of the stabilities of the $\mathrm{Ni}\left(\mathrm{NH}_{3}\right)^{2+}$ and $\mathrm{Ni}\left(\mathrm{CH}_{3} \mathrm{NH}_{2}\right)^{2+}$ complexes at $I=0.5 \mathrm{M}$; the difference amounts to about $0.6 \log$ unit $(=2.77-2.19)$ (Table 15), and this is despite the fact that methylamine is by $\Delta \mathrm{p} K_{\mathrm{a}}=1.4$ more basic!
In the present evaluation process described in section 5.1, it will be necessary to dive into a deep hole with uncertain boundaries. However, in section 5.2 it will become obvious that despite all initial uncertainties and assumptions clear-cut results are obtained for aqueous solutions at $25^{\circ} \mathrm{C}$ and $I=0.5 \mathrm{M}$.

\subsection{Estimation of Straight-Line Parameters for Complexes Formed with $\mathrm{RCH}_{2}-\mathrm{NH}_{2}$ Ligands}

How can we obtain $\log K_{\mathrm{M}\left(\mathrm{RCH}_{2}-\mathrm{NH}_{2}\right)}^{\mathrm{M}}$ versus $\mathrm{p} \mathrm{K}_{\mathrm{H}\left(\mathrm{RCH}_{2}-\mathrm{NH}_{2}\right)}^{\mathrm{H}}$ straight-line plots? Evidently, for the definition of a straight line at least two data points are needed. Unfortunately, e.g., for $\mathrm{Ni}^{2+}$ only one data point is available: $\mathrm{H}^{+} / \mathrm{Ni}^{2+} / \mathrm{CH}_{3} \mathrm{NH}_{2}$ (see Table 15). This point is inserted into Figure 10. How can we obtain a second point? Can we correct the $\mathrm{H}^{+} / \mathrm{Ni}^{2+} / \mathrm{NH}_{3}$ system for the inhibition due to a methyl group at $\mathrm{NH}_{3}$ ? Yes, we can by using the available information for the $\mathrm{H}^{+} / \mathrm{Ni}^{2+} / \mathrm{Gly}^{-}$ and $\mathrm{H}^{+} / \mathrm{Ni}^{2+} / \mathrm{Sar}^{-}$systems. Here, the terminal amino group of glycinate is substituted with a methyl group giving sarcosinate (see Figure 9).

By using the slope $m=0.70$ for $\log K$ versus $\mathrm{p} K_{\mathrm{a}}$ plots for amino acetate complexes as estimated by Martin ${ }^{69}$ one can define a straight line through the data point $\mathrm{H}^{+} / \mathrm{Ni}^{2+} / \mathrm{Gly}^{-}$, that is, $\log \mathrm{K}^{\mathrm{Ni}}=$ $(0.70) \cdot \mathrm{p} K_{\mathrm{a}}-1.05$, which holds for glycinate-like systems. Application of this line to sarcosinate with $\mathrm{p} K_{\mathrm{a}}=10.00$ (Table 15) gives an expected stability for the $\mathrm{Ni}(\mathrm{Sar})^{+}$complex of $\log K=5.95$. Since the $\mathrm{p} K_{\mathrm{a}}$ values of glycinate and sarcosinate are not far apart, the result is not very sensitive toward the slope $m$ used. Comparison of the calculated value with the measured one (Table 15) gives a steric inhibition $(S I)$ of $\log S I_{\mathrm{Ni}}=(5.95 \pm 0.10)-(5.24 \pm 0.06)=0.71$ with an estimated error limit of \pm 0.12 .

This value for $\log$ SI agrees well with the following estimation which is based on the $\mathrm{Ni}^{2+}$ complexes of $\mathrm{CH}_{3} \mathrm{NH}_{2}$ and $\left(\mathrm{CH}_{3}\right)_{2} \mathrm{NH}$ at $\mathrm{I}=1.0 \mathrm{M}^{17}$ If one ignores the small basicity

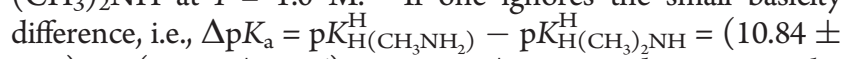
$0.04)-(11.02 \pm 0.06)=-0.18 \pm 0.07$, and compares the 
stability constants of the $\mathrm{Ni}^{2+}$ complexes directly, one obtains log

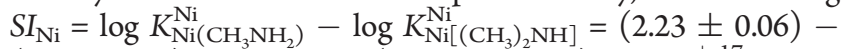
$(1.47 \pm 0.06)=0.76 \pm 0.08$ (error estimated). For $\mathrm{Ag}^{+}{ }^{17}$ despite the very different coordination sphere, follows in excellent agreement $\log S I_{\mathrm{Ag}}=\log K_{\mathrm{Ag}\left(\mathrm{CH}_{3} \mathrm{NH}_{2}\right)}^{\mathrm{Ag}}-\log K_{\mathrm{Ag}\left[\left(\mathrm{CH}_{3}\right)_{2} \mathrm{NH}\right]}^{\mathrm{Ag}}=(3.11 \pm$

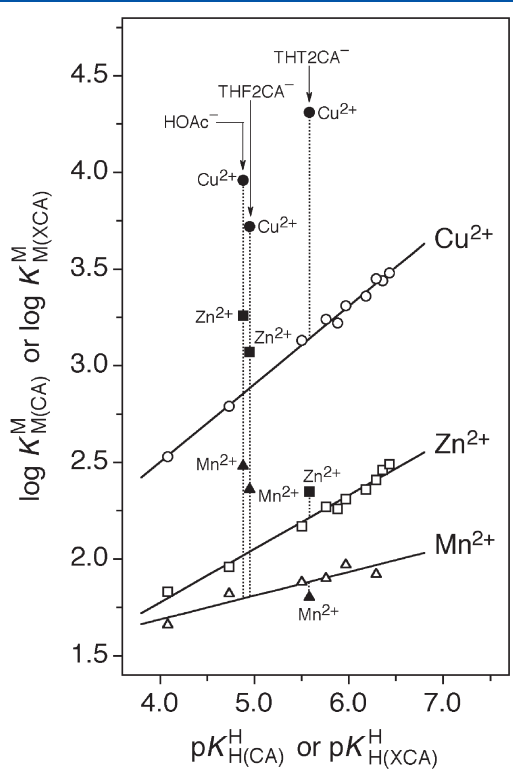

Figure 8. Evidence for an enhanced complex stability of the $\mathrm{Mn}^{2+}$, $\mathrm{Cu}^{2+}$, and $\mathrm{Zn}^{2+} 1: 1$ complexes of $\mathrm{HOAc}^{-}$and THF2 $\mathrm{CA}^{-}$in contrast to the rather different properties of the corresponding complexes formed with THT2CA ${ }^{-}$(see Figure 7) based on the relationship between log $K_{\mathrm{M}(\mathrm{CA})}^{\mathrm{M}}$ and $\mathrm{p} K_{\mathrm{H}(\mathrm{CA})}^{\mathrm{H}}$ for the simple carboxylate ligands $\left(\mathrm{CA}^{-}\right)$listed in Table 13. The parameters of the corresponding least-squares reference lines (eq 10) are summarized in footnote $b$ of Table 13. The data for the points due to the equilibrium constants of the $\mathrm{M}^{2+} / \mathrm{XCA}^{-}$systems $\left(\mathrm{XCA}^{-}=\mathrm{HOAc}^{-}, \mathrm{THF}_{2} \mathrm{CA}^{-}\right.$, or THT2CA $\left.{ }^{-}\right)$are given in Table 14. The vertical dotted lines emphasize the stability differences to the reference lines; they equal $\log \Delta_{\mathrm{M} / \mathrm{XCA}}$ as defined in eqs $11 \mathrm{a}$ and $11 \mathrm{~b}$ (see also Table 14, column 5). All plotted equilibrium constants refer to aqueous solutions containing $50 \%(\mathrm{v} / \mathrm{v}) 1,4$-dioxane at $25^{\circ} \mathrm{C}$ and $I=0.1$ $\mathrm{M}\left(\mathrm{NaClO}_{4}\right)$.
$0.06)-(2.48 \pm 0.06)=0.63 \pm 0.08$ (error estimated). Furthermore, both $\log S I$ values agree within the error limits with that resulting from the glycinate/sarcosinate systems.

Unfortunately, no further data are available for the amines $\mathrm{CH}_{3} \mathrm{NH}_{2}$ and $\left(\mathrm{CH}_{3}\right)_{2} \mathrm{NH}$ for other metal ions; ${ }^{17,18}$ therefore, we use the result from the glycinate/sarcosinate systems, i.e., log $S I_{\mathrm{Ni}}$ $=0.71 \pm 0.12$, which is available for some other metal ions as well. If the stability constant of the $\mathrm{Ni}\left(\mathrm{NH}_{3}\right)^{2+}$ complex is reduced by log $S I_{\mathrm{Ni}}$, one obtains an "ammonia" complex in which the steric inhibition is taken into account, i.e., $\log \mathrm{K}_{\mathrm{Ni}}^{\mathrm{Ni}}\left(\mathrm{NH}_{3}\right){ }_{\mathrm{SI}}=2.77-$ $0.71=2.06$. This value is represented by the arrowhead in the $\mathrm{Ni}^{2+}$ part of Figure 10. Now two points are available and a straight line can be defined, the parameters of which are listed in Table 16 below, and thus, a stability constant for log $K_{\mathrm{Ni}(\mathrm{AEtOH}) \text { op }}^{\mathrm{Ni}}$ can be calculated (see section 5.2). On the basis of the various uncertainties, including in the slope $m$, we apply the generous error limit of $\pm 0.20 \log$ unit (compare this with the situation graphically described in Figure 10 and you will note that this error limit is generous indeed).

Because in the case of $\mathrm{Cu}^{2+}$ the data pair $\mathrm{H}^{+} / \mathrm{Cu}^{2+} / \mathrm{CH}_{3} \mathrm{NH}_{2}$ is available (Table 15), the procedure described above can analogously be applied for $\mathrm{Cu}^{2+}$ (Figure 10). The resulting straight-line parameters are listed in Table 16; because in this case the slope $m$ is somewhat larger, we use \pm 0.25 log unit as an (oversized) error limit for a calculation at $\mathrm{p} K_{\mathrm{H}(\mathrm{AEtOH})}^{\mathrm{H}}=9.62$.

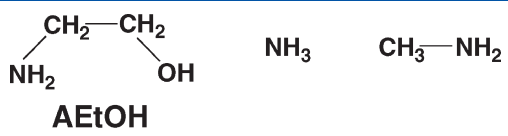<smiles>CNCC(=O)O</smiles>

Figure 9. Structures of 2-aminoethanol (AEtOH) and some related ligands needed for evaluation of the properties of its complexes, that is, of ammonia $\left(\mathrm{NH}_{3}\right)$, methylamine $\left(\mathrm{CH}_{3}-\mathrm{NH}_{2}\right)$, glycinate $\left(\mathrm{Gly}^{-}\right)$, and sarcosinate $\left(\mathrm{Sar}^{-}\right)$.

Table 14. Comparison of the Measured Stability Constants, $K_{M}^{\mathrm{M}(\mathrm{XCA})}$ (eqs 4a, 4b, and 6), of M(HOAc) ${ }^{+}$and Some Related Complexes with the Calculated Stability Constants, $K_{M}^{M}(\mathrm{XCA})$ op (eqs 1 and 7$)$, for Isomers with a Sole Carboxylate Coordination of $\mathbf{M}^{2+}$, and Extent of Intramolecular Chelate Formation According to Equilibria 1 and 2 in the $\mathrm{M}(\mathrm{XCA})^{+}$Complexes As Defined by $K_{\mathrm{I}}$ (eqs 3 and 9) and \% M(XCA) $)_{\mathrm{cl}}^{+}\left(\right.$eq 13) for Aqueous Solutions Containing 50\% (v/v) 1,4-Dioxane at $25^{\circ} \mathrm{C}$ and $\mathrm{I}=0.1 \mathrm{M}$ $\left(\mathrm{NaClO}_{4}\right)^{a, b}$

\begin{tabular}{|c|c|c|c|c|c|c|}
\hline $\mathrm{XCA}^{-}$ & $\mathrm{M}^{2+}$ & $\log K_{\mathrm{M}(\mathrm{XCA})}^{\mathrm{M}}$ & $\log K_{\mathrm{M}(\mathrm{XCA})_{\mathrm{op}}}^{\mathrm{M}}$ & $\log \Delta_{\mathrm{M} / \mathrm{XCA}}$ & $K_{\mathrm{I}}$ & $\% \mathrm{M}(\mathrm{XCA})_{\mathrm{cl}}^{+}$ \\
\hline \multirow[t]{3}{*}{$\mathrm{HOAc}^{-}$} & $\mathrm{Mn}^{2+}$ & $2.48 \pm 0.06$ & $1.80 \pm 0.05$ & $0.68 \pm 0.08$ & $3.79 \pm 0.86$ & $79 \pm 4$ \\
\hline & $\mathrm{Cu}^{2+}$ & $3.96 \pm 0.06$ & $2.86 \pm 0.02$ & $1.10 \pm 0.06$ & $11.59 \pm 1.83$ & $92 \pm 1$ \\
\hline & $\mathrm{Zn}^{2+}$ & $3.26 \pm 0.06$ & $2.02 \pm 0.03$ & $1.24 \pm 0.07$ & $16.38 \pm 2.68$ & $94 \pm 1$ \\
\hline \multirow[t]{3}{*}{$\mathrm{THF} \mathrm{CA}^{-}$} & $\mathrm{Mn}^{2+}$ & $2.36 \pm 0.06$ & $1.81 \pm 0.05$ & $0.55 \pm 0.08$ & $2.55 \pm 0.64$ & $72 \pm 5$ \\
\hline & $\mathrm{Cu}^{2+}$ & $3.72 \pm 0.06$ & $2.88 \pm 0.02$ & $0.84 \pm 0.06$ & $5.92 \pm 1.01$ & $86 \pm 2$ \\
\hline & $\mathrm{Zn}^{2+}$ & $3.07 \pm 0.06$ & $2.04 \pm 0.03$ & $1.03 \pm 0.07$ & $9.72 \pm 1.66$ & $91 \pm 2$ \\
\hline \multirow[t]{3}{*}{$\mathrm{THT}_{2 \mathrm{CA}^{-}}$} & $\mathrm{Mn}^{2+}$ & $1.80 \pm 0.06$ & $1.88 \pm 0.05$ & $-0.08 \pm 0.08$ & 0 & 0 \\
\hline & $\mathrm{Cu}^{2+}$ & $4.31 \pm 0.06$ & $3.14 \pm 0.02$ & $1.17 \pm 0.06$ & $13.79 \pm 2.15$ & $93 \pm 1$ \\
\hline & $\mathrm{Zn}^{2+}$ & $2.35 \pm 0.06$ & $2.21 \pm 0.03$ & $0.14 \pm 0.07$ & $0.38 \pm 0.21$ & $28 \pm 11$ \\
\hline
\end{tabular}

${ }^{a}$ The stability constants listed in column 3 are for the $\mathrm{M}(\mathrm{HOAc})^{+}$and $\mathrm{M}(\mathrm{THF} 2 \mathrm{CA})^{+}$complexes of $\mathrm{Cu}^{2+}$ and $\mathrm{Zn}^{2+}$ from ref 58 and those for $\mathrm{Mn}(\mathrm{HOAc})^{+}, \mathrm{Mn}(\mathrm{THF} 2 \mathrm{CA})^{+}$, and $\mathrm{M}(\mathrm{THT} 2 \mathrm{CA})^{+}$from ref 56. The error limits are for all cases assumed to be within \pm 0.06 log unit. The error limits of the derived data in the table were calculated according to the error propagation after Gauss. ${ }^{b}$ The acidity constants of the monoprotonated ligands are $\mathrm{p} K_{\mathrm{H}(\mathrm{HOAc})}^{\mathrm{H}}=4.88 \pm 0.03$ (cf. ref 58), $\mathrm{p} K_{\mathrm{H}(\mathrm{THF} 2 \mathrm{CA})}^{\mathrm{H}}=4.95 \pm 0.01$ (cf. ref 58), and $\mathrm{p} K_{\mathrm{H}(\mathrm{THF} 2 \mathrm{CA})}^{\mathrm{H}}=5.58 \pm 0.01$ (cf. ref 56). These values, together with the straight-line equations defined in footnote $b$ of Table 13 , were used to calculate the values listed for $\log K_{\mathrm{M}}^{\mathrm{M}}(\mathrm{XCA})$ op. 
Table 15. Logarithms of the Stability Constants of Several Metal-Ion 1:1 Complexes (eqs 4a and 4b) Formed with Ligands Containing an Amino Group (AL) and Which Are Used Toward Evaluation of the Properties of the Complexes Formed with 2-Aminoethanol (AEtOH) (eqs 4a, 4b, and 6), the Constants of Which Are also Listed ${ }^{a, b}$

\begin{tabular}{|c|c|c|c|c|c|c|c|c|c|}
\hline \multirow[b]{2}{*}{$\mathrm{AL}$} & \multirow[b]{2}{*}{$I$} & \multirow[b]{2}{*}{$\mathrm{p} K_{\mathrm{H}(\mathrm{AL})}^{\mathrm{H}}$} & \multicolumn{7}{|c|}{$\log K_{\mathrm{M}(\mathrm{AL})}^{\mathrm{M}}$ for $\mathrm{M}^{2+}=$} \\
\hline & & & $\mathrm{Mn}^{2+}$ & $\mathrm{Co}^{2+}$ & $\mathrm{Ni}^{2+}$ & $\mathrm{Cu}^{2+}$ & $\mathrm{Zn}^{2+}$ & $\mathrm{Cd}^{2+}$ & $\mathrm{Pb}^{2+}$ \\
\hline \multirow[t]{2}{*}{ AEtOH } & 0.1 & $9.52 \pm 0.03$ & 0.81 & 2.20 & $3.02 \pm 0.04$ & 4.50 & 2.41 & & $4.10 \pm 0.05$ \\
\hline & $0.5^{c}$ & $9.62 \pm 0.03$ & $0.88^{d}$ & 2.23 & $3.12 \pm 0.06$ & 4.60 & 2.50 & $2.45^{e}$ & $4.20^{f}$ \\
\hline \multirow[t]{3}{*}{$\mathrm{NH}_{3}$} & 0.1 & $9.26 \pm 0.05$ & & 2.08 & 2.73 & 4.10 & 2.33 & 2.57 & \\
\hline & $0.5^{g}$ & $9.33 \pm 0.04$ & 0.88 & 2.09 & 2.77 & 4.11 & 2.31 & 2.60 & $1.45^{h}$ \\
\hline & 1.0 & $9.43 \pm 0.05$ & 0.90 & $2.10 \pm 0.04$ & $2.80 \pm 0.03$ & $4.12 \pm 0.04$ & $2.30 \pm 0.10$ & $2.62 \pm 0.08$ & $(1.55)^{h}$ \\
\hline \multirow[t]{2}{*}{$\mathrm{CH}_{3} \mathrm{NH}_{2}$} & 0.5 & $10.72 \pm 0.06$ & & & $2.19^{i}$ & $4.07^{j}$ & & & \\
\hline & 1.0 & $10.84 \pm 0.04$ & & & 2.23 & $(4.11)^{j}$ & & & \\
\hline $\mathrm{Gly}^{-}$ & 0.5 & $9.54 \pm 0.03$ & $2.60 \pm 0.05$ & $4.55 \pm 0.04$ & $5.63 \pm 0.03$ & $8.10 \pm 0.07$ & $4.85 \pm 0.04$ & 4.18 & $4.60 \pm 0.20$ \\
\hline $\mathrm{Sar}^{-}$ & 0.5 & $10.00 \pm 0.01$ & & & 5.24 & 7.75 & 4.31 & & \\
\hline
\end{tabular}

${ }^{a}$ In addition, the negative logarithms of the acidity constants of the monoprotonated ligands (eqs $14 \mathrm{a}$ and $14 \mathrm{~b}$ ) are given (aqueous solution; $25^{\circ} \mathrm{C}$ ). ${ }^{b}$ All constants are collected from ref 17 except where otherwise indicated; the listed error limits are those given in the literature. The two values given in parentheses do not refer to $I=1.0 \mathrm{M}$ (see below). ${ }^{c}$ The constants given for the $\mathrm{Co}^{2+}, \mathrm{Ni}^{2+}, \mathrm{Cu}^{2+}$, and $\mathrm{Zn}^{2+}$ complexes are identical with those determined by Djurdjevic and Bjerrum. ${ }^{64 d}$ Value obtained by adding $0.07 \log$ unit (average of the differences at $I=0.1$ and $0.5 \mathrm{M} \mathrm{for} \mathrm{Co}^{2+}, \mathrm{Ni}^{2+}$, and $\mathrm{Zn}^{2+}$ ) to 0.81 . ${ }^{e}$ In ref 64 the value of $2.65 \log$ units is given for $I=2.0 \mathrm{M}$; deduction of $0.20 \log$ unit (average of the difference for $\mathrm{Co}^{2+}, \mathrm{Ni}^{2+}$, and $\mathrm{Zn}^{2+}$ at $I=2.0$ and $0.5 \mathrm{M}$ ) gives the listed value of $2.45 .{ }^{f}$ The difference for $\mathrm{Cu}^{2+}$ at $I=0.1$ and $0.5 \mathrm{M}$ equals $0.10 \log$ unit; this value is added to 4.10 (valid at $I=0.1 \mathrm{M}$ ) to give 4.20 (cf. refs 65-67). The value of 4.10 is taken from the work of Hancock and Nakani. ${ }^{68} \mathrm{For} \mathrm{Co}^{2+}, \mathrm{Ni}^{2+}, \mathrm{Cu}^{2+}, \mathrm{Zn}^{2+}, \mathrm{and} \mathrm{Cd}^{2+}$ the values at $I=0.1$ and $1.0 \mathrm{M}$ are averaged and listed. In the case of $\mathrm{Mn}^{2+}$ the average of the differences $(0.02 \log$ unit) resulting at $I=0.5$ and $1.0 \mathrm{M}$ for $\mathrm{Co}^{2+}, \mathrm{Ni}^{2+}, \mathrm{Cu}^{2+}, \mathrm{Zn}^{2+}$, and $\mathrm{Cd}^{2+}$ is deducted from $0.90(\mathrm{I}=1.0 \mathrm{M}){ }^{h}$ This value is based on 1.55 , which holds for $5 \mathrm{M} \mathrm{NH}_{4} \mathrm{NO}_{3}$ by deducting 0.10 $\log$ unit. ${ }^{i}$ The basicity difference at $I=0.5$ and $1.0 \mathrm{M}$ amounts to $0.12 \log$ unit; assuming a slope of $m=0.33$ one obtains $2.23-0.04=2.19 .{ }^{j}$ At $I=2.0 \mathrm{M}$ 4.11 was measured; the basicity difference between $I=2.0$ and $0.5 \mathrm{M}$ amounts to $10.80-10.72=0.08$; assuming a slope of $m=0.5$ one obtains $4.11-0.04=4.07$ as given above.

Since no $\mathrm{H}^{+} / \mathrm{M}^{2+} / \mathrm{CH}_{3} \mathrm{NH}_{2}$ data are available for the $\mathrm{Zn}^{2+}$ system, a different procedure needs to be applied. However, based on the $\mathrm{Zn}^{2+} / \mathrm{Gly}^{-} / \mathrm{Sar}^{-}$data (Table 15) the steric inhibition can still be determined: $\log S I_{\mathrm{Zn}}=0.86( \pm 0.12$; estimated $)[=5.17-$ 4.31]. The reduction of the stability constant for $\mathrm{Zn}\left(\mathrm{NH}_{3}\right)^{2+}$ $\left(\right.$ at $\left.\mathrm{p} K_{\mathrm{H}\left(\mathrm{NH}_{3}\right)}^{\mathrm{H}}=9.33\right)$ by $\log S I_{\mathrm{Zn}}$ gives $\log \mathrm{p} K_{\mathrm{Zn}(\mathrm{NH})_{3} \mathrm{SI}}^{\mathrm{Zn}}=2.31-$ $0.86=1.45$ ( \pm 0.16 ; estimated $)$. This data pair is represented by the arrowhead in the $\mathrm{Zn}^{2+}$ part of Figure 10. What is needed now is the slope $m$ that goes through the "arrowhead".

Since such slopes are also needed for the other $\mathrm{M}^{2+}$ systems, we calculated the averages of the straight-line slopes $m$ resulting from $\log K$ versus $\mathrm{p} K_{\mathrm{a}}$ plots for the pyridine, ${ }^{70} o$-amino(methyl)pyridine, $^{70}$ imidazole, $^{71}$ and benzimidazole ${ }^{72}$ families: The values for $m_{\mathrm{av}}$ are $\left(\mathrm{M}^{2+}\right.$ in parentheses $) 0.132\left(\mathrm{Mn}^{2+}\right), 0.172\left(\mathrm{Co}^{2+}\right)$, $0.195\left(\mathrm{Ni}^{2+}\right), 0.396\left(\mathrm{Cu}^{2+}\right), 0.233\left(\mathrm{Zn}^{2+}\right)$, and $0.241\left(\mathrm{Cd}^{2+}\right)$. These values can now be expressed as percentages by defining once $m_{\mathrm{Cu} / \text { av }}$ as $100 \%$ and once $m_{\mathrm{Ni} / \text { av }}$ as $100 \%$. Because the slopes of the amine straight lines for the $\mathrm{Ni}^{2+}$ and $\mathrm{Cu}^{2+}$ systems have been determined (see upper parts in Figure 10 and also Table 16), one can now calculate the expected "amine" slopes, once via the $\mathrm{Ni}^{2+}$ and once via the $\mathrm{Cu}^{2+}$ systems. The averages of these calculations for the straight lines of the "amine" family are $m=0.108\left(\mathrm{Mn}^{2+}\right)$, $0.137\left(\mathrm{Co}^{2+}\right), 0.190\left(\mathrm{Zn}^{2+}\right)$, and $0.196\left(\mathrm{Cd}^{2+}\right)$ (see also Table 16).

Now, with the slope $m_{\mathrm{Zn}}=0.190$ at hand, one can draw a straight line through the mentioned "arrowhead" (see the $\mathrm{Zn}^{2+}$ part of Figure 10) and define in this way the straight-line parameters. The corresponding data are listed in Table 16.

For the $\mathrm{Mn}^{2+}, \mathrm{Co}^{2+}$, and $\mathrm{Cd}^{2+}$ systems no $\mathrm{Sar}^{-}$data are available, thus preventing calculation of the steric inhibition log $S I_{M}$ for these metal ions. However, as we have seen earlier in this section, the log SI values are rather independent from the type of metal ion involved. Therefore, we use the average of the values obtained for $\mathrm{Ni}^{2+}\left(\log S I_{\mathrm{Ni}}=0.71\right.$; see earlier text and Figure 10),
$\mathrm{Cu}^{2+}(0.67)$, and $\mathrm{Zn}^{2+}(0.86)$, that is, $\log \mathrm{SI}_{\mathrm{M}}=0.75$ (with an estimated error limit of \pm 0.15 log unit). The corresponding evaluation procedure is graphically shown in the lower part of Figure 10 for the $\mathrm{Mn}^{2+}$ system. Evaluation of the $\mathrm{Co}^{2+}$ and $\mathrm{Cd}^{2+}$ systems was done analogously. The resulting straight-line parameters are listed in Table 16.

A special case is $\mathrm{Pb}^{2+}$ because no slopes $m$ for heteroaromatic amine families are available as used above. However, from the so-called Stability Ruler of Martin ${ }^{65,66}$ it follows that $\mathrm{Pb}^{2+}$ behaves like either $\mathrm{Zn}^{2+}$ (e.g., with $\mathrm{Gly}^{-}$, see Table 15) or $\mathrm{Cu}^{2+}$ (with $\mathrm{O}$ donors, for which the slopes $m_{\mathrm{Cu}}$ approximately equal $m_{\mathrm{Pb}} ;{ }^{67}$ see also Table 9). Hence, regarding the evaluation of $\mathrm{Pb}(\mathrm{AEtOH})^{2+}$ we apply the average of the slopes obtained for $\mathrm{Cu}^{2+}$ and $\mathrm{Zn}^{2+}$, i.e., $m_{\mathrm{Pb}}=0.322[=0.5(0.453+0.190)]$ (see Table16). Thus, together with the data point for $\mathrm{H}^{+} / \mathrm{Pb}^{2+} / \mathrm{NH}_{3}$ (Table 15) and the steric inhibition, $\log S I_{\mathrm{Pb}}=0.75$ (see above), the straightline parameters can be defined; the results are listed in Table 16. To be on the safe side, we use here for the calculation with $\mathrm{p} K_{\mathrm{H}(\mathrm{AEtOH})}^{\mathrm{H}}=9.62$ (see section 5.2) as an error limit \pm 0.3 $\log$ unit.

To conclude, the straight-line parameters summarized in Table 16 for simple amine complexes are estimations but are generally useful and applicable in the $\mathrm{p} K_{\mathrm{a}}$ range $9.2-10$ for any kind of evaluation. The fact that the parameters are estimations and contain uncertainties is considered in the large error limits recommended (Table 16, column 4); they should help to prevent misinterpretations. Indeed, as we will see in the next section 5.2, despite the large error limits, useful results are obtained.

\subsection{Extent of Hydroxyl Group-Metal-lon Binding in Com- plexes of 2-Aminoethanol and Related Ligands}

Stability constant data are available for 2-aminoethanol $(\mathrm{AEtOH})$, DL-1-amino-2-propanol (AiPrOH; an isopropanol 


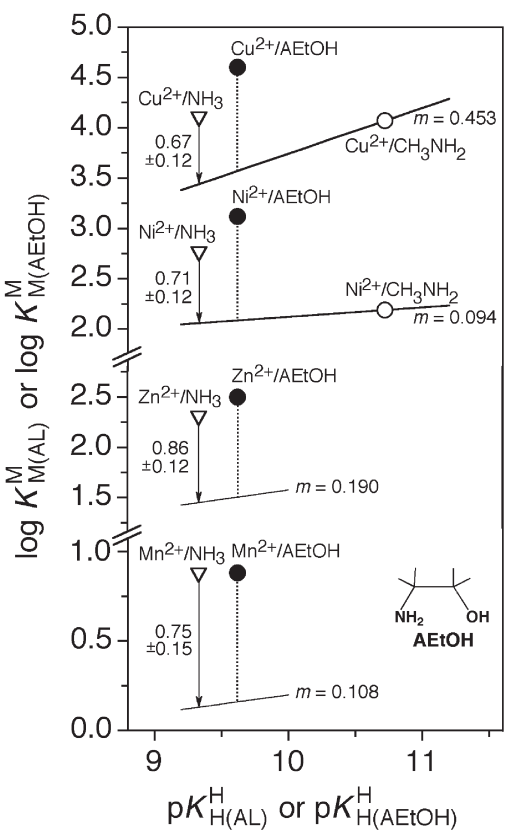

Figure 10. Graphical demonstration of the processes leading to reference

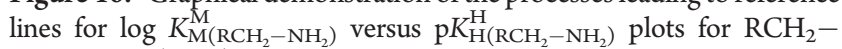
$\mathrm{NH}_{2}$ ligands (= AL), allowing thus to define the stability enhancements, log $\Delta_{\mathrm{M} / \mathrm{AEtOH}}(\mathrm{Table} 17$, column 4$)$, for the $\mathrm{M}(\mathrm{AEtOH})^{2+}$ complexes. In the case of $\mathrm{Ni}^{2+}$, one point for the reference line is defined by the $\mathrm{H}^{+} / \mathrm{Ni}^{2+} /$ $\mathrm{CH}_{3} \mathrm{NH}_{2}$ data (Table 15) and the other one by correcting the $\mathrm{H}^{+} / \mathrm{Ni}^{2+} /$ $\mathrm{NH}_{3}$ system for the steric inhibition due to a methyl group. This steric inhibition is obtained from the glycinate/sarcosinate data (see text in section 5.1 and Table 15) and amounts to $\log S I_{\mathrm{Ni}}=0.71( \pm 0.12$; error limit estimated). Deduction of this value from the stability constant of the $\mathrm{Ni}\left(\mathrm{NH}_{3}\right)^{2+}$ complex, $\log \mathrm{K}_{\mathrm{Ni}\left(\mathrm{NH}_{3}\right)}^{\mathrm{Ni}}=2.77$, gives 2.06 for the sterically inhibited coordination of $\mathrm{Ni}^{2+}$ to " $\mathrm{NH}_{3}$ "; this value is represented by the arrowhead in the $\mathrm{Ni}^{2+}$ part of the figure. Now the straight line for $\mathrm{Ni}\left(\mathrm{RCH}_{2}-\mathrm{NH}_{2}\right)^{2+}$ complexes is defined; the corresponding parameters are listed in Table 16. The analogous evaluation procedure is shown for the $\mathrm{Cu}^{2+}$ systems (see also the text in section 5.1). In the case of $\mathrm{Zn}^{2+}$ only the data point represented by the arrowhead is available, and therefore, the estimated slope, $m_{\mathrm{Zn}}=0.190$ (see text), is used to define the reference line. In the case of $\mathrm{Mn}^{2+}$ also the position of the arrowhead needed to be estimated, as explained in the text (section 5.1). The stability enhancements (eqs $11 \mathrm{a}$ and $11 \mathrm{~b}$ ) for the $\mathrm{M}(\mathrm{AEtOH})^{2+}$ complexes are represented by the vertical dotted lines seen in the figure. It needs to be emphasized that errors in the $\log S I_{M}$ values and in the slopes $m_{\mathrm{M}}$ do not affect drastically the size of the stability enhancements, $\log \Delta_{\mathrm{M} / \mathrm{AEtOH}}($ Table 17 , column 4 ), as is evident from the various parts of the figure, especially if one "moves" the $\log S I_{\mathrm{M}}$ values within their error limits. Thus, it becomes evident

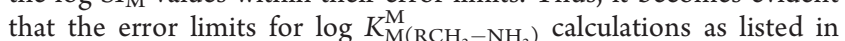
Table 16 (column 4) are generously chosen. All equilibrium constants used in this figure refer to aqueous solution at $25^{\circ} \mathrm{C}$ and $I=0.5 \mathrm{M}$; the corresponding data are taken from Table 15.

derivative), and 3-aminopropanol (APrOH), the structures of which are shown in Figure 11. Having now available the straightline plots for simple amine complexes, an evaluation regarding the participation of the alcoholic hydroxyl group in metal-ion binding is possible. It may be added in this context that it was previously concluded that the stability of amine complexes decreases with increasing alkyl substitution $\left(\mathrm{NH}_{3}, \mathrm{CH}_{3} \mathrm{NH}_{2}\right.$, $\mathrm{CH}_{3} \mathrm{CH}_{2} \mathrm{NH}_{2},\left(\mathrm{CH}_{3}\right)_{2} \mathrm{NH}$, etc.) and that the "trend is attributable to steric effects ... with no apparent inductive contribution" ${ }^{73}$ This view concurs with ours.
Table 16. Estimated Straight-Line Parameters (eq 10) ${ }^{a}$ for $\mathrm{M}^{2+}$ 1:1 Complexes Formed with Simple Amine Ligands $\left(\mathrm{RCH}_{2}-\mathrm{NH}_{2}\right)$, Valid for Aqueous Solution at $25{ }^{\circ} \mathrm{C}$ and $I=0.5 \mathrm{M}^{b}$

\begin{tabular}{lcrc}
$\mathrm{M}^{2+}$ & $m$ & \multicolumn{1}{c}{$b$} & $\log$ (error limits) $^{b}$ \\
$\mathrm{Mn}^{2+}$ & 0.108 & -0.878 & 0.20 \\
$\mathrm{Co}^{2+}$ & 0.137 & 0.062 & 0.20 \\
$\mathrm{Ni}^{2+}$ & 0.094 & 1.182 & 0.20 \\
$\mathrm{Cu}^{2+}$ & 0.453 & -0.786 & 0.25 \\
$\mathrm{Zn}^{2+}$ & 0.190 & -0.323 & 0.20 \\
$\mathrm{Cd}^{2+}$ & 0.196 & 0.021 & 0.20 \\
$\mathrm{~Pb}^{2+}$ & 0.322 & -2.304 & 0.3
\end{tabular}

${ }^{a}$ The slopes $(m)$ and intercepts $(b)$ for the straight reference lines for

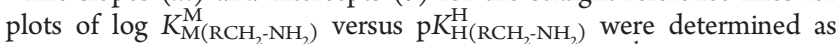
described in the text of section 5.1; see also Figure $10 .{ }^{b}$ The straight-line

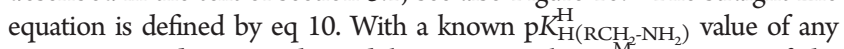

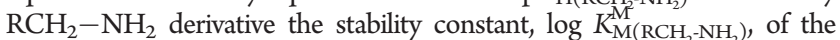
corresponding $\mathrm{M}\left(\mathrm{RCH}_{2}-\mathrm{NH}_{2}\right)^{2+}$ complex (eqs 4a, 4b, and 6) can be calculated. The recommended, estimated error limits given in the fourth column should be used for any calculation in the $\mathrm{p} K_{\mathrm{a}}$ range of $9.2-10$.

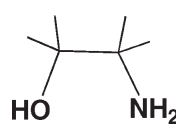

AEtOH

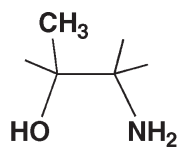

AiPrOH

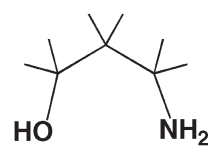

APrOH
Figure 11. Structural relationship of DL-1-amino-2-propanol (AiPrOH; an isopropanol derivative) and 3-aminopropanol ( $\mathrm{APrOH})$ with 2-aminoethanol (AEtOH).

On the basis of the results described in sections 3 and 4, participation of the hydroxyl group in metal-ion binding of $\mathrm{AEtOH}$ and its derivatives (Figure 11) is expected and, in fact, already evident from Figure 10; the data points due to $\mathrm{H}^{+}$/ $\mathrm{M}^{2+} / \mathrm{AEtOH}$ are always far above their reference line. Hence, there is no doubt that equilibrium 1 operates. Indeed, Hancock ${ }^{74}$ discussed already 30 years ago the stability of AEtOH complexes in relation to the chelate effect. That the hydroxyl group is involved in metal-ion binding of AEtOH and related ligands was confirmed for $\mathrm{Cu}^{2+}$ by spectrophotometric and EPR studies, ${ }^{75}$ where it was concluded that compounds of the mentioned type "act as multidentate ligands through amino and hydroxyl groups". However, in none of the studies any quantification regarding the position of equilibrium 1 was attempted.

Application of the straight-line parameters assembled in Table 16 together with the acidity constant $\mathrm{p} K_{\mathrm{H}(\mathrm{AEtOH})}^{\mathrm{H}}=$ 9.62 allows calculation of $\log K_{\mathrm{M}(\mathrm{AEtOH}) \mathrm{op}}^{\mathrm{M}}$, that is, of the open isomer (eqs 1, 2, and 7), and thus, the stability enhancements, $\log \Delta_{\mathrm{M} / \mathrm{AEtOH}}$ (eqs 1la and $11 \mathrm{~b}$ ), can be quantified. These results lead to the intramolecular equilibrium constants, $K_{\mathrm{I}}$ (eq 12), and the formation degrees of the chelated species (eq 13). The corresponding results are assembled in Table 17 for seven $\mathrm{M}(\mathrm{AEtOH})^{2+}$ systems; for the other two ligands considered, $\mathrm{AiPrOH}$ and $\mathrm{APrOH}$ (Figure 11), only data for their $\mathrm{Ni}^{2+}$ complexes are available. ${ }^{17}$

Many conclusions are possible based on the data assembled in Table 17; a few are given below:

(i) Most impressive are probably the high formation degrees of the chelated species which vary between about $80 \%$ 
Table 17. Comparison of the Measured Stability Constants, $K_{M(A E t O H) \exp }^{\mathrm{M}}$ (eqs 4a, 4b, and 6), of the 1:1 Complexes Formed between 2-Aminoethanol $(\mathrm{AEtOH})$ and Several $\mathrm{M}^{2+}$ with the Stability Constants, $K_{\mathrm{M}(\mathrm{AEtOH}) \text { op }}^{\mathrm{M}}$ (eq 7 ), for Isomers with a Sole $-\mathrm{NH}_{2}$ Group Coordination at $\mathbf{M}^{2+a}$

\begin{tabular}{|c|c|c|c|c|c|}
\hline $\mathrm{M}^{2+}$ & $\log K_{\mathrm{M}(\mathrm{AEtOH}) \exp ^{b}}^{\mathrm{M}}$ & $\log K_{\mathrm{M}(\mathrm{AEtOH})_{\mathrm{op}}{ }^{c}}^{\mathrm{M}}$ & $\log \Delta_{\mathrm{M} / \mathrm{AEtOH}}$ & $K_{\mathrm{I}}$ & $\% \mathrm{M}(\mathrm{AEtOH})_{\mathrm{cl}}^{2+}$ \\
\hline $\mathrm{Mn}^{2+}$ & $0.88 \pm 0.10$ & $0.16 \pm 0.20$ & $0.72 \pm 0.22$ & $4.35 \pm 2.77$ & $81 \pm 10$ \\
\hline $\mathrm{Co}^{2+}$ & $2.23 \pm 0.06$ & $1.38 \pm 0.20$ & $0.85 \pm 0.21$ & $6.08 \pm 3.40$ & $86 \pm 7$ \\
\hline $\mathrm{Ni}^{2+}$ & $3.12 \pm 0.06$ & $2.09 \pm 0.20$ & $1.03 \pm 0.21$ & $9.72 \pm 5.15$ & $91 \pm 4$ \\
\hline $\mathrm{Cu}^{2+}$ & $4.60 \pm 0.06$ & $3.57 \pm 0.25$ & $1.03 \pm 0.26$ & $9.72 \pm 6.34$ & $91 \pm 6$ \\
\hline $\mathrm{Zn}^{2+}$ & $2.50 \pm 0.06$ & $1.51 \pm 0.20$ & $0.99 \pm 0.21$ & $8.77 \pm 4.70$ & $90 \pm 5$ \\
\hline $\mathrm{Cd}^{2+}$ & $2.45 \pm 0.10$ & $1.91 \pm 0.20$ & $0.54 \pm 0.22$ & $2.47 \pm 1.79$ & $71 \pm 15$ \\
\hline $\mathrm{Pb}^{2+}$ & $4.20 \pm 0.10$ & $0.8 \pm 0.3$ & $3.40 \pm 0.32$ & $2511 \pm 1829$ & $100 \pm 0.07$ \\
\hline \multicolumn{6}{|c|}{$\mathrm{AiPrOH}^{d}$} \\
\hline $\mathrm{Ni}^{2+}$ & $3.15 \pm 0.10^{e}$ & $2.08 \pm 0.20$ & $1.07 \pm 0.22$ & $10.75 \pm 6.05$ & $91 \pm 4$ \\
\hline \multicolumn{6}{|c|}{$\mathrm{APrOH}^{d}$} \\
\hline $\mathrm{Ni}^{2+}$ & $2.77 \pm 0.10^{f}$ & $2.14 \pm 0.20$ & $0.63 \pm 0.22$ & $3.27 \pm 2.20$ & $77 \pm 13$ \\
\hline
\end{tabular}

${ }^{a}$ The observed stability increase is expressed by $\log \Delta_{\mathrm{M} / \mathrm{AEtOH}}($ eqs $11 \mathrm{a}$ and $11 \mathrm{~b})$. The extent of intramolecular chelate formation according to equilibria 1 and 2 in the $\mathrm{M}(\mathrm{AEtOH})^{2+}$ complexes is quantified by $K_{\mathrm{I}}$ (eqs $\left.3,9,12\right)$ and $\% \mathrm{M}(\mathrm{AEtOH})_{\mathrm{cl}}^{2+}$ (eq 13) for aqueous solutions at $25^{\circ} \mathrm{C}$ and $I=0.5 \mathrm{M}$. In the two bottom entries the corresponding results for the $\mathrm{Ni}^{2+}$ complexes of DL-1-amino-2-propanol (AiPrOH) and 3-aminopropanol (APrOH) are given. ${ }^{b}$ All values are from refs 17, 64, and 68 (see also the top rows in Table 15). Since mostly no error limits are given in the references (see Table 15) an error limit of $\pm 0.06 \log$ unit is assumed, except in those cases where the constant had to be corrected due to a change in $I$; here an error limit of $\pm 0.10 \mathrm{log}$ unit is applied. ${ }^{c}$ Calculated with the straight-line equations defined in Table 16 for a simple $\mathrm{M}^{2+}$-amino group coordination and $\mathrm{pK}_{\mathrm{H}(\mathrm{AEtOH})}^{\mathrm{H}}=9.62 .{ }^{17 d}{ }^{d}$ The acidity constants $\left(25^{\circ} \mathrm{C} ; I=0.5 \mathrm{M}\right)$ are $\mathrm{p} K_{\mathrm{H}(\mathrm{AiPrOH})}^{\mathrm{H}}=9.60$ and $\mathrm{p} K_{\mathrm{H}(\mathrm{APrOH})}^{\mathrm{H}}=10.23 .{ }^{17 e} \operatorname{In} \operatorname{ref} 17, \log K_{\mathrm{Ni}(\mathrm{AiPrOH})}^{\mathrm{Ni}}=3.20$ is given for $I=1.0 \mathrm{M}\left(25^{\circ} \mathrm{C}\right)$; from this value $0.05 \log$ unit is deducted to adjust it for $I=0.5 \mathrm{M} .{ }^{f} \mathrm{In}$ ref $17, \log K_{\mathrm{Ni}(\mathrm{APrOH})}^{\mathrm{Ni}}=2.82$ is given for $I=1.0 \mathrm{M}$ $\left(25^{\circ} \mathrm{C}\right)$; deduction of $0.05 \log$ unit gives the above value for $I=0.5 \mathrm{M}$.

$\left(\mathrm{Mn}^{2+}\right)$ and $100 \%\left(\mathrm{~Pb}^{2+}\right)$; hence, the closed isomer in equilibrium 1 strongly dominates for all $\mathrm{M}(\mathrm{AEtOH})^{2+}$ systems. It is thus no surprise that for the $\mathrm{Cu}(\mathrm{AEtOH})_{2}^{2+}$ complex (note, this is a 1:2 species) it could be shown ${ }^{74,75}$ that deprotonation of the $-\mathrm{OH}$ group in the alkaline $\mathrm{pH}$ range $(>8)$ is possible.

(ii) A comparison of the formation degrees of the $\mathrm{M}(\mathrm{HOAc})^{+}$ systems (Tables 7 and 11) with those for the $\mathrm{M}(\mathrm{AEtOH})^{2+}$ species (Table 17) shows that they are rather similar. For $\mathrm{Mn}^{2+}, \mathrm{Cu}^{2+}$, and $\mathrm{Pb}^{2+}$ the trend is $\%$ $\mathrm{M}(\mathrm{HOAc})_{\mathrm{cl}}^{+}<\% \mathrm{M}(\mathrm{AEtOH})^{2+}$, whereas for $\mathrm{Co}^{2+}$ and $\mathrm{Ni}^{2+}$ it seems to be reverse. For $\mathrm{Zn}^{2+}$ and $\mathrm{Cd}^{2+}$ it holds $\%$ $\mathrm{M}(\mathrm{HOAc})_{\mathrm{cl}}^{+} \approx \% \mathrm{M}(\mathrm{AEtOH})^{2+}$, with the stability enhancements being about one-half the size for the $\mathrm{Cd}^{2+}$ complexes compared to the $\mathrm{Zn}^{2+}$ ones in both instances.

(iii) Especially impressive is the large stability enhancement, $\log \Delta_{\mathrm{Pb} / \mathrm{AEtOH}}$, which amounts to more than $3 \log$ units, that is, $\mathrm{Pb}^{2+}$ is outrunning $\mathrm{Zn}^{2+}$ in its affinity toward the hydroxyl group of AEtOH, i.e., $\log \Delta_{\mathrm{Zn} / \mathrm{AEtOH}}$ amounts to ca. 1 log unit only. $\mathrm{Cd}^{2+}$, the softest of the three metal ions, reaches a $\log \Delta_{\mathrm{Cd} / \mathrm{AEtOH}}$ value of only about $0.5 \log$ unit. As already indicated by Martin, ${ }^{65,66}$ the properties of $\mathrm{Pb}^{2+}$ are difficult to predict. However, the same order for the formation degrees of chelates was found with these three metal ions in their complexes formed with uridylyl$\left(5^{\prime} \rightarrow 3^{\prime}\right)-\left[5^{\prime}\right]$ uridylate $\left(\mathrm{pUpU}^{3-}\right)$. The primary binding site for $\mathrm{M}^{2+}$ is the terminal phosphate group: An interaction with the bridging phosphate unit occurs to $93 \%$ with $\mathrm{Pb}^{2+}$ $(\log \Delta=1.16 \pm 0.26)$, to $26 \%$ with $\mathrm{Zn}^{2+}(\log \Delta=0.13 \pm$ $0.08)$, and to about $0 \%$ with $\mathrm{Cd}^{2+}(\log \Delta=-0.01 \pm 0.06){ }^{76}$

(iv) Finally, the stability enhancements and formation degrees of the $\mathrm{Ni}^{2+}$ complexes (Table 17) formed with AEtOH and $\mathrm{AiPrOH}$ allow the conclusion that a methyl substitution at the ethylene bridge does not affect the mentioned properties. This is different if the ethylene bridge is replaced by a propylene one: Comparison of the data for the $\mathrm{Ni}(\mathrm{AEtOH})^{2+}$ and $\mathrm{Ni}(\mathrm{APrOH})^{2+}$ complexes shows that the 5-membered chelates are more stable than the 6-membered ones; this is in accord with the observations made in sections 3.3 and 4.3 .

5.3. Comparison of the Metal-Ion-Binding Properties of 2-Aminoethanol and Triethanolamine

In the above context it is worthwhile to include into the considerations the ligand triethanolamine (TEA), $\mathrm{N}\left(\mathrm{CH}_{2} \mathrm{CH}_{2}-\right.$ $\mathrm{OH})_{3}$, which is closely related to 2-aminoethanol (AEtOH), $\mathrm{NH}_{2} \mathrm{CH}_{2} \mathrm{CH}_{2} \mathrm{OH}$. This will not only hint to caveats one should be aware of in comparisons, but in addition, these comparisons will provide some valuable insights.

The complexes of TEA have been studied for $\mathrm{Co}^{2+}, \mathrm{Ni}^{2+}$, $\mathrm{Cu}^{2+}, \mathrm{Zn}^{2+}$, and $\mathrm{Pb}^{2+}$ at $25^{\circ} \mathrm{C}$ and $\mathrm{I}=0.1 \mathrm{M}\left(\mathrm{NaNO}_{3}\right)^{6,}{ }^{6}$ whereas those for the $\mathrm{M}(\mathrm{AEtOH})^{2+}$ species also refer to $25^{\circ} \mathrm{C}$ but mostly to $I=0.5 \mathrm{M}$ (Table 17). However, this difference in I does not hamper the comparisons made below because, e.g., the difference between the acidity constants at $I=0.1 \mathrm{M}\left(\mathrm{p} K_{\mathrm{H}(\mathrm{TEA})}^{\mathrm{H}}=\right.$ $7.85 \pm 0.10)^{17}$ and $I=0.5 \mathrm{M}\left(\mathrm{p} K_{\mathrm{H}(\mathrm{TEA})}^{\mathrm{H}}=7.97 \pm 0.07\right){ }^{17}$ is small. Indeed, this difference leads in the case of $\mathrm{Cu}^{2+}$ to a difference in complex stability of $0.05 \log$ unit only (by applying the straightline parameters of Table 16). Hence, this and the even smaller differences for the other metal ions are all far within the error limits considered below.

We concentrate in our comparisons on the $\mathrm{M}(\mathrm{TEA})^{2+}$ complexes of $\mathrm{Cu}^{2+}, \mathrm{Zn}^{2+}$, and $\mathrm{Pb}^{2+}$, being representative examples; ${ }^{68}$ their stability constants are $\log K_{\mathrm{M}(\mathrm{TEA})}^{\mathrm{M}}=4.07 \pm 0.03\left(\mathrm{Cu}^{2+}\right)$, $2.05 \pm 0.01\left(\mathrm{Zn}^{2+}\right)$, and $3.39 \pm 0.02\left(\mathrm{~Pb}^{2+}\right)$. These values are by $0.43 \pm 0.07\left(\mathrm{Cu}^{2+}\right), 0.36 \pm 0.06\left(\mathrm{Zn}^{2+}\right)$, and $0.71 \pm 0.05\left(\mathrm{~Pb}^{2+}\right)$ log units smaller if compared with the corresponding ones given in Table $15(I=0.1 \mathrm{M})$ for the $\mathrm{M}(\mathrm{AEtOH})^{2+}$ species. Despite the 
higher potential denticity of TEA, this reduced stability might at first sight lead to the conclusion that $\mathrm{M}^{2+}$-hydroxyl group binding is reduced due to steric crowding of the three $\mathrm{CH}_{2} \mathrm{CH}_{2}$ $\mathrm{OH}$ chains. However, this conclusion would mean that the differences in basicity between TEA and AEtOH are ignored because $\mathrm{p} K_{\mathrm{H}(\mathrm{TEA})}^{\mathrm{H}}=7.97 \pm 0.07(I=0.5 \mathrm{M})^{17}$ and $\mathrm{p} K_{\mathrm{H}(\mathrm{AEtOH})}^{\mathrm{H}}=$ $9.62 \pm 0.03$ ( $I=0.5 \mathrm{M}$; Table 15$)$.

Application of this $\mathrm{p} \mathrm{K}_{\mathrm{H}(\mathrm{TEA})}^{\mathrm{H}}$ value to the straight-line parameters valid for $\mathrm{RCH}_{2} \mathrm{NH}_{2}$ species (Table 16) gives stability constants for an open $\mathrm{M}(\mathrm{TEA})^{2+}$ isomer in which no steric crowding of the three $\mathrm{CH}_{2} \mathrm{CH}_{2} \mathrm{OH}$ residues is considered, i.e., only one residue "exists". We define this species as $\mathrm{M}(\mathrm{TEA})_{\mathrm{op}(1)}^{2+}$ and obtain

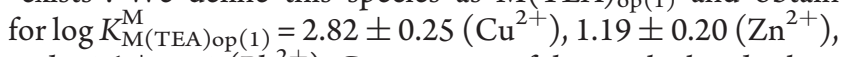
and $0.26 \pm 0.30\left(\mathrm{~Pb}^{2+}\right)$. Comparison of these calculated values with the measured ones (at $I=0.1 \mathrm{M})^{68}$ according to eqs $11 \mathrm{a}$ and $11 \mathrm{~b}$ gives the stability enhancements $\log \Delta_{\mathrm{M} / \mathrm{TEA}(1)}=1.25$ $\pm 0.25\left(\mathrm{Cu}^{2+}\right), 0.86 \pm 0.20\left(\mathrm{Zn}^{2+}\right)$, and $3.13 \pm 0.30\left(\mathrm{~Pb}^{2+}\right)$. These stability enhancements are within their error limits identical with those observed for the $\mathrm{M}(\mathrm{AEtOH})^{2+}$ species, that is, $\log \Delta_{\mathrm{M} / \mathrm{AEtOH}}=1.03 \pm 0.26\left(\mathrm{Cu}^{2+}\right), 0.99 \pm 0.21$ $\left(\mathrm{Zn}^{2+}\right)$, and $3.40 \pm 0.32\left(\mathrm{~Pb}^{2+}\right)$ (see Table 17), indicating that the $\mathrm{M}^{2+}-\mathrm{OH}$ interaction in the $\mathrm{M}(\mathrm{TEA})_{\mathrm{cl}(1)}^{2+}$ isomers is at least as intense as in the $\mathrm{M}(\mathrm{AEtOH})_{\mathrm{cl}}^{2+}$ species.

Though the evaluation procedure in the preceding paragraph certainly describes the situation better than if the basicity differences between TEA and AEtOH are ignored, it is not really satisfying because the calculations are based on $\mathrm{RCH}_{2}-\mathrm{NH}_{2}$ reference lines (Table 16) and thus provide only the lower limits for the $\mathrm{M}^{2+}-\mathrm{OH}$ interactions. Correct reference lines should be based on a series of $\left(\mathrm{RCH}_{2}\right)_{3} \mathrm{~N}$ derivatives and their complexes, yet this information does not exist. However, in section 5.1 we have seen that the steric inhibition introduced by replacing one $\mathrm{H}$ atom in $\mathrm{NH}_{3}$ by a $\mathrm{RCH}_{2}$ substituent amounts on average to log $S I_{\mathrm{M}}=0.75 \pm 0.15$ for any of the divalent metal ions considered here (see also Figure 10). If one assumes that each $\mathrm{RCH}_{2}$ substituent in TEA has the same steric effect on metal-ion coordination, overall the value should be tripled. To be on the safe side, we shall assume only that the two extra $\mathrm{RCH}_{2}$ substituents together encompass the same steric inhibition as the first one; this then means that the $\log K_{M}^{\mathrm{M}}$ (TEA)op(1) values need to be reduced further by $\log S I_{M}=0.75 \pm 0.15$. Then we obtain for the open $\mathrm{M}(\mathrm{TEA})_{\mathrm{op}(2)}^{2+}$ isomers the stability constants $\log K_{\mathrm{M} \text { (TEA)op(2) }}^{\mathrm{M}}=2.07 \pm 0.29\left(\mathrm{Cu}^{2+}\right), 0.44 \pm 0.25$ $\left(\mathrm{Zn}^{2+}\right)$, and $-0.49 \pm 0.34\left(\mathrm{~Pb}^{2+}\right)$.

With the indicated assumption one obtains for the overall stability increase the values $\log \Delta_{\mathrm{M} / \mathrm{TEA}(2)}=2.00 \pm 0.29\left(\mathrm{Cu}^{2+}\right)$, $1.61 \pm 0.25\left(\mathrm{Zn}^{2+}\right)$, and $3.88 \pm 0.34\left(\mathrm{~Pb}^{2+}\right)$ due to the three $\mathrm{CH}_{2} \mathrm{CH}_{2} \mathrm{OH}$ residues possibly participating in metal-ion coordination in the $\mathrm{M}(\mathrm{TEA})^{2+}$ species. These stability enhancements are by $0.97 \pm 0.39\left(\mathrm{Cu}^{2+}\right), 0.62 \pm 0.33\left(\mathrm{Zn}^{2+}\right)$, and 0.48 $\pm 0.47\left(\mathrm{~Pb}^{2+}\right)$ log units larger than those observed for the $\mathrm{M}(\mathrm{AEtOH})^{2+}$ complexes (Table 17, column 4). These results appear reasonable because despite all steric crowding the likelihood is high that out of three $\mathrm{CH}_{2} \mathrm{CH}_{2} \mathrm{OH}$ residues more than one will participate in metal-ion binding. In other words, despite the lower overall stability of the $\mathrm{M}(\mathrm{TEA})^{2+}$ complexes compared with that of the $\mathrm{M}(\mathrm{AEtOH})^{2+}$ species (which is due to the lower basicity of TEA $\left.\left(\Delta \mathrm{p} K_{\mathrm{a}}=1.66 \pm 0.08\right)\right)$, it is evident that more than one of the $\mathrm{CH}_{2} \mathrm{CH}_{2} \mathrm{OH}$ residues participate in metalion binding. A separation of the individual contribution of each $\mathrm{CH}_{2} \mathrm{CH}_{2} \mathrm{OH}$ residue to the observed stability enhancement is with the rough and limited data available in this case not advisible.
However, in principle, it could be done as shown in section 8 for other ligands offering more than one hydroxyl group for metalion coordination.

Clearly, from the above evaluations it follows that the three hydroxy groups of TEA will participate in metal-ion binding in varying extents. Furthermore, despite all uncertainties the evaluations prove that the stability enhancement for the $\mathrm{Pb}(\mathrm{TEA})^{2+}$ complex is especially pronounced, confirming the high affinity of $\mathrm{Pb}^{2+}$ toward hydroxyl groups as it was already evident from the $\mathrm{Pb}(\mathrm{AEtOH})^{2+}$ species (Table 17), where the chelated or closed form (eq 1) reaches about $100 \%$. This tremendous stability increase of the $\mathrm{Pb}^{2+}$ complexes originates also in the low affinity of $\mathrm{Pb}^{2+}$ for $\mathrm{N}$ sites, e.g., for $\mathrm{NH}_{3}$, which is much more pronounced for $\mathrm{Cu}^{2+}$ and $\mathrm{Zn}^{2+}$ (see Table 15).

The ligand TEA also allows interesting comparisons for the alkaline earth ions. ${ }^{77}$ The corresponding stability constants ${ }^{77}$ at $25^{\circ} \mathrm{C}$ and $I=1.0 \mathrm{M}$ are $\log K_{\mathrm{M}(\mathrm{TEA})}^{\mathrm{M}}=0.24 \pm 0.02\left(\mathrm{Mg}^{2+}\right)$, $0.78 \pm 0.01\left(\mathrm{Ca}^{2+}\right), 0.38 \pm 0.01\left(\mathrm{Sr}^{2+}\right)$, and $0.36 \pm 0.01\left(\mathrm{Ba}^{2+}\right)$. The stability of the $\mathrm{Ca}(\mathrm{TEA})^{2+}$ complex sticks out, and this leads immediately to the following question: Are the hydroxyl groups of TEA involved in $\mathrm{M}^{2+}$ binding? Here a comparison with the stability constants of the complexes formed with ammonia is helpful: $\log K_{\mathrm{M}\left(\mathrm{NH}_{3}\right)}^{\mathrm{M}}=0.24\left(\mathrm{Mg}^{2+}\right), 0.0\left(\mathrm{Ca}^{2+}\right),-0.2\left(\mathrm{Sr}^{2+}\right)$, and $-0.3\left(\mathrm{Ba}^{2+}\right) .{ }^{17}$ All these $\log \mathrm{K}$ values refer to $25^{\circ} \mathrm{C}$ and $I=1.0 \mathrm{M}$ except the one for $\mathrm{Mg}\left(\mathrm{NH}_{3}\right)^{2+}$, which holds for $I=$ $2 \mathrm{M}$. For the $\mathrm{M}\left(\mathrm{NH}_{3}\right)^{2+}$ species the stability of the complexes decreases with increasing ionic radii as one might have expected. However, these stability constants for the $\mathrm{M}\left(\mathrm{NH}_{3}\right)^{2+}$ species may directly be compared with those for the $\mathrm{M}(\mathrm{TEA})^{2+}$ complexes despite the different basicities of the two ligands, $\mathrm{p} \mathrm{K}_{\mathrm{H}\left(\mathrm{NH}_{3}\right)}^{\mathrm{H}}=9.43 \pm$ 0.05 (Table 15) and $\mathrm{p} K_{\mathrm{H}(\mathrm{TEA})}^{\mathrm{H}}=8.05 \pm 0.01$ (cf. ref 77) $\left(25^{\circ} \mathrm{C}\right.$; $I=1.0 \mathrm{M}) .^{17,77}$ The reason for this is that in the case of the alkaline earth ions the slopes $m$ of $\log K$ versus $\mathrm{p} K_{\mathrm{a}}$ plots for ligands with $\mathrm{N}$ donor sites are zero or at least very close to it, ${ }^{70-72}$ in accord with the fact that the given stability constants for the $\mathrm{M}\left(\mathrm{NH}_{3}\right)^{2+}$ complexes are equal to those determined for the complexes formed by the alkaline earth ions with benzimidazoles ${ }^{72}$ and ortho-methylpyridines. $^{70}$

Consequently, comparison of the above data is valid and allows the following conclusions:

(i) The stability differences $\log \Delta_{\mathrm{M} / \mathrm{TEA}}$ follow the order $\mathrm{Mg}^{2+}<\mathrm{Ca}^{2+}>\mathrm{Sr}^{2+} \approx \mathrm{Ba}^{2+}$.

(ii) It appears that in the $\mathrm{Mg}(\mathrm{TEA})^{2+}$ complex the $\mathrm{CH}_{2} \mathrm{CH}_{2} \mathrm{OH}$ residues do not participate in a significant manner in metal-ion binding.

(iii) In contrast, in the $\mathrm{Ca}^{2+}, \mathrm{Sr}^{2+}$, and $\mathrm{Ba}^{2+}$ complexes of TEA the $\mathrm{CH}_{2} \mathrm{CH}_{2} \mathrm{OH}$ residues are clearly involved in $\mathrm{M}^{2+}$ binding. In fact, all three hydroxyl groups of TEA coordinate to $\mathrm{Sr}^{2+}$ and $\mathrm{Ba}^{2+}$ in the solid state (see section 11.1).

(iv) The stability enhancement, $\log \Delta_{\mathrm{Ca} / \mathrm{TEA}} \cong 0.78$, for the $\mathrm{Ca}(\mathrm{TEA})^{2+}$ complex indicates chelate formation (eqs $11 \mathrm{a}-13$ ) on the order of $83 \%$ (not distinguishing between the three possibilities of $\mathrm{CH}_{2} \mathrm{CH}_{2} \mathrm{OH}$ binding).

It is interesting to note that the mentioned $83 \%$ for $\mathrm{Ca}(\mathrm{TEA})_{\mathrm{cl}}^{2+}$ is within the error limits identical with the percentages determined for $\mathrm{Ca}(\mathrm{HOAc})_{\mathrm{cl}}^{+}$and $\mathrm{Ca}(2 \mathrm{HOPr})_{\mathrm{cl}}^{+}($Table 7$)$. However, more important for the present context is the result described in section 4.1, namely, that $\mathrm{Ca}^{2+}$ is especially suitable for hydroxyl group binding within the alkaline earth ions. Indeed, this is confirmed by the results for the $\mathrm{M}(\mathrm{TEA})^{2+}$ complexes (see point (i) above). 


\section{IMIDAZOLE RESIDUE AS A PRIMARY BINDING SITE IN LIGANDS CONTAINING ALSO A HYDROXYL GROUP}

Unfortunately, literature data regarding imidazole derivatives $(\mathrm{ImD})$ are very limited. ${ }^{17,18}$ In fact, information is available only for two ligands, namely, 2-hydroxymethylimidazole ( $\operatorname{Im} 2 \mathrm{OH})$ and 4-hydroxymethylimidazole ( $\operatorname{Im} 4 \mathrm{OH})$, and their $\mathrm{Cu}^{2+}$ complexes. The $\mathrm{Cu}^{2+}$ complex of 2 -methylimidazole ( $\operatorname{Im} 2 \mathrm{Me}$ ) is needed for evaluation of steric effects, values of pyridine $(\mathrm{Py})$ are used for correcting ionic strength $(I)$ effects, and histidine is considered because of its tautomers (see below). The structures of all five ligands are shown in Figure 12.

The available equilibrium constants for the mentioned systems are listed in Table 18; they are valid for aqueous solutions at $25^{\circ} \mathrm{C}$ but at various ionic strengths. ${ }^{17,57,78}$ Therefore, some of the values were corrected for ionic strength effects to give a series of data valid for $I=0.5 \mathrm{M}$ (see the footnotes in Table 18). The reason for selecting $I=0.5 \mathrm{M}$ is that from previous studies ${ }^{71} \log$ $K_{\mathrm{M}(\operatorname{ImD})}^{\mathrm{M}}$ versus $\mathrm{p} K_{\mathrm{H}(\mathrm{ImD})}^{\mathrm{H}}$ straight-line plots are available. The one for $\mathrm{Cu}^{2+}$ is defined in eq 15

$\log K_{\mathrm{Cu}(\mathrm{ImD})}^{\mathrm{Cu}}=(0.376 \pm 0.004) \cdot \mathrm{p} K_{\mathrm{H}(\mathrm{ImD})}^{\mathrm{H}}+(1.522 \pm 0.025)$

These straight-line parameters are valid for the $\mathrm{p} K_{\mathrm{a}}$ range from about 4 to $8\left(25^{\circ} \mathrm{C}, I=0.5 \mathrm{M}\right)$ with an SD value of $0.018 \log$ unit $(3 \sigma)$.<smiles>[NH3+]C(Cc1c[nH]cn1)C(=O)[O-]</smiles><smiles>Cc1ncc[nH]1</smiles><smiles>OCc1c[nH]cn1</smiles>

Im4OH<smiles>OCc1ncc[nH]1</smiles>

Im2OH
However, before eq 15 can be applied, it is necessary to consider the structure of the imidazole derivatives a bit more in detail. The monoprotonated form of 2-methylimidazole, $\mathrm{H}(\operatorname{Im} 2 \mathrm{Me})^{+}$, is a symmetrical acid (see Figure 12). The consequence is that $\mathrm{H}(\operatorname{Im} 2 \mathrm{Me})^{+}$has two equal possibilities for the deprotonation reaction to form neutral $\operatorname{Im} 2 \mathrm{Me}$; in other words, $\mathrm{H}(\operatorname{Im} 2 \mathrm{Me})^{+}$is too acidic by a factor of 2 , and the intrinsic basicity is therefore quantified by the micro acidity constant defined in eqs $16 a, 16 \mathrm{~b}$, and $16 \mathrm{c}$

$$
\begin{gathered}
\mathrm{p} k_{\mathrm{a} / \mathrm{H}(\operatorname{Im} 2 \mathrm{Me})}=\mathrm{p} K_{\mathrm{H}(\operatorname{Im} 2 \mathrm{Me})}^{\mathrm{H}}+0.30 \\
=(8.04 \pm 0.01)+0.30 \\
=8.34 \pm 0.01
\end{gathered}
$$

Exactly the same reasonings hold for 2-hydroxymethylimidazole, i.e., $\mathrm{H}(\mathrm{Im} 2 \mathrm{OH})^{+}$; consequently, in this case eqs $17 \mathrm{a}$ and $17 \mathrm{~b}$ apply

$$
\begin{gathered}
p k_{\mathrm{a} / \mathrm{H}(\operatorname{Im} 2 \mathrm{OH})}=\mathrm{p} K_{\mathrm{H}(\operatorname{Im} 2 \mathrm{OH})}^{\mathrm{H}}+0.30 \\
=6.78+0.30=7.08 \pm 0.06 \\
\text { (error limit estimated) }
\end{gathered}
$$

How is the situation with the asymmetrical compound 4-hydroxymethylimidazole? For histidine it has been concluded that in the neutral imidazole group the proton is located $80 \%$ at $\mathrm{N} 1$ and $20 \%$ at N3 (see Figure 12). ${ }^{69}$ Since in $\mathrm{Im} 4 \mathrm{OH}$ the substituent, i.e., the $\mathrm{CH}_{2} \mathrm{OH}$ group, is also in position 4 just as the glycine residue in histidine, the proton distribution is probably similar in both instances. An exact percentage of the isomeric distribution cannot be given, but the correction factor for $\mathrm{p} K_{\mathrm{H}(\mathrm{Im} 4 \mathrm{OH})}^{\mathrm{H}}$ is evidently significantly below $0.3 \mathrm{pK}$ unit. Therefore, we prefer to use in the evaluations given below the experimentally derived acidity constant $\mathrm{p} K_{\mathrm{H}(\mathrm{Im} 4 \mathrm{OH})}^{\mathrm{H}}=6.54$ (Table 18).

Application of the straight-line parameters from eq 15 together with the microacidity constants for $\mathrm{H}(\operatorname{Im} 2 \mathrm{Me})^{+}$and $\mathrm{H}(\mathrm{Im} 2 \mathrm{OH})^{+}$(eqs 16a, 16b, 16c, 17a, and 17b) and the acidity constant for $\mathrm{H}(\mathrm{Im} 4 \mathrm{OH})^{+}$(Table 18) leads to the situation seen in Figure 13. The straight line given in the figure is defined by data valid for imidazole and such derivatives that cannot exercise any steric effect on metal-ion binding at the $\mathrm{N}$ site. It is thus immediately evident that the methyl group at $\mathrm{C} 2$ in $\mathrm{Im} 2 \mathrm{Me}$ hinders $\mathrm{Cu}^{2+}$ binding at $\mathrm{N} 1$ (or N3) very significantly. A large part of this steric hindrance is overcome in the $\mathrm{H}^{+} / \mathrm{Cu}^{2+} /$ Im $2 \mathrm{OH}$ system because the hydroxyl group of the 2-methylhydroxy residue participates in metal-ion binding; in other words, we observe a relative stability enhancement. The same is evidently true for the $\mathrm{Im} 4 \mathrm{OH}$ ligand system.

Figure 12. Structures of 2-hydroxymethylimidazole ( $\mathrm{Im} 2 \mathrm{OH})$ and 4-hydroxymethylimidazole ( $\mathrm{Im} 4 \mathrm{OH})$; both ligands are able to form 5 -membered chelates with metal ions. The other ligands shown, pyridine

\begin{tabular}{|c|c|c|c|c|c|c|c|c|}
\hline \multirow[b]{2}{*}{$I(\mathrm{M})$} & \multicolumn{2}{|c|}{ Py } & \multicolumn{2}{|c|}{$\mathrm{Im} 4 \mathrm{OH}$} & \multicolumn{2}{|c|}{$\mathrm{Im} 2 \mathrm{OH}$} & \multicolumn{2}{|c|}{$\operatorname{Im} 2 \mathrm{Me}$} \\
\hline & $\mathrm{p} K_{\mathrm{a}}$ & $\log K^{\mathrm{Cu}}$ & $\mathrm{p} K_{\mathrm{a}}$ & $\log K^{\mathrm{Cu}}$ & $\mathrm{p} K_{\mathrm{a}}$ & $\log K^{\mathrm{Cu}}$ & $\mathrm{p} K_{\mathrm{a}}$ & $\log K^{\mathrm{Cu}}$ \\
\hline 0.1 & $5.26 \pm 0.02$ & $2.49 \pm 0.06$ & 6.46 & 3.96 & & & $7.90 \pm 0.02$ & \\
\hline 0.5 & $5.34 \pm 0.05$ & $2.60 \pm 0.04$ & $6.54^{b}$ & $4.07^{b}$ & $6.78^{c}$ & $4.09^{c}$ & $8.04 \pm 0.01$ & $3.35 \pm 0.06$ \\
\hline 3 & & & 7.42 & 4.25 & 7.66 & 4.27 & & \\
\hline
\end{tabular}
(Py), 2-methylimidazole (Im2Me), and histidine (His), are needed in the evaluation procedures (section 6) of the hydroxymethylimidazoles.

Table 18. Negative Logarithms of the Acidity Constants (eqs 14a and 14b) of Several Imidazole Derivatives (ImD) and Related Ligands (Figure 12) As Well As Logarithms of the Stability Constants (eqs $4 a$ and $4 b$ ) of the Corresponding C ${ }^{2+}$ Complexes in Aqueous Solution at $25^{\circ} \mathrm{C}$ and Various Ionic Strength $(I)^{a}$

${ }^{a}$ The values for pyridine (Py) are from refs $70(I=0.5 \mathrm{M})$ and $78(I=0.1 \mathrm{M})$, all others are from ref 17 except the derived values. ${ }^{b, c} b$ The differences observed for the pyridine systems at $I=0.1$ and $0.5 \mathrm{M}$ were added to the $\operatorname{Im} 4 \mathrm{OH}$ values at $I=0.1 \mathrm{M}$ to obtain those for $I=0.5 \mathrm{M}$. ${ }^{c}$ On the basis of the differences that follow from the listed values for the $\operatorname{Im} 4 \mathrm{OH}$ systems at $I=0.5$ and $3 \mathrm{M}$. 


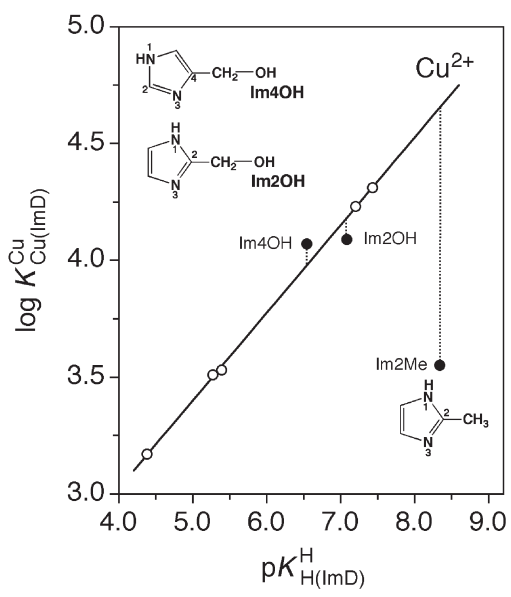

Figure 13. Complex stabilities of the $\mathrm{Cu}^{2+} 1: 1$ complexes formed with $\operatorname{Im} 4 \mathrm{OH}, \operatorname{Im} 2 \mathrm{OH}$, and $\operatorname{Im} 2 \mathrm{Me}(\bullet$, see Figure 12$)$ in relation to the straight-reference line (eq 15, Table 19) which is based on the simple imidazole derivatives $(\bigcirc$; from left to right) $N$-(2,3,5,6-tetrafluorophenyl)imidazole, 5-chloro-1-methylimidazole, 4-(imidazol-1-yl)acetophenone, 1-methylimidazole, and imidazole (for details see ref 71). The steric inhibition of $\mathrm{Cu}^{2+}$ coordination by the methyl group in $\operatorname{Im} 2 \mathrm{Me}$ is clearly seen, and consequently, the stability enhancing effect of the hydroxyl group in the two hydroxymethylimidazoles $(\mathrm{Im} 4 \mathrm{OH}$, $\operatorname{Im} 2 \mathrm{OH}$ ) is evidenced. The corresponding equilibrium constants are listed in Table 18. All plotted equilibrium constants refer to aqueous solutions at $25^{\circ} \mathrm{C}$ and $I=0.5 \mathrm{M}$.

Table 19. Comparison of the Measured (exp) Stability Constants, $K_{\mathrm{Cu}(\mathrm{ImD}) \exp }^{\mathrm{Cu}}($ eqs $4 \mathrm{a}$ and $4 \mathrm{~b})$, of the $\mathrm{Cu}^{2+} 1: 1 \mathrm{Com}-$ plexes Formed by $\operatorname{Im} 2 \mathrm{Me}, \operatorname{Im} 2 \mathrm{OH}$, and $\operatorname{Im} 4 \mathrm{OH}$ with the Calculated (calc) Stability Constants Based on eq 15 and the Appropriate Acidity Constants ${ }^{a}$

\begin{tabular}{cccr}
$\mathrm{Cu}(\operatorname{ImD})^{2+}$ & $\log K_{\mathrm{Cu}(\operatorname{ImD}) \exp }^{\mathrm{Cu}}$ & $\log K_{\mathrm{Cu}(\operatorname{ImD}) \text { calc }}^{\mathrm{Cu}}$ & \multicolumn{1}{c}{$\log \Delta_{\mathrm{Cu} / \mathrm{ImD}}$} \\
$\mathrm{Cu}(\operatorname{Im} 2 \mathrm{Me})^{2+}$ & $3.35 \pm 0.06^{b}$ & $4.66 \pm 0.04^{c}$ & $-1.31 \pm 0.08$ \\
$\mathrm{Cu}(\operatorname{Im} 2 \mathrm{OH})^{2+}$ & $4.09 \pm 0.10^{d}$ & $4.18 \pm 0.02$ & $-0.09 \pm 0.10$ \\
$\mathrm{Cu}(\operatorname{Im} 4 \mathrm{OH})^{2+}$ & $4.07 \pm 0.10^{d}$ & $3.98 \pm 0.02$ & $0.09 \pm 0.10$
\end{tabular}

a The stability differences are defined by $\log \Delta_{\mathrm{Cu} / \mathrm{ImD}}$ according to eqs $11 \mathrm{a}$ and $11 \mathrm{~b}$. The applied (micro) acidity constants are $\mathrm{p} k_{\mathrm{a} / \mathrm{H}(\operatorname{Im} 2 \mathrm{Me})}=8.34$ (eqs 16a, 16b, and $\left.16 \mathrm{c}\right), \mathrm{p} k_{\mathrm{a} / \mathrm{H}(\operatorname{Im} 2 \mathrm{OH})}=7.08$ (eqs $17 \mathrm{a}$ and $17 \mathrm{~b})$, and $\mathrm{p} K_{\mathrm{H}(\mathrm{Im} 4 \mathrm{OH})}^{\mathrm{H}}=6.54$ (Table 18). ${ }^{b}$ Value from the literature $^{17}$ (see also Table 18); an error of $\pm 0.06 \log$ unit is assumed. ${ }^{c}$ Since $\mathrm{p} k_{\mathrm{a} / \mathrm{H}(\mathrm{Im} 2 \mathrm{Me})}$ is slightly larger than $\mathrm{p} K_{\mathrm{a}}=8$, the error limit was doubled (see text in section 6, just below eq 15). ${ }^{d}$ Value corrected for a change in $I$ (see Table 18); therefore, the error limit is taken as $\pm 0.10 \log$ unit.

The steric effects and stability enhancements indicated in Figure 13 are quantified in Table 19. These data allow us now to define exactly the stability enhancement due to the hydroxyl group in the $\mathrm{Cu}(\mathrm{Im} 2 \mathrm{OH})^{2+}$ complex. This is expressed in eqs $18 \mathrm{a}, 18 \mathrm{~b}$, and $18 \mathrm{c}$

$$
\begin{gathered}
\log \Delta_{\mathrm{Cu} / \mathrm{Im} 2 \mathrm{OH} / \mathrm{cor}}=\log \Delta_{\mathrm{Cu} / \mathrm{Im} 2 \mathrm{OH}}-\log \Delta_{\mathrm{Cu} / \mathrm{Im} 2 \mathrm{Me}} \\
=(-0.09 \pm 0.10)-(-1.31 \pm 0.07) \\
=1.22 \pm 0.12
\end{gathered}
$$

The steric inhibition in the $\mathrm{Cu}(\mathrm{Im} 4 \mathrm{OH})^{2+}$ species is much less clear because the $-\mathrm{CH}_{2} \mathrm{OH}$ side chain has only one $\mathrm{N}$, i.e.,
Table 20. Extent of Chelate Formation According to the Intramolecular Equilibrium 1 in the $\mathrm{Cu}-(\operatorname{Im} 2 \mathrm{OH})^{2+}$ and $\mathrm{Cu}(\mathrm{Im} 4 \mathrm{OH})^{2+}$ Complexes As Quantified by the Dimensionless Equilibrium Constant $K_{\mathrm{I}}$ (eqs 9 and 12) and the Percentage of

\begin{tabular}{|c|c|c|c|c|}
\hline $\mathrm{Cu}(\operatorname{ImD})^{2+}$ & $\begin{array}{c}\log \\
\Delta_{\mathrm{Cu} / \mathrm{ImD}}{ }^{a}\end{array}$ & $\begin{array}{c}\log \\
\Delta_{\mathrm{Cu} / \mathrm{ImD} / \text { cor }}\end{array}$ & $K_{\mathrm{I}}$ & $\begin{array}{c}\% \\
\mathrm{Cu}(\operatorname{ImD})_{\mathrm{cl}}^{2+}\end{array}$ \\
\hline $\mathrm{Cu}(\operatorname{Im} 2 \mathrm{Me})^{2+}$ & $-1.31 \pm 0.07$ & & & \\
\hline $\mathrm{Cu}(\operatorname{Im} 2 \mathrm{OH})^{2+}$ & $-0.09 \pm 0.10$ & $1.22 \pm 0.12^{b}$ & $15.60 \pm 4.59$ & $94 \pm 2$ \\
\hline $\mathrm{Cu}(\operatorname{Im} 4 \mathrm{OH})^{2+}$ & $0.09 \pm 0.10$ & $1.40 \pm 0.12$ & $24.12 \pm 6.94$ & $96 \pm 1$ \\
\hline & & $0.75 \pm 0.12^{c}$ & $4.62 \pm 1.55$ & $82 \pm 5$ \\
\hline
\end{tabular}
the Closed Isomers, $\mathrm{Cu}(\mathrm{ImD})_{\mathrm{cl}}^{2+}($ eq 13), in Aqueous Solution at $25^{\circ} \mathrm{C}$ and $\mathrm{I}=0.5 \mathrm{M}$

${ }^{a}$ Values from column 4 of Table $19 .{ }^{b}$ See eqs 18a, 18b, and $18 \mathrm{c} .{ }^{c}$ Assuming only one-half of the steric effect (see text in section 6) gives $\log \Delta_{\text {cor }}=$ $\log \Delta_{\mathrm{Cu} / \mathrm{Im} 4 \mathrm{OH}}-0.5(-1.31 \pm 0.07)=(0.09 \pm 0.10)+(0.66 \pm 0.07)=$ $0.75 \pm 0.12$.

$\mathrm{N} 3$, at which $\mathrm{Cu}^{2+}$ may coordinate and give rise to chelate formation. Considering that probably the tautomer of $\operatorname{Im} 4 \mathrm{OH}$ seen in Figure 12 dominates with 80\%, the analogous correction for the steric inhibition as expressed in eqs $18 \mathrm{a}, 18 \mathrm{~b}$, and $18 \mathrm{c}$ would possibly be appropriate. On the other hand, one can imagine that the steric inhibition observed for $\mathrm{Cu}(\operatorname{Im} 2 \mathrm{Me})^{2+}$ is only about $50 \%$ relevant for $\mathrm{Cu}(\mathrm{Im} 4 \mathrm{OH})^{2+}$ because $\mathrm{Cu}^{2+}$ might also bind to $\mathrm{N} 1$ (the $\mathrm{H}$ being then at N3) without any chelate formation. Since no unequivocal decision between these two possibilities is possible, we evaluated both of them, which means one gives the maximal participation of the hydroxyl group in $\mathrm{Cu}^{2+}$ binding (which we consider as the more likely situation) and the other the minimal one. Thus, application of eqs 12 and 13 leads to the results summarized in Table 20 .

From the results given in Table 20 for $\mathrm{Cu}(\mathrm{Im} 2 \mathrm{OH})_{\mathrm{cl}}^{+}$it is clear that 5-membered chelates form and that the hydroxyl group may participate in metal-ion binding having an imidazole group as the primary binding site. Though the situation with $\mathrm{Cu}-(\mathrm{Im} 4 \mathrm{OH})^{2+}$ is equivocal, the data still prove that chelates form. Furthermore, these results in combination with those of Table 17 indicate, at least for $\mathrm{Cu}^{2+}$, that the imidazole group is a slightly better primary binding site than an amino unit in combination with the hydroxyl group. Considering that not only $\mathrm{Cu}^{2+}$ but also other divalent metal ions like $\mathrm{Mn}^{2+}$ or $\mathrm{Zn}^{2+}$ as well as the alkaline earth metal ions are able to coordinate with the imidazole group, ${ }^{71}$ one may assume that also in these instances an interaction with a hydroxyl group can take place if this is properly situated.

\section{PYRIDYL NITROGEN IS AN IDEAL PRIMARY METAL- ION-BINDING SITE FOR A HYDROXYL-METAL-ION INTERACTION}

The most simple compound in the present context is $o$-(hydroxymethyl)pyridine (HOMPy), and there are two fortunate circumstances which facilitate an evaluation of the role that the hydroxyl group plays in this compound in metal-ion coordination: (i) the necessary straight-line parameters for $\log K_{\mathrm{M}(\mathrm{PyD})}^{\mathrm{M}}$ versus $\mathrm{p} K_{\mathrm{H}(\mathrm{PyD})}^{\mathrm{H}}$ plots of $o$-methylpyridine derivatives (PyD) are available; the corresponding parameters (as far as needed now) are listed in Table $21 ;^{70}$ hence, the position of equilibrium 1 can be calculated in a straightforward manner, based on the measured equilibrium constants of M(HOMPy) ${ }^{2+}$ complexes. $^{17}$ (ii) Several closely related ligands together with stability constants of the corresponding metal-ion complexes are available, ${ }^{17}$ allowing 
Table 21. Straight-Line Parameters for the Stabilities of $\mathbf{M}^{2+}$ 1:1 Complexes of ortho-Substituted Pyridine-Type Ligands (PyD) and Basicities of the Corresponding Pyridine Derivatives (aqueous solution; $25^{\circ} \mathrm{C}, I=0.5 \mathrm{M}$ )

$\begin{array}{cccc}\mathrm{M}^{2+} & m & b & \mathrm{SD} \\ \mathrm{Mn}^{2+} & 0.052 \pm 0.026 & -0.230 \pm 0.145 & 0.07 \\ \mathrm{Co}^{2+} & 0.066 \pm 0.030 & -0.254 \pm 0.167 & 0.08 \\ \mathrm{Ni}^{2+} & 0.115 \pm 0.037 & -0.403 \pm 0.205 & 0.10 \\ \mathrm{Cu}^{2+} & 0.397 \pm 0.027 & -0.889 \pm 0.146 & 0.07 \\ \mathrm{Zn}^{2+} & 0.103 \pm 0.025 & -0.398 \pm 0.128 & 0.08 \\ \mathrm{Cd}^{2+} & 0.131 \pm 0.031 & -0.028 \pm 0.172 & 0.09\end{array}$

${ }^{a}$ The above listed information is collected from Tables 3 and 4 of ref 70 . The ligands employed in the determination of the reference lines are 2-methyl-5-bromopyridine, 2-amino-5-bromopyridine, tubercidin (= 7deazaadenosine), $\alpha$-picoline (= 2-methylpyridine), and 2-aminopyridine. $^{70}{ }^{b}$ The slopes $m$ and intercepts $b$ (see eq 10) for the straightreference lines for plots of $\log K_{\mathrm{M}(\mathrm{PyD})}^{\mathrm{M}}$ versus $\mathrm{p} K_{\mathrm{H}(\mathrm{PyD})}^{\mathrm{H}}$ were calculated ${ }^{70}$ by the least-squares procedure from the experimentally determined equilibrium constants. ${ }^{70}$ The errors given with $m$ and $b$ correspond to one standard deviation $(1 \sigma)$. The column at the right lists three times the standard deviation (SD) resulting from the differences between the experimental and the calculated values for the various ligand systems. ${ }^{a}$ The listed SD values $(3 \sigma)$ are considered as reasonable error limits for any stability constant calculation in the $\mathrm{p} K_{\mathrm{a}}$ range of 3.5-7.0.<smiles>OCc1ccccn1</smiles><smiles>CC(O)c1ccccn1</smiles><smiles>OCC(O)c1ccccn1</smiles><smiles>COCc1ccccn1</smiles><smiles>Cc1cccc(C)n1</smiles><smiles>OCc1cccc(CO)n1</smiles>

Figure 14. Chemical structures of $o$-(hydroxymethyl)pyridine (HOMPy), which is able to form a 5-membered chelate, and of several other related pyridine derivatives (OPy), that is, $o$-[1-(1-hydroxyethyl)] pyridine (HOEPy), o-[1-(1,2-dihydroxyethyl)]pyridine (DHOEPy), $o$-(methoxymethyl)pyridine (MOMPy), and 2,6-(dihydroxymethyl)pyridine $((\mathrm{HOM}) 2 \mathrm{Py})$ as well as 2,6-dimethylpyridine (DMPy) which is needed for comparisons.

interesting comparisons as we shall see below. The structures of all the ligands to be considered are shown in Figure 14.

Figure 15 provides the straight-line plots for the complexes of $\mathrm{Mn}^{2+}, \mathrm{Cu}^{2+}$, and $\mathrm{Zn}^{2+}$ as examples. ${ }^{70}$ The corresponding data points for the $\mathrm{H}^{+} / \mathrm{M}^{2+} / \mathrm{HOMPy}$ systems ${ }^{17}$ are also inserted into

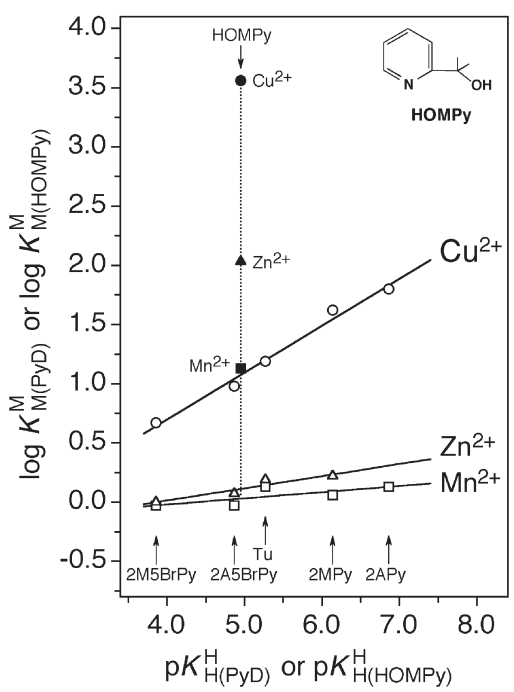

Figure 15. Evidence for an enhanced complex stability of the $\mathrm{Mn}^{2+}(\boldsymbol{\square})$, $\mathrm{Cu}^{2+}(\mathbf{O})$, and $\mathrm{Zn}^{2+}(\mathbf{\Delta})$ 1:1 complexes of HOMPy based on the relationship between $\log K_{\mathrm{M}(\mathrm{PyD})}^{\mathrm{M}}$ and $\mathrm{p} K_{\mathrm{H}(\mathrm{PyD})}^{\mathrm{H}}$ for the simple $o$-methylpyridine-type ligands (PyD) ( $\mathrm{O}$, from left to right) 2-methyl5-bromopyridine (2M5BrPy), 2-amino-5-bromopyridine (2A5BrPy), tubercidin (= 7-deazaadenosine) $(\mathrm{Tu}), 2$-methylpyridine $(2 \mathrm{MPy})$, and 2 -aminopyridine (2APy) (for details see ref 70). The parameters of the corresponding least-squares references lines (eq 10) are summarized in Table 21. The data for the points due to the equilibrium constants of the $\mathrm{M}^{2+} / \mathrm{HOMPy}$ systems are given in Table 22 . The vertical dotted lines emphasize the stability differences to the reference lines; they equal log $\Delta_{\mathrm{M} / \mathrm{HOMPy}}$, as defined in eqs 11a and $11 \mathrm{~b}$ (see also Table 22, column 5). All plotted equilibrium constants refer to aqueous solutions at $25^{\circ} \mathrm{C}$ and $I=0.5 \mathrm{M}$.

the figure. It is evident that these data points are by about 1 $\left(\mathrm{Mn}^{2+}\right)$ to $2.5 \log$ units $\left(\mathrm{Cu}^{2+}\right)$ above their reference lines; hence, the stability enhancement $\log \Delta_{\mathrm{M} / \text { HOMPy }}$ (eqs 11a and $11 \mathrm{~b})$ is rather large, and therefore, the formation degree of the chelated or closed species, $\mathrm{M}(\mathrm{HOMPy})_{\mathrm{cl}}^{2+}$, must be quite high.

Application of the straight-line parameters, provided in the literature $^{70}$ and assembled in Table 21 , together with the acidity constants given in footnote $b$ of Table $22,{ }^{17}$ allows a detailed evaluation of the complexes of the ligands ${ }^{17,79}$ shown in Figure 14 by using eqs $10-13$. The results of the corresponding calculations are summarized in Table 22, where OPy = HOMPy, HOEPy, DHOEPy, MOMPy, DMPy, or (HOM)2Py (see also Figure 14).

It is immediately evident from Table 22 that the formation degrees of the chelated species as indicated in equilibrium 1 are very high, namely, throughout at least $90 \%$. Therefore, it is difficult to discuss the finer details of the results on the basis of $\%$ $\mathrm{M}(\mathrm{OPy})_{\mathrm{cl}}^{2+}$; hence, in the discussion below we use instead the stability enhancements $\log \Delta_{\mathrm{M} / \mathrm{OPy}}($ Table 22, column 5), which are also a direct reflection of the intensity with which the hydroxyl groups in the various ligands (Figure 14) participate in metal-ion binding. ${ }^{24,25}$ Clearly, many conclusions are possible based on the data summarized in Table 22; only a few are mentioned below:

(i) For the $\mathrm{M}(\mathrm{HOMPy})^{2+}$ complexes the stability enhancements $\log \Delta_{\mathrm{M} / \mathrm{HOMPy}}$ vary between about $1.1\left(\mathrm{Mn}^{2+}\right)$ and $2.7 \log$ units $\left(\mathrm{Ni}^{2+}\right)$. Compared with the results discussed in the preceding section, these are remarkably large values. The lower affinity of $\mathrm{Cd}^{2+}$, compared to the one of $\mathrm{Zn}^{2+}$, toward hydroxyl groups is confirmed (see sections $4.2,4.3$ and 5.2), that is, $\log \Delta_{\mathrm{Cd} / \text { HOMPy }}=1.03 \pm 0.13$ versus $\log$ $\Delta_{\mathrm{Zn} / \mathrm{HOMPy}}=1.92 \pm 0.17$. 
Table 22. Comparison of the Measured (exp) Stability Constants, $K_{M}^{M}$ (OPy)exp (eqs 4a, 4b, and 6), of the $M^{2+} 1: 1$ Complexes Formed by o-(Hydroxymethyl)pyridine (HOMPy), o-[1-(1-Hydroxyethyl)]pyridine (HOEPy), o-[1-(1,2-Dihydroxyethyl)] pyridine (DHOEPy), o-(Methoxymethyl)pyridine (MOMPy), 2,6-Dimethylpyridine (DMPy) (for Comparison), and 2,6-(Dihydroxymethyl)pyridine $((\mathrm{HOM}) 2 \mathrm{Py})^{b}$ with the Calculated (calc) Stability Constants for the Open Isomers with a Sole $\mathrm{M}^{2+}-\mathrm{N}$ Coordination (at a Single $o$-Substituted Pyridine, Like $o$-Methylpyridine or o-Aminopyridine (see Figure 15)), $K_{M}^{\mathrm{M}(\mathrm{OPy}) \text { op }}(\text { eqs } 1 \text { and } 7)^{a}$

\begin{tabular}{|c|c|c|c|c|c|c|}
\hline OPy & $\mathrm{M}^{2+}$ & $\log _{M}^{M}(\mathrm{OPy}) \exp$ & $\log _{M}^{M}\left(\right.$ OPy $_{\text {op }}{ }^{c}$ & $\log \Delta_{\mathrm{M} / \mathrm{OPy}}$ & $K_{\mathrm{I}}$ & $\% \mathrm{M}(\mathrm{OPy})_{\mathrm{cl}}^{2+}$ \\
\hline \multirow[t]{6}{*}{ HOMPy } & $\mathrm{Mn}^{2+}$ & $1.13 \pm 0.15^{d}$ & $0.03 \pm 0.07$ & $1.10 \pm 0.17$ & $11.59 \pm 4.80$ & $92.1 \pm 3.0$ \\
\hline & $\mathrm{Co}^{2+}$ & $2.23 \pm 0.15^{d}$ & $0.07 \pm 0.08$ & $2.16 \pm 0.17$ & $143.54 \pm 56.58$ & $99.3 \pm 0.3$ \\
\hline & $\mathrm{Ni}^{2+}$ & $2.90 \pm 0.06^{e}$ & $0.17 \pm 0.10$ & $2.73 \pm 0.12$ & $536.03 \pm 144.21$ & $99.8 \pm 0.1$ \\
\hline & $\mathrm{Cu}^{2+}$ & $3.56 \pm 0.06^{e}$ & $1.08 \pm 0.07$ & $2.48 \pm 0.09$ & $301.00 \pm 64.11$ & $99.7 \pm 0.1$ \\
\hline & $\mathrm{Zn}^{2+}$ & $2.03 \pm 0.15^{d}$ & $0.11 \pm 0.08$ & $1.92 \pm 0.17$ & $82.18 \pm 32.56$ & $98.8 \pm 0.5$ \\
\hline & $\mathrm{Cd}^{2+}$ & $1.65 \pm 0.10^{f}$ & $0.62 \pm 0.09$ & $1.03 \pm 0.13$ & $9.72 \pm 3.32$ & $90.7 \pm 2.9$ \\
\hline HOEPy & $\mathrm{Cu}^{2+}$ & $3.77 \pm 0.15^{d}$ & $1.11 \pm 0.07$ & $2.66 \pm 0.17$ & $456.09 \pm 174.22$ & $99.8 \pm 0.1$ \\
\hline DHOEPy & $\mathrm{Cu}^{2+}$ & $3.88 \pm 0.15^{d}$ & $0.97 \pm 0.07$ & $2.91 \pm 0.17$ & $811.83 \pm 309.81$ & $99.9 \pm 0.1^{g}$ \\
\hline MOMPy & $\mathrm{Cu}^{2+}$ & $3.06 \pm 0.15^{d}$ & $0.93 \pm 0.07$ & $2.13 \pm 0.17$ & $133.90 \pm 51.42$ & $99.3 \pm 0.3$ \\
\hline DMPy & $\mathrm{Ni}^{2+}$ & $0.20 \pm 0.06^{e}$ & $(0.39 \pm 0.10)^{h}$ & $(-0.19 \pm 0.12)^{h}$ & & \\
\hline \multirow[t]{2}{*}{$(\mathrm{HOM}) 2 \mathrm{Py}$} & $\mathrm{Cu}^{2+}$ & $3.81 \pm 0.10^{f}$ & $0.70 \pm 0.14^{h}$ & $3.11 \pm 0.17$ & $1287.25 \pm 510.34$ & $99.9 \pm 0.1^{g}$ \\
\hline & $\mathrm{Cd}^{2+}$ & $1.79 \pm 0.10^{f}$ & $0.37 \pm 0.15^{h}$ & $1.42 \pm 0.18$ & $25.30 \pm 10.92$ & $96.2 \pm 1.6^{g}$ \\
\hline
\end{tabular}

${ }^{a}$ The observed stability increase is expressed by $\log \Delta_{\mathrm{M} / \mathrm{OPy}}$ (eqs 11a and $11 \mathrm{~b}$ ). The extent of chelate formation according to the intramolecular equilibria 1 and 2 for the $\mathrm{M}(\mathrm{OPy})^{2+}$ complexes is quantified by the dimensionless equilibrium constant $K_{\mathrm{I}}$ (eqs 7 and 9 ) and the percentage of the closed isomers, $\mathrm{M}(\mathrm{OPy})_{\mathrm{cl}}^{2+}$ (eq 13). All data refer to aqueous solution at $25^{\circ} \mathrm{C}$ and $I=0.5 \mathrm{M}^{17}{ }^{17}$ The corresponding acidity constants ${ }^{17}$ at $25^{\circ} \mathrm{C}$ and $I=0.5 \mathrm{M}^{17}$ are $\mathrm{p} K_{\mathrm{H}(\mathrm{HOMPy})}^{\mathrm{H}}=4.95\left(\right.$ at $I=0.1 \mathrm{M}, \mathrm{p} K_{\mathrm{a}}=4.90 \pm 0.02 ;{ }^{17}$ hence, $\left.\Delta \mathrm{p} K_{\mathrm{a}}=0.05\right), \mathrm{p} K_{\mathrm{H}(\mathrm{HOEPy})}^{\mathrm{H}}=4.98($ at $I=0.1 \mathrm{M})+0.05($ correction for change in $I$ to $0.5 \mathrm{M})=5.03, \mathrm{p} K_{\mathrm{H}(\mathrm{DHOEPy})}^{\mathrm{H}}=4.64+0.05=4.69, \mathrm{p} K_{\mathrm{H}(\text { MOMPy })}^{\mathrm{H}}=4.53+0.05=4.58, \mathrm{p} K_{\mathrm{H}(\mathrm{DMPy})}^{\mathrm{H}}=6.92 \pm 0.04$, and $\mathrm{p} K_{\mathrm{H}[(\mathrm{HOM}) 2 \mathrm{Py}]}^{\mathrm{H}}=4.49\left(\mathrm{at} 20^{\circ} \mathrm{C}\right.$ : 4.39). ${ }^{c}$ Note eqs $11 \mathrm{a}$ and $11 \mathrm{~b}$, i.e., $\log K_{\mathrm{M}(\mathrm{OPy}) \mathrm{calc}}^{\mathrm{M}}=\log \mathrm{K}_{\mathrm{M}(\mathrm{OPy}) \text { op. }}^{\mathrm{M}}{ }^{\mathrm{M}}$ Corrected value: On the basis of the values for $\mathrm{Ni}(\mathrm{HOMPy})^{2+}$ and Cu$(\mathrm{HOMPy})^{2+}$ at $I=0.1$ and $0.5 \mathrm{M}$ (cf. ref 17), the values listed in ref 17 are increased by $0.13 \log$ unit; to be on the safe side an error limit of $\pm 0.15 \log$ unit is applied. ${ }^{e}$ In those instances where no error limit is given in the literature ${ }^{17} \pm 0.06 \log$ unit is employed. ${ }^{f}$ The values given in refs 17 and 79 refer to $20{ }^{\circ} \mathrm{C}$ and $I=0.5 \mathrm{M}$ $\left(\mathrm{NaNO}_{3}\right)$; these values were reduced by $0.05 \log$ unit to account for the difference in temperature; an error limit of \pm 0.10 log unit is used in these instances. ${ }^{g}$ See section $8 .{ }^{h}$ Application of the straight-reference line ${ }^{70}$ gives an expected value for the $\mathrm{Ni}^{2+}$ complex with the $o$-methylpyridine derivative of $0.39 \pm 0.10 \log$ unit, that is, inhibition by a second $o$-methyl group amounts to $-0.19 \pm 0.12 \log$ unit. Therefore, the calculated values for the $\mathrm{Cu}^{2+}$ and $\mathrm{Cd}^{2+}$ complexes have been reduced by a further $0.19 \pm 0.12 \mathrm{log}$ unit assuming that inhibition in the $\mathrm{Cu}^{2+}$ and $\mathrm{Cd}^{2+}$ complexes corresponds to that observed in the $\mathrm{Ni}^{2+}$ complex. The error limits were calculated according to the error propagation after Gauss.

(ii) The stability enhancements for the $\mathrm{M}(\mathrm{HOMPy})^{2+}$ complexes follow to a large part the Irving-Williams series, ${ }^{80,81}$ yet the value for the $\mathrm{Ni}^{2+}$ complex is by $\Delta \log \Delta_{\mathrm{M} / \mathrm{HOMPy}}=$ $0.25 \pm 0.15[=(2.73 \pm 0.12)-(2.48 \pm 0.09)]$ larger than the one of the $\mathrm{Cu}^{2+}$ complex. Why? This has clearly to do with the different coordination spheres of the two metal ions. $\mathrm{Ni}^{2+}$ is octahedral, and this means that upon binding of the primary site, i.e., the pyridyl moiety, four more sites for binding of the hydroxyl group are sterically accessible. In contrast, $\mathrm{Cu}^{2+}$ with its Jahn-Teller-distorted coordination sphere ${ }^{82}$ prefers to coordinate further liganding groups to its equatorial (or square-planar) sites and there are only two of these. In other words, binding of the hydroxyl group to $\mathrm{Ni}^{2+}$ is for statistical reasons favored by a factor of $2(4 / 2)$ and corresponds to $0.3 \log$ unit, which is in accord with the above given difference. Similar observations have been made before. ${ }^{83}$

(iii) Replacement of one of the methylene hydrogens in the $\mathrm{CH}_{2}-\mathrm{OH}$ residue by a $\mathrm{CH}_{3}$ group does not significantly affect hydroxyl $-\mathrm{M}^{2+}$ binding as is evident from the data for $\mathrm{Cu}(\text { HOMPy })^{2+}$ and $\mathrm{Cu}(\text { HOEPy })^{2+}$ (Table 22, column 5).

(iv) As one might expect, a further hydroxyl group, as in $o$-[1-(1,2-dihydroxyethyl)]pyridine (DHOEPy), leads to a further stability enhancement of about $0.25 \log$ unit. This indicates that the second hydroxyl group is also partly involved in $\mathrm{Cu}^{2+}$ binding (Table 22, rows 7 and 8), that is, there are two different closed isomers possible: one with one $\mathrm{OH}$ group involved, and one with both $\mathrm{OH}$ groups participating (see section 8). Of course, the determined stability enhancement, $\log \Delta_{\mathrm{M} / \mathrm{DHOEPy}}=2.91$, encompasses both isomers.

(v) Replacement of the hydroxyl group in HOMPy by a methoxy moiety giving MOMPy (Figure 14) leads to a decrease in the stability enhancement of about $0.35 \log$ unit. This confirms the observation of sections 4.1.2 and 4.2 that an ether oxygen is a somewhat poorer binding site than a hydroxyl group.

(vi) o-(Hydroxymethyl)pyridine (HOMPy) has one hydroxymethyl residue; insertion of the same group in the other ortho position leads to 2,6-(dihydroxymethyl)pyridine $[(\mathrm{HOM}) 2 \mathrm{Py}]$, and the consequence is that the stability enhancement increases further by about $0.63 \mathrm{log}$ unit $(3.11-2.48)$ in the case of $\mathrm{Cu}^{2+}$ and by about $0.39 \mathrm{log}$ unit $(1.42-1.03)$ in the case of the $\mathrm{Cd}^{2+}$ complexes. Naturally, also in the $\mathrm{M}[(\mathrm{HOM}) 2 \mathrm{Py}]^{2+}$ complexes two closed isomers are possible, one involving only one $\mathrm{OH}$ group and one which involves both $\mathrm{OH}$ groups. Of course, the stability enhancement, $\log \Delta_{\mathrm{M} /(\mathrm{HOM}) 2 \mathrm{Py}}$ encompasses both isomers (see section 8).

\section{ISOMERIC QUANTIFICATION OF METAL-ION BINDING WITH LIGANDS OFFERING TWO HYDROXYL GROUPS}

In the preceding section we have seen that the ligands $o$-[1-(1,2-dihydroxyethyl)]pyridine (DHOEPy) and 
2,6-(dihydroxymethyl)pyridine ((HOM)2Py) (Figure 14), which offer two hydroxyl groups, give rise to a stability enhancement which goes beyond that observed for the corresponding complexes containing only a single hydroxyl group. Below we shall now attempt to quantify the extent of the participation of the second hydroxyl group in metal-ion binding.

Taking into account the additional isomer, equilibrium 5 needs to be extended to equilibrium 19 (charges are omitted for simplicity) $29,84,85$

$$
\begin{aligned}
& \mathrm{M}+\mathrm{PBS}(\mathrm{OH})(\mathrm{OH}) \rightleftharpoons \mathrm{M}\left[\mathrm{PBS}(\mathrm{OH})_{\mathrm{op}}(\mathrm{OH})_{\mathrm{op}}\right] \\
& \rightleftharpoons \mathrm{M}\left[\mathrm{PBS}(\mathrm{OH})_{\mathrm{cl}}(\mathrm{OH})_{\mathrm{op}}\right] \rightleftharpoons \mathrm{M}\left[\mathrm{PBS}(\mathrm{OH})_{\mathrm{cl}}(\mathrm{OH})_{\mathrm{cl}}\right]
\end{aligned}
$$

The corresponding experimentally accessible overall stability constant is then defined by eq 20 (cf. with eqs $4 \mathrm{a}, 4 \mathrm{~b}$, and 6) and the open (op) isomer (cf. with eq 7 ) by eq 21

$$
\begin{aligned}
& K_{\mathrm{M}[\mathrm{PBS}(\mathrm{OH})(\mathrm{OH})]}^{\mathrm{M}} \\
& \quad=\left(\left[\mathrm{M}\left[\mathrm{PBS}(\mathrm{OH})_{\mathrm{op}}(\mathrm{OH})_{\mathrm{op}}\right]\right]+\left[\mathrm{M}\left[\mathrm{PBS}(\mathrm{OH})_{\mathrm{cl}}(\mathrm{OH})_{\mathrm{op}}\right]\right]\right. \\
& \left.\quad+\left[\mathrm{M}\left[\mathrm{PBS}(\mathrm{OH})_{\mathrm{cl}}(\mathrm{OH})_{\mathrm{cl}}\right]\right]\right) /([\mathrm{M}][\mathrm{PBS}(\mathrm{OH})(\mathrm{OH})])
\end{aligned}
$$

$$
\begin{aligned}
& K_{\mathrm{M}\left[\mathrm{PBS}(\mathrm{OH})_{\mathrm{op}}(\mathrm{OH})_{\mathrm{op}}\right]}^{\mathrm{M}} \\
& \quad=\left[\mathrm{M}\left[\mathrm{PBS}(\mathrm{OH})_{\mathrm{op}}(\mathrm{OH})_{\mathrm{op}}\right]\right] /([\mathrm{M}][\mathrm{PBS}(\mathrm{OH})(\mathrm{OH})])
\end{aligned}
$$

The positions of the two intramolecular equilibria, which are part of equilibrium 19, are defined by the following two intramolecular dimensionless equilibrium constants $K_{\mathrm{I}(1)}$ and $K_{\mathrm{I}(2)}$

$$
K_{\mathrm{I}(1)}=\left[\mathrm{M}\left[\mathrm{PBS}(\mathrm{OH})_{\mathrm{cl}}(\mathrm{OH})_{\mathrm{op}}\right]\right] /\left[\mathrm{M}\left[\mathrm{PBS}(\mathrm{OH})_{\mathrm{op}}(\mathrm{OH})_{\mathrm{op}}\right]\right]
$$

$K_{\mathrm{I}(2)}=\left[\mathrm{M}\left[\mathrm{PBS}(\mathrm{OH})_{\mathrm{cl}}(\mathrm{OH})_{\mathrm{cl}}\right]\right] /\left[\mathrm{M}\left[\mathrm{PBS}(\mathrm{OH})_{\mathrm{cl}}(\mathrm{OH})_{\mathrm{op}}\right]\right]$

Combination of eqs $20-23$ leads to eqs $24 \mathrm{a}$ and $24 \mathrm{~b}$

$$
\begin{aligned}
& K_{\mathrm{M}[\mathrm{PBS}(\mathrm{OH})(\mathrm{OH})]}^{\mathrm{M}}= K_{\mathrm{M}[\mathrm{PBS}(\mathrm{OH}) \mathrm{op}(\mathrm{OH}) \mathrm{op}]}^{\mathrm{M}} \\
&+K_{\mathrm{I}(1)} \cdot K_{\mathrm{M}[\mathrm{PBS}(\mathrm{OH}) \mathrm{op}(\mathrm{OH}) \mathrm{op}]}^{\mathrm{M}} \\
&+K_{\mathrm{I}(1)} \cdot K_{\mathrm{I}(2)} \cdot K_{\mathrm{M}[\mathrm{PBS}(\mathrm{OH}) \mathrm{op}(\mathrm{OH}) \mathrm{op}]}^{\mathrm{M}} \\
&=K_{\mathrm{M}[\mathrm{PBS}(\mathrm{OH}) \mathrm{op}(\mathrm{OH}) \mathrm{op}]}^{\mathrm{M}}\left(1+K_{\mathrm{I}(1)}+K_{\mathrm{I}(1)} \cdot K_{\mathrm{I}(2)}\right)
\end{aligned}
$$

Of course, if the second closed isomer, $\mathrm{M}\left[\mathrm{PBS}(\mathrm{OH})_{\mathrm{cl}}(\mathrm{OH})_{\mathrm{cl}}\right]$, does not exist, $K_{\mathrm{I}(2)}$ becomes zero and then eq $24 \mathrm{~b}$ equals eq $8 \mathrm{~b}$.

If we define a "total" (tot) intramolecular equilibrium constant $K_{\mathrm{I}(\text { tot })}$ as given in eq 25

$$
K_{\mathrm{I}(\mathrm{tot})}=K_{\mathrm{I}(1)}+K_{\mathrm{I}(1)} \cdot K_{\mathrm{I}(2)}=K_{\mathrm{I}(1)}\left(1+K_{\mathrm{I}(2)}\right)
$$

we obtain eqs 26a, 26b, and 26c, which is analogous to eq 9

$$
\begin{aligned}
& K_{\mathrm{I}(\text { tot })}=\frac{\left[\mathrm{M}\left[\mathrm{PBS}(\mathrm{OH})_{\mathrm{cl}}(\mathrm{OH})_{\mathrm{op}}\right]\right]+\left[\mathrm{M}\left[\mathrm{PBS}(\mathrm{OH})_{\mathrm{cl}}(\mathrm{OH})_{\mathrm{cl}}\right]\right]}{\left[\mathrm{M}\left[\mathrm{PBS}(\mathrm{OH})_{\mathrm{op}}(\mathrm{OH})_{\mathrm{op}}\right]\right]} \\
& =\frac{K_{\mathrm{M}[\mathrm{PBS}(\mathrm{OH})(\mathrm{OH})]}^{\mathrm{M}}}{K_{\mathrm{M}[\mathrm{PBS}(\mathrm{OH}) \mathrm{op}(\mathrm{OH}) \mathrm{op}]}^{\mathrm{M}}}-1 \\
& =10^{\log \Delta}-1
\end{aligned}
$$

Clearly, eq 26c follows from eqs $11 \mathrm{a}$ and $11 \mathrm{~b}$ in analogy to eq 12. A value for $K_{\mathrm{I}(\mathrm{tot})}$ is easily obtained via eq 26c. What is needed, however, is a value either for $K_{\mathrm{I}(1)}$ or $K_{\mathrm{I}(2)}$ to calculate the other one. It is evident that for the present two instances the following holds:

(i) $K_{\mathrm{I}(1)}$ for the $\mathrm{Cu}(\mathrm{DHOEPy})^{2+}$ system is well-defined by the $K_{\mathrm{I}}$ value obtained for $\mathrm{Cu}(\mathrm{HOEPy})^{2+}$ (see Table 21 and compare the structures in Figure 14).

(ii) Similarly, $K_{\mathrm{I}}$ for $\mathrm{M}(\mathrm{HOMPy})^{2+}$ represents well $K_{\mathrm{I}(1)}$ for the $\mathrm{M}[(\mathrm{HOM}) 2 \mathrm{Py}]^{2+}$ systems if multiplied by two because in $\mathrm{M}[(\mathrm{HOM}) 2 \mathrm{Py}]^{2+}$ there are two possibilities for the formation of the macrochelate whereas in $\mathrm{M}(\mathrm{HOMPy})^{2+}$ there is only one.

The corresponding results are summarized in Table 23, where $\mathrm{PBS}(\mathrm{OH})(\mathrm{OH})=$ DHOEPy or $(\mathrm{HOM}) 2 \mathrm{Py}$.

The results of Table 23 reveal immediately that all three isomers formulated in equilibrium 19 occur, the open isomer, $\mathrm{M}\left[\mathrm{PBS}(\mathrm{OH})_{\mathrm{op}}(\mathrm{OH})_{\mathrm{op}}\right]^{2+}$, being a minority species. That $\mathrm{Cu}-\left[(\mathrm{DHOEPy})(\mathrm{OH})_{\mathrm{cl}}(\mathrm{OH})_{\mathrm{op}}\right]^{2+}$ reaches apparently a somewhat larger formation degree than $\mathrm{Cu}\left[(\mathrm{DHOEPy})(\mathrm{OH})_{\mathrm{cl}^{-}}\right.$ $\left.(\mathrm{OH})_{\mathrm{cl}}\right]^{2+}$ is no surprise because the latter species is expected to form only with strained 5-membered rings. In fact, model building indicates that the second $\mathrm{OH}$ group interacts preferably with an apical position of $\mathrm{Cu}^{2+}$, an interaction which is commonly weaker than the equatorial interactions. For the $\mathrm{M}\left[(\mathrm{HOM}) 2 \mathrm{Py}(\mathrm{OH})_{\mathrm{cl}^{-}}(\mathrm{OH})_{\mathrm{cl}}\right]^{2+}$ species the steric restrictions are less demanding, both for $\mathrm{Cu}^{2+}$ and for $\mathrm{Cd}^{2+}$. In the case of $\mathrm{Cu}^{2+}$ the isomer with two hydroxyl groups coordinated appears to be slightly dominating, whereas with $\mathrm{Cd}^{2+}$ the relatively low hydroxyl- $\mathrm{Cd}^{2+}$ affinity (see sections $4.2,4.3,5.2$, and 7 ) is also reflected here, leading for $\mathrm{Cd}\left[(\mathrm{HOM}) 2 \mathrm{Py}(\mathrm{OH})_{\mathrm{cl}}(\mathrm{OH})_{\mathrm{cl}}\right]^{2+}$ to a formation degree of only about $22 \%$.

The take home message of this section is that a single primary binding site, in the present case a pyridine residue, is enough to facilitate binding of (at least) two hydroxyl groups, that is, the PBS may be symmetrically located between the two hydroxyl groups or the structure may be of an unsymmetrical nature, meaning that first the neighboring hydroxyl group must coordinate to the metal ion before the second one is able to do so.

\section{EFFECT OF THE PRIMARY BINDING SITE ON THE EXTENT OF THE HYDROXYL-METAL-ION INTERACTION}

The ligands hydroxymethylphosphonate $\left(\mathrm{HMP}^{2-}\right)$, hydroxyacetate $\left(\mathrm{HOAc}^{-}\right)$, 2-aminoethanol (AEtOH), 2-hydroxymethylimidazole $(\mathrm{Im} 2 \mathrm{OH})$, and $o$-(hydroxymethyl)pyridine (HOMPy) are all able to form 5-membered chelates according to equilibrium 1 with the divalent metal ions considered in this account. In all instances the primary binding site is considered here as being 
Table 23. Formation Degrees of the Three $\mathrm{M}[\mathrm{PBS}(\mathrm{OH})(\mathrm{OH})]^{2+}$ Isomers Seen in Equilibrium 19 for $\mathrm{M}(\mathrm{DHOEPy})^{2+}$ and $\mathrm{M}[(\mathrm{HOM}) 2 \mathrm{Py}]^{2+}$ Systems; Calculated with eqs 25 and $26 \mathrm{c}$ As Well As eq 13 (aqueous solution; $25^{\circ} \mathrm{C} ; \mathrm{I}=0.5 \mathrm{M}$ ) ${ }^{a, b}$

\begin{tabular}{|c|c|c|c|c|c|c|}
\hline no. ${ }^{a}$ & $\mathrm{PBS}(\mathrm{OH})(\mathrm{OH})$ & $\mathrm{M}^{2+}$ & $\log \Delta$ & $\% \mathrm{M}[\mathrm{PE}$ & $\mathrm{BS}(\mathrm{OH})(\mathrm{OH})]_{\mathrm{cl}(\mathrm{tot})}^{2+}$ & $\% \mathrm{M}\left[\mathrm{PBS}(\mathrm{OH})_{\mathrm{op}}(\mathrm{OH})_{\mathrm{op}}\right]^{2+}$ \\
\hline 1a & \multirow{3}{*}{$\begin{array}{l}\text { DHOEPy } \\
(\mathrm{HOM}) 2 \mathrm{Py}\end{array}$} & $\mathrm{Cu}^{2+}$ & $2.91 \pm 0.17$ & $811.83 \pm 309.81$ & $99.88 \pm 0.05$ & $0.12 \pm 0.05$ \\
\hline $2 \mathrm{a}$ & & $\mathrm{Cu}^{2+}$ & $3.11 \pm 0.17$ & $1287.25 \pm 510.34$ & $99.92 \pm 0.03$ & $0.08 \pm 0.03$ \\
\hline $3 a$ & & $\mathrm{Cd}^{2+}$ & $1.42 \pm 0.18$ & $25.30 \pm 10.92$ & $96.20 \pm 1.58$ & $3.80 \pm 1.58$ \\
\hline no. ${ }^{a}$ & $\mathrm{PBS}(\mathrm{OH})(\mathrm{OH})$ & $\mathrm{M}^{2+}$ & $K_{\mathrm{I}(1)}$ & $\% \mathrm{M}\left[\mathrm{PBS}(\mathrm{OH})_{\mathrm{cl}}(\mathrm{OH})_{\mathrm{op}}\right]^{2+}$ & $K_{\mathrm{I}(2)}$ & $\% \mathrm{M}\left[\mathrm{PBS}(\mathrm{OH})_{\mathrm{cl}}(\mathrm{OH})_{\mathrm{cl}}\right]^{2+}$ \\
\hline $1 \mathrm{~b}$ & DHOEPy & $\mathrm{Cu}^{2+}$ & $456.09 \pm 174.22^{c}$ & $55 \pm 10^{d}$ & $0.780 \pm 0.320^{e}$ & $45 \pm 10^{f}$ \\
\hline $2 b$ & $(\mathrm{HOM}) 2 \mathrm{Py}$ & $\mathrm{Cu}^{2+}$ & $602.00 \pm 90.67^{g}$ & $48 \pm 6^{d}$ & $1.138 \pm 0.302^{e}$ & $52 \pm 6^{f}$ \\
\hline $3 b$ & & $\mathrm{Cd}^{2+}$ & $19.44 \pm 4.70^{h}$ & $74 \pm 12^{d}$ & $0.301 \pm 0.215^{e}$ & $22 \pm 12^{f}$ \\
\hline \multicolumn{7}{|c|}{ 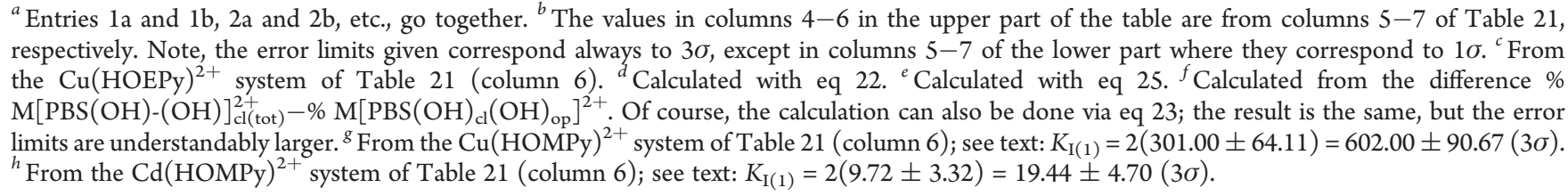 } \\
\hline
\end{tabular}

Table 24. Comparison of the Stability Enhancements, $\log \Delta_{\mathrm{M} / \mathrm{PBS}-\mathrm{OH}}\left(\mathrm{eqs} 11 \mathrm{a}\right.$ and $11 \mathrm{~b}$ ), for a Series of PBS $-\mathrm{OH}$ Ligands ${ }^{a}$ Which Are Able To Form 5-Membered Chelates According to Equilibrium 1 in Aqueous Solution at $25^{\circ} \mathrm{C}$

\begin{tabular}{|c|c|c|c|c|c|c|}
\hline $\mathrm{M}^{2+}$ & $\operatorname{HMP}^{2-}(0.1 \mathrm{M})^{a}$ & $\mathrm{HOAc}^{-}(0.1 \mathrm{M})$ & $\mathrm{HOAc}^{-}(2 \mathrm{M})$ & AEtOH (0.5 M) & $\operatorname{Im} 2 \mathrm{OH}(0.5 \mathrm{M})$ & HOMPy (0.5 M \\
\hline $\mathrm{Ba}^{2+}$ & $(0.10)^{b}$ & $0.42 \pm 0.13$ & & & & \\
\hline $\mathrm{Sr}^{2+}$ & $(0.12)^{b}$ & $0.50 \pm 0.13$ & & & & \\
\hline $\mathrm{Ca}^{2+}$ & $0.13 \pm 0.08$ & $0.78 \pm 0.08$ & & & & \\
\hline $\mathrm{Mg}^{2+}$ & $0.12 \pm 0.10$ & $0.54 \pm 0.07$ & & & & \\
\hline $\mathrm{Mn}^{2+}$ & $(0.18)^{b}$ & $0.60 \pm 0.16$ & & $0.72 \pm 0.22$ & & $1.10 \pm 0.17$ \\
\hline $\mathrm{Co}^{2+}$ & $(0.24)^{b}$ & & $1.12 \pm 0.08$ & $0.85 \pm 0.21$ & & $2.16 \pm 0.17$ \\
\hline $\mathrm{Ni}^{2+}$ & $(0.28)^{b}$ & & $1.23 \pm 0.04$ & $1.03 \pm 0.21$ & & $2.73 \pm 0.12$ \\
\hline $\mathrm{Cu}^{2+}$ & $0.30 \pm 0.08$ & $0.79 \pm 0.08$ & $0.77 \pm 0.05$ & $1.03 \pm 0.26$ & $1.22 \pm 0.12$ & $2.48 \pm 0.09$ \\
\hline $\mathrm{Zn}^{2+}$ & $(0.25)^{b}$ & $1.04 \pm 0.06$ & $1.05 \pm 0.09$ & $0.99 \pm 0.21$ & & $1.92 \pm 0.17$ \\
\hline $\mathrm{Cd}^{2+}$ & $(0.13)^{b}$ & & $0.50 \pm 0.08$ & $0.54 \pm 0.22$ & & $1.03 \pm 0.13$ \\
\hline $\mathrm{Pb}^{2+}$ & & & $0.52 \pm 0.20$ & $3.40 \pm 0.32$ & & \\
\hline
\end{tabular}

${ }^{a}$ Next to the abbreviation of the ligands the ionic strength $(I)$ is given to which the values listed in the column refer. ${ }^{b}$ The values given in parentheses are estimates based on general experience. The corresponding error limits are estimated as $\pm 0.15 \log$ unit.

(overwhelmingly) monodentate, even though indications exist that phosph(on)ate residues may bind divalent metal ions in equilibrium also in a semichelate fashion (for details see ref 28), that is, one of the phosph(on)ate oxygens is inner-sphere coordinated and another one outer-sphere with a water molecule between the metal ion and the phosph(on)ate oxygen. For the carboxylate group similar reasonings exist. ${ }^{86}$ In the solid state 4-membered chelates have (rarely) been observed with both groups, but in aqueous solution such strained 4-membered rings are not expected to persist. $^{28}$

The extent of the hydroxyl-metal-ion interaction may be described via the formation degrees of the chelated species (eq 13) or via the stability enhancements, $\log \Delta_{\mathrm{M} / \mathrm{PBS}-\mathrm{OH}}$ (eqs 11a and 11b). We use here the latter version because differences in the properties are easily identified. This is evident from the following: The stability enhancements $\log \Delta_{\mathrm{M} / \mathrm{PBS}-\mathrm{OH}}=0.1,0.3,1.0,2.0$, or 3.0 correspond to the formation degrees $\% \mathrm{M}(\mathrm{PBS}-\mathrm{OH})_{\mathrm{cl}}=21 \%, 50 \%, 90 \%, 99 \%$, or $99.9 \%$, respectively (for details see ref 25 ).

The stability enhancements, $\log \Delta_{\mathrm{M} / \mathrm{PBS}-\mathrm{OH}}$ for the five ligand systems, $\mathrm{PBS}-\mathrm{OH}$, mentioned above are collected in Table 24. The various results are taken from Tables 2, 7, 11, 17, 20, and 22. Next to the ligand symbols on top of the various columns of
Table 24 the ionic strength $(I)$ is given to which the data listed below in the columns refer. From the two entries for the $\mathrm{M}(\mathrm{HOAc})^{+}$ complexes at $I=0.1$ and $2 \mathrm{M}$ (columns 3 and 4 ) it is evident that the ionic strength effect on the difference $\log \Delta_{\mathrm{M} / \mathrm{PBS}-\mathrm{OH}}$ in this range of $I$ is small. Consequently, we may directly compare the values valid for the various $\mathrm{M}(\mathrm{PBS}-\mathrm{OH})$ complexes.

Table 24 allows many comparisons; a few are given below:

(i) The most complete series for a given metal ion is the one for $\mathrm{Cu}^{2+}$. In this case, the stability enhancement due to the hydroxyl- $\mathrm{Cu}^{2+}$ interaction increases in the series $\mathrm{Cu}(\mathrm{HMP})<\mathrm{Cu}(\mathrm{HOAc})^{+}<\mathrm{Cu}(\mathrm{AEtOH})^{2+}$ $<\mathrm{Cu}(\mathrm{Im} 2 \mathrm{OH})^{2+} \ll \mathrm{Cu}(\mathrm{HOMPy})^{2+}$. This means the more the charge on $\mathrm{Cu}^{2+}$ is neutralized by the PBS, the less is the affinity of $\mathrm{M}^{2+}$ for the hydroxyl group. It needs to be emphasized in this context that the global overall stability constants as defined by eqs $4 \mathrm{a}$ and $4 \mathrm{~b}$ do not at all follow the above order, which is the result of the position of the intramolecular equilibrium 1 . Furthermore, this order is also not related to the basic properties ( $\mathrm{p} K_{\mathrm{a}}$ values) of the primary binding sites (PBS).

(ii) The conclusion given in (i) also holds for the $\mathrm{Mn}(\mathrm{PBS}-\mathrm{OH})$ complexes. In fact, the same is true for the complexes 
of $\mathrm{Co}^{2+}, \mathrm{Ni}^{2+}, \mathrm{Zn}^{2+}$, or $\mathrm{Cd}^{2+}$, even though here the series is $\mathrm{M}(\mathrm{HMP})<\mathrm{M}(\mathrm{HOAc})^{+} \approx \mathrm{M}(\mathrm{AEtOH})^{2+}$ $<\mathrm{M}(\mathrm{HOMPy})^{2+}$. The apparent equality of the stability enhancements (within the error limits) for several of the $\mathrm{M}(\mathrm{HOAc})^{+}$and $\mathrm{M}(\mathrm{AEtOH})^{2+}$ complexes is probably real, though to some extent it could also be due to the assumptions that had to be made in evaluating the $\mathrm{M}(\mathrm{AEtOH})^{2+}$ complexes (see section 5 ).

(iii) It is interesting to note that the stability enhancements observed for the $\mathrm{Cd}^{2+}$ complexes are approximately onehalf the size found for the corresponding $\mathrm{Zn}^{2+}$ species, thus confirming the somewhat reduced affinity of $\mathrm{Cd}^{2+}$ for the hydroxyl group as indicated in several preceding sections (4.2, 4.3, 5.2, and 7).

(iv) The corresponding properties of $\mathrm{Pb}^{2+}$ depend strongly on the PBS: With $\mathrm{HOAc}^{-}$, the PBS being a carboxylate group, the stability enhancements observed for the $\mathrm{Cu}^{2+}$, $\mathrm{Cd}^{2+}$, and $\mathrm{Pb}^{2+}$ complexes are relatively similar, whereas for AEtOH, the PBS being now an amino group, log $\Delta_{\mathrm{Pb} / \mathrm{AEtOH}}$ is outrunning strongly even the corresponding $\mathrm{Cu}^{2+}$ value (see also sections 5.2 and 5.3 regarding the properties of $\left.\mathrm{Pb}^{2+}\right)$.

(v) The very large stability enhancements observed for the $\mathrm{M}(\mathrm{HOMPy})^{2+}$ complexes (Table 24 , column 7 ) are in accord with the conclusion regarding the charge density on the metal ion given in (i) because the pyridyl group is not only a $\sigma$ donor via its nitrogen but also an excellent $\pi$ acceptor, at least with transition elements, thus reducing the charge density on the central metal ion. Indeed, the enhanced stability of mixed ligand complexes, composed of pyridyl residues and O-donor ligands is well known.,87-91

(vi) Unfortunately, for $\mathrm{M}(\operatorname{Im} 2 \mathrm{OH})^{2+}$ complexes, except for $\mathrm{Cu}^{2+}$, no data are available. However, from studies of mixed ligand complexes it is known that the imidazole group with its nitrogen is approximately in between the properties observed for ligands with amino and pyridyl residues. ${ }^{92,93}$ This means that the imidazole residue is a better $\sigma$ donor compared to the pyridyl moiety ${ }^{94}$ but a poorer $\pi$ acceptor. These reasonings are of relevance for complexes formed in proteins, ${ }^{52}$ where the imidazole group of histidine is an important binding site. Also, for ribozymes and other nucleic acids, the imidazole unit is part of purine residues and an eager metal-ion binding site. $^{1,13-15,63,95}$ In addition, modified DNAs with imidazole residues as nucleobases have been synthesized lately; in these altered DNAs metal ions coordinate tightly to the $\mathrm{N} 3$ position. $^{10}$

\section{EXTENT OF HYDROXYL-METAL-ION INTERACTIONS IN COMPLEXES HAVING A BIDENTATE PRIMARY BINDING SITE}

The ligand $\mathrm{N}$-hydroxyethylglycinate $\left(\mathrm{HOGly}^{-}\right)$has a glycinate-like bidentate binding site which leads to 5-membered chelates, and it offers in addition an ethylhydroxy group which, depending on the metal ion involved, may give rise to formation of a further 5-membered chelate (Figure 16). Since the stability constants of the $\mathrm{M}(\mathrm{HOGly})^{+}$complexes of $\mathrm{Ca}^{2+}, \mathrm{Mg}^{2+}, \mathrm{Mn}^{2+}$, $\mathrm{Co}^{2+}, \mathrm{Ni}^{2+}, \mathrm{Cu}^{2+}$, and $\mathrm{Zn}^{2+}$ have been measured in aqueous solution $\left(25^{\circ} \mathrm{C}\right.$; $\left.I=0.1 \mathrm{M}, \mathrm{KCl}\right),{ }^{96,97}$ these systems are ideal for the present purpose, that is, to see to what extent the hydroxyl<smiles>CNCC(=O)O[Na]</smiles>
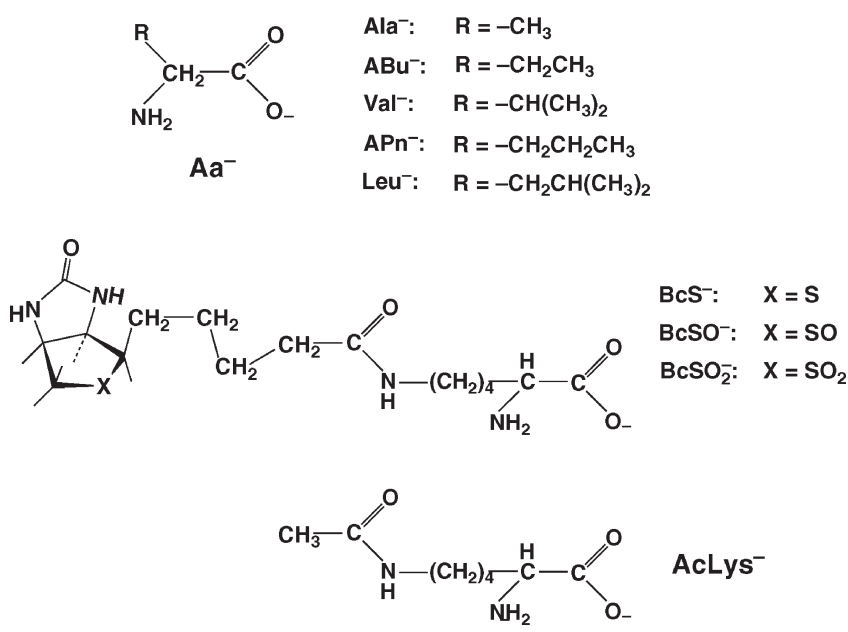

Figure 16. Chemical structure of $N$-hydroxyethylglycinate (HOGly ${ }^{-}$), the properties of which will be compared in section 10 with those of glycinate $\left(\mathrm{Gly}^{-}\right)$and sarcosinate $\left(\mathrm{Sar}^{-}=\mathrm{N}\right.$-methylglycinate). The other amino acetates $\left(\mathrm{Aa}^{-}\right)$, the structures of which are shown, are used to define the straight-line plots (e.g., Figure 17): alaninate ( $\left.\mathrm{Ala}^{-}\right), 2$-aminobutanoate $\left(\mathrm{ABu}^{-}\right)$, valinate $\left(\mathrm{Val}^{-}\right), 2$-aminopentanoate $\left(\mathrm{APn}^{-}\right)$, leucinate ( $\left.\mathrm{Leu}^{-}\right)$, biocytinate $\left(\mathrm{BcS}^{-}=\varepsilon-N\right.$ - $d$-biotinyl-L-lysinate), biocytinate sulfoxide $\left(\mathrm{BcSO}^{-}\right)$, biocytinate sulfone $\left(\mathrm{BcSO}_{2}^{-}\right)$, and $\varepsilon$ - $N$-acetyl-L-lysinate $\left(\right.$ AcLys $\left.^{-}\right)$.

group is able to participate in metal-ion binding if a bidentate primary site is involved.

Because the $N$-hydroxyethyl substituent is expected to lead to some steric hindrance in the open form of the $\mathrm{M}(\mathrm{HOGly})^{+}$ complexes (in analogy to equilibria 1 and 2), this inhibition needs to be quantified. In a first approximation one may assume that a methyl substituent at the amino group of glycinate mimics this steric effect well. Therefore, next to glycinate $\left(\mathrm{Gly}^{-}\right)$also sarcosinate ( $\mathrm{Sar}^{-}=N$-methylglycinate) and their complexes are considered in this section; the structure of these ligands is shown in the upper part of Figure 16 together with the one of HOGly ${ }^{-}$.

Of course, a possible stability enhancement $\log \Delta_{\mathrm{M} / \mathrm{HOGly}}$ according to eqs $11 \mathrm{a}$ and $11 \mathrm{~b}$ can only be determined if the stability of the open complexes, $\mathrm{M}(\mathrm{HOGly})_{\mathrm{op}}^{+}$, is known. These

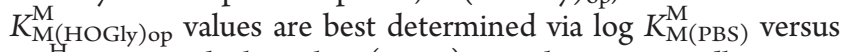
$\mathrm{p} K_{\mathrm{H}(\mathrm{PBS})}^{\mathrm{H}}$ straight-line plots (eq 10) as we have repeatedly seen in the preceding sections. For this purpose we collected the available stability constants of the complexes formed with the nine amino acetates and derivatives $\left(\mathrm{Aa}^{-}\right)$shown in the middle and lower parts of Figure 16. Not in all instances were the data for all considered metal ions available from a single source, but still, we collected data mainly valid for $25^{\circ} \mathrm{C}$ and $I=0.1 \mathrm{M} .^{17,22,98-105}$ On the other hand, for several ligands more constants are available, ${ }^{100}$ which are close to the ones used, e.g., for Leu ${ }^{-}$ (cf. ref 22) and Gly ${ }^{-87}$ The acidity constants of the monoprotonated ligands and the stability constants of the complexes employed now in the evaluation are summarized in Table 25.

In the construction of the straight-line plots we considered only the basicity of the amino nitrogen, that is, the $\mathrm{p} K_{\mathrm{H}(\mathrm{Aa})}^{\mathrm{H}}$ values, as this property is affected by the kind of the 
Table 25. Logarithms of the Stability Constants for the 1:1 Complexes (eqs $4 a$ and $4 b$ ) Formed between Several Divalent Metal Ions $\left(\mathrm{M}^{2+}\right)$ and Various Amino Acetate Ligands $\left(\mathrm{Aa}^{-}\right)$Including Glycinate $\left(\mathrm{Gly}^{-}\right)$, Sarcosinate (Sar $\left.{ }^{-}\right)$, and $\mathrm{N}$-Hydroxyethylglycinate $\left(\right.$ HOGly $^{-}$) (see Figure 16 for the Structures) As Well As Negative Logarithms of the Acidity Constants (eqs 14a and 14b) of the Corresponding $\mathrm{H}(\mathrm{Aa})^{ \pm}$Species, Determined by Potentiometric $\mathrm{pH}$ Titrations, of Aqueous Solutions at (mostly) $25{ }^{\circ} \mathrm{C}$

\begin{tabular}{|c|c|c|c|c|c|c|c|c|c|}
\hline \multirow[b]{2}{*}{$\mathrm{Aa}^{-}$} & \multirow[b]{2}{*}{$I(\mathrm{ref})^{a}$} & \multirow[b]{2}{*}{$\mathrm{p} K_{\mathrm{H}(\mathrm{Aa})}^{\mathrm{H}}$} & \multicolumn{7}{|c|}{$\log K_{\mathrm{M}(\mathrm{Aa})}^{\mathrm{M}}$ for $\mathrm{M}^{2+}=$} \\
\hline & & & $\mathrm{Ca}^{2+}$ & $\mathrm{Mg}^{2+}$ & $\mathrm{Mn}^{2+}$ & $\mathrm{Co}^{2+}$ & $\mathrm{Ni}^{2+}$ & $\mathrm{Cu}^{2+}$ & $\mathrm{Zn}^{2+}$ \\
\hline \multirow[t]{5}{*}{$\mathrm{Ala}^{-}$} & $0.1(98)$ & $9.83 \pm 0.03$ & & & $2.67 \pm 0.05$ & $4.44 \pm 0.05$ & & $8.25 \pm 0.07$ & $4.51 \pm 0.05$ \\
\hline & $0.1(99)$ & $9.84 \pm 0.01$ & & & & & & $8.22 \pm 0.02$ & \\
\hline & $0.1(22)$ & $9.82 \pm 0.01$ & & & & & & $8.33 \pm 0.02$ & $4.62 \pm 0.04$ \\
\hline & $0.05-0.5(100)$ & $9.72 \pm 0.05$ & & & $2.60 \pm 0.15$ & $4.33 \pm 0.05$ & $5.41 \pm 0.08$ & $8.14 \pm 0.10$ & $4.63 \pm 0.08$ \\
\hline & $0.1(17)$ & $9.71 \pm 0.04$ & $1.00 \pm 0.10^{b}$ & $1.54 \pm 0.10^{b}$ & $2.45 \pm 0.10^{b}$ & $4.31 \pm 0.07$ & $5.36 \pm 0.04$ & $8.11 \pm 0.07$ & $4.58 \pm 0.07$ \\
\hline \multirow[t]{5}{*}{$\mathrm{Val}^{-}$} & $0.1(99)$ & $9.66 \pm 0.02$ & & & & & & $8.15 \pm 0.02$ & \\
\hline & $0.1-0.5(100)$ & $9.54 \pm 0.05$ & & & & & $5.27 \pm 0.05$ & $7.98 \pm 0.08$ & $4.46 \pm 0.06$ \\
\hline & $0.15(101)^{c}$ & $9.32 \pm 0.01$ & & & $2.34 \pm 0.09$ & $4.24 \pm 0.06^{a}$ & & & \\
\hline & $0.5(102)^{d}$ & $9.48 \pm 0.01$ & & & & $4.32 \pm 0.06$ & & & \\
\hline & $0.1(17)$ & $9.52 \pm 0.05$ & & & & & $5.3 \pm 0.1$ & $8.10 \pm 0.05$ & $4.52 \pm 0.06$ \\
\hline \multirow[t]{5}{*}{$\mathrm{Leu}^{-}$} & $0.1(99)$ & $9.72 \pm 0.01$ & & & & & & $8.19 \pm 0.01$ & \\
\hline & $0.1(103)$ & $9.66 \pm 0.01$ & & & $2.49 \pm 0.03$ & & & & $4.56 \pm 0.02$ \\
\hline & $0.1-0.2(100)$ & $9.66 \pm 0.03$ & & & & & $5.57 \pm 0.05^{e}$ & & \\
\hline & $\sim 0.1(104)$ & $9.77 \pm 0.06^{a}$ & & & & $4.51 \pm 0.06^{a}$ & $5.62 \pm 0.06^{a}$ & & \\
\hline & $0.1(17)$ & $9.58 \pm 0.07$ & & & & & $5.33 \pm 0.06^{a}$ & $8.14 \pm 0.07$ & $4.56 \pm 0.06^{a}$ \\
\hline $\mathrm{ABu}^{-}$ & $0.1(17)$ & $9.63 \pm 0.02$ & & & & $4.23 \pm 0.07$ & $5.30 \pm 0.08$ & $8.11 \pm 0.10$ & $4.54 \pm 0.05$ \\
\hline $\mathrm{APn}^{-}$ & $0.1(105)$ & $9.64 \pm 0.01$ & & & & $4.15 \pm 0.01$ & $5.27 \pm 0.02$ & $8.12 \pm 0.01$ & $4.42 \pm 0.02$ \\
\hline AcLys $^{-}$ & $0.1(98)$ & $9.63 \pm 0.02$ & & & $2.50 \pm 0.05$ & $4.27 \pm 0.05$ & & $8.09 \pm 0.06$ & $4.51 \pm 0.05$ \\
\hline $\mathrm{BcS}^{-}$ & $0.1(98)$ & $9.29 \pm 0.02$ & & & $2.47 \pm 0.05$ & $4.10 \pm 0.05$ & & $7.73 \pm 0.03$ & $4.38 \pm 0.03$ \\
\hline $\mathrm{BcSO}^{-}$ & $0.1(98)$ & $9.30 \pm 0.02$ & & & $2.45 \pm 0.05$ & & & $7.87 \pm 0.05$ & $4.33 \pm 0.05$ \\
\hline $\mathrm{BcSO}_{2}^{-}$ & $0.1(98)$ & $9.31 \pm 0.03$ & & & $2.44 \pm 0.05$ & & & $7.83 \pm 0.05$ & $4.32 \pm 0.05$ \\
\hline $\mathrm{Gly}^{-}$ & $0.1(17)$ & $9.57 \pm 0.05$ & $1.09 \pm 0.04$ & $1.66 \pm 0.06^{a}$ & $2.80 \pm 0.05$ & $4.67 \pm 0.05$ & $5.74 \pm 0.09$ & $8.19 \pm 0.04$ & $4.96 \pm 0.04$ \\
\hline \multirow[t]{2}{*}{$\mathrm{Sar}^{-}$} & $0.1(17)$ & $9.98 \pm 0.04$ & & & $2.54 \pm 0.10^{f}$ & & $5.39 \pm 0.06^{a}$ & $7.68 \pm 0.06^{a}$ & $4.53 \pm 0.06^{a}$ \\
\hline & $\sim 0.1(104)$ & $10.09 \pm 0.06^{a}$ & & & & $4.34 \pm 0.06^{a}$ & & & \\
\hline HOGly $^{-}$ & $0.1(96,97)$ & $9.05 \pm 0.01$ & $4.32 \pm 0.01$ & $3.11 \pm 0.01$ & $4.15 \pm 0.01$ & $7.30 \pm 0.01$ & $9.11 \pm 0.02$ & $9.56 \pm 0.01$ & $7.57 \pm 0.01$ \\
\hline \multicolumn{10}{|c|}{ 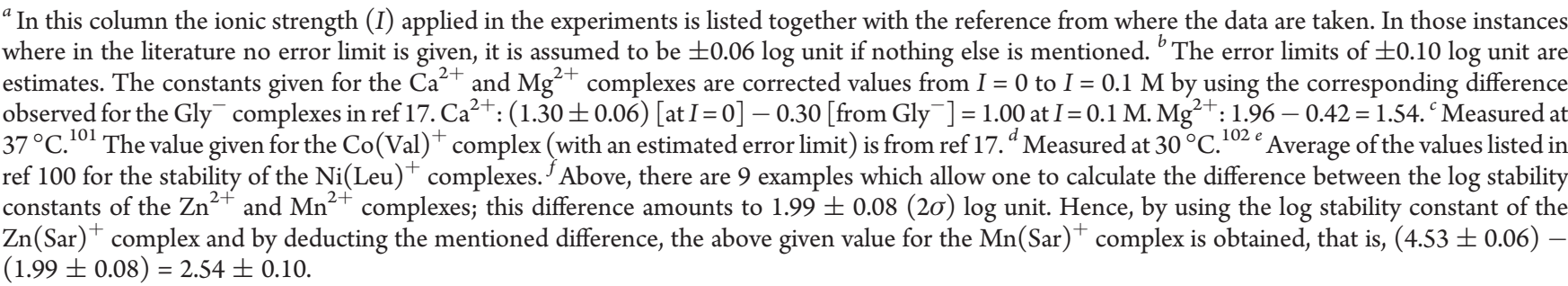 } \\
\hline
\end{tabular}

nearby substituent (see Figure 16 and Table 25). The basicity of the carboxylate group, which is further away, is hardly affected by the varying substituents as is evident from the following acidity constants which hold for the 2 -fold protonated $\mathrm{H}_{2}(\mathrm{Aa})^{+}$ species: $\mathrm{p}_{\mathrm{H}_{2}(\mathrm{Ala})}^{\mathrm{H}}=2.26 \pm 0.03, \mathrm{p} K_{\mathrm{H}_{2} \text { (AcLys) }}^{\mathrm{H}}=2.24 \pm 0.01$, and $\mathrm{pK}_{\mathrm{H}(\mathrm{BcS})}^{\mathrm{H}}=2.26 \pm 0.03$. ${ }^{98}$ The corresponding observations have also been made in other instances, especially in ref 100 but also, e.g., in refs 17, 22 and 99. An additional reason for neglecting these acidity constants is that the scatter among the results from various authors is in part relatively large, i.e., larger than the scatter in the $\mathrm{p} K_{\mathrm{H}(\mathrm{Aa})}^{\mathrm{H}}$ values. This is understandable because the low $\mathrm{pH}$ range around 2 is close to the limit that can be measured with glass electrodes and where the type of calibration of the $\mathrm{pH}$ meter also may affect the results.

In Figure 17 three representative examples of plots of log $K_{\mathrm{M}(\mathrm{Aa})}^{\mathrm{M}}$ versus $\mathrm{p} K_{\mathrm{H}(\mathrm{Aa})}^{\mathrm{H}}$ are shown. In the case of $\mathrm{Cu}^{2+}, \mathrm{Zn}^{2+}$, and $\mathrm{Mn}^{2+}, 16,14$, and 9 data pairs are available, respectively, as follows from Table 25 (see the open circles in Figure 17). From all three parts of Figure 17 it is evident that there is a significant dependence of $\log K_{\mathrm{M}(\mathrm{Aa})}^{\mathrm{M}}$ on $\mathrm{p} K_{\mathrm{H}(\mathrm{Aa})}^{\mathrm{H}}$. However, the scatter of the data points is rather large, and deletion of a single point either at the lower or upper end of the $\mathrm{p} K_{\mathrm{H}(\mathrm{Aa})}^{\mathrm{H}}$ scale may affect the slope, $m$, and thus the least-squares treatment and its result relatively strongly.

To avoid ambiguities and also to make the matter simple, we decided to use the slope, $m=0.7$, as previously proposed by Martin $^{69}$ in all instances. Therefore, in the least-squares calculation the slope $m=0.7$ was kept constant and only the intercept $b$ with the $y$ axis was varied. The resulting parameters according to eq 10 are listed in Table 26. The error limits given in column 4 are estimates; they are based on the scatter of the data around the straight line with a slope of 0.7 and emphasize especially the error at $\mathrm{pK} H(\mathrm{Aa})$ of about 9 or 10 . It needs further to be emphasized that a change in the slope $m$ of \pm 0.2 in the $\mathrm{p} K_{\mathrm{H}(\mathrm{Aa})}^{\mathrm{H}}$ range of ca. 9-10 does not significantly affect the outcome of the 


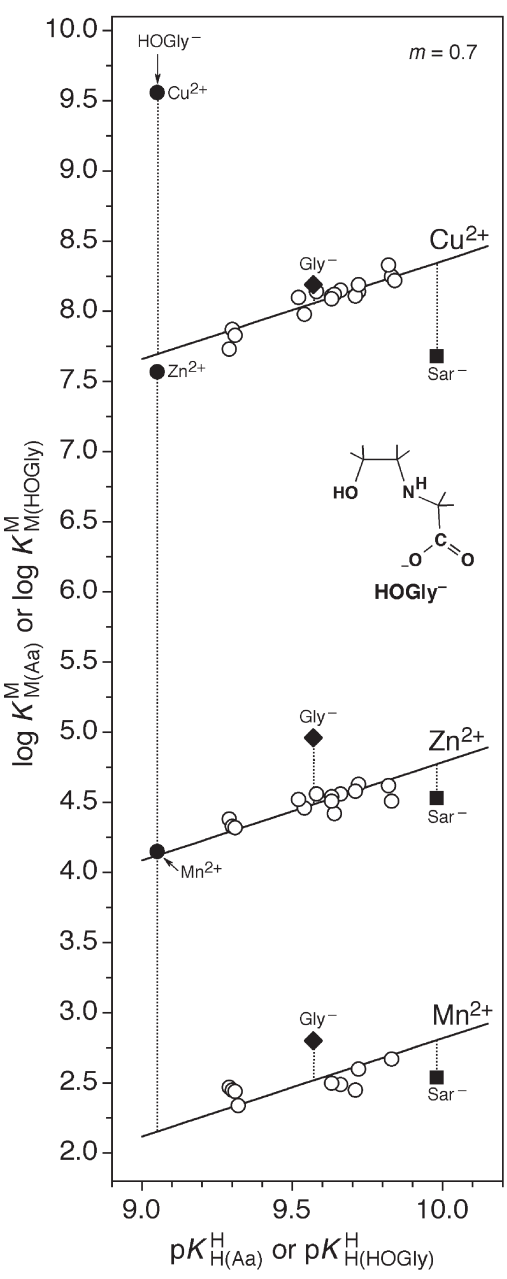

Figure 17. Evidence for an enhanced complex stability of the $\mathrm{Mn}^{2+}$, $\mathrm{Cu}^{2+}$, and $\mathrm{Zn}^{2+}$ 1:1 complexes of HOGly ${ }^{-}(\mathbf{)})$ based on the relationship between $\log K_{\mathrm{M}(\mathrm{Aa})}^{\mathrm{M}}$ and $\mathrm{p} K_{\mathrm{H}(\mathrm{Aa})}^{\mathrm{H}}$ for the simple amino acetate ligands $(O)$ shown in the middle and lower parts of Figure 16. The parameters, with slope $m=0.7$ being kept fixed, of the corresponding least-squares reference lines (eq 10) are summarized in Table 26. The data points for the $\mathrm{H}^{+} / \mathrm{M}^{2+} / \mathrm{Gly}^{-}(\downarrow)$ and $\mathrm{H}^{+} / \mathrm{M}^{2+} / \mathrm{Sar}^{-}(\mathbf{\square})$ systems are shown for comparison. The vertical dotted lines emphasize the (positive or negative) stability differences to the reference lines; these differences equal $\log \Delta_{\mathrm{M} / \mathrm{Aa}}$ as defined by eqs $11 \mathrm{a}$ and $11 \mathrm{~b}$. All plotted equilibrium constants are listed in Table 25; they refer to aqueous solutions (mostly) at $25^{\circ} \mathrm{C}$ and (mostly) $I=0.1 \mathrm{M}$.

calculations for the $\log \Delta_{\mathrm{M} / \mathrm{HOGly}}$ values. This is especially true as the data points for the $\mathrm{H}^{+} / \mathrm{M}^{2+} / \mathrm{HOGly}^{-}$systems are far above their reference lines, thus indicating without any calculation a large stability enhancement for the $\mathrm{M}(\mathrm{HOGly})^{+}$complexes.

Two more points need to be emphasized in the context of Figure 17

(i) The data point for a given $\mathrm{H}^{+} / \mathrm{M}^{2+} / \mathrm{Gly}^{-}$system (rhomb) is always above the straight line defined by the corresponding alaninate-type complexes. This is in accord with the observation of Martin ${ }^{69}$ that the $\mathrm{M}(\mathrm{Gly})^{+}$complexes are somewhat more stable than the corresponding $\mathrm{M}(\mathrm{Ala})^{+}$species despite the lower basicity of Gly compared to $\mathrm{Ala}^{-}$(see also the data in Table 25).

(ii) Substitution of a methyl group at the amino nitrogen of $\mathrm{Gly}^{-}$leads to a significant steric inhibition of metal-ion coordination, and therefore, not only are the stabilities of
Table 26. Straight-Line Parameters (eq 10) ${ }^{a}$ for $\mathrm{M}^{2+}$ 1:1 Complexes Formed with the Simple Amino Acetate Ligands $\left(\mathrm{Aa}^{-}\right)$Shown in the Lower Part of Figure 16, Valid for Aqueous Solutions at $25^{\circ} \mathrm{C}$ and $I=0.1 \mathrm{M}^{b}$

$\begin{array}{lccc}\mathrm{M}^{2+} & m & b & \log \text { (error limits) } \\ \mathrm{Mn}^{2+} & 0.70 & -4.18 & \pm 0.2 \\ \mathrm{Co}^{2+} & 0.70 & -2.43 & \pm 0.15 \\ \mathrm{Ni}^{2+} & 0.70 & -1.37 & \pm 0.2 \\ \mathrm{Cu}^{2+} & 0.70 & 1.36 & \pm 0.1 \\ \mathrm{Zn}^{2+} & 0.70 & -2.21 & \pm 0.15\end{array}$

${ }^{a}$ The slopes $(m)$ were fixed at 0.70 (see text in section 10 ), and the intercepts (b) for the straight reference lines from plots of log $K_{\mathrm{M}(\mathrm{Aa})}^{\mathrm{M}}$ versus $\mathrm{p} K_{\mathrm{H}(\mathrm{Aa})}^{\mathrm{H}}$ were calculated by the least-squares procedure from the experimentally determined equilibrium constants listed in Table 25 for the ligands shown in the lower part of Figure 16 (see also Figure 17). ${ }^{b}$ The straight-line equation is defined by eq 10 . With a known $\mathrm{p} K_{\mathrm{H}(\mathrm{Aa})}^{\mathrm{H}}$ value of any amino acetate derivative $\left(\mathrm{Aa}^{-}\right)$, the stability constant $\log K_{\mathrm{M}(\mathrm{Aa})}^{\mathrm{M}}$ for the corresponding $\mathrm{M}(\mathrm{Aa})^{+}$complex (eqs $4 \mathrm{a}$ and $4 \mathrm{~b})$ can be calculated. The estimated error limits given in the fourth column should be used for any calculation in the $\mathrm{p} K_{\mathrm{H}(\mathrm{Aa})}^{\mathrm{H}}$ range of $9-10$.

the $\mathrm{M}(\mathrm{Sar})^{+}$complexes always lower than those of the corresponding $\mathrm{M}(\mathrm{Gly})^{+}$species (despite the higher basicity of Sar ${ }^{-}$compared to that of $\mathrm{Gly}^{-}$) (Table 25) but also the data points for the $\mathrm{H}^{+} / \mathrm{M}^{2+} / \mathrm{Sar}^{-}$systems (full squares) are also always below the reference lines typical for the alaninate-type complexes (see Figure 17).

The stability constant of the open form of the $\mathrm{M}(\mathrm{HOGly})^{+}$ complexes is therefore given by the intercept that follows from $\mathrm{p} K_{\mathrm{H}(\mathrm{HOGly})}^{\mathrm{H}}=9.05$ (cf. refs 96 and 97) with the straight line of the alaninate-type complexes (Ala-type), and this value needs then to be increased by $\log \Delta_{M / \text { Gly }}$ to obtain the glycinate-like coordination, which thereafter needs to be adjusted for the total steric inhibition, which means that $\left[\log \Delta_{M / G l y}-\left(-\log \Delta_{M / S a r}\right)\right]$ needs to be deducted. This is expressed in eqs $27 \mathrm{a}$ and $27 \mathrm{~b}$

$$
\begin{gathered}
\log K_{\mathrm{M}(\text { HOGly }) \text { op }}^{\mathrm{M}}=\log K_{\mathrm{M}(\text { Ala-type })}^{\mathrm{M}}+\log \Delta_{\mathrm{M} / \text { Gly }} \\
-\left[\log \Delta_{\mathrm{M} / \mathrm{Gly}}-\left(-\log \Delta_{\mathrm{M} / \mathrm{Sar}}\right)\right] \\
=\log K_{\mathrm{M}(\text { Ala-type })}^{\mathrm{M}}+\left(-\log \Delta_{\mathrm{M} / \text { Sar }}\right)
\end{gathered}
$$

Since the values for $\log K_{\mathrm{M} \text { (HOGly })}^{\mathrm{M}}\left(=K_{\mathrm{M} \text { (HOGly)exp }}^{\mathrm{M}}\right)$ are known (Table 25, bottom row) eqs $11 \mathrm{a}$ and $11 \mathrm{~b}$ can be applied and the stability enhancements $\log \Delta_{\mathrm{M} / \mathrm{HOGly}}$ can be calculated. The corresponding results are summarized in Table 27.

From column 6 of Table 27 it is evident that the stability enhancements for the $\mathrm{M}(\mathrm{HOGly})^{+}$complexes of $\mathrm{Mn}^{2+}, \mathrm{Co}^{2+}$, $\mathrm{Ni}^{2+}, \mathrm{Cu}^{2+}$, and $\mathrm{Zn}^{2+}$ are tremendous. Even for the lowest case, the $\mathrm{Mn}(\mathrm{HOGly})^{+}$complex, $\log \Delta_{\mathrm{Mn} / \mathrm{HOGly}}$ still equals approximately 2.3. Consequently, it follows from eqs 12 and 13 that the formation degree of the closed and chelated species, $\mathrm{Mn}(\mathrm{HOGly})_{\mathrm{cl}}^{+}$, amounts to about $99.5 \%$. For the most favorable case, $\mathrm{Ni}(\mathrm{HOGly})_{\mathrm{cl}}^{+}$, a formation degree of practically $100 \%$ is reached. Since the formation degrees of all the other $\mathrm{M}(\text { HOGly })_{\mathrm{cl}}^{+}$species $\left(\mathrm{M}^{2+}=\mathrm{Co}^{2+}, \mathrm{Cu}^{2+}, \mathrm{Zn}^{2+}\right)$ varies only in the indicated narrow range of $0.5 \%$, no further calculations were made.

Why is the stability enhancement for the $\mathrm{Cu}(\mathrm{HOGly})^{+}$ complex relatively low? If we consider the equatorial squareplanar coordination sphere of $\mathrm{Cu}^{2+}$ (see also section 7, point 
Table 27. Comparison of the Measured (exp) Stability Constants, $K_{M}^{\mathrm{M}}$ (HoGly)exp (eqs 4a, 4b, and 6), of the $\mathbf{M}^{2+} 1: 1 \mathrm{Complexes}^{2}$ Formed by $\mathrm{N}$-Hydroxyethylglycinate ( $\mathrm{HOGly}^{-}$) with the Calculated Stability Constants According to eqs $27 \mathrm{a}$ and $27 \mathrm{~b}$ for the Open Isomers with a Sole Glycinate-Like Coordination of $\mathbf{M}^{2+}, K_{\mathbf{M}(\mathrm{HOGly}) \text { op }}^{\mathrm{M}}(\mathrm{eqs} 1 \text { and } 7)^{a, b}$

\begin{tabular}{|c|c|c|c|c|c|}
\hline $\mathrm{M}^{2+}$ & $\log K_{\mathrm{M}(\mathrm{HOGly}) \exp }^{\mathrm{M}}$ & $\log K_{\mathrm{M}(\text { Ala-type })}^{\mathrm{M}}$ & $\log \Delta_{\mathrm{M} / \mathrm{Sar}}{ }^{c}$ & $\log K_{\mathrm{M}(\mathrm{HOGly}) \mathrm{op}}^{\mathrm{M}}$ & $\log \Delta_{\mathrm{M} / \mathrm{HOGly}}$ \\
\hline $\mathrm{Ca}^{2+}$ & $4.32 \pm 0.01$ & & & $1.09 \pm 0.04^{d}$ & $>3.2$ \\
\hline $\mathrm{Mg}^{2+}$ & $3.11 \pm 0.01$ & & & $1.66 \pm 0.06^{d}$ & $>1.4$ \\
\hline $\mathrm{Mn}^{2+}$ & $4.15 \pm 0.01$ & $2.16 \pm 0.2$ & $-0.27 \pm 0.22$ & $1.89 \pm 0.30$ & $2.26 \pm 0.30$ \\
\hline $\mathrm{Co}^{2+}$ & $7.30 \pm 0.01$ & $3.91 \pm 0.15$ & $-0.29 \pm 0.16$ & $3.62 \pm 0.22$ & $3.68 \pm 0.22$ \\
\hline $\mathrm{Ni}^{2+}$ & $9.11 \pm 0.02$ & $4.97 \pm 0.2$ & $-0.23 \pm 0.21$ & $4.74 \pm 0.29$ & $4.37 \pm 0.29$ \\
\hline $\mathrm{Cu}^{2+}$ & $9.56 \pm 0.01$ & $7.70 \pm 0.1$ & $-0.67 \pm 0.12$ & $7.03 \pm 0.16$ & $2.53 \pm 0.16$ \\
\hline $\mathrm{Zn}^{2+}$ & $7.57 \pm 0.01$ & $4.13 \pm 0.15$ & $-0.25 \pm 0.16$ & $3.88 \pm 0.22$ & $3.69 \pm 0.22$ \\
\hline
\end{tabular}

${ }^{a}$ The stability differences are expressed by $\log \Delta_{\mathrm{M} / \mathrm{HOGly}}$ (eqs 11a and $11 \mathrm{~b}$ ) (aqueous solution; $25^{\circ} \mathrm{C} ; \mathrm{I}=0.1 \mathrm{M}$ ). ${ }^{b}$ The values in the second column are from the bottom row of Table 25 . The values in the third column were calculated with $\mathrm{p} K_{\mathrm{H}(\mathrm{HOGly})}^{\mathrm{H}}=9.05$ (refs 96 and 97 ) and the straight-line

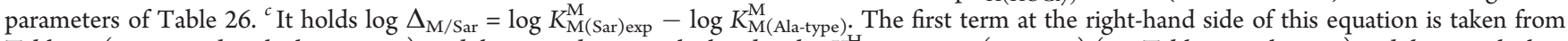
Table 25 (see second to the last entries), and the second one is calculated with $\mathrm{p} K_{\mathrm{H}(\mathrm{Sar})}^{\mathrm{H}}=9.98$ (or 10.09) (see Table 25, column 3 ) and the straight-line parameters listed in Table 26. ${ }^{d}$ These values correspond to $\log K_{\mathrm{M}(\mathrm{Gly})}^{\mathrm{M}}($ see Table 25$)$; in this way, a lower limit is obtained for log $\Delta_{\mathrm{M} / \mathrm{HOGly}}$, where $\mathrm{M}^{2+}=\mathrm{Ca}^{2+}$ or $\mathrm{Mg}^{2+}$ (see also text in section 10).

(ii)), there are only 4 possibilities for coordination of a bidentate ligand (glycinate-like binding) whereas there are 12 such possibilities in an octahedral coordination sphere. Moreover, once the glycinate-like coordination has occurred, only 1 possibility for coordination of the hydroxyl group remains in the case of $\mathrm{Cu}^{2+}$, in contrast to the 3 possibilities that are offered by an octahedral sphere. Hence, this consideration alone (4/12 times 1/3) amounts already to a statistical disadvantage for $\mathrm{Cu}^{2+}$ of about $1 \log$ unit.

As one would expect, the global stability constants given in the last row of Table 25 for the $\mathrm{M}(\mathrm{HOGly})^{+}$complexes are in general of a similar size or somewhat lower than those of the corresponding complexes formed with iminodiacetate $\left[=\mathrm{Ida}^{2-}=\right.$ $\left.\mathrm{HN}-\left(\mathrm{CH}_{2} \mathrm{COO}\right)_{2}^{2-}\right] \cdot{ }^{17,106}$ However, here is also a caveat needed because in a few instances, especially with $\mathrm{Ca}^{2+}$ and $\mathrm{Ni}^{2+}$, the stability of the $\mathrm{M}(\mathrm{HOGly})^{+}$complexes is roughly by 1 log unit larger than the one for the $\mathrm{M}$ (Ida) species; this result may be correct but is surprising, and therefore, it would be desirable that the stabilities of the $\mathrm{M}(\mathrm{HOGly})^{+}$complexes are determined again. This suggestion is even more enforced by the observation that the stability constants of the $\mathrm{Mn}^{2+}, \mathrm{Co}^{2+}$, $\mathrm{Ni}^{2+}, \mathrm{Cu}^{2+}$, and $\mathrm{Zn}^{2+}$ complexes formed with the buffer ligand Bicinate $[=N, N$-bis (2-hydroxyethyl)glycinate = $\left.\left(\mathrm{HO}-\mathrm{CH}_{2} \mathrm{CH}_{2}\right)_{2} \mathrm{NCH}_{2} \mathrm{COO}^{-}\right]^{107,108}$ are all lower than those of the corresponding $\mathrm{M}(\mathrm{HOGly})^{+}$complexes, even though in the $\mathrm{M}(\text { Bicinate })^{+}$complexes a further $-\mathrm{CH}_{2} \mathrm{CH}_{2} \mathrm{OH}$ residue for $\mathrm{M}^{2+}$ binding is available. Yet, Bicinate is less basic $\left(\Delta \mathrm{p} K_{\mathrm{a}}=0.8\right)^{96,97,108}$ and it could further be that the additional substituent at the amino nitrogen rather hinders than promotes $\mathrm{M}^{2+}$ coordination (see also sections 5.3). Furthermore, in section 5.1 we have seen that the $\mathrm{Ni}\left[\left(\mathrm{CH}_{3}\right)_{2} \mathrm{NH}\right]^{2+}$ complex is by ca. 0.8 log unit less stable than the $\mathrm{Ni}\left(\mathrm{CH}_{3} \mathrm{NH}_{2}\right)^{2+}$ one even though in this case the basicity difference between the two ligands is small. However, it needs to be emphasized that the conclusions presented above about the very large stability enhancements are still valid, even if the $\log \Delta_{M / H O G l y}$ values listed in Table 27 should in some instances be smaller by about 1 log unit.

Unfortunately, the stabilities of the $\mathrm{Ca}^{2+}$ and $\mathrm{Mg}^{2+}$ complexes formed with $\mathrm{Sar}^{-}$are unknown, and reference lines like those seen in Figure 17 could also not be defined, though there is an indication that again the $\mathrm{M}(\mathrm{Gly})^{+}$complexes of $\mathrm{Ca}^{2+}$ and $\mathrm{Mg}^{2+}$ are slightly more stable than the corresponding $\mathrm{M}(\mathrm{Ala})^{+}$species (see Table 25). However, to be on the safe side, we simply evaluated the differences in complex stability between the $\mathrm{M}(\mathrm{HOGly})^{+}$and the corresponding $\mathrm{M}(\mathrm{Gly})^{+}$species. Clearly, this procedure provides a lower limit for the stability enhancements experienced by the $\mathrm{Mg}(\mathrm{HOGly})^{+}$and $\mathrm{Ca}(\mathrm{HOGly})^{+}$ complexes due to coordination of the hydroxyl group (see the two top entries in Table 27). Consequently, the formation degrees of the closed $\mathrm{M}(\mathrm{HOGly})_{\mathrm{cl}}^{+}$species, calculated according to eqs 12 and 13, based on these values, are also lower limits; they are $96 \%$ and $99.9 \%$, respectively. These lower limits of the formation degrees of the chelated species are remarkably high and worthwhile to be noted with a view toward biological systems.

Overall, it is evident that participation of the hydroxyl group in metal-ion binding in the $\mathrm{M}(\mathrm{HOGly})^{+}$complexes is very high. Hence, the indications given in ref 96 that at high $\mathrm{pH}$ values coordinated hydroxyl groups may be deprotonated leading to coordinated hydroxylate groups seems to be a realistic suggestion, at least for $\mathrm{Cu}^{2+}$.

\section{METAL-ION COMPLEXES OF LIGANDS WITH TWO OR MORE HYDROXYL GROUPS AND AT LEAST FOUR BINDING SITES}

11.1. Complexes of the Alkaline Earth lons with Bistris and Some Related Buffers: Reduced Solvent Polarity Favors Metal-Ion-Hydroxyl Group Interactions

Despite the caveat expressed in the preceding section 10, it is remarkable that the stability constant of the $\mathrm{Ca}(\mathrm{HOGly})^{+}$ complex is evidently by about $1.2 \mathrm{log}$ units larger than that of $\mathrm{Mg}(\mathrm{HOGly})^{+}$(Table 27), a result in accord with the observations made in sections 4.1 and 5.3. This can only mean that the coordination sphere of $\mathrm{Ca}^{2+}$ is especially fitting to the steric conditions of $\mathrm{HOGly}^{-}$. A corresponding observation ${ }^{109}$ has been made for Bistris [= 2-[bis(2-hydroxyethyl)amino]2(hydroxymethyl)-1,3-propanediol; see Figure 18 below], a rather common buffer compound for many years. ${ }^{110,111}$ In this case, the $\mathrm{Ca}^{2+}$ complex is favored over the $\mathrm{Mg}^{2+}$ one by $1.9 \mathrm{log}$ units $\left(\log K_{\mathrm{Ca}(\text { Bistris })}^{\mathrm{Ca}}=2.25 \pm 0.02\right.$ compared to $\log K_{\mathrm{Mg}(\text { Bistris })}^{\mathrm{Mg}}=$ $0.34 \pm 0.05),{ }^{109}$ confirming for the $\mathrm{Ca}^{2+}$ ion its ideal affinity and geometry for hydroxyl group coordination (see also below). In contrast, the similarity and low stability of the complexes formed 
with $\mathrm{Mg}^{2+}$ and $\mathrm{Mn}^{2+}\left(\log K_{\mathrm{Mn} \text { (Bistris) }}^{\mathrm{Mn}}=0.70 \pm 0.05\right)^{109}$ are remarkable as well. It may be added that the high stability of the $\mathrm{Ca}(\text { Bistris })^{2+}$ complex was confirmed $^{112}$ and that it was repeatedly pointed out that the use of this type of buffers can give misleading results ${ }^{112-114}$ because the 'free' metal-ion concentration in a system is affected. This is not only true for the formation of binary but also of ternary complexes, e.g., with ATP $^{4-107,109,112-115}$

The points indicated above deserve a more detailed discussion which will provide further insights into $\mathrm{M}^{2+}-\mathrm{OH}$ interactions. Therefore, we do not consider now only Bistris but also the two related buffer ligands Tris and TEA. The corresponding structures are shown in Figure 18, and the stability constants of their complexes formed with the alkaline earth ions are assembled in

$$
\mathrm{HO}-\mathrm{CH}_{2}-\mathrm{CH}_{2}-\mathrm{NH}_{2} \quad \text { AEtOH }
$$<smiles>NC(CO)(CO)CO</smiles><smiles>OCCN(CCO)CCO</smiles>

\section{TEA}<smiles>OCCN(CCO)C(CO)(CO)CO</smiles>

\section{Bistris}

Figure 18. Chemical structures of 2-aminoethanol and of the related buffer ligands 2-amino-2-(hydroxymethyl)-1,3-propanediol (Tris), triethanolamine (TEA), and 2-[bis(2-hydroxyethyl)amino]-2-(hydroxymethyl)1,3-propanediol (Bistris).
Table 28, where those for the $\mathrm{M}\left(\mathrm{NH}_{3}\right)^{2+}$ species are also given for comparison.

The stability constants listed in the two top rows of Table 28 show that complex stability decreases for the $\mathrm{M}\left(\mathrm{NH}_{3}\right)^{2+}$ and $\mathrm{M}(\text { Tris })^{2+}$ complexes with increasing ionic radii, that is, $0.65 \AA$ $\left(\mathrm{Mg}^{2+}\right)<0.99 \AA\left(\mathrm{Ca}^{2+}\right)<1.13 \AA\left(\mathrm{Sr}^{2+}\right)<1.35 \AA\left(\mathrm{Ba}^{2+}\right)$ (see Figure 2 in ref 77; cf. also ref 116). This is the common order in complex stability and holds, e.g., also for the corresponding complexes of oxalate or glycinate. ${ }^{81}$ Considering that the slope $m$ for $\log K$ versus $\mathrm{p} K_{\mathrm{a}}$ plots is close to zero for $\mathrm{N}$ ligands as discussed in section 5.3, the stability constants for the M$\left(\mathrm{NH}_{3}\right)^{2+}$ and $\mathrm{M}$ (Tris $)^{2+}$ complexes may in a first approximation directly be compared. This evidences stability differences of about $0.3 \log$ unit in favor of the $\mathrm{M}(\text { Tris })^{2+}$ species of $\mathrm{Ca}^{2+}$, $\mathrm{Sr}^{2+}$, and $\mathrm{Ba}^{2+}$. From this follows (eqs 11a-13) an approximate formation degree of about $50 \%$ for a chelated isomer involving one $\mathrm{HO}-\mathrm{CH}_{2}$ residue in aqueous solution. Clearly, this interaction is weak and does probably not occur to any significant extent in $\mathrm{Mg}(\text { Tris })^{2+}$.

For the $\mathrm{M}(\mathrm{TEA})^{2+}$ complexes the situation changes: The $\mathrm{Ca}(\mathrm{TEA})^{2+}$ complex is now clearly the most stable one among the alkaline earth ion species (Table 28, row 3). It appears again that in the $\mathrm{Mg}(\mathrm{TEA})^{2+}$ complex none of the $\mathrm{CH}_{2} \mathrm{CH}_{2} \mathrm{OH}$ residues participates in a significant manner in metal-ion binding, whereas for the $\mathrm{Ca}^{2+}, \mathrm{Sr}^{2+}$, and $\mathrm{Ba}^{2+}$ complexes they are clearly important (see section 5.3).

Even in the $\mathrm{Mg}$ (Bistris $)^{2+}$ complex, hardly a single hydroxyl group is involved in $\mathrm{Mg}^{2+}$ binding despite the availability of five such sites (Figure 18). This is different with the $\mathrm{Ca}^{2+}, \mathrm{Sr}^{2+}$, and $\mathrm{Ba}^{2+}$ complexes: If we form the differences between the stability constants of their $\mathrm{M}$ (Bistris $)^{2+}$ complexes and those of the corresponding $\mathrm{M}\left(\mathrm{NH}_{3}\right)^{2+}$ species, we obtain the lower limits of the stability enhancements, $\log \Delta_{M / \text { Bistris }}$ (eqs 11a and $11 \mathrm{~b}$ ), because the basicity of Bistris is by about $2.7 \mathrm{pK}$ units lower; these lower limits are $\log \Delta_{\mathrm{M} / \text { Bistris }}=2.25\left(\mathrm{Ca}^{2+}\right), 1.64\left(\mathrm{Sr}^{2+}\right)$, and $1.15\left(\mathrm{Ba}^{2+}\right)$. Hence, the formation degrees for single hydroxyl

Table 28. Logarithms of the Stability Constants for the 1:1 Complexes (eqs 4a and 4b) Formed between the Alkaline Earth Ions $\left(\mathrm{M}^{2+}\right)$ and the Ligands (L), i.e., Ammonia $\left(\mathrm{NH}_{3}\right)$, 2-Amino-2-(hydroxymethyl)-1,3-propanediol (Tris), Triethanolamine (TEA), and 2-[Bis(2-hydroxyethyl)amino]-2-(hydroxymethyl)-1,3-propanediol (Bistris), As Well As Negative Logarithms of the Acidity Constants (eqs 14a and 14b) of the Corresponding $\mathrm{H}(\mathrm{L})^{+}$Species, Determined by Potentiometric $\mathrm{pH}$ Titrations in Water and Mixed Water/Organic Solvents $\left(25^{\circ} \mathrm{C}\right)^{a}$

\begin{tabular}{|c|c|c|c|c|c|c|c|}
\hline \multirow[b]{2}{*}{$\mathrm{L}$} & \multirow[b]{2}{*}{ solvent } & \multirow[b]{2}{*}{$I$ (Inert Salt) ${ }^{b}$} & \multirow[b]{2}{*}{$\mathrm{p} K_{\mathrm{H}(\mathrm{L})}^{\mathrm{H}}$} & \multicolumn{4}{|c|}{$\log K_{\mathrm{M}(\mathrm{L})}^{\mathrm{M}}$ for $\mathrm{M}^{2+}=$} \\
\hline & & & & $\mathrm{Mg}^{2+}$ & $\mathrm{Ca}^{2+}$ & $\mathrm{Sr}^{2+}$ & $\mathrm{Ba}^{2+}$ \\
\hline $\mathrm{NH}_{3}$ & $\mathrm{H}_{2} \mathrm{O}$ & $1.0\left(\mathrm{NH}_{4} \mathrm{NO}_{3}\right)$ & $9.43 \pm 0.05$ & 0.24 & $0.0^{c}$ & $-0.2^{c}$ & $-0.3^{c}$ \\
\hline Tris & $\mathrm{H}_{2} \mathrm{O}$ & $1.0\left(\mathrm{TMA}^{+} / \mathrm{K}^{+}\right)$ & $8.31 \pm 0.01$ & $0.30 \pm 0.01$ & $0.25 \pm 0.02$ & $0.11 \pm 0.02$ & $0.02 \pm 0.02$ \\
\hline TEA & $\mathrm{H}_{2} \mathrm{O}$ & $1.0\left(\mathrm{TMA}^{+} / \mathrm{K}^{+}\right)$ & $8.05 \pm 0.01$ & $0.24 \pm 0.02$ & $0.78 \pm 0.01$ & $0.38 \pm 0.01$ & $0.36 \pm 0.01$ \\
\hline Bistris & $\mathrm{H}_{2} \mathrm{O}$ & $1.0\left(\mathrm{TMA}^{+} / \mathrm{K}^{+}\right)$ & $6.74 \pm 0.01$ & $0.34 \pm 0.05$ & $2.25 \pm 0.02$ & $1.44 \pm 0.02$ & $0.85 \pm 0.03$ \\
\hline Bistris & $50 \%$ Diox $(0.17)^{d}$ & $0.5\left(\mathrm{TMA}^{+} / \mathrm{K}^{+}\right)$ & $6.72 \pm 0.01$ & $0.51 \pm 0.02$ & $2.91 \pm 0.01$ & $2.24 \pm 0.01$ & $1.33 \pm 0.01$ \\
\hline Bistris & $50 \% \mathrm{CH}_{3} \mathrm{OH}(0.31)$ & $0.5\left(\mathrm{TMA}^{+} / \mathrm{K}^{+}\right)$ & $6.61 \pm 0.01$ & $0.43 \pm 0.01$ & $2.94 \pm 0.01$ & $2.22 \pm 0.01$ & $e$ \\
\hline Bistris & $75 \%$ DMSO $(0.43)^{d}$ & $0.5\left(\mathrm{TMA}^{+}\right)$ & $7.26 \pm 0.01$ & $0.44 \pm 0.01$ & $2.16 \pm 0.02$ & $2.19 \pm 0.01$ & $1.25 \pm 0.01$ \\
\hline Bistris & $90 \%$ DMSO (0.70) & $0.25\left(\mathrm{TMA}^{+}\right)$ & $7.47 \pm 0.01$ & $0.91 \pm 0.04$ & $1.64 \pm 0.01$ & $1.87 \pm 0.01$ & $1.14 \pm 0.03$ \\
\hline Tris & $90 \%$ DMSO (0.70) & $0.25\left(\mathrm{TMA}^{+} / \mathrm{Rb}^{+}\right)$ & $10.11 \pm 0.01$ & $0.50 \pm 0.22$ & $0.25 \pm 0.10$ & $0.76 \pm 0.06$ & $0.41 \pm 0.02$ \\
\hline TEA & $90 \%$ DMSO (0.70) & $0.25\left(\mathrm{TMA}^{+}\right)$ & $8.24 \pm 0.01$ & $0.51 \pm 0.03$ & $0.82 \pm 0.02$ & $0.80 \pm 0.02$ & $0.58 \pm 0.04$ \\
\hline
\end{tabular}

${ }^{a}$ The values for the $\mathrm{NH}_{3}$ systems are from ref 17 ; all others are from ref $77 .{ }^{b}$ In all instances the nitrate $\left(\mathrm{NO}_{3}^{-}\right)$salts were used, i.e., of the tetramethylammonium ion $\left(\mathrm{TMA}^{+}\right), \mathrm{K}^{+}$or $\mathrm{Rb}^{+}$; if $\mathrm{TMA}^{+}$and $\mathrm{K}^{+}$or $\mathrm{Rb}^{+}$are listed, it means that the titration curves were the same with either cation and no buffer depression was observed. ${ }^{c}$ In these cases $I=2 \mathrm{M}\left(\mathrm{NH}_{4} \mathrm{NO}_{3}\right) .{ }^{17 d}$ Diox $=1$,4-dioxane; DMSO = dimethylsulfoxide. The percentages are given as $\mathrm{v} / \mathrm{v}$. The number in parentheses is the mole fraction of the organic part of the aqueous solvent mixture. ${ }^{e} \mathrm{Ba}\left(\mathrm{NO}_{3}\right)_{2}$ was not soluble under the given conditions. 
group interactions are about $99 \%\left(\mathrm{Ca}^{2+}\right), 98 \%\left(\mathrm{Sr}^{2+}\right)$, and $93 \%$ $\left(\mathrm{Ba}^{2+}\right)\left(\right.$ eqs 11a-13). Of course, the $\mathrm{M}^{2+}-\mathrm{OH}$ interaction will most likely be divided between several of the $\mathrm{HO}-\mathrm{CH}_{2}$ residues. ${ }^{77}$

Before we consider the solvent influence on the stabilities of the complexes (Table 28, lower part), it seems appropriate to view first the acid-base properties of the ligands. Quite generally one expects for dissociation of a neutral species into two charged ones an inhibition if less water for solvation of the charged species becomes available. Indeed, e.g., for $\mathrm{CH}_{3} \mathrm{COOH}$ it holds $\mathrm{p} K_{\mathrm{H}(\mathrm{Ac})}^{\mathrm{H}}=4.57 \pm 0.01\left(\right.$ Table $\left.4 ; 25^{\circ} \mathrm{C} ; I=0.1 \mathrm{M}\right)$ in water and $5.97 \pm 0.01$ in $50 \%$ aqueous (v/v) 1,4-dioxane (Table $13 ; 25{ }^{\circ} \mathrm{C} ; \mathrm{I}=0.1 \mathrm{M}$ ), and this is also in accord with the observations made in section 3.2 for monoprotonated glycerol 1-phosphate (Figure 3; Table 3). In contrast, one would expect that a protonated and charged species like in equilibria 14a and $14 \mathrm{~b}$ is less affected by a change in the solvent because on both sides of the equilibrium charged species occur. In fact, deprotonation may even become favored because the organic part of the solvent mixture may facilitate solvation of the uncharged species. Indeed, e.g., for ammonia it holds $\mathrm{p} K_{\mathrm{H}\left(\mathrm{NH}_{3}\right)}^{\mathrm{H}}=9.26 \pm 0.05$ (Table $15 ; 25^{\circ} \mathrm{C} ; I=0.1 \mathrm{M}$ ) in water and 8.91 in $50 \%$ aqueous (wt) methanol $\left(25^{\circ} \mathrm{C} ; \quad I=0.1 \mathrm{M}\right),{ }^{117}$ and for $\gamma$-picoline (4-methylpyridine) one observes $\mathrm{p} K_{\mathrm{H}(P c)}^{\mathrm{H}}=6.18$ in water and 5.11 in $50 \%$ aqueous $(\mathrm{v} / \mathrm{v}) 1,4$-dioxane $\left(25^{\circ} \mathrm{C} ; I=0.1 \mathrm{M}\right) .{ }^{118}$

The properties of $\mathrm{H}$ (Bistris) ${ }^{+}$in water $\left(\mathrm{pK}_{\mathrm{H} \text { (Bistris) }}^{\mathrm{H}}=6.74\right.$; Table 28), 50\% aqueous dioxane (6.72), and $50 \%$ aqueous methanol (6.61) correspond approximately to this expectation, meaning that the influence of these mixed solvents on the acidity constants is small. This also holds for $\mathrm{H}(\mathrm{TEA})^{+}$in going from water $\left(\mathrm{p} K_{\mathrm{H} \text { (TEA) }}^{\mathrm{H}}=8.05\right.$; Table 28$)$ to $90 \%$ aqueous $\mathrm{DMSO}$ (8.24). However, for $\mathrm{H}(\text { Bistris })^{+}$the basicity increases significantly from water $\left(\mathrm{pK}_{\mathrm{H} \text { (Bistris) }}^{\mathrm{H}}=6.74\right.$; Table 28$)$ to $90 \% \mathrm{DMSO}$ (7.47). This is even more true for $\mathrm{H}(\text { Tris })^{+}$, where the change from water $\left(\mathrm{p} K_{\mathrm{H} \text { (Tris) }}^{\mathrm{H}}=8.31\right)$ to $90 \%$ DMSO (10.11) amounts to an increase of $\Delta \mathrm{p} K_{\mathrm{a}}=1.8$. This can only mean that in $\mathrm{H}$ (Bistris) $)^{+}$ and even more so in $\mathrm{H}(\mathrm{Tris})^{+}$the proton at the nitrogen is intramolecularly "solvated" by the hydroxyl groups under the influence of the organic solvent molecules and that this inhibits the release of the proton. The take home message here is that the hydroxyl groups in Bistris and Tris can become involved in rather strong hydrogen bonds and that thus part of the hydroxyl groups may possibly interact in an outer-sphere manner with a partially hydrated metal ion. In this context one should also mention that Bistris binds alkali ions quite well in 90\% DMSO; complex stability decreases within the series $\mathrm{Li}^{+}\left(\log K_{\mathrm{Li}}^{\mathrm{Li}(\text { Bistris })}=0.61 \pm 0.01\right)>$ $\mathrm{Na}^{+}(0.54 \pm 0.01)>\mathrm{K}^{+}(0.36 \pm 0.01)>\mathrm{Rb}^{+}(0.26 \pm 0.01) .{ }^{77}$

In the discussion above about the situation in aqueous solution we observed some selectivity of TEA toward $\mathrm{Ca}^{2+}$ and a very pronounced one of Bistris toward the same ion. It is now interesting to compare the stability constants valid for mixed organic solvents (lower part of Table 28) with those for water: (i) A subtle change in water activity by changing the solvent from water to $50 \%$ aqueous dioxane or $50 \%$ aqueous methanol increases the stability of the $\mathrm{M}(\text { Bistris })^{2+}$ complexes but does not change the stability order; it remains $\mathrm{Mg}^{2+}<\mathrm{Ca}^{2+}>\mathrm{Sr}^{2+}>$ $\mathrm{Ba}^{2+}$. (ii) A more significant change, i.e., by going from water to $75 \%$ aqueous DMSO, leaves the stability of $\mathrm{Ca}(\text { Bistris })^{2+}$ practically unaffected but favors the stability of $\mathrm{Sr}$ (Bistris) ${ }^{2+}$ considerably, with the result that now both complexes have the same stability in this solvent. (iii) Furthermore, the change to $90 \%$ DMSO (solvent permittivity $\varepsilon \approx 47$ for pure DMSO) weakens the stability of the $\mathrm{M}(\text { Bistris })^{2+}$ complexes, with the exception of $\mathrm{Mg}(\text { Bistris })^{2+}$, and changes the stability order completely $\mathrm{Mg}^{2+}<\mathrm{Ca}^{2+}<\mathrm{Sr}^{2+}>\mathrm{Ba}^{2+}$, i.e., the most stable complex is now $\operatorname{Sr}(\text { Bistris })^{2+}$. (iv) A similar effect is observed for the $\mathrm{M}(\mathrm{TEA})^{2+}$ complexes: In water the most stable complex is $\mathrm{Ca}(\text { TEA })^{2+}$, whereas in $90 \% \mathrm{DMSO} \mathrm{Ca}(\text { TEA })^{2+}$ and $\operatorname{Sr}(\mathrm{TEA})^{2+}$ have the same stability. (v) Strange enough, $\mathrm{Ca}(\text { Tris })^{2+}$ shows the same stability in water and $90 \%$ DMSO, whereas for the other three metal ions complex stability increases, especially for $\operatorname{Sr}(\mathrm{Tris})^{2+}$, by going from water to $90 \%$ DMSO; this leads to the irregular order for the stability of the complexes $\mathrm{Sr}^{2+}>\mathrm{Mg}^{2+} \approx \mathrm{Ba}^{2+}>\mathrm{Ca}^{2+}$.

The initially high stability of the $\mathrm{Ca}(\text { Bistris })^{2+}$ complex in water may be explained by postulating a cage-like orientation of the hydroxyl groups and the nitrogen of Bistris; ${ }^{77,109}$ in this structural arrangement $\mathrm{Ca}^{2+}$ would fit well, whereas the ionic radius of $\mathrm{Mg}^{2+}$ is too small and the radii of $\mathrm{Sr}^{2+}$ and $\mathrm{Ba}^{2+}$ are too large to allow an optimal interaction with the hydroxyl groups. This selectivity is further promoted in the case of Coulombic interactions and hydrogen bonds by a subtle decrease in the permittivity as it occurs by going from water $(\varepsilon=78.5$; cf. Table 3$)$ to $50 \%$ aqueous dioxane $(\varepsilon=35.2)$. Of course, once the concentration of the organic molecules increases further, the $\mathrm{M}^{2+}-\mathrm{OH}$ interactions and the hydrogen bonds may be either favored or disturbed depending on the ligand and metal ion involved, giving rise to the dominating stability of the $\mathrm{Sr}^{2+}$ species.

That metal-ion-dipole interactions are important for the stability of complexes involving hydroxyl groups is also evident from $\mathrm{X}$-ray structural studies. The structure of $\left[\mathrm{Sr}(\mathrm{TEA})_{2}\right]\left(\mathrm{NO}_{3}\right)_{2}$ shows an approximately cubic eight-coordinated $\mathrm{Sr}^{2+}$, which is surrounded by the eight donor atoms of the two TEA ligands. ${ }^{119}$ The two $\mathrm{NO}_{3}^{-}$ ions are not linked to the cation but interact in strong hydrogen bonds with the $\mathrm{OH}$ groups of the TEA molecules. In accord with prominent $\mathrm{M}^{2+}$-dipole interactions, the $\mathrm{Sr}-\mathrm{O}$ distances of 2.534-2.594 $\AA$ are shorter than the $\mathrm{Sr}-\mathrm{N}$ bonds with $2.830 \AA^{119}$ In the related $\mathrm{Ba}^{2+}$ complex $\left[\mathrm{Ba}(\mathrm{TEA})_{2}-\left(\mathrm{CH}_{3} \mathrm{COO}\right)\right] \mathrm{CH}_{3} \mathrm{COO}$ the cation has a coordination number of nine and is bound to the eight donor atoms of two TEAs and to an oxygen atom of one acetate. ${ }^{120}$ The $\mathrm{Ba}-\mathrm{N}$ distances are 3.025 and $3.108 \AA$, while the $\mathrm{Ba}-\mathrm{O}$ distances are again shorter. The latter distances are between 2.743 and $2.805 \AA$, and the one to the $\mathrm{O}$ atom of the coordinated acetate is $2.726 \AA$ (the other acetate is more than $5 \AA$ away). However, again hydrogen bonds are formed between the hydroxyl groups of TEA and the acetate ions. ${ }^{120}$

To conclude, it is evident that the amino nitrogen and the hydroxyl groups of TEA can bind inner-sphere to the alkaline earth ions and that the hydroxyl groups are in addition able to undergo hydrogen bonding. Since the structural TEA unit is also part of Bistris (Figure 18), the same may be surmised for this ligand, and Tris also contains at least the aminoethanol unit. With regard to aqueous solution, the $\mathrm{M}(\text { Bistris })^{2+}$ complexes exist certainly in the form of several isomers which are in an intramolecular (and hence concentration-independent) equilibrium with each other and which differ by the number of coordinated hydroxyl groups. It seems that the one extreme is an aminoethanol-like coordination and the other a 5- or 6-fold coordination, depending on the steric conditions of the coordination sphere of the metal ion. Further isomers may form through hydrogen bonding between the hydroxyl groups and coordinated water molecules. Corresponding isomeric equilibria are also expected to occur with the $\mathrm{M}(\text { Tris })^{2+}$ and $\mathrm{M}(\text { TEA })^{2+}$ complexes. 
Table 29. Logarithms of the Stability Constants for the 1:1 Complexes (eqs 4a, 4b, and 6) Formed between Several (Mainly 3d) Divalent Metal Ions $\left(\mathrm{M}^{2+}\right)$ and the Ligands (L), i.e., Ammonia $\left(\mathrm{NH}_{3}\right)$, 2-Aminoethanol (AEtOH), 2-Amino-2-(hydroxymethyl)1,3-propanediol (Tris), Triethanolamine (TEA), and 2-[Bis(2-hydroxyethyl)amino]-2-(hydroxymethyl)-1,3-propanediol (Bistris) (see Figure 18 for the Structures), As Well As Negative Logarithms of the Acidity Constants (eqs 14a and 14b) of the Corresponding $\mathrm{H}(\mathrm{L})^{+}$Species, Determined by Potentiometric $\mathrm{pH}$ Titrations, of Aqueous Solutions $\left(25^{\circ} \mathrm{C}\right)^{a}$

\begin{tabular}{lcccccccc}
\multicolumn{1}{c}{} & \multicolumn{9}{c}{$\log K_{\mathrm{M}(\mathrm{L})}^{\mathrm{M}}$ for $\mathrm{M}^{2+}=$} \\
\cline { 3 - 9 } $\mathrm{L}$ & $\mathrm{p} K_{\mathrm{H}(\mathrm{L})}^{\mathrm{H}}$ & $\mathrm{Mn}^{2+}$ & $\mathrm{Co}^{2+}$ & $\mathrm{Ni}^{2+}$ & $\mathrm{Cu}^{2+}$ & $\mathrm{Zn}^{2+}$ & $\mathrm{Cd}^{2+}$ & $\mathrm{Pb}^{2+}$ \\
$\mathrm{NH}_{3}$ & $9.33 \pm 0.04$ & $0.88 \pm 0.06$ & $2.09 \pm 0.06$ & $2.77 \pm 0.06$ & $4.11 \pm 0.06$ & $2.31 \pm 0.06$ & $2.60 \pm 0.06$ & $1.45 \pm 0.10$ \\
$\mathrm{AEtOH}$ & $9.62 \pm 0.03$ & $0.88 \pm 0.10$ & $2.23 \pm 0.06$ & $3.12 \pm 0.06$ & $4.60 \pm 0.06$ & $2.50 \pm 0.06$ & $2.45 \pm 0.10$ & $4.20 \pm 0.10$ \\
Tris & $8.13 \pm 0.01$ & $\leq 0.9^{b}$ & $1.73 \pm 0.02$ & $2.74 \pm 0.02$ & $4.05 \pm 0.02$ & $1.94 \pm 0.03$ & $1.94 \pm 0.02$ & $\leq 2.7^{b}$ \\
TEA & $7.85 \pm 0.10$ & & $2.25 \pm 0.05$ & $2.76 \pm 0.01$ & $4.07 \pm 0.03$ & $2.05 \pm 0.01$ & $3.39 \pm 0.02$ \\
Bistris & $6.72 \pm 0.01$ & $0.70 \pm 0.05$ & $1.78 \pm 0.03$ & $3.59 \pm 0.02$ & $5.27 \pm 0.01$ & $2.38 \pm 0.03$ & $2.47 \pm 0.02$ & $4.32 \pm 0.04$
\end{tabular}

${ }^{a}$ Source of the data and ionic strength $(I)$ of the measurements: $\mathrm{NH}_{3}$ ( $I=0.5 \mathrm{M}$; from Table 15; error limits estimated), AEtOH $(I=0.5 \mathrm{M}$; from Tables 15 and 17$)$, Tris $(I=0.1 \mathrm{M}),{ }^{115}$ TEA $(I=0.1 \mathrm{M}){ }^{17,68}$ and Bistris $(I=1.0 \mathrm{M}){ }^{109}{ }^{6}$ There are indications that the given limit for the stability constant of $\mathrm{Pb}(\text { Tris })^{2+}$ is close to the actual value. ${ }^{115}$ This is probably also true for $\mathrm{Mn}(\text { Tris })^{2+}$ (see Figure 4 in ref 109).

A final remark: One observes in aqueous solution a stability enhancement of $\log \Delta_{M / \text { Bistris }}=2.25$ (Table 28) for $\mathrm{Ca}(\text { Bistris })^{2+}$, whereas for $\mathrm{Ni}$ (Bistris) ${ }^{2+}$ only a modest 0.82 log unit results (see Table 29). This discrepancy has certainly to do with neglection of the basicity difference between $\mathrm{NH}_{3}$ and Bistris, which is not acceptable in the case of $\mathrm{Ni}^{2+}$ (section 5.3). Furthermore, it seems that the coordination sphere of $\mathrm{Ca}^{2+}$ allows a higher flexibility due to Coulombic ligand binding compared to $\mathrm{Ni}^{2+}$, as the latter prefers distinct directions for ligand atom coordination due to its d-orbitals.

\subsection{Complexes of Several 3d and Related Metal lons with} Bistris and Derivatives

In section 5.2 it has been shown that the formation degree of the chelated isomer is large for the $\mathrm{M}(\mathrm{AEtOH})^{2+}$ complexes, varying between about $70 \%$ for $\mathrm{Cd}(\mathrm{AEtOH})_{\mathrm{cl}}^{2+}$ and $100 \%$ for $\mathrm{Pb}(\mathrm{AEtOH})_{\mathrm{cl}}^{2+}($ Table 17). These formation degrees are reflected in the stability enhancements (eqs $11 \mathrm{a}$ and $11 \mathrm{~b}$ ), $\log \Delta_{\mathrm{Cd} / \mathrm{AEtOH}}=0.54$ and $\log \Delta_{\mathrm{Pb} / \mathrm{AEtOH}}=3.4$, those for the $\mathrm{M}(\mathrm{AEtOH})^{2+}$ complexes of $\mathrm{Mn}^{2+}, \mathrm{Co}^{2+}, \mathrm{Ni}^{2+}, \mathrm{Cu}^{2+}$, and $\mathrm{Zn}^{2+}$ are in between (Table 17).

Because these results for the $\mathrm{M}(\mathrm{AEtOH})^{2+}$ complexes are on solid ground, we listed the corresponding stability constants again in Table 29, together with the stability constants for the $\mathrm{M}\left(\mathrm{NH}_{3}\right)^{2+}, \mathrm{M}(\text { Tris })^{2+}, \mathrm{M}(\mathrm{TEA})^{2+}$, and $\mathrm{M}(\text { Bistris })^{2+}$ complexes (Figure 18) of $\mathrm{Mn}^{2+}, \mathrm{Co}^{2+}, \mathrm{Ni}^{2+}, \mathrm{Cu}^{2+}, \mathrm{Zn}^{2+}, \mathrm{Cd}^{2+}$, and $\mathrm{Pb}^{2+}$. These constants should allow useful comparisons and thus conclusions regarding the structures of these complexes.

The stability constants of the $\mathrm{M}(\text { Tris })^{2+}$ and $\mathrm{M}\left(\mathrm{NH}_{3}\right)^{2+}$ species in Table 29 are for the $\mathrm{Ni}^{2+}$ and $\mathrm{Cu}^{2+}$ complexes identical within their error limits. Because Tris is by $1.2 \mathrm{pK}$ units less basic than $\mathrm{NH}_{3}$, this must mean that the hydroxyl groups of Tris are involved in metal-ion binding. The same may be surmised for $\mathrm{Co}(\text { Tris })^{2+}$ and $\mathrm{Zn}$ (Tris) ${ }^{2+}$, which are only 0.36 and 0.37 log unit less stable than the corresponding ammonia complexes.

A more quantitative evaluation appears possible in the case of Tris by using the straight-line parameters listed in Table 16. These parameters hold for $\mathrm{RCH}_{2}-\mathrm{NH}_{2}$ ligands, a structural unit almost equaling the one of Tris, i.e., the $\mathrm{R}_{3} \mathrm{C}-\mathrm{NH}_{2}$ unit. Certainly, there is the possibility that a $\mathrm{R}_{3} \mathrm{C}$ residue hinders $\mathrm{M}^{2+}$ binding at the amino group more than a $\mathrm{RCH}_{2}$ residue, but the difference is not expected to be dramatic. More important, the stability constants calculated for the open isomer of $\mathrm{M}(\text { Tris })^{2+}$ will be an upper limit because a possible small inhibiting effect of the $\mathrm{R}_{3} \mathrm{C}$ group is ignored. This means that the values calculated for the formation degree of the species in which the hydroxyl groups are involved in $\mathrm{M}^{2+}$ coordination are lower limits, and thus, we cannot be misguided by the results.

Application of $\mathrm{p} K_{\mathrm{H} \text { (Tris) }}^{\mathrm{H}}=8.13$ to the straight-line parameters of Table 16 gives the stabilities of the open isomers of the $\mathrm{M}(\text { Tris })^{2+}$ species, that is, $\log K_{\mathrm{M} \text { (Tris) op }}^{\mathrm{M}}=0.00 \pm 0.20\left(\mathrm{Mn}^{2+}\right)$, $1.18 \pm 0.20\left(\mathrm{Co}^{2+}\right), 1.95 \pm 0.20\left(\mathrm{Ni}^{2+}\right), 2.90 \pm 0.25\left(\mathrm{Cu}^{2+}\right)$, $1.22 \pm 0.20\left(\mathrm{Zn}^{2+}\right), 1.61 \pm 0.20\left(\mathrm{Cd}^{2+}\right)$, and $0.31 \pm 0.30$ $\left(\mathrm{Pb}^{2+}\right)$. Together with the experimentally measured constants (Table 29, row 3), the stability enhancements due to hydroxyl group participation in the $\mathrm{M}(\mathrm{Tris})^{2+}$ complexes follow from these data according to eqs $11 \mathrm{a}$ and $11 \mathrm{~b}: \log \Delta_{\mathrm{M} / \text { Tris }}=\mathrm{ca} .0 .9 \pm$ $0.3\left(\mathrm{Mn}^{2+}\right.$; see footnote $b$ in Table 29), $0.55 \pm 0.20\left(\mathrm{Co}^{2+}\right), 0.79$ $\pm 0.20\left(\mathrm{Ni}^{2+}\right), 1.15 \pm 0.25\left(\mathrm{Cu}^{2+}\right), 0.72 \pm 0.20\left(\mathrm{Zn}^{2+}\right), 0.33 \pm$ $0.20\left(\mathrm{Cd}^{2+}\right)$, and ca. $2.4 \pm 0.4\left(\mathrm{~Pb}^{2+}\right.$; see footnote $b$ in Table 29). These stability enhancements are within their error limits nearly identical with the ones determined for the $\mathrm{M}(\mathrm{AEtOH})^{2+}$ complexes (see log $\Delta_{\mathrm{M} / \mathrm{AEtOH}}$ in Table 17). Of course, this also holds for the formation degrees of the chelated species, which reach for $\mathrm{M}$ (Tris) $)_{\mathrm{cl}}^{2+}$ the following percentages: 87 $\pm 9 \%\left(\mathrm{Mn}^{2+}\right), 72 \pm 13 \%\left(\mathrm{Co}^{2+}\right), 84 \pm 7 \%\left(\mathrm{Ni}^{2+}\right), 93 \pm 4 \%$ $\left(\mathrm{Cu}^{2+}\right), 81 \pm 9 \%\left(\mathrm{Zn}^{2+}\right), 53 \pm 22 \%\left(\mathrm{Cd}^{2+}\right)$, and $99.6 \pm 0.4 \%$ $\left(\mathrm{Pb}^{2+}\right)$. It is remarkable that the lowest formation degree for $\mathrm{M}(\text { Tris })_{\mathrm{cl}}^{2+}$ is reached with $\mathrm{Cd}^{2+}$ and the highest one with $\mathrm{Pb}^{2+}$, an observation already made for the $\mathrm{M}(\mathrm{AEtOH})_{\mathrm{cl}}^{2+}$ species (see above and Table 17). Overall, these results indicate that in aqueous solution to the largest part only one of the hydroxyl groups of Tris, aside from the amino group, is involved in metalion coordination.

This agrees with an X-ray study ${ }^{121}$ of $[\mathrm{Cu}($ Tris $-\mathrm{H})($ Tris $)] \mathrm{Br}$ in which one Tris has lost a proton (a reaction that occurs in the alkaline $\mathrm{pH}$ range) and two square-planar $\mathrm{Cu}(\mathrm{II})$ units are held together by two $\mathrm{H}$ bonds of the type $\mathrm{O}-\mathrm{H} \cdots \mathrm{O}$, which involve $\mathrm{O}$ atoms coordinated to the metal ions. Only one hydroxyl group of Tris (deprotonated or not) participates in $\mathrm{Cu}$ (II) binding; the distances are all in the range from 1.94 (O) to 2.02 (N/O) $\AA$. Similar results are found for the mononuclear $[\mathrm{Cu}($ Tris $\mathrm{H})($ Tris $\left.)\left(\mathrm{H}_{2} \mathrm{O}\right)\right] \mathrm{X}\left(\mathrm{X}=\mathrm{Cl}^{-}, \mathrm{Br}^{-}, \mathrm{I}^{-}\right)$species, ${ }^{122}$ which contain a distorted octahedral arrangement: The $\mathrm{Cu}-\mathrm{O}$ (water) distance is $2.37 \AA$, that of the second hydroxyl group of the deprotonated 
Tris amounts to $2.75 \AA$, and the distances in the basal $\mathrm{CuN}_{2} \mathrm{O}_{2}$ plane vary between $1.94(\mathrm{O})$ and $2.01 \AA(\mathrm{N} / \mathrm{O})$. Hence, again only one hydroxyl group of the Tris ligand actually coordinates. ${ }^{122}$ However, the simultaneous coordination of two hydroxyl groups is possible: ${ }^{123} \mathrm{The} \mathrm{Ni}(\mathrm{II})$ in the somewhat distorted octahedral arrangement in $\left[\mathrm{Ni}(\text { Tris })_{2}\right]\left(\mathrm{ClO}_{4}\right)_{2}$ is surrounded by two symmetry-related Tris with $\mathrm{Ni}-\mathrm{O}$ distances of 2.059 and $2.082 \AA$ and a $\mathrm{Ni}-\mathrm{N}$ one of $2.055 \AA$. Interestingly, in the mixed-ligand $\left[\mathrm{Zn}(\mathrm{Tris})_{2}(\mathrm{Sac})\right] \mathrm{Sac}$ complex (where Sac $=$ saccharinate, i.e., the anion of saccharine, a well-known artificial sweetener ${ }^{124}$ one Tris coordinates with one and the other with two hydroxyl groups: $\mathrm{Zn}$ (II) is in a distorted octahedron with a $\mathrm{Zn}-\mathrm{N}(\mathrm{Sac})$ distance of $2.098 \AA$, those with the Tris- $\mathrm{N}$ atoms being 2.049 and $2.063 \AA$, and the distances to the $\mathrm{O}$ atoms varying between 2.126 and $2.372 \AA$. Clearly, the solid state describes the maximal numbers of the hydroxyl group participations. In aqueous solution, this number is expected to be smaller and the interaction(s) will involve intramolecular equilibria.

For the $\mathrm{M}(\mathrm{TEA})^{2+}$ complexes of $\mathrm{Co}^{2+}, \mathrm{Ni}^{2+}, \mathrm{Cu}^{2+}, \mathrm{Zn}^{2+}$, and $\mathrm{Pb}^{2+}$ the evaluations in section 5.3 led to the conclusion that the hydroxyl groups of TEA participate in metal-ion binding in varying extents. This is confirmed by the solid state structures discussed in section 11.1: $\operatorname{In}\left[\mathrm{M}(\mathrm{TEA})_{2}\right]^{2+}$ species all four donor atoms of a TEA molecule may bind to $\mathrm{M}^{2+}$. Of course, for aqueous solutions it is again expected that part of the hydroxyl groups are released from the coordination sphere of $\mathrm{M}^{2+}$. However, that the hydroxyl group participation in aqueous solution is larger in the M(TEA $)^{2+}$ complexes than in those of $\mathrm{M}(\mathrm{Tris})^{2+}$ follows from a comparison of the stability constants given in Table 29: The constants for the M(TEA $)^{2+}$ complexes are either of the same size or larger than those of $\mathrm{M}(\text { Tris })^{2+}$, despite the lower basicity of TEA compared with that of Tris $\left(\Delta \mathrm{p} K_{\mathrm{a}}\right.$ ca. 0.3 ; Table 29, column 2$)$. The stability increase is again most remarkable for $\mathrm{Pb}(\mathrm{TEA})^{2+}$.

Hydroxyl group participation must be considerably more pronounced in the $\mathrm{M}(\text { Bistris })^{2+}$ complexes because those with $\mathrm{Ni}^{2+}, \mathrm{Cu}^{2+}, \mathrm{Zn}^{2+}$, and $\mathrm{Pb}^{2+}$ are $0.83,1.20,0.33$, and $0.93 \log$ units, respectively, more stable than their M(TEA) ${ }^{2+}$ counterparts, despite the significantly lower basicity of Bistris compared with TEA $\left(\Delta \mathrm{p} K_{\mathrm{a}}=1.13\right)$. The stabilities of the Bistris complexes of $\mathrm{Mn}^{2+}, \mathrm{Co}^{2+}$, or $\mathrm{Cd}^{2+}$ are approximately of the same size or larger than those of the Tris species. Since $\Delta \mathrm{p} K_{\mathrm{a}}=1.41$ in this case (Table 29), hydroxyl group participation must be more pronounced in the $\mathrm{M}(\text { Bistris })^{2+}$ than in the $\mathrm{M}(\text { Tris })^{2+}$ complexes, where the formation degrees of the closed species are already quite large as we have seen above. Unfortunately, an exact quantitative evaluation is not possible for the $\mathrm{M}(\text { Bistris })^{2+}$ complexes, but all qualitative comparisons evidence a significant involvement of the various hydroxyl groups (Figure 18) in metal-ion coordination of Bistris. For $\mathrm{Pb}$ (Bistris) $)^{2+}$ the stability enhancement due to the hydroxyl groups amounts to (more than) $3 \log$ units $\left(=\log \Delta_{\mathrm{Pb} / \mathrm{Bistris}}\right)$ as the crude comparison with the stability of the $\mathrm{Pb}\left(\mathrm{NH}_{3}\right)^{2+}$ complex shows (Table 29), not yet taking into account the basicity difference of $2.6 \mathrm{pK}$ units between the involved ligands. Indeed, the comparison with $\mathrm{Pb}(\mathrm{AEtOH})^{2+}$ indicates now a $\log \Delta_{\mathrm{Pb} / \text { Bistris }}$ value of about 4 (cf. the basicity difference and the $\log \Delta_{\mathrm{Pb} / \mathrm{AEtOH}}$ value in Table 17).

The fact that the hydroxyl groups of Bistris play an important role in metal-ion coordination is confirmed by the five following crystal structures with either $\mathrm{Co}^{2+}, \mathrm{Ni}^{2+}$, or $\mathrm{Cu}^{2+}:{ }^{125}$ In all instances, Bistris binds with five sites to $\mathrm{M}^{2+}$ in a distorted
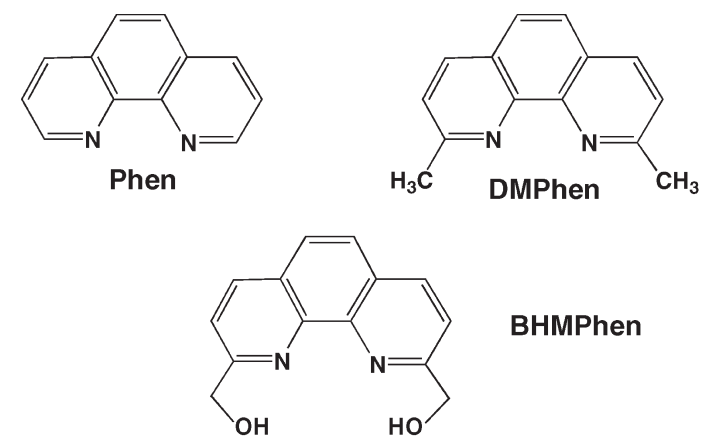

BHMPhen<smiles>CC(N)C(O)O</smiles>

Ala $^{-}$<smiles>NCc1ccccn1</smiles>

AMPy<smiles>CC(O)CNCC(C)O</smiles><smiles>O=C([O-])CN(CCN(CC(=O)[O-])CC(=O)O)CC(=O)[O-]</smiles>

Edta $^{4-}$
Figure 19. Chemical structures of some open-chain ligands containing hydroxyl groups next to primary binding sites, together with some related ligands: 1,10-phenanthroline (Phen), 2,9-dimethyl-1,10-phenanthroline (DMPhen), 2,9-bis(hydroxymethyl)-1,10-phenanthroline (BHMPhen), alaninate $\left(\mathrm{Ala}^{-}\right), \mathrm{N}, \mathrm{N}$-bis(2-hydroxyethyl)alanine (BHEAla ${ }^{-}$), o-(aminomethyl)pyridine (AMPy), 2-((bis(2-hydroxyethyl)amino)methylpyridine (BHEAMPy), di(2-hydroxypropyl)amine (DHPA), tri(2-hydroxypropylamine (THPA), and ethylenediamine$N, N, N^{\prime}, N^{\prime}$-tetraacetate $\left(\right.$ Edta $\left.^{4-}\right)$.

octahedral geometry and only one $\mathrm{CH}_{3} \mathrm{OH}$ group of the 2-hydroxymethyl-1,3-propanediol residue (see Tris, Figure 18) remains uncoordinated. In $\left[\mathrm{Ni}\right.$ (Bistris) $\left.\left(\mathrm{H}_{2} \mathrm{O}\right)\right] \mathrm{SO}_{4} \cdot \mathrm{H}_{2} \mathrm{O}$ and $\left[\mathrm{Cu}(\right.$ Bistris $\left.)\left(\mathrm{H}_{2} \mathrm{O}\right)\right] \mathrm{SO}_{4}$ the metal ions are ligated by four hydroxyl oxygen atoms, the nitrogen atom, and a water molecule. The complexes $[\mathrm{Ni}($ Bistris $)(\mathrm{Cl})] \mathrm{Cl} \cdot \mathrm{H}_{2} \mathrm{O}$ and $[\mathrm{Co}($ Bistris $)-(\mathrm{HCOO})](\mathrm{HCOO})$ contain the corresponding coordination sphere, but $\mathrm{H}_{2} \mathrm{O}$ is replaced by $\mathrm{Cl}^{-}$or $\mathrm{HCOO}^{-}$, respectively. ${ }^{125}$ The $[\mathrm{Cu}($ Bistris $)(\mathrm{Cl})] \mathrm{Cl}$ complex is best considered as being trigonal bipyrimidal because one $\mathrm{Cu}-\mathrm{O}$ (hydroxyl) bond is with $2.727 \AA$ very long whereas the distance of the five other atoms are between 1.915 and $2.307 \AA$. The bond lengths in two representative examples are as follows: (i) For $\left[\mathrm{Ni}(\right.$ Bistris $\left.)\left(\mathrm{H}_{2} \mathrm{O}\right)\right] \mathrm{SO}_{4}$ it holds 
Table 30. Logarithms of the Stability Constants for the 1:1 Complexes (eqs 4a and 4b) Formed between Several Divalent Metal Ions $\left(\mathrm{M}^{2+}\right)$ and Some Open-Chain (Figure 19) or Macrocyclic Ligands (Figure 20) (L) Bearing Next to N Sites also Hydroxyl Groups $^{a, b}$

\begin{tabular}{|c|c|c|c|c|c|c|c|c|c|c|c|}
\hline \multirow[b]{2}{*}{ no. } & \multirow[b]{2}{*}{$\mathrm{L}$} & \multirow[b]{2}{*}{$\mathrm{p} K_{\mathrm{H}(\mathrm{L})}^{\mathrm{H}}$} & \multicolumn{9}{|c|}{$\log K_{\mathrm{M}(\mathrm{L})}^{\mathrm{M}}$ for $\mathrm{M}^{2+}=$} \\
\hline & & & $\mathrm{Ba}^{2+}$ & $\mathrm{Sr}^{2+}$ & $\mathrm{Ca}^{2+}$ & $\mathrm{Mg}^{2+}$ & $\mathrm{Ni}^{2+}$ & $\mathrm{Cu}^{2+}$ & $\mathrm{Zn}^{2+}$ & $\mathrm{Cd}^{2+}$ & $\mathrm{Pb}^{2+}$ \\
\hline 1 & Phen & $4.92 \pm 0.05$ & $0.4 \pm 0.2$ & $0.7 \pm 0.1$ & $1.00 \pm 0.10$ & $1.48 \pm 0.07$ & 8.7 & $9.13 \pm 0.03$ & $6.38 \pm 0.08$ & $5.66 \pm 0.04$ & $4.62 \pm 0.06$ \\
\hline 2 & DMPhen & $5.83 \pm 0.04$ & & & & & 5.0 & 5.2 & 4.1 & 4.1 & \\
\hline 3 & BHMPhen & $4.70 \pm 0.01$ & $2.04 \pm 0.03$ & $2.46 \pm 0.03$ & $3.74 \pm 0.03$ & $1.70 \pm 0.02$ & $7.42 \pm 0.06$ & $7.56 \pm 0.03$ & $6.56 \pm 0.03$ & $7.49 \pm 0.03$ & $7.32 \pm 0.05$ \\
\hline 4 & $\mathrm{Ala}^{-}$ & $9.71 \pm 0.04$ & & & 0.80 & & $5.36 \pm 0.04$ & $8.11 \pm 0.07$ & $4.58 \pm 0.07$ & $3.98 \pm 0.02$ & 4.15 \\
\hline 5 & $\mathrm{BHEAla}^{-}$ & 8.47 & & & 2.26 & & 5.98 & 8.34 & 5.16 & 4.97 & 6.20 \\
\hline 6 & $\mathrm{AMPy}$ & 8.61 & & & $0.0^{c}$ & & 7.11 & 9.5 & 5.28 & & $3.95 \pm 0.05$ \\
\hline 7 & BHEAMPy & $6.92 \pm 0.01$ & & & $1.0 \pm 0.1$ & & $7.34 \pm 0.02$ & $9.2 \pm 0.1$ & $5.25 \pm 0.02$ & & $5.43 \pm 0.03$ \\
\hline 8 & DHPA & $8.86 \pm 0.01$ & & & & & $2.86 \pm 0.01$ & $4.58 \pm 0.02$ & & $2.31 \pm 0.02$ & $2.70 \pm 0.05$ \\
\hline 9 & THPA & $7.91 \pm 0.01$ & & & & & $3.46 \pm 0.01$ & $4.97 \pm 0.01$ & & $2.98 \pm 0.10^{d}$ & $3.62 \pm 0.01$ \\
\hline 10 & Edta $^{4-}$ & & 7.80 & 8.68 & 10.61 & 8.83 & & & $13.85 \pm 0.05$ & 14.58 & \\
\hline 11 & TACDD & & & & 3.1 & & & 23.3 & 16.2 & 14.3 & 15.9 \\
\hline 12 & HCHTACDD & & & & & & & & $13.85 \pm 0.05$ & $14.58 \pm 0.05$ & $11.40 \pm 0.05$ \\
\hline 13 & TKHPTACOD & & 3.74 & & 5.68 & & & 19.48 & 13.45 & 17.46 & 15.07 \\
\hline 14 & TODACOD & & 3.0 & & 1.7 & & & 6.1 & & 5.3 & 6.8 \\
\hline 15 & BHETODACOD & & 5.3 & & 4.1 & & & 6.6 & & 8.0 & 9.2 \\
\hline
\end{tabular}

${ }^{a}$ Data for some Edta ${ }^{4-}$ complexes are given for comparison, and the acidity constants (eqs $14 \mathrm{a}$ and $14 \mathrm{~b}$ ) for $\mathrm{H}(\mathrm{L})^{+}$species are listed only as far as needed. ${ }^{b} b$ The constants refer to aqueous solutions at (or close to) $25^{\circ} \mathrm{C}$ with $I$ at (or close to) $0.1 \mathrm{M}$. The data, including the error limits (as far as available), are from the following sources: entries 1 and 2 from ref 17, entry 3 from ref 116, entries 4 and 5 from ref $127,{ }^{17}$, entries 6 and 7 from ref 128 , entries 8 and 9 from ref 129 , entry 10 from ref $130,{ }^{17}$, entries 11 and $12^{130}$ and 13 from refs 130 and $131,{ }^{27}$ and entries 14 and 15 from ref $132 .{ }^{c}$ Estimate, see ref $128 .{ }^{d}$ In ref 129 in Table 1 the log stability constant $2.31 \pm 0.02$ (the same value as listed for Cd(DHPA) ${ }^{2+}$ is given for Cd(THPA) ${ }^{2+}$ ); this is evidently a typing error. In fact, from the straight-line plot in Figure 3 it follows a stability difference of $0.67 \log$ unit, and therefore, the value given above was correspondingly corrected; the error limit is an estimate.

$\mathrm{Ni}-\mathrm{O}($ water $)=1.985 \AA, \mathrm{Ni}-\mathrm{N}=2.053 \AA$, the remaining for $\mathrm{Ni}-\mathrm{O}$ bonds are between 2.073 and $2.087 \AA$. The fact that the $\mathrm{Ni}-\mathrm{O}$ (water) bond is the shortest one may indicate that the 5-fold coordination of Bistris is not strain-free. (ii) For $[\mathrm{Co}($ Bistris $)(\mathrm{HCOO})](\mathrm{HCOO})$ one finds $\mathrm{Co}-\mathrm{OOCH}=1.993 \AA$, $\mathrm{Co}-\mathrm{N}=2.130 \AA$, and for the four $\mathrm{Co}-\mathrm{O}$ (hydroxyl) bonds 2.105-2.131 $\AA^{125}$ Again, the monodentate ligand shows the shortest distance.

There is a further interesting X-ray structure ${ }^{126}$ of a Mn(III)-Bistris complex, $\left[\mathrm{Mn}(\right.$ Bistris-2H $\left.)\left(\mathrm{N}_{3}\right)\right]$, containing a 2-fold deprotonated Bistris. The $\mathrm{Mn}$ (III) ion is coordinated by the $\mathrm{NO}_{4}$ - pentadentate chelating $(\text { Bistris }-2 \mathrm{H})^{2-}$ ligand. As expected for a $\mathrm{d}^{4}$ ion in near-octahedral geometry, it exhibits Jahn-Teller distortion which occurs by elongation of the $\mathrm{O}-\mathrm{Mn}-\mathrm{O}$ axis $(2.208$ and $2.235 \AA$ ). The other distances are two short $\mathrm{Mn}-\mathrm{O}$ bonds (1.867 and $1.907 \AA$ ), the $\mathrm{Mn}-\mathrm{N}$ bond of $2.063 \AA$, and a further $\mathrm{Mn}-\mathrm{N}$ bond of $1.973 \AA$ involving the terminal $\mathrm{N}$ of the azide ion. ${ }^{126}$ Only highly polarizing metal ions like $\mathrm{Mn}(\mathrm{III})$ or $\mathrm{Cu}(\mathrm{II})$ (with Tris) are able to deprotonate $\mathrm{HO}-\mathrm{CH}_{2}$ groups via $\mathrm{M}-\mathrm{O}$ coordination. In fact, in aqueous solution this is expected to occur only at the upper end of the physiological $\mathrm{pH}$ range.

11.3. Quest for Selectivity in Metal-Ion Coordination Involving Hydroxyl Groups

To this end we consider first the open-chain ligands seen in Figure 19. The stability constants of the corresponding complexes are assembled in entries $1-9$ in Table $30.1^{17,27,116,127-132}$

We shall first compare the stability constants of the complexes formed with 2,9-bis(hydroxymethyl)-1,10-phenanthroline (BHMPhen) with those formed by 1,10-phenanthroline (Phen) itself as well as by its 2,9-dimethyl derivative (DMPhen). ${ }^{17,116}$ From the available data it is evident (Table 30) that the steric inhibition by methyl groups located ortho to the coordinating pyridine-type nitrogens is enormous, varying between about $1.6\left(\mathrm{Cd}^{2+}\right)$ and ca. $3.9 \log$ units $\left(\mathrm{Cu}^{2+}\right)$. With this in mind, it is revealing to consider the stabilities of the M(BHMPhen $)^{2+}$ complexes: Since the basicities of Phen and DMPhen are similar, we can directly compare the constants and see that in the case of $\mathrm{Ni}^{2+}$ and $\mathrm{Cu}^{2+}$ participation of the hydroxyl groups cannot fully compensate for the effect of the ortho substituents, whereas with $\mathrm{Zn}^{2+}$ matters are approximately balanced out. However, with $\mathrm{Cd}^{2+}$ and $\mathrm{Pb}^{2+}$ we observe stability enhancements of about 1.8 and $2.7 \mathrm{log}$ units, respectively, from $\mathrm{M}(\text { Phen })^{2+}$ to $\mathrm{M}(\mathrm{BHMPhen})^{2+}$. Of course, the true stability enhancement due to coordination of the hydroxyl groups follows from a comparison of the stabilities of the $\mathrm{M}(\mathrm{BHMPhen})^{2+}$ with the $M(D M P h e n)^{2+}$ species: Not all values are available, but for $\mathrm{Ni}^{2+}, \mathrm{Cu}^{2+}$, and $\mathrm{Zn}^{2+}$ the stability enhancements amount to about $2.4 \log$ units, indicating a strong coordination of the hydroxyl groups.

The largest stability enhancement of $3.4 \mathrm{log}$ units is observed for the $\mathrm{Cd}^{2+}$ complex (Table 30). Because BHMPhen is a highly symmetrical ligand preformed for metal-ion coordination, we may in a first approximation conclude that the stability enhance-

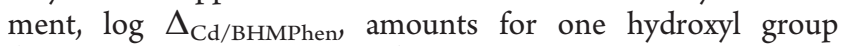
(ignoring any statistical effects) to about 1.7 log units. From this follows for aqueous solution a formation degree (eqs 11a-13) of $98 \%$ of the chelate involving one hydroxyl group, and the same is true also for the other side. This result is in excellent agreement with a recent X-ray structure ${ }^{133}$ of $\left[\mathrm{Cd}(\mathrm{BHMPhen})_{2}\right]\left(\mathrm{ClO}_{4}\right)_{2}$, in which $\mathrm{Cd}^{2+}$ is eight-coordinate with $\mathrm{Cd}-\mathrm{N}$ bonds that average $2.35 \AA$ and 
$\mathrm{Cd}-\mathrm{O}$ bonds averaging $2.50 \AA$, indicating tight binding of the two ligands.

From the constants listed in Table 30 it follows that for $\mathrm{Pb}$ (BHMPhen $)^{2+}$ at least the same formation degree for the chelated species must be assumed as given above for the $\mathrm{Cd}(\text { BHMPhen })^{2+}$ species. This agrees with a crystal structure analysis ${ }^{116}$ of $[\mathrm{Pb}$ (BHMPhen $\left.)\left(\mathrm{ClO}_{4}\right)_{2}\right] \cdot \mathrm{H}_{2} \mathrm{O}$, in which $\mathrm{Pb}^{2+}$ is eight coordinate: All four donor atoms of BHMPhen are bound; the average $\mathrm{Pb}-\mathrm{N}$ bonds amount to $2.486 \AA$, and the $\mathrm{Pb}-\mathrm{O}$ (hydroxyl) bonds to $2.617 \AA$ 的 the lone pair of $\mathrm{Pb}^{2+}$ seems to be positioned opposite to the $\mathrm{N}$ atoms. One of the perchlorate $\mathrm{O}$ donors is with $2.538 \AA$ relatively close to $\mathrm{Pb}^{2+}$; the other with $2.994 \AA$ further away; in addition, interactions occur with two neighboring perchlorates (2.708 and $3.026 \AA$ ).

There is also an X-ray structure of a $\mathrm{Ca}^{2+}$ complex in which two ligand molecules are coordinated, [ $\left.\mathrm{Ca}(\mathrm{BHMPhen})_{2}\right]$ $\left(\mathrm{ClO}_{4}\right)_{2} \cdot{ }^{116} \mathrm{Ca}^{2+}$ is eight-coordinate, with an average $\mathrm{Ca}-\mathrm{N}$ distance of $2.501 \AA$ and $\mathrm{Ca}-\mathrm{O}$ bonds of $2.422 \AA$. Note, here the oxygen bonds are shorter than the $\mathrm{N}$ ones, which agrees with the constants listed in Table 30. BHMPhen discriminates among the alkali earth ions and coordinates $\mathrm{Ca}^{2+}$ especially well, the stability enhancement, $\log \Delta_{\mathrm{Ca} / \mathrm{BH} M P h e n}$ due to one hydroxyl group being at least $1.5 \log$ units. Consequently, a formation degree of about $97 \%$ for the chelate on either side in aqueous solution is reached. Overall, it is evident that a ligand with a preorganized structure like BHMPhen, which locates the hydroxyl groups close to the metal ion, renders these hydroxyl groups to excellent binding sites.

A comparison of the stability constants of the $\mathrm{M}(\mathrm{Ala})^{+}$and $\mathrm{M}\left(\right.$ BHEAla $^{+}$complexes (Figure 19) shows, ${ }^{127}$ especially if one takes the different basicities of the ligands into account (Table 30), that the stability enhancement due to hydroxyethyl groups is most pronounced for $\mathrm{Pb}\left(\mathrm{BHEAla}^{+}\right.$, followed by $\mathrm{Ca}\left(\mathrm{BHEAla}^{+}\right.$and $\mathrm{Cd}\left(\mathrm{BHEAla}^{+}\right.$. Hence, hydroxyl group binding seems at least as pronounced as discussed for the $\mathrm{M}(\mathrm{TEA})^{2+}$ complexes in sections 5.3 and 11.2. For the ligands AMPy and BHEAMPy (Figure 19) and their complexes ${ }^{128}$ the situation is quite similar: The stability enhancement is again largest for the $\mathrm{Pb}\left(\right.$ BHEAMPy $^{2+}$ and $\mathrm{Ca}\left(\right.$ BHEAMPy) $^{2+}$ complexes. This also holds for the available data (Table 30) of the complexes formed with DHPA and THPA (Figure 19); ${ }^{129}$ the most pronounced stability enhancement is observed for the $\mathrm{Pb}(\mathrm{THPA})^{2+}$ complex.

From the foregoing it follows that the size of the cation and preorganization of a ligand, as concluded before, ${ }^{27,128-131}$ are important issues with regard to selectivity and discrimination between different metal ions. That this is quite a general phenomenon, which does not only hold for ligands containing hydroxyl groups, follows from entry 10 of Table 30: The $\mathrm{Ca}(\mathrm{Edta})^{2-}$ complex is by far the most stable one among the complexes formed with the alkaline earth ions. Of course, if the size of a metal ion does not fit well to the conditions dictated by the ligand, strain will be created. This is possibly seen in the crystal structure ${ }^{129}$ of $\left[\mathrm{Ni}\left(\mathrm{NH}_{2}-\mathrm{CH}_{2} \mathrm{CH}_{2}-\mathrm{NH}-\mathrm{CH}_{2} \mathrm{CH}_{2}-\mathrm{OH}\right)_{2}\right]\left(\mathrm{NO}_{3}\right)_{2}$. In this complex $\mathrm{Ni}^{2+}$ is hexacoordinate, with the two ligand molecules bound in a meridional manner. The average $\mathrm{Ni}-\mathrm{N}$ bond length is $2.08 \AA$, and that of the two $\mathrm{Ni}-\mathrm{O}$ bonds is $2.15 \AA$. Of course, at this point one could conclude that this result simply reflects the larger affinity of $\mathrm{Ni}^{2+}$ toward $\mathrm{N}$ donors, compared with $\mathrm{O}$ donors. However, one could also argue that in a strain-free situation the two bond lengths should be more similar; after all, in $\mathrm{Ni}\left(\mathrm{H}_{2} \mathrm{O}\right)_{6}^{2+}$ the $\mathrm{Ni}-\mathrm{O}$ distances amount to $2.06 \AA$ only. ${ }^{129}$
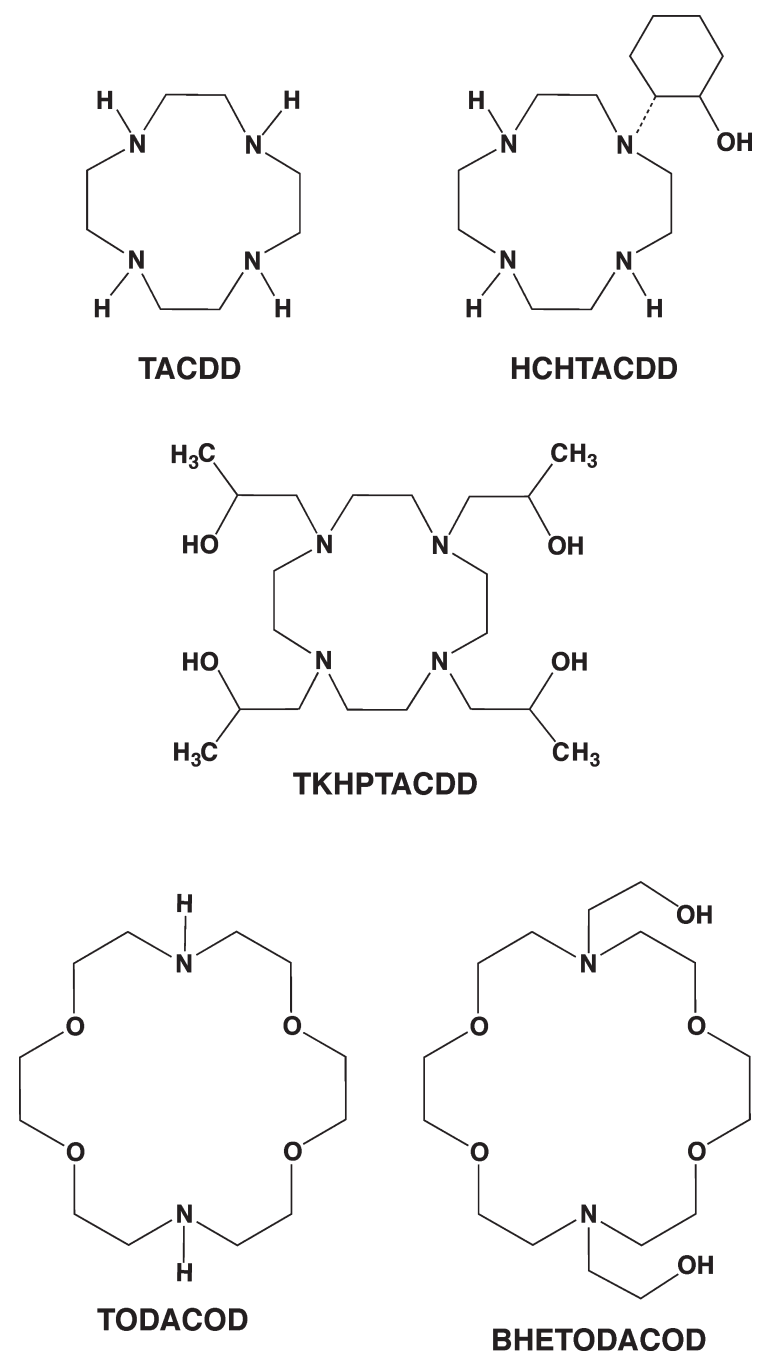

Figure 20. Chemical structures of some macrocycles, together with derivatives carrying hydroxyl groups: 1,4,7,10-tetraazacyclododecane (TACDD), 1-(2-hydroxycyclohexyl)-1,4,7,10-tetraazacyclododecane (HCHTACDD), 1,4,7,10-tetrakis(2-hydroxypropyl)-1,4,7,10-tetraazacyclododecane (TKHPTACDD), 1,4,10,13-tetraoxa-7,16-diazacyclooctadecane (TODACOD), and 7,16-bis(2-hydroxyethyl)-1,4,10,13-tetraoxa-7,16-diazacyclooctadecane (BHETODACOD).

In the design of ligands that lead to selectivity and to a (partial) preorganization of the potential binding sites, macrocycles have been employed for years. ${ }^{128-130}$ Therefore, in the remaining part of this section we shall shortly consider the ligands shown in Figure 20. The stability constants of the corresponding complexes, as far as they are known, are listed in entries $11-15$ of Table 30.

A comparison of the stability constants of the complexes formed with TACDD (cyclen) with those of HCHTACDD (Figure 20) ${ }^{130}$ shows for the three metal ions studied, $\mathrm{Zn}^{2+}, \mathrm{Cd}^{2+}$, and $\mathrm{Pb}^{2+}$, that the initial steric inhibition due to the cyclohexyl substituent is overcome only in the Cd(HCHTACDD $)^{2+}$ complex by coordination of the hydroxyl group. The corresponding $\mathrm{Zn}^{2+}$ and $\mathrm{Pb}^{2+}$ complexes are less stable than their $\mathrm{M}(\mathrm{TACDD})^{2+}$ species. It may be mentioned that in the crystal structure of $[\mathrm{Cu}(\mathrm{HCHTACDD})]\left(\mathrm{ClO}_{4}\right)_{2}$ $\mathrm{Cu}^{2+}$ is five-coordinate, being $0.47 \AA$ above the plane defined by the four $\mathrm{N}$ atoms (average of the $\mathrm{Cu}-\mathrm{N}$ distances 2.01(1) $\AA$ ), 
interacting in an average distance (there are two individual complexes in the unit cell) of 2.16(3) $\AA$ with the $\mathrm{O}$ of the 2-hydroxycyclohexyl residue. This indicates that in all these $\mathrm{M}(\mathrm{HCHTACDD})^{2+}$ complexes the hydroxyl group coordinates despite a reduced stability and that it helps to achieve selectivity.

The selectivity for $\mathrm{Cd}^{2+}$ coordination can be further promoted $^{131}$ by using TKHPTACDD (Figure 20) as a ligand, that is, cyclen having four 2-hydroxypropyl substituents at the ring nitrogens. $\mathrm{Cd}(\mathrm{TKHPTACDD})^{2+}$ is by $3.16 \mathrm{log}$ units more stable than the simple Cd(TACDD $)^{2+}$ complex; in contrast, in all other M(TKHPTACDD $)^{2+}$ species the stability is decreased, namely, with $\mathrm{Cu}^{2+}$ by 3.82 and with $\mathrm{Zn}^{2+}$ and $\mathrm{Pb}^{2+}$ by 2.75 and $0.83 \log$ units, respectively. Here it may be recalled that with simple ligands the stability enhancement due to hydroxyl group coordination is with $\mathrm{Cd}^{2+}$ only about one-half the size as with $\mathrm{Zn}^{2+}$ (section 9, point (iii)); now the situation is reverse.

The selectivity for $\mathrm{Pb}^{2+}$, which exists to a certain extent already in the macrocycle TODACOD (Table 30, row 14) containing in its ring $2 \mathrm{~N}$ and $4 \mathrm{O}$ atoms (Figure 20), can be further promoted by two 2-hydroxyethyl substituents at the $\mathrm{N}$ atoms. ${ }^{132} \mathrm{~Pb}(\mathrm{BHETODACOD})^{2+}$ is now by 1.2 and $2.6 \mathrm{log}$ units more stable (Table 30, row 15) than the analogous complexes with $\mathrm{Cd}^{2+}$ and $\mathrm{Cu}^{2+}$, respectively. Also, $\mathrm{Ba}^{2+}$ can be discriminated toward $\mathrm{Ca}^{2+}$ by $1.2 \mathrm{log}$ units using the same ligand. In this context it is interesting that the selectivity for $\mathrm{Ba}^{2+}$ can be further improved by forming an ethylene bridge between the two hydroxyethyl substituents, which leads then to the cryptand containing three 18-membered rings, each having two $\mathrm{N}$ and four $\mathrm{O}$ atoms as potential binding sites: Now the log stability constant of 9.5 for the $\mathrm{Ba}$ (cryptand) ${ }^{2+}$ complex is by 4.2 log units larger than that of the $\mathrm{Ca}^{2+}$ complex. ${ }^{132}$

These few examples demonstrate nicely how a combination of macrocycles and well-"localized" hydroxyl groups allow the design of ligands that favor especially large metal ions.

\section{GENERAL CONCLUSIONS}

Already in section 9 we have seen that for monodentate primary binding sites the intensity of the hydroxyl-metal-ion interaction increases with the decreasing charge present in the coordinating atom. This leads to very high formation degrees of the closed species; for example, for $o$-(hydroxymethyl)pyridine (HOMPy) formation degrees of ca. $92 \%$ and $99 \%$ are reached with $\mathrm{Mn}(\mathrm{HOMPy})_{\mathrm{cl}}^{2+}$ and $\mathrm{Zn}(\mathrm{HOMPy})_{\mathrm{cl}}^{2+}$, respectively (Table 22$)$. Of course, with 2,6-(dihydroxymethyl)pyridine, due to the presence of two hydroxyl groups, their participation in metal binding increases further (Table 22), but still, the percentages of the complexes in which one hydroxyl group is coordinated and two such groups are bound can be quantified (Table 23).

With regard to biological systems the observations made with hydroxyacetate $\left(\mathrm{HOAc}^{-}\right)$are certainly of more relevance. Despite the negatively charged carboxylate group, which constitutes the primary binding site, still formation degrees of $71 \%$, $75 \%$, and $91 \%$ are reached for $\mathrm{Mg}(\mathrm{HOAc})_{\mathrm{cl}}^{+}, \mathrm{Mn}(\mathrm{HOAc})_{\mathrm{cl}}^{+}$, and $\mathrm{Zn}(\mathrm{HOAc})_{\mathrm{cl}}^{+}$, respectively (Table 7$)$. A change from the formation of 5-membered to 6-membered chelates as they may occur with 3-hydroxypropanoate diminishes the hydroxylmetal-ion interaction very significantly (section 4.3; Table 12). On the other hand, a decreasing solvent polarity as it results from addition of 1,4-dioxane to an aqueous solution of the components favors the interaction (section 4.4); such a reduced solvent polarity is expected to occur in active site cavities of both enzymes ${ }^{42}$ and ribozymes. ${ }^{43}$ Quite generally, a hydroxyl group is superior to an ether oxygen when it comes to metal-ion binding.

Another observation of relevance for biological systems is the pronounced affinity of $\mathrm{Ca}^{2+}$ toward hydroxyl groups, compared to that of the other alkaline earth ions. This becomes especially evident from the $\mathrm{Ca}(\mathrm{HOAc})^{+}$(see section 4.1.2; Table 7) and the $\mathrm{Ca}(\mathrm{HOGly})^{+}$species (section 10; Table 27), which showed a large formation degree of the chelated species indicated in equilibrium 1 . Such a specific behavior of $\mathrm{Ca}^{2+}$ might be the decisive factor for the atypical strong influence of $\mathrm{Ca}^{2+}$ on group II intron ribozyme catalysis and folding, ${ }^{50,51,134}$ as well as, for example, the in vitro selection of a group I intron that is reactive in the presence of $\mathrm{Ca}^{2+}$ only. ${ }^{135}$

A further point that warrants emphasis is the observation that with $\mathrm{N}$-hydroxyethylglycinate $\left(\mathrm{HOGly}^{-}\right)$, which offers the bidentate glycinate-like unit as the primary binding site, participation of the hydroxyl group in metal-ion coordination increases dramatically, leading in general to formation degrees of above $99.5 \%$ for the $\mathrm{M}(\mathrm{HOGly})^{+}$species (section 10$)$. The reason for this observation is evidently the "rigidity" that results upon the glycinate-type binding; this brings the hydroxyl group close to the vicinity of the metal ion, and in addition, the movement of the hydroxyl group in space becomes restricted. This is in line with the above-mentioned observation that 5-membered chelates involving a hydroxyl group are more stable than 6-membered ones. With regard to biological systems, e.g., regarding ribozymes, this insight is important because one may easily imagine that a metal ion is orientated in a proper manner by initial binding, leading to an $-\mathrm{OH}$ interaction. Even more remarkable, such a "directed" hydroxyl-metal-ion interaction may give rise to a stability enhancement of 2 log units (see Table 27).

As one would expect, combination of a well-suited primary binding site with a large number of hydroxyl groups leads to a higher complex stability and increased selectivity. For example, some selectivity is already observed with the simple ligand 2-aminoethanol (section 5.2; Table 17), yet in ligands which contain the residue in a manifold manner like in triethanolamine (section 5.3) or in buffers like Tris or Bistris (see Figure 18) the selectivity toward $\mathrm{Ca}^{2+}$ (section 11.1 ) or $\mathrm{Pb}^{2+}$ (section 11.2) increases. Further selectivity can be achieved by using relatively rigid open-chain ligands, like 2,9-bis(hydroxymethyl)-1,10-phenanthroline (Figure 19), or by employing macrocycles as "primary binding sites". Their combination with hydroxyl groups allows, e.g., construction of a ligand selective for $\mathrm{Cd}^{2+}$, that is, its complexes with $\mathrm{Zn}^{2+}$ or $\mathrm{Pb}^{2+}$ are of lower stability (Table 30 ).

From the information collected from crystal structure studies one may in a first approximation conclude (ignoring strained ligands and their complexes) that the alkali earth ions bind more tightly to the oxygens of hydroxyl groups, compared to $\mathrm{N}$ binding sites, i.e., the $\mathrm{M}-\mathrm{O}$ bond distances are shorter than the $\mathrm{M}-\mathrm{N}$ ones. On the contrary, for the $3 \mathrm{~d}$ transition-metal ions like $\mathrm{Ni}^{2+}$ or $\mathrm{Cu}^{2+}$ as well as $\mathrm{Cd}^{2+}$, the $\mathrm{M}-\mathrm{N}$ distances are usually a bit shorter than the $\mathrm{M}-\mathrm{O}$ (hydroxyl) ones. A further point to be emphasized in the context of these "polyhydroxyl" ligands is the observation that a decreasing solvent polarity can enhance complex stability but also affect the selectivity, e.g., in the sense that a selectivity for $\mathrm{Ca}^{2+}$ turns into one for $\mathrm{Sr}^{2+}$ (section 11.1; Table 28). In any case, the summarized results indicate that in biosystems, like in the accumulation of sugar moieties as in RNA (or DNA) or in polysaccharides, due to distinct folding, high-affinity sites, e.g., for $\mathrm{Ca}^{2+}$, may be created; $\mathrm{Mg}^{2+}$ is less apt for this type of binding. 
On the other hand, one should also realize that already a small stability enhancement, $\log \Delta_{\mathrm{M} / \mathrm{PBS}-\mathrm{OH}}$ (eqs 11a and $11 b)$, may have dramatic effects. For example, an enhancement of only $0.1 \mathrm{log}$ unit gives rise to a formation degree of about $20 \%$ of the corresponding chelated species. In other words, one may create in this way a special structure, e.g., toward reactivity, by investing only about $0.6 \mathrm{~kJ} \mathrm{~mol}^{-1}$ in the change in free energy $\left(\Delta G^{0}\right) \cdot{ }^{25}$ One may recall in this context the following order: Stability enhancements of $0.1,0.3$, and $1 \log$ unit give rise to formation degrees of the chelated species of $20 \%, 50 \%$, and $90 \%$, and the $\left.\Delta G_{(25}^{0}{ }^{\circ} \mathrm{C}\right)$ values involved herewith correspond to $-0.57,-1.71$, and $-5.7 \mathrm{~kJ} \mathrm{~mol}^{-1}$, respectively. ${ }^{25}$

It is hoped that the presented results initiate searches for metal-ion-hydroxyl group interactions in proteins (serine), but especially in nucleic acids: In RNA, due to the presence of the $2^{\prime}$-OH of the ribosyl residue, hydroxyl groups occur in legions. These hydroxyl groups can be activated by metal ions leading to a metal-ion-activated breakdown of the RNA, which can be used to identify metal-ion binding sites within folded RNAs. ${ }^{136}$ Most relevant, in many ribozyme reactions the nucleophile, that is, the $2^{\prime}-\mathrm{OH}$ or $3^{\prime}-\mathrm{OH}$ of a specific ribose moiety, gets activated by metal-ion binding, as directly implicated by crystal structures of group I and II intron ribozymes. $11,137,138$

\section{AUTHOR INFORMATION}

\section{Corresponding Author}

*To whom correspondence should be addressed. R.K.O.S.: phone, ++41-44-635 4652; fax, ++41-44-6356802; e-mail, roland.sigel@aci.uzh.ch. H.S.: phone, ++41-61-267 1007; fax, ++41-61-2671017; e-mail, helmut.sigel@unibas.ch.

\section{Author Contributions \\ ${ }^{\S}$ Mostly done at the University of Zürich, Switzerland, during a visit from PAAET, Kuwait.}

\section{BIOGRAPHIES}

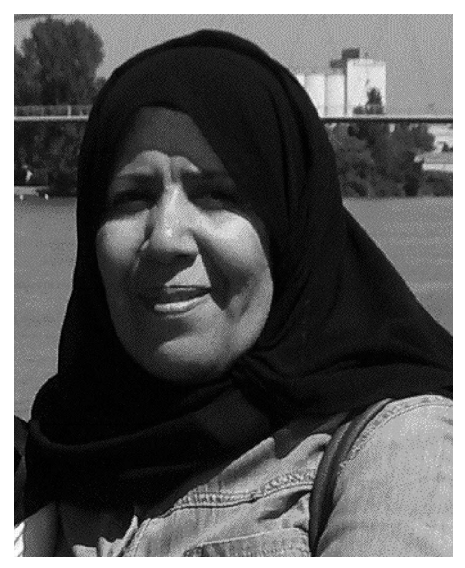

Fawzia M. Al-Sogair, born 1957 in Kuwait, graduated from the University of Kuwait with a B.SC. degree in Chemistry and Statics in 1979. She joined the research group of Professor S. ElEzaby at the same university, working on transition-metal complexes of biological ligands, in particular, vitamin $\mathrm{B}_{6}$, and received her Master's degree in 1983. Thereafter she worked with Professor Y. Sulfab at the University of Maunsora in Egypt, investigating the properties of copper(III) imine-oxime complexes in the presence of inorganic reducing agents, and obtained her Ph.D. degree in Chemistry in 1990. Afterward she joined the analytical geochemistry laboratories of SaudiAramco in Dhahran, Saudi Arabia, from where she transferred to the Medical School of the King Faisal University in Damam, Saudi Arabia, as an Assistant Professor. In 2005 she moved to her present position in the Science Department of the College of Basic Education, PAAET (Public Authority of Applied Education and Training), Kuwait. Her research interests focus on the preparation of metal-ion complexes of biological relevance, including determination of the stability constants of such complexes and examining their redox properties. She spent the summer of 2010 in the group of Professor Roland K. O. Sigel at the University of Zürich, working on the interaction of metal complexes with RNA.

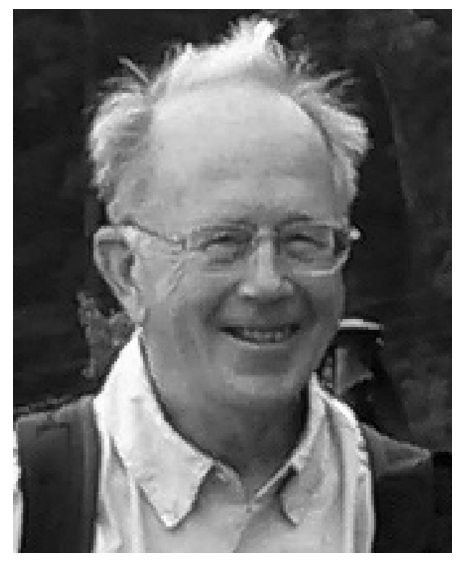

Bert P. Operschall graduated as a mechanical engineer from the Swiss Federal Institute of Technology, Zürich, Switzerland. He worked as a chemical engineer for Ciba Ltd., Ciba-Geigy Ltd., and Novartis Ltd. After retiring from industry he discovered his interest in Bioinorganic Chemistry and joined the research group of Professor Helmut Sigel at the University of Basel; he coauthored about 10 publications.

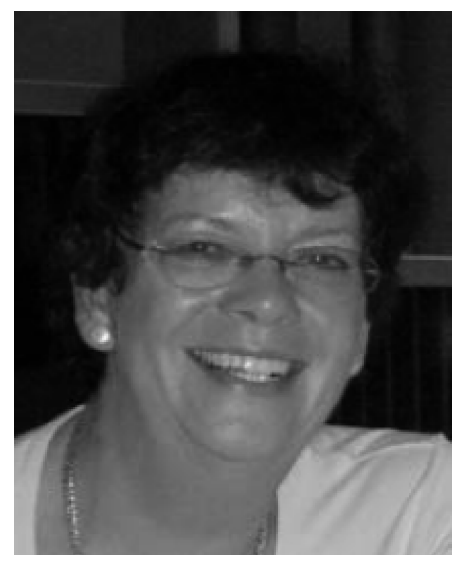

Astrid Sigel has studied languages, worked as secretary and technical assistant, and is an editor of the Metal Ions in Biological Systems series (until Volume 44) as well as of the Sigels' new series Metal Ions in Life Sciences (since 2006, now published by Springer, Volume 10 being in press). She also coedited the Handbooks on Toxicity of Inorganic Compounds (1988), on Metals in Clinical and Analytical Chemistry (1994; both with H. G. Seiler), and on Metalloproteins (2001; with Ivano Bertini) and coauthored several papers on topics in Bioinorganic Chemistry. 


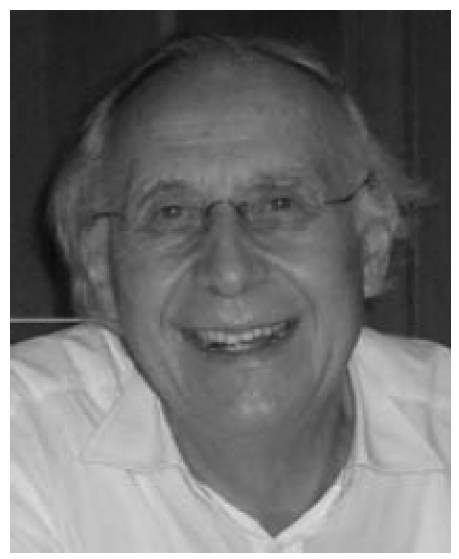

Helmut Sigel is Emeritus Professor (2003) at the University of Basel, Switzerland, with a long-standing interest in metal-ion complexes of nucleotides, coenzymes, and other ligands of biological relevance. $\mathrm{He}$ is a member of several chemical societies and serves on various editorial and advisory boards. Together with Astrid Sigel (University of Basel) and Roland K. O. Sigel (University of Zürich, Switzerland) he is an editor of the previous series Metal Ions in Biological Systems (1973-2005; 44 volumes) as well as of Sigels' new series Metal Ions in Life Sciences (since 2006); he is also a coeditor of three handbooks, has published over 300 articles, and has lectured worldwide. He was named Protagonist in Chemistry (2002) by ICA (issue 339); among further honors are the P. Ray Award (Indian Chemical Society, of which he is also an Honorary Fellow), the Werner Prize (Swiss Chemical Society), a Doctor of Science honoris causa degree (Kalyani University, India), appointments as Visiting Professor (e.g., Austria, China, Japan, Kuwait, United Kingdom), and Endowed Lectureships.

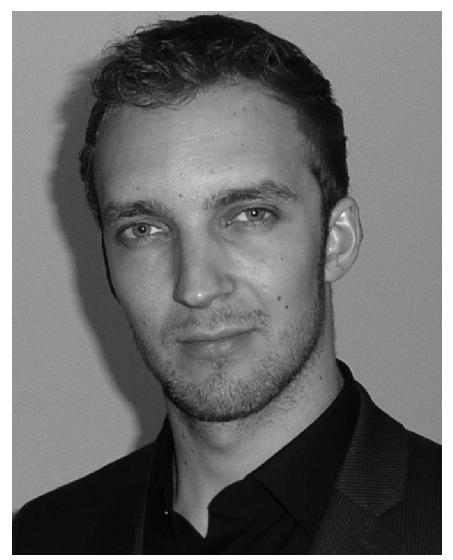

Joachim Schnabl was born in 1982 in Baden, Switzerland. In 2008 he graduated in Chemistry at the University of Zürich, Switzerland, completing his studies with a Diploma thesis under the supervision of Roland Sigel. He continued his work in Bioinorganic Chemistry as a Ph.D. student in Professor Sigel's group from summer 2008 until present. His research comprises investigations on the interactions of metallo-based cylinder molecules with RNA by NMR spectroscopy, X-ray crystallography, as well as other methods, a project that is part of the European COST D39 program.

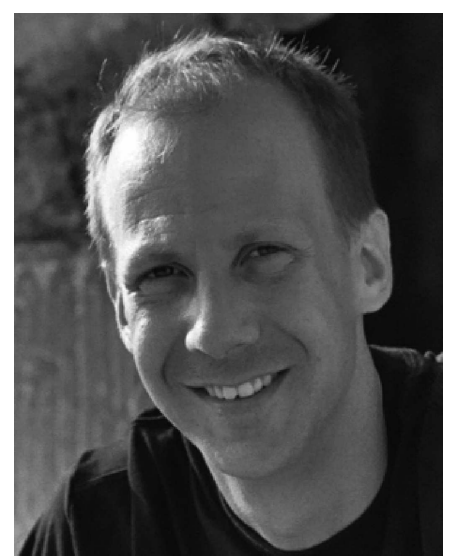

Roland K. O. Sigel is Associate Professor (2009) of Inorganic Chemistry at the University of Zürich, Switzerland. From 2003 to 2008 he was endowed with a Förderungsprofessur of the Swiss National Science Foundation and is a recipient of an ERC Starting Grant 2010. He received his doctoral degree summa cum laude (1999) from the University of Dortmund, Germany, working with Bernhard Lippert on the effect of platinum(II) coordination on the acid-base and hydrogen-bonding properties of nucleobases. Thereafter he spent nearly 3 years at Columbia University, New York, USA, with Anna Marie Pyle (now Yale University) studying ribozymes. During the 6 years abroad he received several fellowships from various sources, including a European TMR Fellowship and one from the Swiss Academy of Natural Sciences. He was awarded the EuroBIC Medal in 2008 and the Alfred Werner Prize (Swiss Chemical Society) in 2009. His research interests are in Bioinorganic Chemistry and focus on the structural and catalytic role of metal ions in ribozymes, especially group II introns, and on related topics by applying a broad combination of tools, including biochemical syntheses, stability-constant measurements, singlemolecule fluorescence, and NMR spectroscopy. He was also an editor of Volumes 43 and 44 of the Metal Ions in Biological Systems series and is coediting now the new series Metal Ions in Life Sciences.

\section{ACKNOWLEDGMENT}

Financial support by the Kuwait Foundation for the Advancement of Science, KFAS (grant 2010-1505-01 to F.M.A.-S.), the Swiss National Science Foundation (grants 200021-117999 and 200021-124834 to R.K.O.S.), the Swiss State Secretariat for Education and Research (COST D39) (to R.K.O.S.), the European Research Commission (ERC Starting Grant 2010 to R.K.O.S.), and the Universities of Basel (H.S.) and Zürich (R.K. O.S.) is gratefully acknowledged.

\section{ABBREVIATIONS AND DEFINITIONS}

See also figures containing structural formulas; for the macrocycles see Figure 20

$\begin{array}{ll}\mathrm{Aa}^{-} & \text {amino acetate } \\ \mathrm{ABu}^{-} & \text {2-aminobutanoate } \\ \mathrm{AcLys}{ }^{-} & \varepsilon \text { - } N \text {-acetyl-L-lysinate } \\ \mathrm{AEtOH} & \text { 2-aminoethanol } \\ \mathrm{AiPrOH} & \text { DL-1-amino-2-propanol } \\ \mathrm{AL} & \text { ligand with an amino group } \\ \mathrm{Ala}^{-} & \text {alaninate }\end{array}$




\begin{tabular}{|c|c|}
\hline AMPy & $o$-(aminomethyl)pyridine \\
\hline $\mathrm{APn}^{-}$ & 2-aminopentanoate $=$norvalinate \\
\hline $\mathrm{APrOH}$ & 3-aminopropanol \\
\hline $\mathrm{ATP}^{4-}$ & adenosine $5^{\prime}$-triphosphate \\
\hline$b$ & intercept of a straight line with the $y$ axis $\left(y_{0}\right)$ \\
\hline $\mathrm{BcS}^{-}$ & biocytinate $=\varepsilon-N$-d-biotinyl-L-lysinate \\
\hline $\mathrm{BcSO}^{-}$ & biocytinate sulfoxide \\
\hline $\mathrm{BcSO}_{2}^{-}$ & biocytinate sulfone \\
\hline $\mathrm{BHEAla}^{-}$ & $N, N$-bis(2-hydroxyethyl)alanine \\
\hline BHEAMPy & 2-((bis(2-hydroxyethyl)amino)methyl)pyridine \\
\hline BHMPhen & 2,9-bis(hydroxymethyl)-1,10-phenanthroline \\
\hline Bistris & $\begin{array}{l}\text { 2-[bis }(2 \text {-hydroxyethyl)amino]-2- } \\
\text { (hydroxymethyl)-1,3-propanediol }\end{array}$ \\
\hline Bistris $-2 \mathrm{H}$ & 2-fold deprotonated Bistris \\
\hline $\mathrm{CA}^{-}$ & carboxylate ligand \\
\hline calc & calculated (value) \\
\hline $\mathrm{CH}_{3} \mathrm{OAc}^{-}$ & methoxyacetate \\
\hline $\mathrm{cl}$ & closed (or chelated isomer) \\
\hline $\mathrm{DHAP}^{2-}$ & $\begin{array}{l}\text { dihydroxyacetone phosphate } \\
\left(\mathrm{HO}-\mathrm{CH}_{2}-\mathrm{C}(\mathrm{O})-\mathrm{CH}_{2}-\mathrm{O}-\mathrm{PO}_{3}^{2-}\right)\end{array}$ \\
\hline DHOEPy & $o$-[1-(1,2-dihydroxyethyl)] pyridine \\
\hline $\mathrm{DHPA}$ & di(2-hydroxypropyl)amine \\
\hline DMPhen & 2,9-dimethyl-1,10-phenenthroline \\
\hline DMPy & 2,6-dimethylpyridine \\
\hline Edta $^{4-}$ & ethylenediamine- $N, N, N^{\prime}, N^{\prime}$-tetraacetate \\
\hline $\mathrm{EtOAc}^{-}$ & ethoxyacetate \\
\hline $\exp$ & experimental (or measured value) \\
\hline $\mathrm{G}_{1} \mathrm{P}^{2-}$ & glycerol 1-phosphate \\
\hline $\mathrm{Gly}^{-}$ & glycinate \\
\hline $\mathrm{His}^{-}$ & histidinate \\
\hline $\mathrm{HMOP}^{2-}$ & hydroxymethyl phosphate \\
\hline $\mathrm{HMP}^{2-}$ & hydroxymethylphosphonate \\
\hline $\mathrm{HOAc}^{-}$ & hydroxyacetate $=$glycolate \\
\hline $4 \mathrm{HOBu}^{-}$ & 4hydroxybutanoate $\left(\mathrm{HO}-\mathrm{CH}_{2} \mathrm{CH}_{2} \mathrm{CH}_{2}-\mathrm{COO}^{-}\right)$ \\
\hline $\mathrm{HOCA}^{-}$ & hydroxy carboxylate \\
\hline HOEPy & $o$-[1-(1-hydroxyethyl) $]$ pyridine \\
\hline HOGly $^{-}$ & $N$-hydroxyethylglycinate \\
\hline HOMPy & $o$-(hydroxymethyl)pyridine \\
\hline$(\mathrm{HOM}) 2 \mathrm{Py}$ & 2,6-(dihydroxymethyl)pyridine \\
\hline $2 \mathrm{HOPr}^{-}$ & D-2-hydroxypropanoate $=$lactate \\
\hline $3 \mathrm{HOPr}^{-}$ & 3-hydroxypropanoate $\left(\mathrm{HO}-\mathrm{CH}_{2} \mathrm{CH}_{2}-\mathrm{COO}^{-}\right)$ \\
\hline I & ionic strength \\
\hline $\mathrm{Ida}^{2-}$ & iminodiacetate \\
\hline $\operatorname{Im} 2 \mathrm{Me}$ & 2-methylimidazole \\
\hline $\operatorname{Im} 2 \mathrm{OH}$ & 2-hydroxymethylimidazole \\
\hline $\mathrm{Im} 4 \mathrm{OH}$ & 4-hydroxymethylimidazole \\
\hline $\operatorname{ImD}$ & imidazole derivative \\
\hline $\mathrm{L}$ & general ligand \\
\hline $\mathrm{Leu}^{-}$ & leucinate \\
\hline$m$ & slope of a straight line \\
\hline $\mathrm{M}^{2+}$ & divalent metal ion \\
\hline MOMPy & $o$-(methoxymethyl)pyridine \\
\hline $\mathrm{OCA}^{-}$ & hydroxy carboxylate \\
\hline op & open (isomer) \\
\hline OPy & hydroxypyridine derivative \\
\hline PBS & primary binding site \\
\hline $\mathrm{PEE}^{2-}$ & (2-phosphonoethoxy)ethane \\
\hline & $\left(\mathrm{CH}_{3} \mathrm{CH}_{2}-\mathrm{O}-\mathrm{CH}_{2} \mathrm{CH}_{2}-\mathrm{PO}_{3}^{2-}\right)$ \\
\hline Phen & 1,10-phenanthroline \\
\hline $\mathrm{PME}^{2-}$ & (phosphonomethoxy)ethane \\
\hline & $\left(\mathrm{CH}_{3} \mathrm{CH}_{2}-\mathrm{O}-\mathrm{CH}_{2}-\mathrm{PO}_{3}^{2-}\right)$ \\
\hline $\mathrm{Pr}^{-}$ & propanoate \\
\hline
\end{tabular}

$\begin{array}{ll}\mathrm{pUpU}^{3-} & \text { uridylyl- }\left(5^{\prime} \rightarrow 3^{\prime}\right)-\left[5^{\prime}\right] \text { uridylate } \\ \mathrm{Py} & \text { pyridine } \\ \mathrm{PyD} & \text { pyridine derivative } \\ \mathrm{Sar}^{-} & \text {sarcosinate }=N \text {-methylglycinate } \\ \mathrm{SD} & \text { standard deviation } \\ \text { SI } & \text { steric inhibition } \\ \text { TEA } & \text { triethanolamine } \\ \text { THF2CA } & \text { tetrahydrofuran-2-carboxylate } \\ \text { THPA } & \text { tri(2-hydroxypropyl)amine } \\ \text { THT2CA } & \text { tetrahydrothiophen-2-carboxylate } \\ \text { tot } & \text { total (concentration) } \\ \text { Tris } & \text { 2-amino-2-(hydroxymethyl)-1,3-propanediol } \\ \text { Tris }-\mathrm{H}^{-} & \text {monodeprotonated Tris } \\ \text { Val }^{-} & \text {valinate } \\ \mathrm{XCA}^{-} & \text {THF2CA } \\ \end{array}$

\section{REFERENCES}

(1) Sigel, R. K. O.; Sigel, H. Met. Ions Life Sci. 2007, 2, 109.

(2) Pezzano, H.; Podo, F. Chem. Rev. 1980, 80, 365.

(3) Lang, J.; Chmelová, K.; Štepánek, J.; Kowalewski, J.; Holý, A. J. Mol. Struct. 1999, 480-481, 363.

(4) Reinert, H.; Weiss, R. Hoppe-Seylers Z. Physiol. Chem. 1969, 350, 1321.

(5) Chao, Y. Y. H.; Kearns, D. R. J. Am. Chem. Soc. 1977, 99, 6425.

(6) Yano, S.; Otsuka, M. Met. Ions Biol. Syst. 1996, 32, 27.

(7) Sigel, H. In Coordination Chemistry-20; Banerjea, D., Ed.; IUPAC, Pergamon Press: Oxford, 1980; p 27.

(8) Sigel, H. Coord. Chem. Rev. 1990, 100, 453.

(9) Al-Sogair, F.; Marafie, H. M.; Shuaib, N. M.; Ben Youngo, H.; El-Ezaby, M. S. Int. J. Chem. Kin. 2006, 38, 540.

(10) Johannsen, S.; Megger, N.; Böhme, D.; Sigel, R. K. O.; Müller, J. Nat. Chem. 2010, 2, 229.

(11) Toor, N.; Rajashankar, K.; Keating, K. S.; Pyle, A. M. Nat. Struct. Mol. Biol. 2008, 15, 1221.

(12) Forconi, M.; Sengupta, R. N.; Liu, M. C.; Sartorelli, A. C.; Piccirilli, J. A.; Herschlag, D. Angew. Chem., Int. Ed. 2009, 48, 7171.

(13) Sigel, R. K. O. Eur. J. Inorg. Chem. 2005, 12, 2281.

(14) Sigel, R. K. O.; Pyle, A. M. Chem. Rev. 2007, 107, 97.

(15) Sigel, R. K. O.; Sigel, H. Acc. Chem. Res. 2010, 43, 974.

(16) Schnabl, J.; Sigel, R. K. O. Curr. Opin. Chem. Biol. 2010, 14, 269.

(17) NIST Critically Selected Stability Constants of Metal Complexes, Reference Database 46, Version 8.0; data collected and selected by Smith, R. M., Martell, A. E.; U.S. Department of Commerce, National Institute of Standards and Technology: Gaithersburg, MD, 2004.

(18) IUPAC Stability Constants Database, Release 6, Version 5.83; compiled by Pettit, L. D., Powell, H. K. J. (pettit@acadsoft.co.uk); Academic Software: Timble, Otley, West Yorkshire, U.K., 2008; see also: Pettit, L. D.; Pettit, G. Pure Appl. Chem. 2009, 81, 1585.

(19) Mariam, Y. H.; Martin, R. B. Inorg. Chim. Acta 1979, 35, 23.

(20) Orenberg, J. B.; Fischer, B. E.; Sigel, H. J. Inorg. Nucl. Chem. 1980, 42, 785.

(21) Sigel, H.; Scheller, K. H.; Rheinberger, V. M.; Fischer, B. E. J. Chem, Soc., Dalton Trans. 1980, 1022.

(22) Fischer, B. E.; Sigel, H. J. Am. Chem. Soc. 1980, 102, 2998.

(23) Scheller, K. H.; Hofstetter, F.; Mitchell, P. R.; Prijs, B.; Sigel, H. J. Am. Chem. Soc. 1981, 103, 247.

(24) Martin, R. B.; Sigel, H. Comments Inorg. Chem. 1988, 6, 285.

(25) Sigel, H.; Kapinos, L. E. Coord. Chem. Rev. 2000, 200-202, 563.

(26) (a) Knobloch, B.; Sigel, H.; Okruszek, A.; Sigel, R. K. O. Chem.-Eur. J. 2007, 13, 1804. (b) Mucha, A.; Knobloch, B.; Jeżowska-Bojczuk, M.; Kozłowski, H.; Sigel, R. K. O. Chem.-Eur. J. 2008, 14, 6663.(c) Knobloch, B; Mucha, A; Operschall, B. P.; Sigel, H.; Jeżowska-Bojczuk, M.; Kozłowski, H.; Sigel, R. K. O. Chem.-Eur. J. 2011, 17, 5393. 
(27) Hancock, R. D.; Maumela, H.; de Sousa, A. S. Coord. Chem. Rev. 1996, 148, 315 .

(28) Massoud, S. S.; Sigel, H. Inorg. Chem. 1988, 27, 1447.

(29) Sigel, H.; Chen, D.; Corfü, N. A.; Greğán, F.; Holý, A.; Strašák, M. Helv. Chim. Acta 1992, 75, 2634.

(30) Chen, D.; Greğán, F.; Holý, A.; Sigel, H. Inorg. Chem. 1993, 32, 5377.

(31) Sigel, H.; Song, B. Met. Ions Biol. Syst. 1996, 32, 135.

(32) Rawn, J. D. Biochemistry; N. Patterson Publ.: Burlington, NC, 1989; pp 1040.

(33) Berg, J. M.; Tymoczko, J. L.; Stryer, L. Biochemistry, 6th ed.; Freeman: New York, 2006, pp 527.

(34) Nishihara, M.; Yamazaki, T.; Oshima, T.; Koga, Y. J. Bacteriol. 1999, 181, 1330.

(35) (a) Hall, D. R.; Leonard, G. A.; Reed, C. D.; Watt, C. I.; Berry, A.; Hunter, W. N. J. Mol. Biol. 1999, 287, 383-394. (b) Cooper, S. J.; Leonard, G. A.; McSweeney, S. M.; Thompson, A. W.; Naismith, J. H.; Qamar, S.; Plater, A.; Berry, A.; Hunter, W. N. Structure 1996, 4, 1303.

(36) (a) Idahl, L.-Å.; Lembert, N. Biochem. J. 1995, 312, 287-292.

(b) Civelek, V. N.; Deeney, J. T.; Shalosky, N. J.; Tornheim, K.; Hansford, R. G.; Prentki, M.; Corkey, B. E. Biochem. J. 1996, 318, 615.

(37) Kneer, N.; Lardy, H. Arch. Biochem. Biophys. 2000, 375, 145.

(38) Liang, G.; Chen, D.; Bastian, M.; Sigel, H. J. Am. Chem. Soc. 1992, 114, 7780 .

(39) Schwarzenbach, G.; Anderegg, G. Helv. Chim. Acta 1957, 40, 1229.

(40) Bastian, M.; Chen, D.; Greğán, F.; Liang, G.; Sigel, H. Z. Naturforsch. Teil B 1993, 48, 1279.

(41) (a) Rees, D. C. J. Mol. Biol. 1980, 141, 323-326. (b) Moore, G. R. FEBS Lett. 1983, 161, 171. (c) Rogers, N. K.; Moore, G. R.; Sternberg, M. J. E. J. Mol. Biol. 1985, 182, 613. (d) Harvey, S. C. Proteins Struct. Funct. Genet. 1989, 5, 78. (e) Iversen, G.; Kharkats, Y. I.; Ulstrup, J. J. Mol. Phys. 1998, 94, 297.

(42) (a) Sigel, H.; Martin, R. B.; Tribolet, R.; Häring, U. K.; MaliniBalakrishnan, R. Eur. J. Biochem. 1985, 152, 187. See also the comments in the footnote on page 258 in ref.(b) Bastian, M.; Sigel, H. Inorg. Chim. Acta 1990, 178, 249.

(43) Furler, M.; Knobloch, B.; Sigel, R. K. O. Inorg. Chim. Acta 2009, $362,771$.

(44) (a) Åkerlöf, G.; Short, O. A. J. Am. Chem. Soc. 1936, 58, 1241. (b) Critchfield, F. E.; Gibson, J. A., Jr.; Hall, J. L. J. Am. Chem. Soc. 1953, 75, 1991. (c) Åkerlöf, G.; Short, O. A. J. Am. Chem. Soc. 1953, 75, 6357.

(45) Blindauer, C. A.; Holý, A.; Sigel, H. Collect. Czech. Chem. Commun. 1999, 64, 613.

(46) Fernández-Botello, A.; Operschall, B. P.; Holý, A.; Moreno, V.; Sigel, H. Dalton Trans. 2010, 39, 6344.

(47) Fernández-Botello, A.; Griesser, R.; Holý, A.; Moreno, V.; Sigel, H. Inorg. Chem. 2005, 44, 5104-5117.

(48) Bastian, M.; Sigel, H. Inorg. Chim. Acta 1990, 178, 249.

(49) Liang, G.; Tribolet, R.; Sigel, H. Inorg. Chem. 1988, $27,2877$.

(50) Erat, M. C.; Sigel, R. K. O. J. Biol. Inorg. Chem. 2008, 13, 1025.

(51) Steiner, M.; Rueda, D.; Sigel, R. K. O. Angew. Chem., Int. Ed. 2009, 48, 9739.

(52) In Handbook on Metalloproteins; Bertini, I., Sigel, A., Sigel, H., Eds.; Marcel Dekker Inc.: New York, 2001.

(53) Filipović, I.; Matusinović, T.; Mayer, B.; Piljac, I.; BachDragutinović, B.; Bujak, A. Croat. Chem. Acta 1970, 42, 541.

(54) In Metal Ions in Life Sciences; Sigel, A., Sigel, H., Sigel, R. K. O., Eds.; Royal Society of Chemistry: Cambridge, U.K., 2011; Vol. 8 (Metal Ions in Toxicology. Effects, Interactions, Interdependencies).

(55) Filipović, I.; Piljac, I.; Medved, A.; Savić, S.; Bujak, A.; BachDragutinović, B.; Mayer, B. Croat. Chem. Acta 1968, 40, 131.

(56) Sigel, H.; Griesser, R.; Prijs, B.; McCormick, D. B.; Joiner, M. G. Arch. Biochem. Biophys. 1969, 130, 514.

(57) Malini-Balakrishnan, R.; Scheller, K. H.; Häring, U. K.; Tribolet, R.; Sigel, H. Inorg. Chem. 1985, 24, 2067.

(58) Griesser, R.; Prijs, B.; Sigel, H. Inorg. Nucl. Chem. Lett. 1968, $4,443$.
(59) Sigel, R. K. O.; Song, B.; Sigel, H. J. Am. Chem. Soc. 1997, 119, 744.

(60) Da Costa, C. P.; Okruszek, A.; Sigel, H. ChemBioChem. 2003, 4, 593.

(61) Knobloch, B.; Nawrot, B.; Okruszek, A.; Sigel, R. K. O. Chem.Eur. J. 2008, 14, 3100.

(62) Erat, M. C.; Sigel, R. K. O. Met. Ions Life Sci. 2011, 9, 37.

(63) Freisinger, E.; Sigel, R. K. O. Coord. Chem. Rev. 2007, 251, 1834.

(64) Djurdjevic, P.; Bjerrum, J. Acta Chem. Scand. 1983, A37, 881.

(65) Martin, R. B. Met. Ions Biol. Syst. 1986, 20, 21.

(66) (a) Martin, R. B. In Encyclopedia of Molecular Biology and Molecular Medicine; Meyers, R. A., Ed.; VCH: Weinheim, 1996; Vol. 1, pp 125-134. (b) Martin, R. B. In Molecular Biology and Biotechnology; Meyers, R. A., Ed.; VCH Publishers: New York, 1995; p 83.

(67) Sigel, H.; Da Costa, C. P.; Martin, R. B. Coord. Chem. Rev. 2001, 219-221, 435.

(68) Hancock, R. D.; Nakani, B. S. J. Coord. Chem. 1984, 13, 309.

(69) Martin, R. B. Met. Ions Biol. Syst. 1979, 9, 1.

(70) Kapinos, L. E.; Sigel, H. Inorg. Chim. Acta 2002, 337, 131 (issue in honor of Wieghardt, K. E.).

(71) Kapinos, L. E.; Song, B.; Sigel, H. Inorg. Chim. Acta 1998, 280, 50 (issue in honor of Vol'pin, M. E.).

(72) Kapinos, L. E.; Song, B.; Sigel, H. Chem.—Eur. J. 1999, 5, 1794.

(73) Rorabacher, D. B.; Melendez-Cepeda, C. A. J. Am. Chem. Soc. 1971, 93, 6071 .

(74) Hancock, R. D. Inorg. Chim. Acta 1981, 49, 145.

(75) (a) Tauler, R.; Casassas, E.; Rode, B. M. Inorg. Chim. Acta 1986, 114, 203. (b) Casassas, E.; Gustems, L’o L.; Tauler, R. J. Chem. Soc., Dalton Trans. 1989, 569.

(76) Knobloch, B.; Suliga, D.; Okruszek, A.; Sigel, R. K. O. Chem.Eur. J. 2005, 11, 4163.

(77) Sigel, H.; Scheller, K. H.; Prijs, B. Inorg. Chim. Acta 1982, 66, 147.

(78) Banerjea, D.; Kaden, T. A.; Sigel, H. Inorg. Chem. 1981, 20, 2586.

(79) (a) Pinart, J.; Petitfaux, C.; Faucherre, J. Bull. Soc. Chim. Fr. 1972, 4534. (b) Colin, J.-L.; Pinart, J. Bull. Soc. Chim. Fr. 1974, 2756. (c) Colin, J.-L.; Pinart, J.; Faucherre, J. Bull. Soc. Chim. Fr. 1976, 399.

(80) (a) Irving, H. M.; Williams, R. J. P. Nature 1948, 162, 746. (b) Irving, H. M.; Williams, R. J. P. J. Chem. Soc. 1953, 3192.

(81) Sigel, H.; McCormick, D. B. Acc. Chem. Res. 1970, 3, 201.

(82) Sigel, H.; Martin, R. B. Chem. Rev. 1982, 82, 385.

(83) Sigel, H.; Massoud, S. S.; Tribolet, R. J. Am. Chem. Soc. 1988, 110, 6857.

(84) Sigel, H. Coord. Chem. Rev. 1995, 144, 287.

(85) Sigel, H. Pure Appl. Chem. 1999, 71, 1727.

(86) Babu, C. S.; Lim, C. J. Am. Chem. Soc. 2010, 132, 6290.

(87) (a) Griesser, R.; Sigel, H. Inorg. Chem. 1970, 9, 1238. (b) Griesser, R.; Sigel, H. Inorg. Chem. 1971, 10, 2229.

(88) (a) Sigel, H.; McCormick, D. B. J. Am. Chem. Soc. 1971, 93, 2041. (b) Huber, P. R.; Griesser, R.; Prijs, B.; Sigel, H. Eur. J. Biochem. 1969, 10, 238.

(89) Sigel, H. Met. Ions Biol. Syst. 1973, 2, 63.

(90) Sigel, H.; Fischer, B. E.; Prijs, B. J. Am. Chem. Soc. 1977, 99, 4489.

(91) Fischer, B. E.; Sigel, H. Inorg. Chem. 1979, 18, 425.

(92) Huber, P. R.; Griesser, R.; Sigel, H. Inorg. Chem. 1971, 10, 945.

(93) Sigel, H. Inorg. Chem. 1980, 19, 1411.

(94) Biswas, B.; Salunke-Gawali, S.; Weyhermüller, T.; Bachler, V.; Bill, E.; Chaudhuri, P. Inorg. Chem. 2010, 49, 626.

(95) Erat, M. C.; Kovacs, H.; Sigel, R. K. O. J. Inorg. Biochem. 2010, 104, 611.

(96) Szilágyi, I.; Pál, E.; Horváth, L.; Labádi, I. Magyar Kémiai Folyóirat, Kemiai Közlemények 2005, 111, 83.

(97) Labádi, I.; Pál, E.; Horváth, L.; Szilágyi, I. In Advances in Coordination, Bioinorganic and Inorganic Chemistry; Melník, M., Šima,

J., Tatorko, M., Eds.; Slovak Technical University Press: Bratislava, 2005; p 156.

(98) Griesser, R.; Prijs, B.; Sigel, H.; Föry, W.; Wright, L. D.; McCormick, D. B. Biochemistry 1970, 9, 3285. 
(99) Liang, G.; Tribolet, R; Sigel, H. Inorg. Chim. Acta 1989, 155, 273.

(100) Sóvágó, I.; Kiss, T.; Gergely, A. Pure Appl. Chem. 1993, 65, 1029.

(101) Childs, C. W.; Perrin, D. D. J. Chem. Soc. (A) 1969, 1039.

(102) El-Ezaby, M. S.; Marafie, H. M.; Fareed, S. J. Inorg. Biochem. 1979, 11, 317.

(103) Sigel, H.; Fischer, B. E.; Farkas, E. Inorg. Chem. 1983, 22, 925.

(104) Datta, S. P.; Leberman, R.; Rabin, B. R. Trans. Faraday Soc. 1959, 55, 1982.

(105) Israeli, M.; Pettit, L. D. J. Inorg. Nucl. Chem. 1975, 37, 999.

(106) Anderegg, G.; Arnaud-Neu, F.; Delgado, R.; Felcman, J.; Popov, K. Pure Appl. Chem. 2005, 77, 1445.

(107) Corfu, N. A.; Song, B.; Ji, L.-n. Inorg. Chim. Acta 1992, 192, 243.

(108) Sigel, H. Coord. Chem. Rev. 1993, 122, 227.

(109) Scheller, K. H.; Abel, T. H. J.; Polanyi, P. E.; Wenk, P. K.; Fischer, B. E.; Sigel, H. Eur. J. Biochem. 1980, 107, 455.

(110) (a) Gray, R. D.; Gibson, Q. H. J. Biol. Chem. 1971, 246, 7168.

(b) MacQuarrie, R.; Gibson, Q. H. J. Biol. Chem. 1972, 247, 5686.

(111) Gillard, B. K.; Nelson, T. E. Biochemistry 1977, 16, 3978.

(112) Champeil, P.; Menguy, T.; Soulie, S.; Juul, B.; Gomez de Gracia, A.; Rusconi, F.; Falson, P.; Denoroy, L.; Henao, F.; Le Maire, M.; Møller, J. V. J. Biol. Chem. 1998, 273, 6619.

(113) Montigny, C.; Champeil, P. Anal. Biochem. 2007, 366, 96.

(114) Leverrier, P.; Montigny, C.; Garrigos, M.; Champeil, P. Anal. Biochem. 2007, 371, 215.

(115) Fischer, B. E.; Häring, U. K.; Tribolet, R.; Sigel, H. Eur. J. Biochem. 1979, 94, 523.

(116) Gephart, R. T., III; Williams, N. J.; Reibenspies, J. H.; De Sousa, A. S.; Hancock, R. D. Inorg. Chem. 2008, 47, 10342.

(117) Paabo, M.; Bates, R. G.; Robinson, R. A. J. Phys. Chem. 1966, 70, 247.

(118) Sigel, H. Chimia 1967, 21, 489.

(119) Voegele, J. C.; Fischer, J.; Weiss, R. Acta Crystallogr. 1974, B30, 66 .

(120) Voegele, J. C.; Thierry, J. C.; Weiss, R. Acta Crystallogr. 1974, B30, 70 .

(121) Masi, D.; Mealli, C.; Sabat, M.; Sabatini, A.; Vacca, A.; Zanobini, F. Helv. Chim. Acta 1984, 67, 1818.

(122) Kotila, S. Acta Chem. Scand. 1994, 48, 742.

(123) Ivarsson, G. J. M. Acta Crystallogr. 1982, B38, 1828.

(124) Heren, Z.; Paşaoğlu, H.; Kaştaş, G.; Akdağ, K. Z. Anorg. Allg. Chem. 2008, 634, 1933.

(125) Inomata, Y.; Gochou, Y.; Nogami, M.; Howell, F. S.; Takeuchi,

T. J. Mol. Struct. 2004, 702, 61 .

(126) Stamatatos, T. C.; Abboud, K. A.; Christou, G. Dalton Trans. 2009, 41.

(127) Hancock, R. D.; Bhavan, R.; Wade, P. W.; Boeyens, J. C. A.; Dobson, S. M. Inorg. Chem. 1989, 28, 187.

(128) Damu, K. V.; Shaikjee, M. S.; Michael, J. P.; Howard, A. S.; Hancock, R. D. Inorg. Chem. 1986, 25, 3879.

(129) Wade, P. W.; Hancock, R. D. Inorg. Chim. Acta 1987, 130, 251.

(130) De Sousa, A. S.; Hancock, R. D.; Reibenspies, J. H. J. Chem. Soc., Dalton Trans. 1997, 939.

(131) Hancock, R. D. Pure Appl. Chem. 1993, 65, 941.

(132) Damu, K. V.; Hancock, R. D.; Wade, P. W.; Boeyens, J. C. A.; Billing, D. G.; Dobson, S. M. J. Chem. Soc., Dalton Trans. 1991, 293.

(133) Gephart, R. T., III; Williams, N. J.; Reibenspies, J. H.; De Sousa, A. S.; Hancock, R. D. Inorg. Chem. 2009, 48, 8201.

(134) Steiner, M.; Karunatilaka, K. S.; Sigel, R. K. O.; Rueda, D. Proc. Natl. Acad. Sci. U.S.A. 2008, 105, 13853.

(135) (a) Lehman, N.; Joyce, G. F. Nature 1993, 361, 182. (b) Burton, A. S.; Lehman, N. Biochimie 2006, 88, 819.

(136) Sigel, R. K. O.; Vaidya, A.; Pyle, A. M. Nat. Struct. Biol. 2000, 7, 1111.

(137) Stahley, M. R.; Strobel, S. A. Science 2005, 309, 1587.

(138) Adams, P. L.; Stahley, M. R.; Kosek, A. B.; Wang, J.; Strobel, S. A. Nature 2004, 430, 45. 